Redes com dinâmica espaço-temporal e aplicações computacionais 

Data de Depósito:

Assinatura:

\title{
Redes com dinâmica espaço-temporal e aplicações computacionais
}

\author{
Marcos Gonçalves Quiles
}

\section{Orientadora: Profa. Dra. Roseli Aparecida Francelin Romero}

Co-orientador: Prof. Dr. Zhao Liang

Tese apresentada ao Instituto de Ciências Matemáticas e de Computação - ICMC-USP, como parte dos requisitos para obtenção do título de Doutor em Ciências - Ciências de Computação e Matemática Computacional.

\author{
USP - São Carlos \\ Janeiro de 2009
}



Aos meus pais, Izaias e Lucinda, ao meu grande amor Camila, e a minha "filfa" Nayara. 


\section{Agradecimentos}

Primeiramente gostaria de agradecer aos meus pais, Izaias e Lucinda, por todo amor, carinho, ensinamento e confiança que me transmitiram em todos os momentos da minha vida. Eles sabem que, a cada sonho que realizei, a cada grande conquista, em cada momento difícil, estando perto ou longe, eles sempre foram meus guias. Jamais conseguiria expressar em palavras a gratidão e o amor que sinto por eles.

Ao meu grande amor Camila e a minha "filha" Nayara por todo amor, carinho e compreensão nestes últimos anos. Elas serão sempre meu ponto de apoio diário, meu forte, minha família.

Aos meus orientadores, professores e amigos, Roseli Romero e Zhao Liang. A Roseli por todo o apoio, suporte, dedicação e confiança concedidos durante estes últimos seis anos de convivio. Ao Zhao, primeiramente por ter aceitado me orientar, e por todo o apoio, ensinamento, motivação e conselhos transmitido durante esta fase. Devo a eles grande parte do conhecimento que adquiri nesses últimos anos.

A Reginaldo e Denise por toda amizade, apoio, carinho e por terem sido como meus pais nestes últimos anos. Um agradecimento especial também aos meus cunhados, Vinícius, Josieni e Pedro e aos demais familiares pelo convívio quase diário.

Aos meus irmãos Milene, Marcelo, Márcio e Guédna, por sempre me motivarem a seguir meus sonhos.

A todos os professores que tive durante minha vida. Sem seus ensinamentos jamais teria chegado até aqui.

Aos amigos que fiz durante todos esses anos como estudante.

Ao Professor DeLiang Wang por ter aceitado minha visita acadêmica em seu grupo de pesquisa e por toda atenção fornecida durante esta.

Aos funcionários do ICMC e em especial as secretárias da Pós-Graduação por todo o apoio disponibilizado.

Por fim, gostaria de agradecer a FAPESP pelo suporte financeiro conce- 
dido e por propiciar a oportunidade de realização de um estágio nos Estados Unidos. A CAPES pelo apoio financeiro inicial; e ao Instituto de Ciências Matemáticas e de Computação pelo suporte e estrutura fornecidos para o desenvolvimento desta tese. 


\section{Resumo}

Nas últimas décadas, testemunhou-se um crescente interesse no estudo de sistemas complexos. Tais sistemas são compostos por pelo menos dois componentes fundamentais: elementos dinâmicos individuais e uma estrutura de organização definindo a forma de interação entre estes. Devido a dinâmica de cada elemento e a complexidade de acoplamento, uma grande variedade de fenômenos espaço-temporais podem ser observados. Esta tese tem como objetivo principal explorar o uso da dinâmica espaço-temporal em redes visando a solução de alguns problemas computacionais. Com relação aos mecanismos dinâmicos, a sincronização entre osciladores acoplados, a caminhada aleatória-determinística e a competição entre elementos na rede foram considerados. Referente à parte estrutural da rede, tanto estruturas regulares baseadas em reticulados quanto redes com estruturas mais gerais, denominadas redes complexas, foram abordadas. Este estudo é concretizado com o desenvolvimento de modelos aplicados a dois domínios específicos. O primeiro refere-se à utilização de redes de osciladores acoplados para construção de modelos de atenção visual. Dentre as principais características desses modelos estão: a seleção baseada em objetos, a utilização da sincronização/dessincronização entre osciladores neurais como forma de organização perceptual, a competição entre objetos para aquisição da atenção. Além disso, ao comparar com outros modelos de seleção de objetos baseados em redes osciladores, um número maior de atributos visuais é utilizado para definir a saliência dos objetos. O segundo domínio está relacionado ao desenvolvimento de modelos para detecção de comunidades em redes complexas. Os dois modelos desenvolvidos, um baseado em competição de partículas e outro baseado em sincronização de osciladores, apresentam alta precisão de detecção e ao mesmo tempo uma baixa complexidade computacional. Além disso, o modelo baseado em competição de partículas não só oferece uma nova técnica de detecção de comunidades, mas também apresenta uma abordagem alternativa para realização de aprendizado competitivo. Os estudos realizados nesta tese mostram que a abordagem unificada de dinâmica e estrutura é uma ferramenta promissora para resolver diversos problemas computacionais. 


\section{Abstract}

In the last decades, an increasing interest in complex system study has been witnessed. Such systems have at least two integrated fundamental components: individual dynamical elements and an organizational structure which defines the form of interaction among those elements. Due to the dynamics of each element and the coupling complexity, various spatial-temporal phenomena can be observed. The main objective of this thesis is to explore spatial-temporal dynamics in networks for solving some computational problems. Regarding the dynamical mechanisms, the synchronization among coupled oscillators, deterministic-random walk and competition between dynamical elements are taken into consideration. Referring to the organizational structure, both regular network based on lattice and more general network, called complex networks, are studied. The study of coupled dynamical elements is concretized by developing computational models applied to two specific domains. The first refers to the using of coupled neural oscillators for visual attention. The main features of the developed models in this thesis are: object-based visual selection, realization of visual perceptual organization by using synchronization / desynchronization among neural oscillators, competition among objects to achieve attention. Moreover, in comparison to other object-based selection models, more visual attributes are employed to define salience of objects. The second domain is related to the development of computational models applied to community detection in complex networks. Two developed models, one based on particle competition and another based on synchronization of Integrate-Fire oscillators, present high detection rate and at the same time low computational complexity. Moreover, the model based on particle competition not only offers a new community detection technique, but also presents an alternative way to realize artificial competitive learning. The study realized in this thesis shows that the unified scheme of dynamics and structure is a powerful tool to solve various computational problems. 


\section{Sumário}

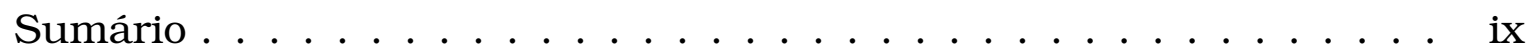

Lista de Figuras . . . . . . . . . . . . . . . xi

1 Introdução 1

1.1 Objetivos e Motivação . . . . . . . . . . . . . . . . 4

1.2 Organização do Texto . . . . . . . . . . . . . . . 7

2 Fundamentos Teóricos $\quad 9$

2.1 Sincronização. . . . . . . . . . . . . . . . 9

2.1.1 Formas de Sincronização . . . . . . . . . . . . . . 10

2.1.2 Sincronização em Redes de Mapas Caóticos . . . . . . . . 11

2.1.3 Sincronização em Redes de Osciladores Contínuos . . . . . 12

2.1.4 Sincronização em Redes de Neurônios Pulsados . . . . . . . 12

2.2 Correlação Temporal . . . . . . . . . . . . . . . . 15

2.2 .1 O Modelo LEGION . . . . . . . . . . . . . . . . 18

2.2 .2 Correlação Oscilatória Caótica . . . . . . . . . . . . . 22

2.2 .3 O Modelo PCNN . . . . . . . . . . . . . . . . . 24

2.3 Atenção Visual . . . . . . . . . . . . . . . . . . . . . 26

2.4 Redes Complexas e Detecção de Comunidades . . . . . . . . . 36

2.4.1 Detecção de Comunidades . . . . . . . . . . . . 38

2.4 .2 Algumas Técnicas . . . . . . . . . . . . . . . . 40

3 Redes de Osciladores Acoplados Aplicados à Atenção Visual 45

3.1 Modelo de Atenção Baseado em PCNN - I . . . . . . . . . . . . 46

3.1.1 Descrição do Modelo . . . . . . . . . . . . . . . . . . 46

3.1.2 Simulações Computacionais . . . . . . . . . . . . . 49

3.2 Modelo de Atenção Baseado em PCNN - II . . . . . . . . . . . . 54

3.2 .1 Descrição do Modelo . . . . . . . . . . . . . . . . . . . 54

3.2.2 Simulações Computacionais . . . . . . . . . . . . . 57

3.3 Modelo de Atenção Baseado em rede de Osciladores WCC . . . . . 61 
3.3.1 Rede de Osciladores Wilson-Cowan Caótico . . . . . . . . 61

3.3 .2 Descrição do Modelo . . . . . . . . . . . . . . . 63

3.3.3 Simulações Computacionais . . . . . . . . . . . . 66

3.4 Modelo de Atenção Baseado em Neurônios I\&D . . . . . . . . . . . 69

3.4.1 Redes de Neurônios I\&D . . . . . . . . . . . . . . . . 69

3.4.2 Sincronização em Redes de Neurônios I\&D . . . . . . . . . . 71

3.4.3 Descrição do Modelo . . . . . . . . . . . . . . 75

3.4.4 Simulações Computacionais . . . . . . . . . . . . 78

3.5 Modelo de Atenção Baseado em LEGION . . . . . . . . . . . . . . . 89

3.5. 1 O Modelo LEGION para Segmentação de Imagens . . . . . . 89

3.5.2 Descrição do Modelo . . . . . . . . . . . . . . . . . . . 92

3.5.3 Simulações Computacionais . . . . . . . . . . . 98

4 Modelos para Detecção de Comunidades 105

4.1 Modelo de Competição de Partículas . . . . . . . . . . . . . 106

4.1 .1 Conceitos Iniciais . . . . . . . . . . . . . . 106

4.1 .2 Descrição do Modelo . . . . . . . . . . . . . . 107

4.1.3 Simulações Computacionais . . . . . . . . . . . 111

4.2 Modelo de Correlação Oscilatória: Neurônios I\&D . . . . . . . . . . 121

4.2.1 Descrição do Modelo . . . . . . . . . . . . . . . . . . 122

4.2.2 Simulações Computacionais . . . . . . . . . . . 123

5 Conclusões 133

5.1 Principais Contribuições e Conclusões . . . . . . . . . . . 136

5.2 Trabalhos Futuros . . . . . . . . . . . . . . 138

$\begin{array}{ll}\text { Referências } & 153\end{array}$ 


\section{Lista de Figuras}

2.1 Séries temporais do GCM. (a) $N=2$ e $c=0,2$; (b) $N=2$ e $c=0,55$;

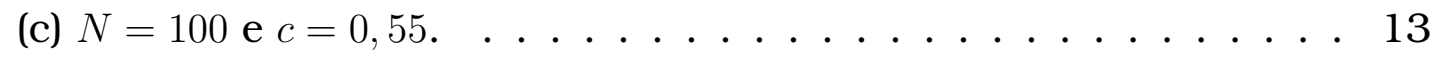

2.2 Desvio padrão das trajetórias $\delta$ versus força de acoplamento $c$. Em cada ponto da curva $\delta$ é calculado em um intervalo de 1000 iterações desconsiderado um período transiente de 2000 iterações. $N=100 \ldots \ldots \ldots \ldots \ldots \ldots \ldots$. . . . . . . . . 14

2.3 Séries temporais de dois osciladores de relaxamento acoplados. (a) $c=0,02 ;$ (b) $c=0,06 \ldots \ldots \ldots \ldots \ldots \ldots$

2.4 Arquitetura típica de uma rede LEGION 2D. Os círculos de cor branca representam osciladores e o circulo de cor preta representa o inibidor global. . . . . . . . . . . . . . 20

2.5 Dinâmica de um oscilador de relaxamento. (a) Compostamento de um oscilador no estado disparando. A trajetória é definida por um ciclo limite representado pela curva em negrito e as seta indicam a direção do movimento. (b) Comportamento dinâmico de um oscilador no estado excitável. Neste caso, um ponto fixo estável é observado e está indicado por um ponto no lado esquerdo inferior do gráfico. . . . . . . . . . . . . . . 21

2.6 O Neurônio PCN obtido em (Johnson, 1994) . . . . . . . . . . . . . 24

2.7 Ilustração da organização perceptual (Gestalt). A forma de um cachorro pode ser observada no centro da cena. . . . . . . . 32

2.8 Fluxograma de geração do mapa de saliência (Itti et al., 1998). . . 33

2.9 Exemplo de rede randômica clusterizada com $N=128, M=4 \mathrm{e}$ $<k>=16$. (a) $z_{\text {out }} /<k>=0,1$. (b) $z_{\text {out }} /<k>=0,5 . \ldots \ldots \ldots$

2.10 Comparação de diversos algoritmos para detecção de comunidades em redes (Obtido em (Danon et al., 2005)). $\phi$ (eixo vertical) representa a precisão no processo de detecção de comunidades e $z_{o u t} /<k>$ é representado pelo eixo horizontal. As siglas utilizada nos gráficos são definidas na Tabela $2.2 \ldots \ldots \ldots$. . . . . . 41 
3.1 Imagens binárias utilizadas em simulações com o modelo PCNN-I (320 $\times 240$ pontos). (a) Imagem composta por uma dupla espiral. (b) Imagem composta por 7 objetos distintos. . . . . . . . . . 50

3.2 Atividade temporal de disparo dos neurônios representando as duas espirais apresentadas na Figura 3.1(a) (a atividade de um neurônio é apresentada por objeto). Os índices no eixo $y$ identificam os objetos presentes na imagem. . . . . . . . . . . 50

3.3 Atividade temporal de disparo dos neurônios representando os sete objetos apresentados na Figura 3.1(b) (a atividade de um neurônio é apresentada por objeto). Os índices no eixo $y$ identificam os objetos presentes na imagem. . . . . . . . . . . . 51

3.4 Imagem em tons de cinza composta por 10 objetos (imagem com $320 \times 240$ pontos). . . . . . . . . . . . . . . .

3.5 Atividade temporal de disparo dos neurônios representando os 10 objetos apresentados na Figura 3.4 (a atividade de um neurônio é apresentada por objeto). Os índices no eixo $y$ identificam os objetos presentes na imagem. Os marcadores no eixo $x$ representam alguns dos possíveis padrões de agrupamentos de objetos que podem ser obtidos. Os marcadores correspondem aos padrões apresentados na Figura 3.6. . . . . . . . . . . . . .

3.6 Exemplo de padrões de agrupamentos de objetos formados na rede alimentada pela Figura 3.4. Ver as séries temporais correspondentes na Figura 3.5 . . . . . . . . . . . . . . 53

3.7 Imagens utilizadas em simulações com o modelo PCNN-II; (a) Imagem composta por cinco objetos com diferentes níveis de intensidade (40 $\times 40$ pontos); (b) Imagem composta por uma dupla espiral $(40 \times 40$ pontos $) . \ldots \ldots \ldots \ldots$. . . . . . . 58

3.8 Atividade temporal de disparo dos neurônio da Rede PCNN-II alimentada pela Figura 3.7(a) (a atividade de um neurônio é apresentada por objeto). Os índices no eixo $y$ identificam os objetos presentes na imagem. . . . . . . . . . . . . .

3.9 Atividade temporal de disparo dos neurônios da Rede PCNN-II alimentada pela Figura 3.7(b) (a atividade de um neurônio é apresentada por objeto). Os índices no eixo $y$ identificam os objetos presentes na imagem. . . . . . . . . . . . . . 60 
3.10 Evolução temporal do potencial dos neurônios $U$ e do limiar de disparo $\theta$ obtida através de simulação utilizando a imagem apresentada na Figura 3.7. As linhas em cor preta representam o limiar de disparo $(\theta)$ para as espirais número 1 e 2 conforme indicado no eixo $y$. As linhas em cor azul e ciano representam os potenciais $U$ para as espirais número 1 e 2 , respectivamente. . . 60

3.11 Diagrama de bifurcação de um oscilador Wilson-Cowan alimentado por um sinal periódico variando o parâmetro $b . \Delta b=0,0001$.

3.12 Atividade temporal de osciladores Wilson-Cowan com $b=0,01$, $0,02,0,034,0,05$ e 0,1 , respectivamente. A escala vertical do segundo para o quinto oscilador estão deslocadas na vertical por $0,5 \ldots \ldots \ldots \ldots \ldots$

3.13 Imagens utilizadas em simulações sem o mecanismo de deslocamento de foco de atenção. (a) Imagem sintética composta por uma dupla-espiral ( $25 \times 25$ pontos). (b) Imagem sintética composta por cinco objetos $(160 \times 120$ pixels $)$.

3.14 Atividade temporal dos osciladores em uma rede alimentada pela imagem apresentada na Figura 3.13(a). O período transiente utilizado pelo processo de segmentação dos objetos não é apresentado $t<200$. Os índices no eixo $y$ identificam os objetos presentes

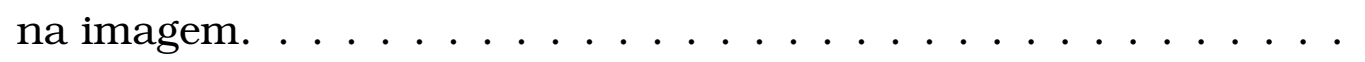

3.15Atividade temporal dos osciladores em uma rede alimentada pela imagem apresentada na Figura 3.13(b). O período transiente utilizado pelo processo de segmentação dos objetos não é apresentado $t<200$. Os índices no eixo $y$ identificam os objetos presentes

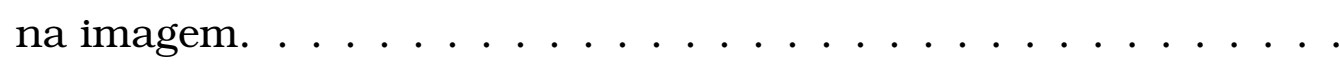

3.16 Imagens utilizadas em simulações sem o mecanismo de deslocamento de foco de atenção. (a) Imagem sintética composta por quatro objetos $(25 \times 25$ pontos). (b) Imagem sintética composta por cinco objetos $(25 \times 25$ pixels $)$. . . . . . . . . . . . . 68

3.17 Atividade temporal dos osciladores em uma rede alimentada pela imagem apresentada na Figura 3.16(a). O período transiente utilizado pelo processo de segmentação dos objetos não é apresentado $t<200$. Os índices no eixo $y$ identificam os objetos presentes

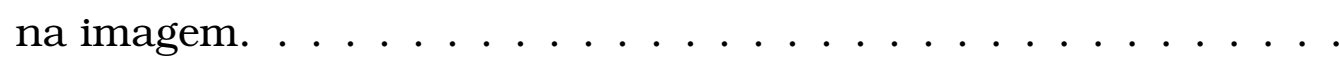

3.18Atividade temporal dos osciladores em uma rede alimentada pela imagem apresentada na Figura 3.13(b). O período transiente utilizado pelo processo de segmentação dos objetos não é apresentado $t<200$. Os índices no eixo $y$ identificam os objetos presentes na imagem. 
3.19Evolução da fase em um ciclo completo com dois osciladores I\&D acoplados. Os pontos de cor vermelha e azul representam os osciladores $O_{1}$ e $O_{2}$ respectivamente. (a) $O_{1}$ encontra-se na origem e $\mathrm{O}_{2}$ é configura com uma fase inicial arbitrária definida por $\phi$. (b) $\mathrm{O}_{2}$ atinge o limiar. (c) $\mathrm{O}_{2}$ dispara e retorna instantaneamente a origem. Ao mesmo tempo, o pulsado gerado pelo disparo de $\mathrm{O}_{2}$ atinge $O_{1}$. Como resultado, $O_{1}$ tem sua fase alterada por $\epsilon(1-\phi)$. (d) $O_{1}$ atinge o limiar de disparo. (e) $O_{1}$ dispara e imediatamente retorna a origem. Um pulso é enviado a $\mathrm{O}_{2}$ alterando sua fase em $\epsilon(1-(1-\phi) \mu) \ldots \ldots \ldots \ldots \ldots$

3.20 Atividade temporal de um rede de neurônios positivamente acoplada. $N=200$ e $\epsilon=0,1$. (a) Grau médio da rede $\langle k\rangle=2$, cada neurônio está, em média, aleatoriamente acoplado a dois outros neurônios; (b) $<k>=4$; (c) $<k>=6$; (d) $<k>=8$. . . . . . . . . .

3.21 Simulação computacional utilizando uma imagem com nove objetos em tons de cinza; (a) Imagem de entrada com $64 \times 64$ pontos; (b) Atividade temporal de disparo dos neurônios representando os objetos (atividade de um neurônio por objeto). Os índices no eixo $y$ identificam os objetos presentes na imagem (a). (c) Ilustração do processo de sincronização/competição. A atividade de 20 neurônios aleatoriamente selecionados de cada objeto é apresen-

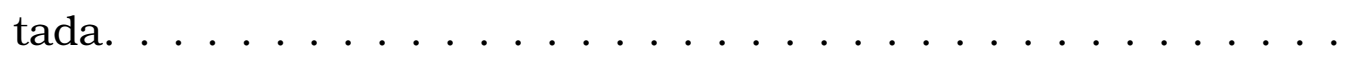

3.22 Simulação computacional variando a heterogeneidade dos distratores. (a), (b), (c) e (d) representam quatro níveis variando de um fundo contendo objetos homogêneos a um padrão de objetos distratores com cores heterogêneas (imagens com $64 \times 64$ pontos).

3.23 Resultado de simulação utilizando a imagem apresentada na Figura 3.22(a). Atividade temporal de disparo dos neurônios representando os objetos (atividade de um neurônio por objeto). Os índices no eixo $y$ identificam os objetos presentes na imagem. . .

3.24 Resultado de simulação utilizando a imagem apresentada na Figura 3.22(b). Atividade temporal de disparo dos neurônios representando os objetos (atividade de um neurônio por objeto). Os índices no eixo $y$ identificam os objetos presentes na imagem. . .

3.25 Resultado de simulação utilizando a imagem apresentada na Figura 3.22(c). Atividade temporal de disparo dos neurônios representando os objetos (atividade de um neurônio por objeto). Os índices no eixo $y$ identificam os objetos presentes na imagem. . . 
3.26 Resultado de simulação utilizando a imagem apresentada na Figura 3.22(d). Atividade temporal de disparo dos neurônios representando os objetos (atividade de um neurônio por objeto). Os índices no eixo $y$ identificam os objetos presentes na imagem. . . 83

3.27 Simulação computacional utilizando uma imagem com 14 objetos variando a cor e o tamanho; (a) Imagem de entrada com $64 \times 64$ pontos; (b) Atividade temporal de disparo dos neurônios representando os objetos (atividade de um neurônio por objeto). Os índices no eixo $y$ identificam os objetos presentes na imagem (a).

3.28 Simulação computacional utilizando uma imagem com 25 objetos variando a orientação; (a) Imagem de entrada com $64 \times 64$ pontos; (b) Atividade temporal de disparo dos neurônios representando os objetos (atividade de um neurônio por objeto). Os índices no eixo $y$ identificam os objetos presentes na imagem (a). . . . . . . .

3.29 Simulação computacional utilizando uma imagem com 23 objetos variando a cor e a orientação; (a) Imagem de entrada com $64 \times 64$ pontos; (b) Atividade temporal de disparo dos neurônios representando os objetos (atividade de um neurônio por objeto). Os índices no eixo $y$ identificam os objetos presentes na imagem (a).

3.30 Simulação computacional com imagem real. (a) Imagem real original. (b) Imagem real tratada utilizada como entrada para rede (imagem com $64 \times 64$ pontos). (c) Atividade temporal de disparo dos neurônios representando os objetos ("fruta" e fundo) identificados pelo índice no eixo $y$ (atividade de dez neurônio aleatoriamente selecionados por objeto). . . . . . . . . . . . 87

3.31 Simulação computacional com imagem real. (a) Imagem real original. (b) Imagem real tratada utilizada como entrada para rede (imagem com $93 \times 70$ pontos). (c) Atividade temporal de disparo dos neurônios representando os objetos ("pássaro" e fundo) identificados pelo índice no eixo $y$ (atividade de dez neurônio aleatoriamente selecionados por objeto). . . . . . . . . . . . .

3.32 Simulação computacional com imagem real. (a) Imagem real original. (b) Imagem real tratada utilizada como entrada para rede (imagem com $64 \times 96$ pontos). (c) Atividade temporal de disparo dos neurônios representando os objetos ("flor" e fundo) identificados pelo índice no eixo y (atividade de dez neurônio aleatoriamente selecionados por objeto) 
3.33 Diagrama de integração dos módulos que compõem o modelo proposto. O modelo é composto por um módulo para o cálculo do mapa de saliência; um módulo de segmentação de imagens (LEGION); e um módulo que implementa a rede de seleção de objetos, incluindo o mecanismo de inibição por retorno (IoR). As setas indicam o fluxo computacional do sistema. As imagens apresentadas abaixo da rede de seleção ilustra a sequência de seleção dos objetos. . . . . . . . . . . . . . . . . . . . . . . 90

3.34 Arquitetura da rede de seleção. Círculos de cor branca representam osciladores com o mecanismo IoR incorporado. Os círculos em cor preta representam os inibidores globais lento e rápido. . . 94

3.35Ilustração do processo de seleção de objetos pela rede proposta. Para esta ilustração, os osciladores são integrados numericamente utilizando o método Runge-Kutta de quarta ordem. (a) representação ilustrativa de um mapa de objeto-saliência com 3 objetos: um quadrado, um objeto a esquerda e um objeto no canto inferior direto da imagem. (b) atividade de cada bloco de osciladores e seus respectivos valores de $r_{i}$. A atividade dos inibidores globais rápido e lento também são ilustradas. . . . . . . .

3.36 Resultado de simulação para uma imagem em nível tons de cinza. (a) Imagem de entrada. Esta figura representa uma cena aérea lago com definição de $160 \times 160$ pontos. (b) Mapa de saliência. (c) Resultado do processo de segmentação onde cada objeto é representado por uma cor distinta. (d) Mapa de objeto-saliência. (e) Primeiro objeto selecionado. (f) Segundo objeto selecionado. . . 98

3.37 Resultado de simulação para uma imagem em nível tons de cinza. (a) Imagem de Ressonância Magnética do cérebro humano $(257 \times$ 257 pontos). (b) Mapa de saliência. (c) Resultado do processo de segmentação. (d) Mapa de objeto-saliência. (e) Primeiro objeto selecionado. (f) Segundo objeto selecionado. . . . . . . . . . . . . . 99

3.38 Resultado de simulação para uma imagem colorida. (a) Imagem natural com $351 \times 256$ pontos. (b) Mapa de saliência. (c) Resultado do processo de segmentação. (d) Mapa de objeto-saliência. (e) Primeiro objeto selecionado. (f) Segundo objeto selecionado. . . . 101

3.39Resultado de simulação para uma imagem colorida. (a) Cena de um lago com $385 \times 256$ pontos. (b) Mapa de saliência. (c) Resultado do processo de segmentação. (d) Mapa de objeto-saliência. (e) Primeiro objeto selecionado. (f) Segundo objeto selecionado. . . . 102 
3.40 Resultado de simulação para uma imagem colorida. (a) Imagem natural com $256 \times 256$ pontos. (b) Mapa de saliência. (c) Resultado do processo de segmentação. (d) Mapa de objeto-saliência. (e) Primeiro objeto selecionado. (f) Segundo objeto selecionado. . . . 102

3.41 Resultado de simulação para uma imagem colorida. (a) Imagem real de uma pessoa no Central Park em Nova York $(341 \times 256$ pontos). (b) Mapa de saliência. (c) Resultado do processo de segmentação. (d) Mapa de objeto-saliência. (e) Primeiro objeto selecionado. (f) Segundo objeto selecionado. . . . . . . . . . . . . . . 103

4.1 Ilustração do processo de detecção de comunidades via competição de partículas (Quiles et al., 2008b). (a) Estado inicial com 4 partículas randomicamente posicionadas na rede; (b) Resultado com 250 iterações (movimentos); (c) Resultado com 3500 iterações; (d) Resultado com 7000 iterações. . . . . . . . . . . . . . . 112

4.2 Taxa de detecção de comunidades correta $\phi$ versus probabilidade de movimentação determinística $p_{\text {det }}$. Nesta simulação, $N=128$, $M=4,\langle k\rangle=16$ e $z_{\text {out }} /\langle k\rangle=0,5$. Cada ponto da curva é representado pela média de 200 execuções. A barra de erro representa o desvio padrão.

4.3 Séries temporais da evolução do modelo para diferentes valores de $p_{\text {det }}$. (a) Evolução da taxa de detecção de comunidades correta $\phi$; (b) Potencial médio dos vértices; (c) Potencial médio das partículas. Estas simulações foram realizadas com redes definidas pelos seguintes parâmetros: $N=128, M=4, z_{\text {out }} /\langle k\rangle=0,4 \mathrm{e}$ $<k>=16$. Cada ponto da curva é representado pela média de 200 execuções.

4.4 Resultados de simulação variando o número de partículas e o número de comunidades. (a) e (c) Taxa de detecção de comunidades correta $\phi$ versus número de partículas na rede $N_{\rho}$. (b) e (d) Potencial médio dos vértices $\left\langle v_{i}^{\omega}\right\rangle$ versus número de partículas na rede $N_{\rho}$. Nas simulações apresentadas nas Figuras (a) e (b), $N=160, M=5, z_{\text {out }} /<k>=0,3, z_{\text {in }} /<k>=0,7,<K>=16$ e $p_{\text {det }}=0,6$. Nas simulações apresentadas nas Figuras (c) e (d), $N=480, M=15, z_{\text {out }} /\langle k\rangle=0,3, z_{\text {in }} /\langle k\rangle=0,7$ e $p_{\text {det }}=0,6 . \ldots 115$ 
4.5 Taxa de detecção de comunidades correta phi versus $\Delta_{v}$ e $\Delta_{\rho}$ para diferentes valores de $z_{\text {out }} /\langle k\rangle$. As cores representam a taxa de detecção de comunidades. (a) $z_{\text {out }} /<k>=0,5$; (b) $z_{\text {out }} /<k>=0,4$; (c) $z_{\text {out }} /<k>=0,3$; (d) $z_{\text {out }} /<k>=0,2$; (e) $z_{\text {out }} /<k>=0,1$; (f) $z_{\text {out }} /<k>=0,0$. Nestas simulações, os seguintes parâmetros foram utilizados: $N=80, M=4, p_{\text {det }}=0,6 \mathrm{e}<k>=10$. Cada ponto na figura representa a média de 100 execuções. . . . . . . .

4.6 Taxa de detecção de comunidades correta $p h i$ versus $\Delta_{v}$ e $\Delta_{\rho}$ para diferentes valores de $N$. As cores representam a taxa de detecção de comunidades. (a) $N=80$; (b) $N=160$; (c) $N=320$; (d) $N=$ 480; (e) $N=640 ;$ (f) $N=800$. Nestas simulações, os seguintes parâmetros foram utilizados: $\left\langle k>=0,5 N / M, M=4, p_{\text {det }}=0,6 \mathrm{e}\right.$ $z_{\text {out }} /\langle k\rangle=0,4$. Cada ponto na figura representa a média de 100 execuções.

4.7 Taxa de detecção de comunidades correta $p h i$ versus $\Delta_{v}$ e $\Delta_{\rho}$ para diferentes valores de $\langle k>$. As cores representam a taxa de detecção de comunidades. (a) $<k>=8$; (b) $<k>=12$; (c) $<k>=$ 16; (d) $<k>=20$; (e) $<k>=24$; (f) $<k>=28$. Nestas simulações, os seguintes parâmetros foram utilizados: $N=128, M=4, p_{\text {det }}=$ 0,6 e $z_{\text {out }} /<k>=0,4$. Cada ponto na figura representa a média de 100 execuções. . . . . . . . . . . . . . . .

4.8 Taxa de detecção de comunidades correta $\phi$ aplicada a redes randômicas clusterizadas com $N=128, M=4 \mathrm{e}\langle k\rangle=16$. O eixo $x$ representa a fração de inter-conexões $z_{\text {out }} /<k>$ e o eixo $y$ representa a proporção de vértices corretamente classificados. Cada ponto da curva é representado pela média de 200 execuções. As barras de erros representam o desvio padrão. $p_{\text {det }}=0,6$. Para $z_{\text {out }} /<k>\leq 0,1, \Delta_{\rho}=0,6$; Para $z_{\text {out }} /<k>>0,1, \Delta_{\rho}=0,4$. . 119

4.9 Número de iterações necessárias para detecção das comunidades versus tamanho da rede $N$. Nestas simulações os seguintes parâmetros foram utilizados: $M=4,<k>=0.5 N / M$ e $p_{\text {det }}=0,6$. Cada ponto da curva é representado pela média de 200 execuções. As barras de erro representam os números mínimo e máximo de iterações necessárias para atingir $\left\langle v^{\omega}\right\rangle \geq 0,9$. (a) $\left.z_{\text {out }} /<k\right\rangle=0,2$. (b) $z_{\text {out }} /<k>=0,4 \ldots \ldots \ldots \ldots$

4.10 Resultado do processo de detecção de comunidades sobre a rede de interação social entre indivíduos pertencentes a um clube de karate (Zachary, 1977). $p_{\text {det }}=0,6 \ldots \ldots \ldots 121$

4.11 Resultado do processo de detecção comunidades sobre a rede interação social entre golfinhos ((Lusseau et al., 2003)). $p_{\text {det }}=0,6.122$ 
4.12 Ilustração do processo de detecção de comunidades usando o modelo proposto. Nesta simulação, $N=128, M=4,\langle k\rangle=16$ e $z_{\text {out }} /<k>=0,2$. (a) Rede randômica clusterizada. (b) Série temporal de disparo dos 128 neurônios. . . . . . . . . . . . . 125

4.13 Precisão do processo de detecção de comunidades $\phi$ versus fração de inter-conexões $z_{\text {out }} /\langle k\rangle$. Nesta simulação, $N=128, M=4 \mathrm{e}$ $<k>=16$. Cada ponto da curva é obtido através da média de 200 execuções. A barra de erro representa o desvio padrão médio. . . 126

4.14 Precisão do processo de detecção de comunidades $\phi$ versus grau médio da rede $\langle k\rangle$. (a) $N=128, M=4$ e $z_{\text {out }} /\langle k\rangle=0,3$. (b) $N=500, M=5$ e $z_{\text {out }} /\langle k\rangle=0,3$. Cada ponto da curva é obtido através da média de 200 execuções. A barra de erro representa o desvio padrão médio. . . . . . . . . . . . . . . . . 127

4.15Séries temporais dos osciladores representando os vértices da rede de interação social entre indivíduos pertencentes a um clube de karate (Zachary, 1977). $c=0,1 . \ldots \ldots \ldots \ldots$

4.16Representação em maior resolução temporal de algumas faixas de $t$ da simulação apresentada na Figura 4.15. . . . . . . . . 128

4.17Resultado do processo de detecção de comunidades sobre a rede de interação social entre indivíduos pertencentes a um clube de

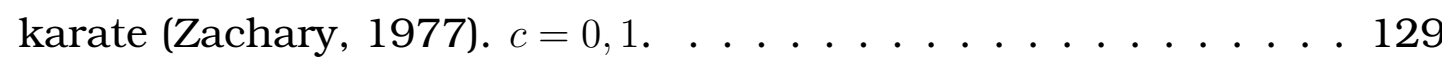

4.18Séries temporais dos osciladores representando os vértices da rede de interação social social entre golfinhos ((Lusseau et al., 2003)). $c=0,3 \ldots \ldots \ldots \ldots$. . . . . . . . . . 129

4.19Representação em maior resolução temporal de algumas faixas de $t$ da simulação apresentada na Figura 4.18. . . . . . . . . 130

4.20 Resultado do processo de detecção comunidades sobre a rede interação social entre golfinhos ((Lusseau et al., 2003)). $c=0,3 . \quad$. 131 


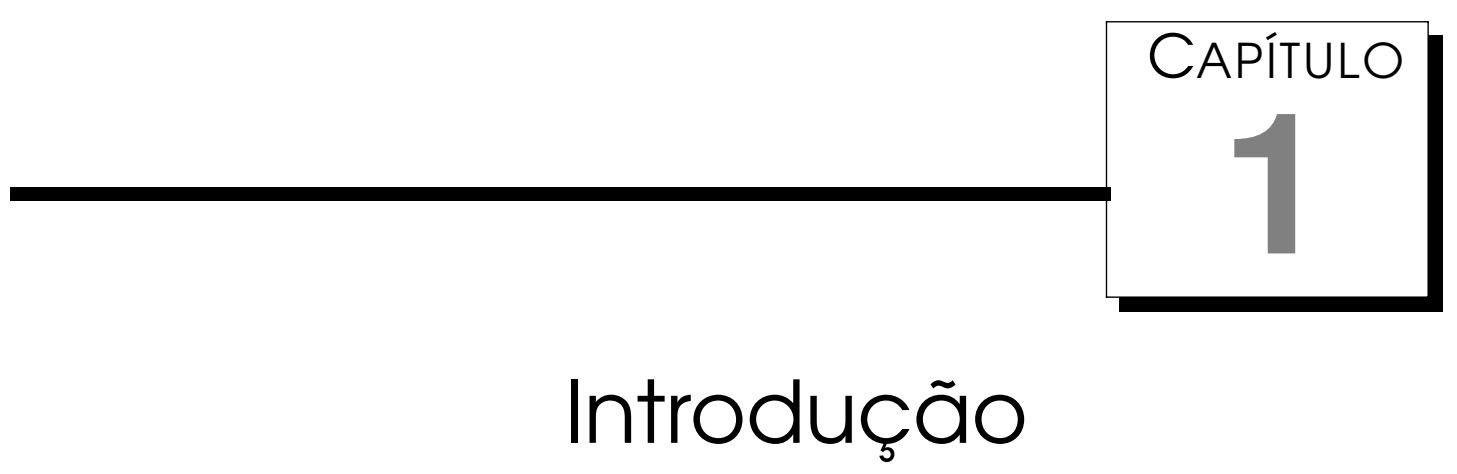

$\mathrm{O}$ estudo de sistemas complexos tem despertado o interesse de cientistas das mais diversas áreas (Bar-Yam, 2003). Ao longo de diversos anos, as ciências foram se especializando em áreas específicas do conhecimento, tais como física, matemática, psicologia, biologia, computação e sociologia. Da mesma forma, a decomposição de um sistema complexo em suas partes fundamentais seguida pelo estudo e compreensão destas foi durante muito tempo a base das ciências. Por exemplo, para compreender a mente humana, neurocientistas buscam primeiro entender a dinâmica dos neurônios. Esta forma de realizar ciência é denominada reducionismo, no qual se parte da premissa que algo complexo pode ser entendido a partir da compreensão de suas partes componentes.

De acordo com reducionismo, uma vez conhecida as partes de um sistema complexo, espera-se que a junção destas e a extrapolação do conhecimento das partes para uma compreensão global sejam definidas por um processo simples. Entretanto, segundo Barabási (2003), a natureza não é um "quebracabeça” bem definido, de tal forma que a junção das peças não segue um caminho trivial único. Além disso, este "quebra-cabeça" foi montado pela natureza de forma brilhante ao longo de milhões de anos seguindo as leis, ainda não totalmente compreendidas, da auto-organização.

Dois componentes essenciais que caracterizam um sistema complexo são os elementos que os compõem e as interações entre estes. Uma forma bastante comum de se estudar tais sistemas é dada através da modelagem dos elementos como sistemas dinâmicos acoplados em uma estrutura de rede. Nas últimas décadas, devido ao aumento significativo do poder computacional, diversos estudos envolvendo a simulação de sistemas dinâmicos acoplados têm 
sido realizados. Dentre estes estudos, uma atenção especial tem sido dada ao estudo de padrões dinâmicos em sistemas caóticos acoplados, por exemplo, ondas espirais, turbulência, padrões estacionários, agrupamento e a sincronização de sistemas caóticos (Kaneko, 1986, 1989, 1990; Pecora \& Carroll, 1990). Geralmente, tais sistemas são representados por estruturas topológicas regulares como reticulados ou redes globalmente acopladas. Uma das principais vantagens destes sistemas está na simplicidade estrutural da rede permitindo que o foco de investigação esteja concentrado na dinâmica dos elementos (Wang \& Chen, 2003). Entretanto, a estrutura topológica da rede pode representar um fator crítico no comportamento dinâmico resultante da interação dos elementos (Wang \& Chen, 2002; Barahona \& Pecora, 2002).

Uma primeira abordagem estabelecida para representar rede com estruturas complexas foi apresentada por Erdös \& Rényi (1959). Tais modelos são conhecidos como grafos randômicos ou redes randômicas. Entretanto, apenas mais recentemente foi observado um novo direcionamento nas pesquisas em redes, com o foco passando da análise das propriedades de grafos regulares para o estudo de propriedades estatísticas e dinâmicas e da formação de grafos de grande escala. Esta nova linha de pesquisa em redes, localizada na intersecção da teoria de grafos com a mecânica estatística, é denominada redes complexas (Albert \& Barabási, 2002; Newman, 2003).

De acordo com Strogatz (2001), algumas características inerentes a este tipo de rede são: a complexidade estrutural; dificuldade de visualização da rede; constante evolução na estrutura da rede devido à inclusão e remoção de vértices e conexões; a diversidade de conexões; e a dinâmica complexa. Devido a estas características, as redes complexas podem ser vistas como uma ferramenta poderosa para representar de forma unificada diversos aspectos de um sistema complexo, tais como função, estrutura e dinâmica. Desta forma, o formalismo das redes complexas é bastante útil para descrever problemas formados por um grande número de agentes que interagem através de determinadas regras, como é o caso da sincronização de sistemas caóticos mencionada anteriormente. Além disso, por seu forte caráter interdisciplinar, relativa simplicidade conceitual e grande aplicabilidade na modelagem de sistemas reais, alguns pesquisadores têm sugerido que as redes complexas representam uma das peças fundamentais para a integração das ciências antes separadas pelo reducionismo (Barabási, 2003). Alguns exemplos de sistemas complexos que podem ser modelados por redes complexas incluem a internet (Faloutsos et al., 1999), a world wide web (WWW) (Albert et al., 1999), redes neurais biológicas (Sponrs, 2002), redes sociais (Scott, 2000), cadeias alimentares (Montoya \& Solé, 2002), redes do metabolismo (Jeong et al., 2000), distribuição da corrente sanguínea (West et al., 1999), as rotas de entrega postal e a distribuição 
de energia elétrica (Albert et al., 2004), dentre outros (Newman, 2003).

Dentre os diversos domínios dos quais podem ser extraídos sistemas complexos, o cérebro é sem dúvidas um dos principais devido à grande quantidade de funções desempenhadas por este e também por sua grande complexidade dinâmica e estrutural.

Um fenômeno que tem sido observado em diversos experimentos envolvendo o cérebro é a sincronização (Eckhorn et al., 1988; Grey et al., 1989; Eckhorn et al., 1990; Engel et al., 1991; Murthy \& Fetz, 1992; Gong et al., 2003). Além disso, a sincronização tem sido associada a diversos mecanismos importantes, como a formação da memória, percepção visual, atenção, dentre outros (Niebur \& Koch, 1994; Fries et al., 2001; Ward, 2003; Axmacher et al., 2006; Buia \& Tiesinga, 2006; Jermakowicz \& Casagrande, 2007; Kim et al., 2007).

Um dos aspectos primordiais relacionados à percepção visual está na integração das características visuais simples como cor, orientação, profundidade e movimento em uma unidade de percepção. Esta integração, realizada em forma de uma organização perceptual, é responsável por organizar a cena visual em um conjunto de objetos perceptiveis. Segundo Wang (2005), uma peça fundamental na solução deste problema está na representação baseada na estrutura temporal dos sinais neurais. Esta estrutura temporal define a base da teoria da correlação temporal (von der Malsburg, 1981).

A teoria da correlação temporal define que um objeto é representado pela correlação temporal dos disparos de células neurais espacialmente distribuídas que representam diferentes características de um mesmo objeto. Enquanto neurônios codificando características de objetos distintos não possuem suas atividades correlacionadas. Uma maneira natural de implementar os mecanismos da teoria da correlação temporal é através da utilização de osciladores, que, neste caso, passa a se chamar teoria da correlação oscilatória (Terman \& Wang, 1995).

Um mecanismo biológico que tem sido diretamente associado à organização perceptual é a atenção visual. A atenção visual é definida como um mecanismo responsável por selecionar qual parte dos estímulos visuais provenientes do ambiente atinge níveis conscientes e é, de fato, analisada pelo cérebro (Desimone \& Duncan, 1995; Pashler, 1998; Yantis, 1998). De uma forma geral, as teorias de atenção visual se dividem em dois grupos de acordo com o mecanismo de seleção considerado: seleção baseada em localização espacial e seleção baseada em objetos (Egeth \& Yantis, 1997; Pashler, 1998; Yantis, 2000). No contexto da atenção baseada em objetos, uma abordagem que pode ser considerada para o desenvolvimento de modelos computacionais da atenção está no uso de redes de osciladores acoplados. Desta forma, se- 
guindo a teoria da correlação oscilatória na qual os osciladores representam os estímulos visuais e a sincronização entre grupos de osciladores representam os objetos, uma rede de osciladores pode ser utilizada para realizar uma segmentação prévia da cena em um conjunto de objetos que posteriormente serão selecionados por um mecanismo de atenção. Ou seja

Outra característica interessante bastante observada em redes reais está na presença de estruturas modulares denominadas comunidades (Newman, 2004a; Danon et al., 2005). As comunidades podem ser definidas como um conjunto de vértices pertencentes à rede no qual a média de ligação entre estes é maior que o número de ligações com os demais vértices da rede.

Uma associação importante que pode ser estabelecida é que, do ponto de vista computacional, a organização perceptual da cena e a identificação das comunidades em uma rede podem ser vistas como problemas semelhantes, onde existe a necessidade de se agrupar elementos próximos enquanto grupos distintos são separados. No caso da organização perceptual, o agrupamento é realizado entre estímulos que representam diferentes características de um mesmo objeto, já na detecção de comunidades em redes o agrupamento é observado entre vértices densamente conectados (comunidades).

\subsection{Objetivos e Motivação}

Com base nas informações descritas acima, esta tese tem como objetivo principal explorar o uso da dinâmica espaço-temporal em redes na solução de alguns problemas computacionais. Este estudo focaliza em uma abordagem unificada dinâmica + estrutura, na qual a dinâmica se refere aos fenômenos produzidos por elementos dinâmicos acoplados e a estrutura representa a organização desses elementos dinâmicos.

Mais especificamente, neste trabalho os seguintes comportamentos dinâmicos foram considerados: sincronização entre osciladores acoplados, caminhada aleatória-determinística e mecanismos de competição entre elementos na rede. Referente à parte estrutural da rede, inicialmente, nos modelos descritos no Capítulo 3 foram utilizadas estruturas regulares baseadas em reticulados com acoplamentos locais, globais e também com acoplamento dinamicamente definidos. Já nos modelos que serão abordados no Capítulo 4, redes com estruturas mais gerais, denominadas redes complexas, foram consideradas.

Este estudo é concretizado com o desenvolvimento de modelos aplicados a dois domínios bem específicos. O primeiro refere-se a utilização de redes de osciladores neurais acoplados para construção de modelos de atenção visual baseado na seleção de objetos. Nestes modelos, principalmente o conceito 
de sincronização dos elementos na rede são estudados. Esse fenômeno de sincronização entre os elementos é uma propriedade fundamental na implementação de modelos de correlação oscilatória. Aqui, a teoria da correlação temporal, mais especificamente a teoria da correlação oscilatória, é empregada como mecanismo de organização perceptual responsável por segmentar a cena visual em um conjunto de objetos perceptiveis. A partir destes objetos, um processo de seleção competitiva imitando o fenômeno de atenção visual é implementado. Com base nesta abordagem descrita acima, cinco modelos de atenção, em ordem crescente de complexidade, foram desenvolvidos utilizando-se diversos modelos de osciladores neurais.

O segundo domínio está relacionado ao desenvolvimento de modelos de ferramentas computacionais aplicadas a tarefa de detecção de comunidades em redes complexas. Recentemente, diversos métodos para detecção de comunidades têm sido propostos (Zhou, 2003; Newman \& Girvan, 2004; Newman, 2004b; Reichardt \& Bornholdt, 2004; Danon et al., 2005; Boccaletti et al., 2007). Entretanto, a precisão no processo de detecção das comunidades e a complexidade computacional desses algoritmos podem ser vistas como características antagônicas, na qual os modelos que apresentam alta eficiência computacional geralmente apresentam uma baixa precisão. Por outro lado, modelos com alta precisão demandam um alto custo de processamento (Danon et al., 2005). Assim, utilizando-se das propriedades de sistemas dinâmicos e de redes complexas, dois novos modelos de detecção de comunidades são propostos. O primeiro modelo é baseado no conceito de competição entre agentes (partículas) pelo domínio de territórios representados pela estrutura da rede. O segundo modelo utiliza a teoria da correlação oscilatória como mecanismo para realizar a detecção das comunidades.

Em aspectos gerais, a junção da dinâmica de elementos simples com a capacidade de representação fornecida pelas redes complexas é um dos grandes motivadores deste trabalho. Esta abordagem unificada (dinâmica + estrutura) representa uma forma promissora, geral e poderosa para tratar diversos problemas computacionais.

Além das motivações gerais envolvendo a aplicação de conceitos de redes complexas e da dinâmica espaço-temporal como ferramentas computacionais, outros fatores também motivaram o desenvolvimento deste trabalho. Dentre estes, os seguintes podem ser destacados:

- A sincronização é um fenômeno típico em sistemas dinâmicos espaçotemporal e tem se mostrado bastante útil em diversas aplicações computacionais, como segmentação de imagens, clusterização de dados, segregação de sinais sonoros, dentre outros. Desta forma, a exploração deste fenômeno como uma abordagem computacional alternativa a técnicas 
clássicas ainda é bastante promissora;

- Atenção visual baseada na seleção de objetos tem recebido grande suporte empírico. Em adicional, a modelagem da atenção visual com redes de osciladores é motivada por estudos sugerindo que a sincronização apresenta um importante papel na solução de problemas como o problema da integração e a atenção visual. Além disso, grande parte dos modelos computacionais de atenção visual modela apenas aspectos de localização deixando de lado a seleção de objetos. Desta forma, por ter sido pouco explorado, o desenvolvimento de modelos baseados na seleção de objetos se apresenta como uma a abordagem interessante para o desenvolvimento de novos modelos de atenção.

- A analise de uma cena visual representa uma tarefa com um alto custo computacional e a atenção visual representa uma importante abordagem para otimizar a quantidade de computações nesta análise (Tsotsos et al., 1995). Desta forma, o desenvolvimento de modelos computacionais de atenção visual pode trazer diversos avanços para a área de visão computacional. Por exemplo, um sistema de reconhecimento de objetos embarcado em um robô pode restringir a análise da cena a algumas regiões julgadas mais importante pelo sistema de atenção evitando uma análise global desta;

- A detecção de comunidades em redes complexas é tarefa importante por revelar estruturas topológicas na rede. Tais técnicas são importantes em aprendizado de máquina, como em agrupamento de dados (Karypis et al., 1999; Cook \& Holder, 2000; Schaeffer, 2007). De maneira geral, a estrutura em comunidades revela similaridade por meio de conexões entre os vértices pertencentes a um mesmo grupo. Estas similaridades, por sua vez, podem revelar agrupamentos nos dados e, de maneira análoga, evidenciar classes em problemas classificação. Além disso, por representar os dados em uma rede, classes/agrupamentos de formatos não triviais podem ser obtidos. Com consequência, o desenvolvimento de novas técnicas de detecção de comunidades pode contribuir para o desenvolvimento de novos algoritmos para aprendizado de máquina;

- Grande parte das técnicas de detecção de comunidades que apresentam alta precisão possuem como desvantagem uma alta complexidade computacional (Danon et al., 2005). Desta forma, o desenvolvimento de técnicas que sejam capazes de detectar comunidades de forma eficiente e com precisão ainda é um campo de pesquisa bastante promissor;

- Por fim, a multidisciplinaridade envolvida nos temas abordados nesta 
tese já é por si só uma grande fonte de motivação.

\subsection{Organização do Texto}

Esta Tese está organizada da seguinte maneira:

- No Capítulo 2 são apresentados os principais fundamentos teóricos relacionados ao desenvolvimento desta tese. Inicialmente, uma breve descrição sobre sincronização é apresentada. Na sequência, a teoria da correlação temporal e sua variação denominada teoria da correlação oscilatória são apresentadas. A terceira seção deste capítulo apresenta os principais conceitos relacionados ao tema atenção visual e detalha um modelo de mapa de saliência. Por fim, a última seção deste capítulo trata o tema redes complexas e detecção de comunidades.

- No Capítulo 3 são apresentados os principais resultados obtidos referentes ao desenvolvimento de modelos computacionais de redes de osciladores neurais aplicadas a atenção visual. Em cada seção deste capítulo, um modelo proposto é descrito e suas respectivas simulações computacionais são apresentadas. Por fim, na última seção, um quadro comparativo destacando as principais características de cada modelo é apresentado.

- No Capítulo 4, os dois modelos para detecção de comunidades proposto nesta tese seguidos de suas simulações computacionais são apresentados.

- No Capítulo 5, primeiramente uma breve descrição cronológica das atividades desenvolvidas durante o programa de doutorado é apresentada. $\mathrm{Na}$ sequência, são discutidas as principais conclusões e contribuições deste trabalho. Por fim, algumas limitações e desafios futuros são apresentados. 


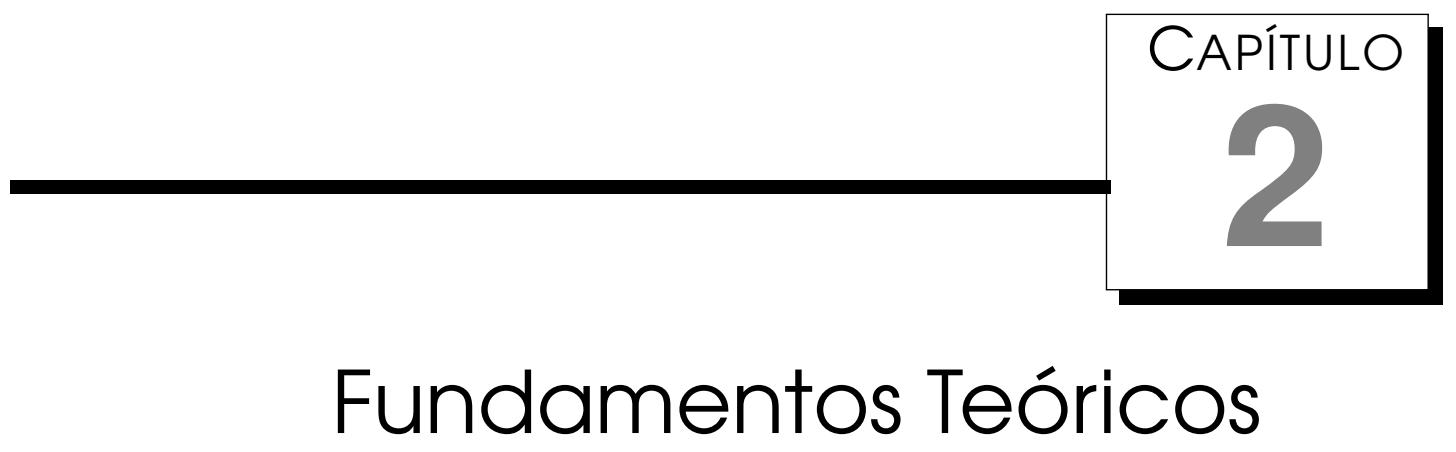

$\mathcal{N}$ este capítulo são apresentados os principais fundamentos teóricos que dão subsidio ao desenvolvimento desta tese. Primeiramente, na Seção 2.1, uma breve introdução sobre sincronização em unidades dinâmicas acopladas é apresentada. Na Seção 2.2, a teoria da correlação temporal e alguns modelos de redes de osciladores baseados nesta teoria são descritos. A Seção 2.3 revisa alguns conceitos sobre o tema atenção visual. Por fim, na Seção 2.4, alguns conceitos sobre redes complexas e detecção de comunidades em redes são apresentados.

\subsection{Sincronização}

De uma forma geral, o estudo da dinâmica espaço-temporal pode ser realizado através de vários modelos matemáticos considerando a forma de interpretação das variáveis: tempo, espaço e de estado. Estes modelos abrangem desde sistemas totalmente contínuos até sistemas totalmente discretos. A Tabela 2.1 apresenta uma descrição dos modelos matemáticos utilizados no estudo da dinâmica espaço-temporal (Crutchfield \& Kaneko, 1987). Dentre estes, os sistemas formados por um conjunto de equações diferenciais ordinárias ou mapas acoplados são mais frequentemente utilizados devido sua simplicidade e praticidade em simulações computacionais.

Através da interação espacial destes modelos acoplados em uma estrutura de rede, uma série de padrões espaço-temporais auto-organizáveis podem emergir, como ondas espirais, sincronização, turbulência, padrões estacionários, agrupamento, dentre outros (Crutchfield \& Kaneko, 1987; Kaneko, 1989, 1990). Destes comportamentos, a sincronização, por se tratar de uma 
Tabela 2.1: Sistemas Dinâmicos Espacialmente Estendidos (Crutchfield \& Kaneko, 1987)

\begin{tabular}{c|c|c|c}
\hline \hline Modelo Matemático & Espaço & Tempo & Estado \\
\hline \hline Equações diferenciais parciais & contínuo & contínuo & contínuo \\
\hline Equações funcionais iteradas & contínuo & discreto & contínuo \\
\hline Equações diferenciais ordinárias & discreto & contínuo & contínuo \\
\hline Mapas acoplados & discreto & discreto & contínuo \\
\hline Autômata celulares & discreto & discreto & discreto \\
\hline
\end{tabular}

característica básica de sistemas não-lineares, representa uma interessante propriedade e tem sido largamente estuda por diversos autores em diversas áreas. O fenômeno da sincronização é bastante comum em diversos sistemas como relógios, emissão de pulsos de luz por vaga-lumes, redes de neurônios, dentre outros (Pikovsky et al., 2001). De uma forma geral, a sincronização pode ser caracterizada por uma tendência de dois ou mais sistemas operarem em sincronia. A seguir, algumas formas possiveis de sincronização são brevemente apresentadas.

\subsubsection{Formas de Sincronização}

O comportamento de sincronização, inclusive sincronização caótica, pode ser obtido de diversas formas: sincronização completa, sincronização por fase, sincronização com atraso, sincronização generalizada, além de outras (Pikovsky et al., 2001; Boccaletti et al., 2002). A sincronização completa é definida por um casamento exato entre as trajetórias geradas por cada um dos sistemas dinâmicos acoplados. Matematicamente, dado uma variável de estado $x$ e uma variável $y$ representando dois sistemas dinâmicos, eles são ditos completamente sincronizados se $|x(t)-y(t)| \rightarrow 0$ conforme $t \rightarrow \infty$. Na sincronização por fase, a diferença entre as fases do sistema permanece constante ou inferior a um limiar, enquanto as amplitudes dos sinais permanecem não correlacionadas. Uma característica interessante da sincronização por fase é que esta é possível de se obter mesmo quando uma pequena força de acoplamento é utilizada (Rosenblum et al., 1996). Além disso, tal forma de sincronização também pode ser observada entre sistemas não idênticos. A terceira forma de sincronização é definida pela sincronização com atraso. Neste caso, quando a força de acoplamento entre dois osciladores não idênticos é aumentada, os estados dos dois osciladores se tornam praticamente idênticos. Entretanto, um pequeno deslocamento temporal (atraso) entre as atividades dos osciladores é observado (Rosenblum et al., 1997). Uma outra forma de sincronização é denominada sincronização generalizada. Esta forma de sincronização é observada quando a trajetória de um sistema pode ser definida em função de 
outras trajetórias (Uchida et al., 2003; Hramov \& Koronovskii, 2005).

Nesta Tese, apenas a sincronização completa entre elementos é abordada. A seguir, alguns exemplos de sistemas dinâmicos acoplados que apresentam sincronização completa são mostrados.

\section{1.2 Sincronização em Redes de Mapas Caóticos}

Os Mapas Globalmente Acoplados (GCM - globally coupled map) representam o caso máximo de acoplamento em uma rede de mapas acoplados, no qual cada elemento caótico da rede está acoplado a todos os demais elementos.

Uma forma simples de representar um GCM é dada por (Kaneko, 1990):

$$
x_{i}(t+1)=(1-c) f\left(x_{i}(t)\right)+\frac{c}{N} \sum_{j=1}^{N} f\left(x_{j}(t)\right)
$$

onde $t \in \mathbb{Z}^{+}$representa o tempo e $i \in \mathbb{Z}^{+}$a posição do mapa no espaço $1 \mathrm{D}$ ( $i=1,2, \ldots, N$ ) sendo $N$ o tamanho (dimensão) do sistema, $c$ define a força de acoplamento e $f(x)$ é definida por um mapa quadrático:

$$
f(x)=1-a x^{2}
$$

onde $a$ representa um parâmetro de bifurcação.

A dinâmica de um GCM consiste na aplicação de uma transformação nãolinear local representada pela função $f(x)$ e a realimentação proveniente do campo médio. Segundo Kaneko (1990) o estudo de sistemas caóticos globalmente acoplados não possui importância apenas no campo da física de sistemas dinâmicos mas também é útil no estudo do processamento de informação biológica, turbulência em fluídos, modelos ecológicos, evolutivos e em economia. Assim, Kaneko (1994) propõe que as redes de elementos caóticos possam ser utilizadas como um ambiente de estudo para uma grande variedade de redes biológicas com dinâmicas complexas.

Um fator importante que pode ser observado é que quando todas as trajetórias são sincronizadas $\left(x_{i}=x_{j} \quad \forall i, j\right)$ o comportamento da rede pode ser descrito por um único mapa. Com base nesta propriedade, foi demonstrado que as redes de mapas globalmente acoplados definidas pelas Equações (2.1) e (2.2) sempre sincronizam quando a força de acoplamento $c>0,5$ (Kaneko, 1990; Zhao \& Macau, 2001).

Na Figura 2.1(a), um exemplo de dois mapas acoplados com uma força $c=0,2$ é apresentado. Pode ser observado que, com a força de acoplamento utilizada as atividades temporais dos mapas permanecem não correlacionadas. Quando a força de acoplamento é aumentada para $c=0,55$, o sincronismo de sistemas caóticos é obtido. Este comportamento síncrono é apresen- 
tado na Figura 2.1(b). Por fim, na Figura 2.1(c) é apresentada a sincronização de um sistema formado por uma rede com $N=100$ e força de acoplamento $c=0,55$.

A Figura 2.2 apresenta um gráfico de sincronização do modelo definido pela Equação (2.1) em função da força de acoplamento $c$. Neste gráfico, o desvio padrão $\delta$ das trajetórias dos $N$ elementos da rede é calculado durante um intervalo de tempo $T$ variando a força de acoplamento. Como mencionado anteriormente, é possivel observar que para uma força de acoplamento $c<0,5$ o sistema não apresenta um sincronismo global. Por outro lado, quando $c>$ 0,5 , todas as trajetórias caóticas do sistema são sincronizadas.

\section{1.3 Sincronização em Redes de Osciladores Contínuos}

Para ilustrar o processo de sincronização entre osciladores periódicos contínuos uma rede com dois osciladores de Relaxamento (van der Pol, 1926; Terman \& Wang, 1995) é utilizada. Um oscilador de relaxamento é composto por uma variável excitatória $x_{i}$ e uma variável inibitória $y_{i}$, definidas pelas seguintes equações:

$$
\begin{aligned}
& \dot{x}_{i}=3 x_{i}-x_{i}^{3}+2-y_{i}+\mathcal{I}_{i}+c x_{j} \\
& \dot{y}_{i}=\epsilon\left(\alpha\left(1+\tanh \left(x_{i} / \beta\right)\right)-y_{i}\right)
\end{aligned}
$$

onde $\mathcal{I}_{i}$ define um sinal externo ao oscilador $i, c$ define a força de acoplamento entre os osciladores $i$ e $j$. Os demais parâmetros bem como a dinâmica deste oscilador são explicados em detalhes na Seção 2.2.1. Aqui, o principal objetivo é ilustrar o processo de sincronização em uma rede com osciladores contínuos acoplados positivamente.

Na Figura 2.3 são apresentadas duas simulações em uma rede com dois osciladores descritos pela Equação (2.3). Na Figura 2.3(a), é possível observar que, com o valor de $c=0.02$ utilizado, a sincronização não é obtida. Quando o valor de $c=0.06$, os dois osciladores sincronizam após alguns ciclos, como apresentado na Figura 2.3(b).

Casos mais gerais utilizando este modelo de oscilador serão detalhados mais adiante nas Seções 2.2.1 e 3.5. A sincronização em osciladores contínuos caóticos é abordada na Seção 3.3.

\section{1.4 Sincronização em Redes de Neurônios Pulsados}

O estudo do sincronismo em redes de neurônios têm atraído a atenção de diversos pesquisadores ao longo dos últimos anos (Mirollo \& Strogatz, 1990; Kuramoto, 1991; Corral et al., 1995; Hopfield \& Herz, 1995; Díaz-Guilera et al., 1998; Campbell et al., 1999; Timme et al., 2006). Uma caracterís- 
(a)

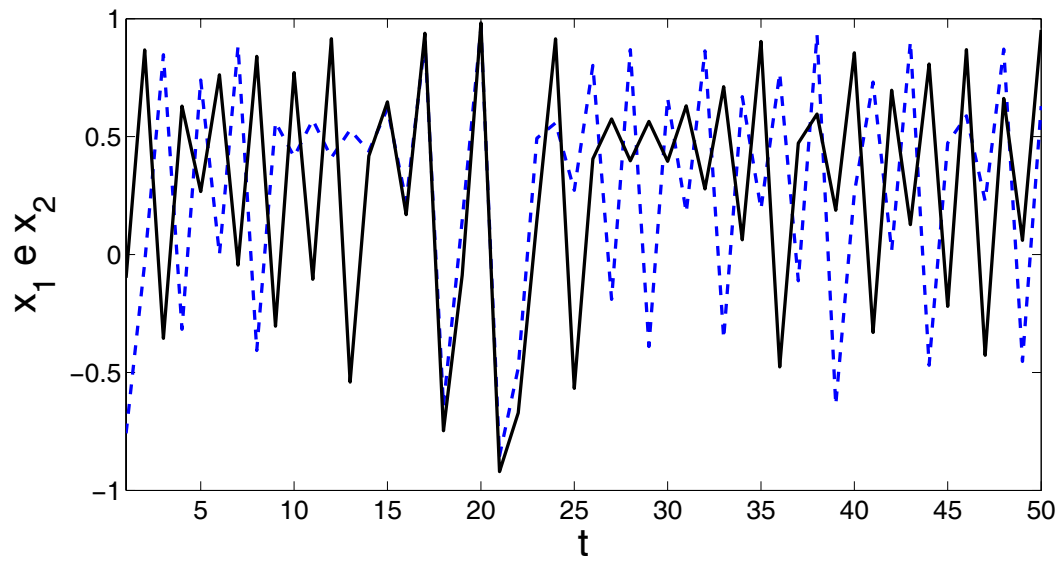

(b)

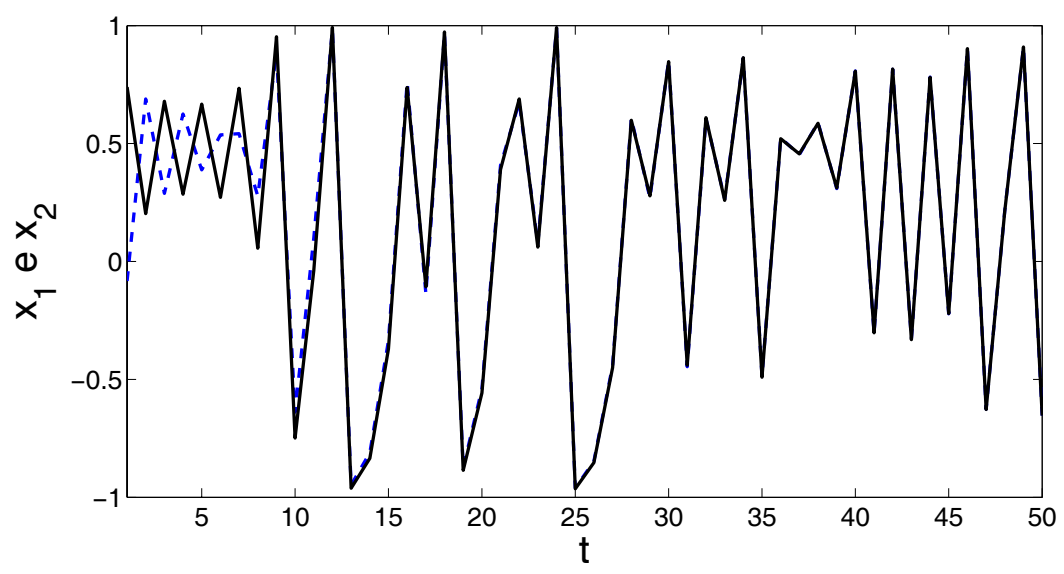

(c)

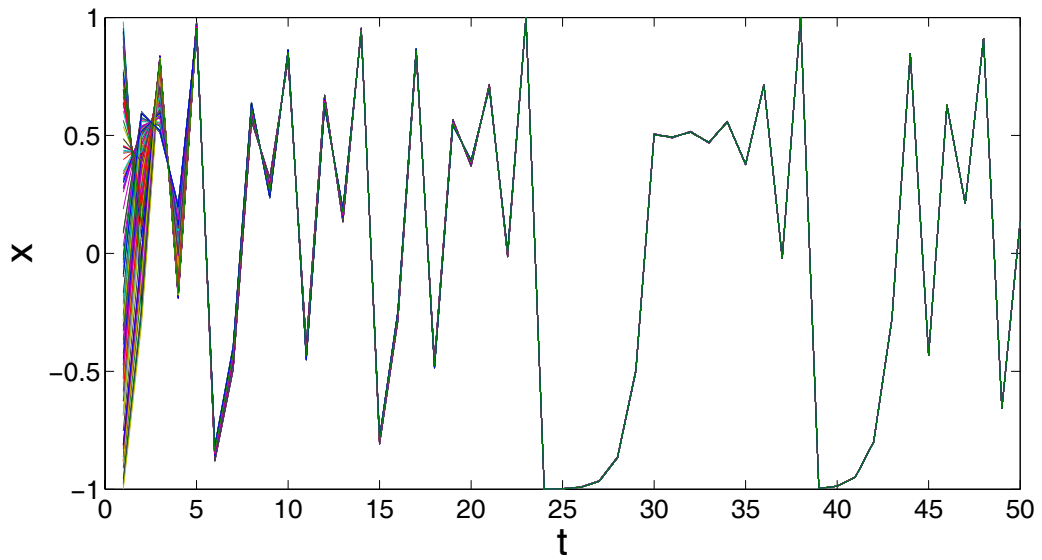

Figura 2.1: Séries temporais do GCM. (a) $N=2$ e $c=0,2$; (b) $N=2$ e $c=0,55$; (c) $N=100$ e $c=0,55$. 


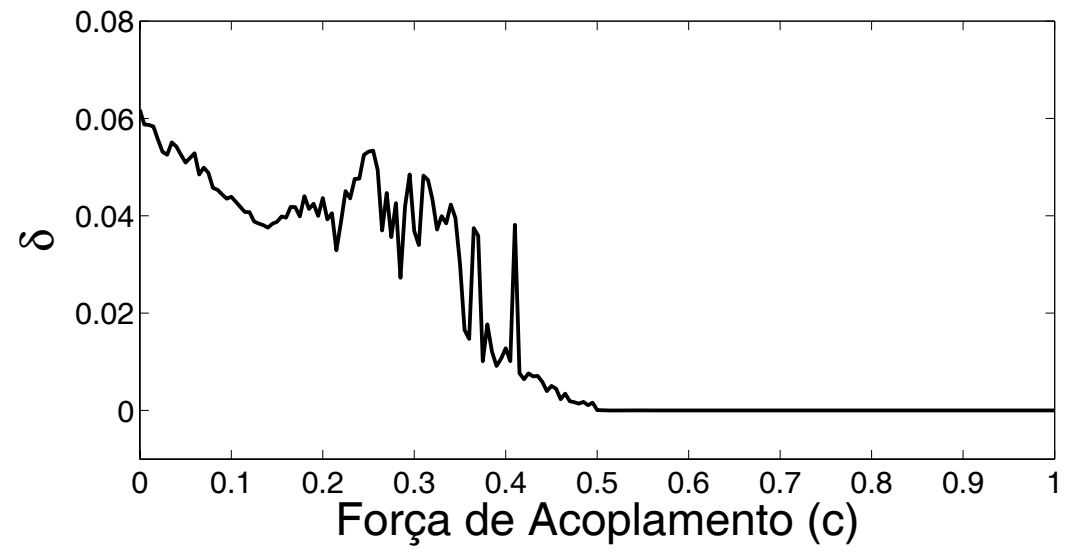

Figura 2.2: Desvio padrão das trajetórias $\delta$ versus força de acoplamento $c$. Em cada ponto da curva $\delta$ é calculado em um intervalo de 1000 iterações desconsiderado um período transiente de 2000 iterações. $N=100$.

(a)

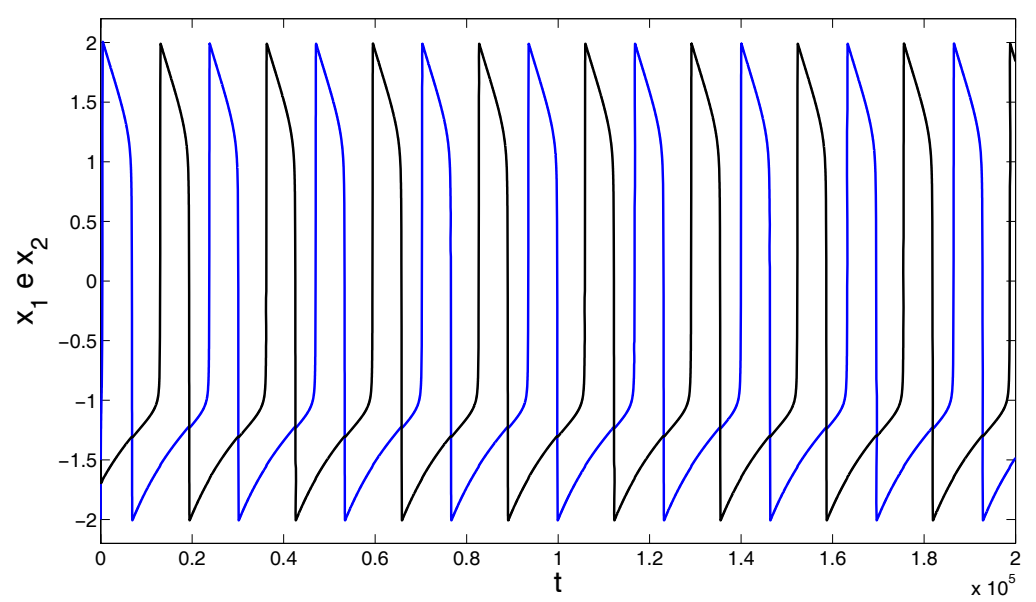

(b)

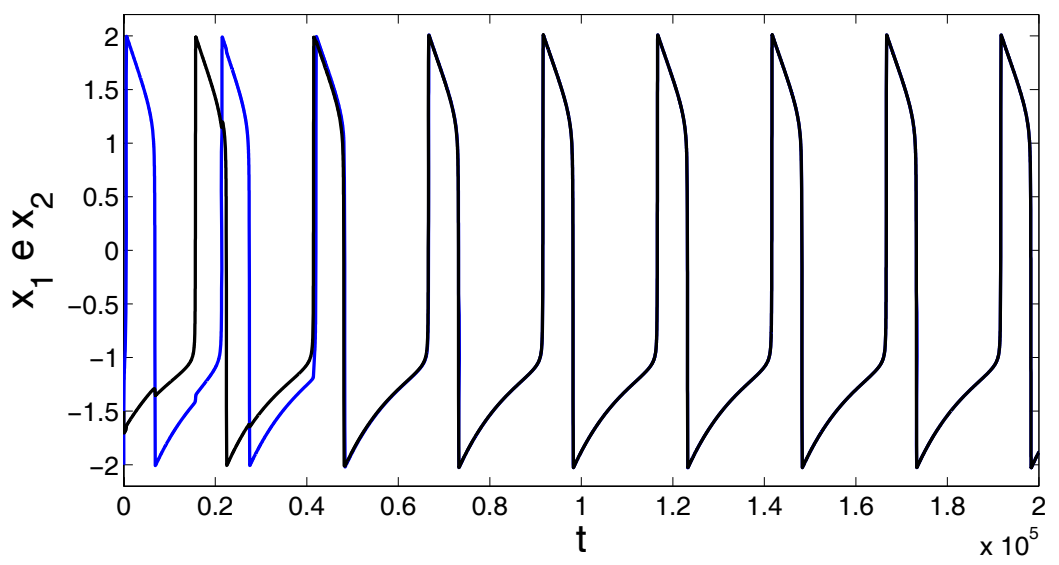

Figura 2.3: Séries temporais de dois osciladores de relaxamento acoplados. (a) $c=0,02$; (b) $c=0,06$. 
tica fundamental em redes formadas por neurônios pulsados está na forma de acoplamento entre os elementos na rede. Ao contrário dos modelos descritos anteriormente onde a influência dos vizinhos é contínua, nestas redes os sinais transmitidos pelas conexões representam pulsos discretos. Assim, um neurônio $j$ recebe estimulação de um neurônio vizinho $i$ apenas quando este emite um pulso (potencial de ação).

Diversos modelos matemáticos têm sido propostos para modelar a dinâmica neural (Izhikevich, 2004). Entretanto, dado sua simplicidade e eficiência computacional quando comparado a outros osciladores neurais, o neurônio Integra e Dispara (I\&D) (Mirollo \& Strogatz, 1990; Izhikevich, 2004) é geralmente adotado em estudos envolvendo dinâmica neural. Diversos autores têm demonstrado que redes compostas por esses osciladores podem exibir um comportamento síncrono. Por exemplo, Mirollo \& Strogatz (1990) demonstraram que uma rede composta por osciladores I\&D globalmente conectada por sinapses excitatórias (positivas) exibe um comportamento de sincronização global.

Uma análise do processo de sincronização bem com alguns exemplos deste fenômeno são adiados para a Seção 3.4.

\subsection{Correlação Temporal}

Experimentos fisiológicos têm evidenciado a existência de atividades rítmicas síncronas em aglomerados neurais em várias regiões do cérebro de diversos mamíferos, como por exemplo no córtex de humanos, gatos e macacos (Eckhorn et al., 1988; Grey et al., 1989; Eckhorn et al., 1990; Engel et al., 1991; Murthy \& Fetz, 1992; Gong et al., 2003). A sincronização em sistemas neurais tem sido associadas a diversos processos cognitivos, como memória, percepção visual, atenção, dentre outros (Niebur \& Koch, 1994; Fries et al., 2001; Ward, 2003; Axmacher et al., 2006; Buia \& Tiesinga, 2006; Kim et al., 2007; Jermakowicz \& Casagrande, 2007). Segundo Sejnowski \& Paulsen (2006), a atividade rítmica no cérebro de mamíferos está relacionada a três processos fundamentais. Primeiro, a informação pode ser representada por oscilações neurais; segundo, a sincronização é responsável por regular o fluxo de informação; por fim, a sincronização auxilia no processo de armazenamento e recuperação de informação.

Embora grandes avanços tenham sido obtidos com respeito ao entendimento de vários processos cognitivos, a forma como o cérebro percebe os objetos a partir do agrupamento de características visuais simples como cor, orientação, profundidade e movimento, isto é, realiza a organização perceptual da cena, ainda não é completamente entendida (Wang, 2005). 
Segundo Kandel et al. (2000),

“... as percepções não são cópias diretas e precisas do mundo à nossa volta... O cérebro não registra simplesmente o mundo externo como uma fotografia tridimensional. Ao contrário, o cérebro constrói uma representação interna dos eventos físicos depois de primeiro analisá-los em suas partes componentes. Ao varrer o campo visual, o cérebro analisa simultaneamente, porém separadamente, a forma dos objetos, seu movimento e sua cor, tudo isso antes de compor uma imagem de acordo com as regras do próprio cérebro." (O Problema da Integração - Binding Problem) (Kandel et al., 2000).

De acordo com Wang (2005), uma peça fundamental na solução do problema da integração está na representação baseada na estrutura temporal dos sinais neurais. Esta estrutura temporal define a base da teoria da correlação temporal (von der Malsburg, 1981).

Segundo von der Malsburg (1981) investigações das funções cerebrais e da organização perceptual indicam um mecanismo de correlação temporal como uma estrutura de representação (codificação temporal). A teoria de correlação temporal define que um objeto é representado pela correlação temporal dos disparos (potenciais de ação) de células neurais espacialmente distribuídas que representam diferentes características de um mesmo objeto. Enquanto neurônios codificando características de objetos distintos não possuem suas atividades correlacionadas.

Uma maneira natural de realizar a correlação temporal é através do uso de osciladores (von der Malsburg \& Schneider, 1986; Terman \& Wang, 1995). Assim, cada oscilador pode representar um conjunto de características (cor, orientação, movimento, profundidade, etc. (Wang, 2005)) de tal forma que cada segmento (objeto) é representado por um conjunto de osciladores com atividades síncronas, enquanto segmentos distintos são representados por grupos de osciladores fora de sincronia. Esta forma especial da correlação temporal é denominada teoria da Correlação Oscilatória (Terman \& Wang, 1995; Wang \& Terman, 1995). Neste caso, as características são representadas por osciladores e o problema da integração é solucionado através da sincronização e dessincronização entre os osciladores neurais (Wang, 2005).

Segundo Terman \& Wang (1995), dois aspectos principais podem ser estabelecidos sobre a correlação oscilatória: primeiro, a sincronização de osciladores que representam características de um mesmo objeto deve ser estabelecida e em segundo a dessincronização entre grupos de osciladores distintos deve ser realizada, sendo que um dos maiores desafios no desenvolvimento de modelos de correlação oscilatória está na implementação simultânea destes dois mecanismos totalmente antagônicos (Zhao \& Macau, 2001; Wang, 2005). 
O primeiro modelo computacional a demonstrar a aplicação da teoria da correlação temporal em um problema real foi proposto em (von der Malsburg \& Schneider, 1986). Neste trabalho, com o objetivo de segregar dois sinais de áudio, um inibidor global foi adotado para dessincronizar os dois grupos de osciladores representando cada um dos sinais, no qual cada grupo corresponde a um conjunto de osciladores globalmente conectados. Entretanto, Terman \& Wang (1995) afirmaram que as simulações apresentadas em (von der Malsburg \& Schneider, 1986) estão relacionadas a um sistema pequeno e que nenhum estudo analítico foi realizado, o que resulta em uma incerteza da generalidade dos resultados obtidos. Assim, com o objetivo de estabelecer uma teoria formal da correlação oscilatória, Wang \& Terman (1995) propuseram uma arquitetura de rede de osciladores localmente acoplados denominada LEGION (Locally Excitatory Globally Inhibitory Oscillator Networks) que foi extensivamente analisada em (Terman \& Wang, 1995). A Seção 2.2.1 apresenta uma descrição deste modelo.

O modelo LEGION (Terman \& Wang, 1995; Wang \& Terman, 1995) tem se mostrado um modelo de correlação oscilatória bastante robusto com diversas aplicações computacionais bem sucedidas. Entretanto, em sua forma original, o modelo apresenta uma limitação referente ao número máximo de segmentos que podem ser obtidos pela rede (Terman \& Wang, 1995; Wang \& Terman, 1997). Considerando esta limitação, em (Wang \& Terman, 1997) foi proposto um algoritmo para segmentação de imagens extraído do sistema de equações diferenciais do modelo LEGION, no qual as propriedades essenciais do modelo são mantidas. Em (Campbell et al., 1999) o modelo LEGION foi modificado substituindo-se os osciladores originais por neurônios do tipo Integra e Dispara. Em ambas as modificações, os autores conjecturam uma capacidade de segmentação infinita.

Uma outra forma de contornar esta limitação do número de segmentos que podem ser obtidos simultaneamente pela rede é dada através das propriedades do caos e da sincronização de sistemas caóticos (Hansel, 1992), onde as flutuações caóticas permitem uma rápida dessincronização dos segmentos. Em (Zhao et al., 2000), um modelo de rede de osciladores caóticos é proposto, no qual a sincronização entre osciladores que representam um mesmo segmento é rapidamente obtida. Simultaneamente, a dessincronização dos segmentos distintos é atingida devido a alta sensibilidade a condição inicial dos sistemas caóticos e a propriedade densa do caos (Zhao et al., 2000). Devido a este comportamento observado experimentalmente na rede, os autores conjecturam que o modelo possui uma capacidade de segmentação ilimitada. Esta forma de correlação oscilatória utilizando osciladores caóticos é denominada Correlação Oscilatória Caótica e será descrita na Seção 2.2.2. 
Diversos modelos de correlação oscilatória têm sido desenvolvidos para as mais diversas tarefas: segmentação (Wang \& Terman, 1996, 1997), segmentação de movimento (Çesmeli \& Wang, 2000), segregação de sinais sonoros (von der Malsburg \& Schneider, 1986; Wang \& Brown, 1999), percepção visual (Chen \& Wang, 2001), clusterização de dados (Rhouma \& Frigui, 2001), dentre outros (Wang, 2005).

As próximas seções apresentam alguns modelos modelos computacionais desenvolvidos sob a teoria da correlação oscilatória (caótica).

\subsubsection{O Modelo LEGION}

O modelo LEGION (Locally Excitatory Globally Inhibitory Oscillator Network) proposta originalmente em (Terman \& Wang, 1995; Wang \& Terman, 1995) têm sido um arquitetura para modelos de Correlação Oscilatória muito utilizada nos últimos anos. Wang e seus colaboradores têm aplicado o LEGION a diversas tarefas, como por exemplo: Estudo numérico e analítico da dinâmica de osciladores acoplados (Terman \& Wang, 1995; Campbell \& Wang, 1996; Wang \& Terman, 1996; Campbell et al., 1999), segmentação de imagens (Wang \& Terman, 1997; Campbell et al., 1999), segregação auditiva (Wang \& Brown, 1999), seleção de objetos (Wang, 1999), dentre outras.

Esta rede têm se mostrado uma eficiente metodologia na implementação de modelos de correlação oscilatória, principalmente pela alta velocidade de aquisição de sincronismo entre os osciladores representando objetos e dessincronia entre os grupos distintos de osciladores. A aquisição de sincronismo pela rede, como analisado em Campbell et al. (1999) utilizando neurônios Integra e Dispara, é obtida de forma bastante rápida, no qual o número de oscilações necessárias para obtenção do sincronismo cresce proporcionalmente ao logaritmo do crescimento da rede. Esta afirmação apresentada em (Campbell et al., 1999) contrasta fortemente com as conclusões apresentadas por Hopfield \& Herz (1995) no qual foi sugerido que, devido a lenta sincronização dos neurônios na rede, este fenômeno não poderia ser utilizado como mecanismo de computação biológico.

A arquitetura LEGION, em sua forma básica, é composta de três elementos principais: osciladores neurais, acoplamentos excitatórios locais e um inibidor global. Um exemplo da arquitetura LEGION é apresentada na Figura 2.4. Os acoplamentos excitatórios locais têm por finalidade sincronizar os grupos de osciladores representando cada um dos objeto presentes na cena visual. Por outro lado, o inibidor global tem como função gerar a dessincronização entre os grupos de osciladores. Desta forma a rede cria um mecanismo de cooperação local e competição global que são os dois requisitos necessários para a implementação da correlação oscilatória. Em sua proposta original o 
modelo LEGION (Terman \& Wang, 1995; Wang \& Terman, 1995) é formado por uma rede de osciladores de relaxamento, no qual cada oscilador é composto por uma variável excitatória $x_{i}$ e uma variável inibitória $y_{i}$, definidas pelas seguintes equações:

$$
\begin{aligned}
& \dot{x}_{i}=3 x_{i}-x_{i}^{3}+2-y_{i}+\mathcal{I}_{i}+S_{i}+\rho \\
& \dot{y}_{i}=\epsilon\left(\alpha\left(1+\tanh \left(x_{i} / \beta\right)\right)-y_{i}\right)
\end{aligned}
$$

onde $\mathcal{I}_{i}$ é o estímulo externo ao elemento $i, S_{i}$ define o acoplamento com os demais elementos da rede e $\epsilon$ é uma constante positiva com valor pequeno, $\rho$ representa o sinal de ruído que tem duas finalidades: testar a robustez do modelo e auxiliar a dessincronização de padrões distintos. Normalmente, com objetivo de reduzir a probabilidade de auto-geração de pulsos de um oscilador isolado, a média de $\rho$ é configurada em $-\rho$. Se $\mathcal{I}_{i}$ for definido como uma constante e os termos $S_{i}$ e $\rho$ eliminados, a Equação (2.4) se torna um típico oscilador de relaxamento (van der Pol, 1926).

A Figura 2.5 apresenta as isóclinas nulas ${ }^{1}$ e a trajetória de um oscilador definido pela Equação (3.48), onde a isóclina nula de $x$ é uma função cúbica e a isóclina nula de $y$ é uma função sigmoide. Se a estimulação externa recebida por um oscilador, $\mathcal{I}_{i}>0$, as isóclinas nulas de $x$ e $y$ da Equação 2.4 se intersectam em apenas um ponto. Neste caso, o estado do oscilador é denominado disparando e uma dinâmica de ciclo limite estável é observada (Figura 2.5(a)). A órbita periódica do oscilador alterna entre duas fases bem definidas denominadas fase ativa e fase de silêncio, que correspondem as fases com alto e baixo valores de $x$ respectivamente (ver Figura 2.5(a)). A transição entre as duas fases ocorre rapidamente em comparação ao o movimento interno observado em cada fase, por essa razão, a transição entre as fases ativa e de silêncio é denominada salto de fase (jumping). O parâmetro $\alpha$ controla quanto tempo o oscilador permanece em cada uma dessas fases. Quando a estimulação externa recebida pelo oscilador $\mathcal{I}<0$, as duas isóclinas nulas da Equação 2.4 se intersectam em um ponto de equilíbrio estável no lado esquerdo da função cúbica (ver Figura 2.5(b)). Neste caso, o oscilador não produz uma órbita periódica e nenhuma oscilação é observada. Entretanto, o oscilador pode ser induzido a oscilar através de estimulações recebidas por acoplamentos com osciladores vizinhos. Devido a essa característica, neste estado o oscilador é denominado excitável. O parâmetro $\beta$ controla a inclinação da função sigmoide. Normalmente $\beta$ é configurado com um valor próximo a zero de tal forma a aproximar a função sigmoide de uma função degrau (Terman \& Wang, 1995).

O acoplamento do sistema representado por $S_{i}$ é definido pela seguinte

\footnotetext{
${ }^{1}$ Definem as curvas quando $\dot{x}=0$ e $\dot{y}=0$.
} 


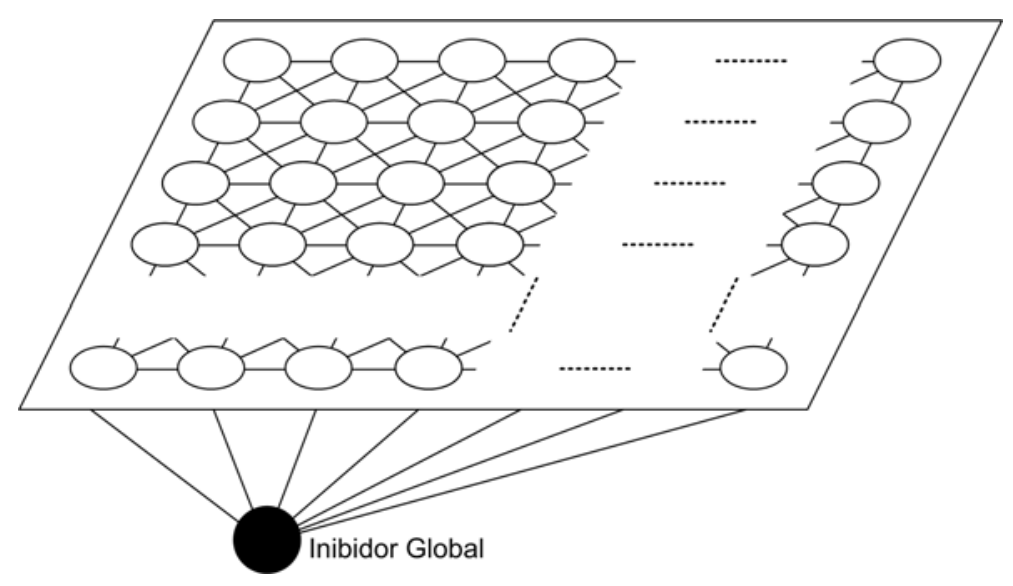

Figura 2.4: Arquitetura típica de uma rede LEGION 2D. Os círculos de cor branca representam osciladores e o circulo de cor preta representa o inibidor global.

equação:

$$
S_{i}=\sum_{k \in N_{i}} W_{i k} S_{\infty}\left(x_{k}, \theta_{x}\right)-W_{z} S_{\infty}\left(z, \theta_{z}\right)
$$

onde $W_{i k}$ é definido como a força de acoplamento entre os osciladores $i$ e $k, N_{i}$ define a vizinhança de interação do oscilador $i$, representada pelos osciladores que fazem conexão direta com este. O parâmetro $\theta_{x}$ é um limiar que indica quando um oscilador pode afetar seus vizinhos. Normalmente, $\theta_{x}$ é escolhido entre a fase de silêncio e a fase ativa do oscilador. $W_{z}$ define a força de ligação entre o oscilador $i$ e o inibidor global definido por $z$. $\theta_{z}$ é um limiar. A função $S_{\infty}$ é definida pela seguinte equação:

$$
S_{\infty}(x, \theta) \equiv \frac{1}{1+e^{\left(1-\kappa\left(x-\theta_{z}\right)\right)}}
$$

onde $\kappa$ é um parâmetro positivo. A dinâmica do inibidor global $z$ definida por:

$$
\dot{z}=\phi\left(\sigma_{\infty}-z\right)
$$

onde o parâmetro $\phi$ controla a velocidade com que o inibidor global reage a sinais provenientes dos osciladores da rede, $\sigma_{\infty} \equiv 0$ se $x_{i}<\theta_{z}$ para todo $i$. Por outro lado, $\sigma_{\infty} \equiv 1$ se pelo menos um oscilador $x_{i} \geq \theta_{z}$. Neste caso, se pelo menos um oscilador estiver acima do limiar, o inibidor global $z$ é estimulado e aproxima 1 e passará a atuar como inibidor na rede assim que $z$ superar o $\operatorname{limiar} \theta_{z}$ (Equação (2.5)).

De uma forma geral, a dinâmica da rede pode ser resumida da seguinte forma: quando um oscilador entra na fase ativa, ele aciona o inibidor global que por sua vez envia um sinal de inibição para toda a rede, conforme descrito pelas Equações (2.4)-(2.7). Além disso, o oscilador que entra na fase ativa, também propaga o seu sinal para os seus respectivos vizinhos que por sua vez 
(a)

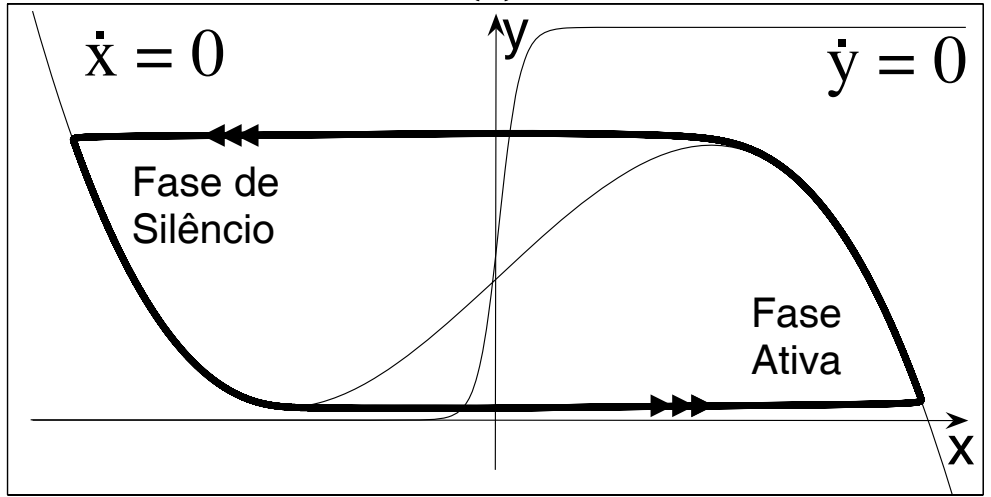

(b)

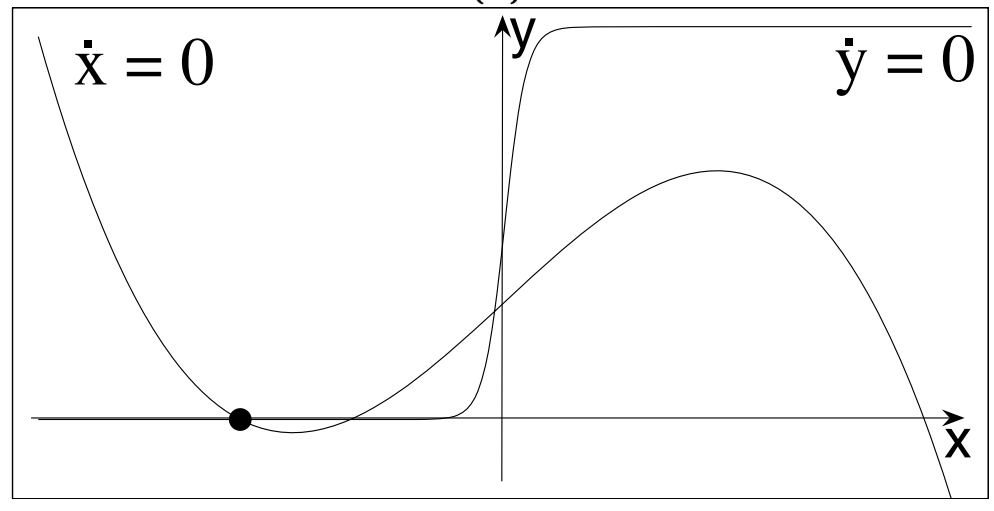

Figura 2.5: Dinâmica de um oscilador de relaxamento. (a) Compostamento de um oscilador no estado disparando. A trajetória é definida por um ciclo limite representado pela curva em negrito e as seta indicam a direção do movimento. (b) Comportamento dinâmico de um oscilador no estado excitável. Neste caso, um ponto fixo estável é observado e está indicado por um ponto no lado esquerdo inferior do gráfico.

continuam o processo. Desta forma, a rede apresenta uma forma cooperativa de ativação local, enquanto o inibidor é responsável pela competição global. O inibidor global pode ser interpretado como uma espécie de mecanismo de atenção no qual, uma vez que um segmento está ativo, os demais são inibidos. Devido aos mecanismos de cooperação responsáveis por sincronizar osciladores vizinhos alimentados por sinais semelhantes e de competição cujo objetivo está na separação temporal dos grupos sincronizados, a rede LEGION se torna uma interessante abordagem ao problema da segmentação de imagens. Neste caso, cada ponto da imagem é representada por um oscilador, a sincronização entre estes definem os objetos/segmentos e a segmentação é realizada pela separação temporal das fases dos osciladores.

Além do modelo utilizando osciladores de relaxamento descrito acima, a arquitetura LEGION também foi implementada utilizando outros modelos de osciladores neurais, como os osciladores Wilson-Cowan (Campbell \& Wang, 1996) e neurônios Integra e Dispara (Campbell et al., 1999). 


\subsubsection{Correlação Oscilatória Caótica}

Como já relatado no início desta seção, uma outra forma de se obter uma rápida sincronização entre os osciladores e dessincronização entre grupos de osciladores distintos está na aplicação das propriedades do caos e da sincronização de sistemas caóticos. Seguindo esta linha, uma nova forma de correlação oscilatória, denominada correlação oscilatória caótica foi desenvolvida (Zhao et al., 2000; Zhao \& Macau, 2001).

Em (Zhao et al., 2000), uma rede de osciladores Wilson-Cowan alimentados por um sinal periódico foi proposta para a tarefa de segmentação de imagens. Este modelo será apresentado na Seção 3.3, pois é utilizado como base para um dos modelos proposto nesta tese. A seguir, um outro modelo baseado em correlação oscilatória caótica é apresentado.

Zhao \& Macau (2001) propuseram um modelo computacional baseado em uma rede de mapas caóticos acoplados aplicada a segmentação de cena. Este modelo é composto por uma rede 2D no qual cada mapa caótico da rede está associado a um pixel da imagem de entrada. Os elementos da rede são considerados ativos quando o pixel associado ao mapa representa um objeto na imagem. Neste caso, o mapa recebe um valor de entrada alto. Quando o pixel associado a um elemento da rede representa o fundo, isto é, não está associado a nenhum objeto da imagem, este é dito inativo.

Inicialmente, o acoplamento na rede é organizado de tal forma que cada elemento ativo está diretamente acoplado aos seus vizinhos ativos mais próximos, enquanto os elementos inativos não estão acoplados. No decorrer da evolução do sistema, todos os elementos ativos, vizinhos de um elemento $(i, j)$ tal que este elemento já esteja acoplado a um elemento $(k, l)$ também serão acoplados ao elemento $(k, l)$. Este processo é repetido até que todos os elementos ativos espacialmente conectados na rede estejam acoplados. A dinâmica da rede é governada pelas seguintes equações:

$$
\begin{gathered}
x_{i j}(t+1)=(1-\epsilon) f\left(x_{i j}(t)\right)+\frac{\epsilon}{K_{i j}\left(\tau_{R}\right)+1} \sum_{k=1}^{N} \sum_{l=1}^{M} J_{k l, i j}\left(\tau_{R}\right) f\left(x_{k l}(t)\right) \\
K_{i j}\left(\tau_{R}\right)=\sum_{k=1}^{N} \sum_{l=1}^{M} J_{k l, i j}\left(\tau_{R}\right) \\
J_{k l, i j}\left(\tau_{R}\right)=\phi_{k l}\left(N_{i j}\left(\tau_{R}\right)\right) z_{i j}(t) z_{k l}(t) \\
J_{k l, i j}\left(\tau_{1}\right)=0 \quad \forall k l, i j
\end{gathered}
$$




$$
\begin{aligned}
& \phi_{k l}\left(N_{i j}\left(\tau_{R}\right)\right)= \begin{cases}1 & \mathrm{se}(k, l) \in N_{i j}\left(\tau_{R}\right) \\
0 & \text { caso contrário }\end{cases} \\
& z_{i j}(t+1)=H\left(\sum_{d=0}^{T} H\left(x_{i j}(t-d)-\theta_{i j}\right)-\Theta_{i j}\right) \\
& N_{i j}\left(\tau_{R}+1\right)=N_{i j}\left(\tau_{R}\right) \cup N_{k l}\left(\tau_{R}\right), \quad \forall(k, l) \in N_{i j}\left(\tau_{R}\right) \\
& N_{i j}\left(\tau_{1}\right)= \begin{cases}\phi & \text { se } z_{i j}=0 \\
\{(k, l) \text { tal que }|k-i| \leq 1 \text { e }|l-j| \leq 1\} & \text { se } z_{i j}(1)=1\end{cases}
\end{aligned}
$$

onde $i j$ e $k l$ são índices dos elementos na rede, sendo $N$ e $M$ as variáveis que definem o tamanho da rede $2 \mathrm{D} N \times M$; $t$ define a escala de tempo rápida. Esta escala é empregada na evolução da variável de estado dos elementos; $x_{i j}(t)$ define a variável de estado do elemento na posição $(i, j)$ da rede no tempo $t$; $\epsilon$ é uma constante que representa a força de acoplamento entre os elementos; a função $f(x)$ é definida como sendo um mapa logístico $f(x)=a x(1-x)$ onde $a$ define a não-linearidade do mapa (parâmetro de bifurcação); $\tau_{R}$ representa a escala de tempo lenta do sistema definida sobre um intervalo de tempo da escala rápida $t$, neste caso, $\tau_{R}$ é definida como: $\tau_{R}=(R-1) T_{0},(R-1) T_{0}+1,(R-1) T_{0}+2, \ldots, R T_{0}-1$, onde $T_{0}$ é um intervalo de tempo definido em $t ; K_{i j}\left(\tau_{R}\right)$ informa o número de elementos acoplados ao elemento $(i, j)$ no instante de tempo $\tau_{R} ; J_{k l, i j}\left(\tau_{R}\right)$ é uma variável binária responsável por indicar se o elemento $(i, j)$ está acoplado ao elemento $(k, l)$ no instante de tempo $\tau_{R} ; N_{i j}\left(\tau_{R}\right)$ é o conjunto de todos os elementos acoplados ao elemento $(i, j)$ no instante de tempo $\tau_{R} ; H(s)$ é a função Heaviside; $z_{i j}(t)$ é uma variável binária que indica se o elemento $(i, j)$ está ativo ou não com base nas últimas $T$ iterações no espaço de tempo $t$; $\theta_{i j}$ representa um limiar utilizado para indicar a atividade instantânea do elemento $(i, j) ; \Theta_{i j}$ é um limiar que define a média de ativação do elemento $(i, j)$ nos últimos $T$ instantes de tempo.

O processo de segmentação utilizando este modelo pode ser definido como segue. Seja uma imagem de entrada composta por diversos objetos onde cada ponto desta imagem é representado por um oscilador na rede. Os osciladores ativos que representam os objetos na imagem são iterativamente acoplados conforme descrito anteriormente. Devido a esse acoplamento entre osciladores e a sincronização de sistemas caóticos, cada objeto passa a ser representado por uma única trajetória e devido as propriedades do caos tais trajetórias associadas aos objetos são separadas ao longo do tempo, permitindo que os 
objetos sejam segmentados.

\subsubsection{O Modelo PCNN}

A Rede Neural de Pulso Acoplado (PCNN - Pulse-Coupled Neural Network) é um modelo de rede neural composta por neurônios pulsados. O modelo PCNN é baseado no modelo Linking-field proposto pelo pesquisador Eckhorn et al. (1990). O modelo Linking-field foi projetado para investigar atividades síncronas observadas entre neurônios de regiões do córtex visual do gato (Eckhorn et al., 1990; Johnson, 1994).

Segundo Johnson \& Padgett (1999), duas propriedades fundamentais do modelo PCNN podem ser ressaltadas: o modelo utiliza pulsos em seu processamento e o acoplamento nos neurônios é realizado através de junções multiplicativas e não aditivas como acontece em outros modelos de neurônios. A utilização de acoplamentos multiplicativos tem como vantagem a não ativação do neurônio quando este não recebe estimulação primária. Esta característica é importante em processamento de imagens, pois, neurônios representando pontos do fundo da cena podem ser ignorados por receberam entrada primária nula permanecendo inativos.

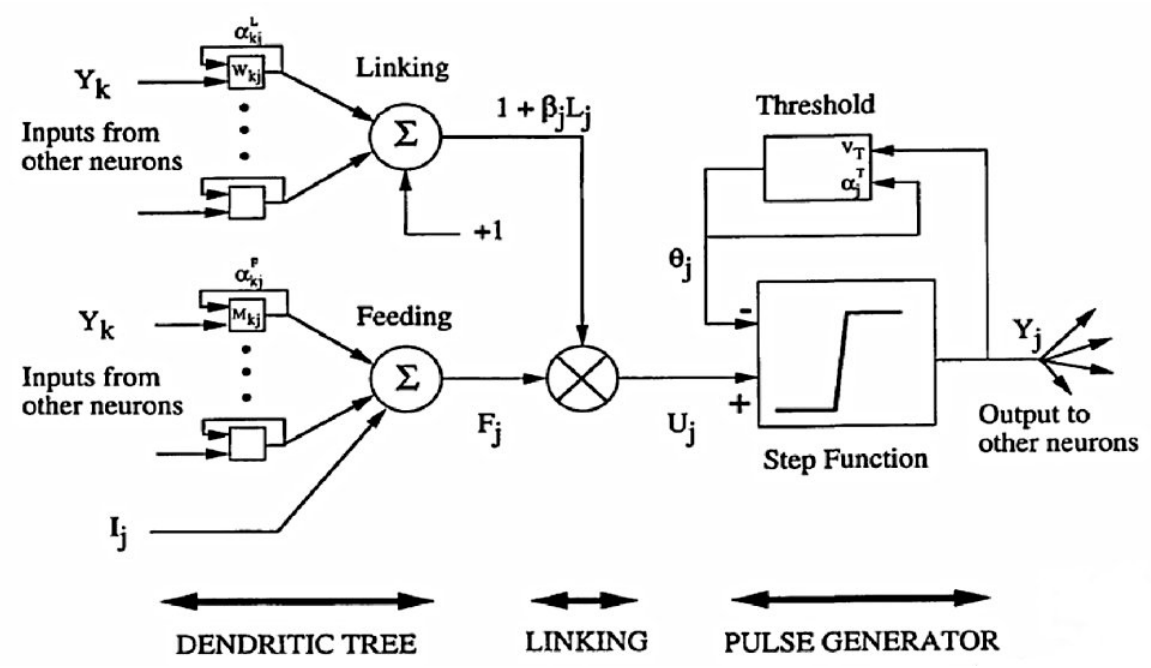

Figura 2.6: O Neurônio PCN obtido em (Johnson, 1994)

Diversos pesquisadores ao longo dos últimos anos têm ampliado o trabalho de Johnson aplicando o modelo original e suas modificações a diversas tarefas: Fusão de Imagens (Broussard et al., 1999), Segmentação de Imagens (Kuntimad \& Ranganath, 1999), Visão Foveal (Kinser, 1999), Remoção de Sombras em Imagens ( $\mathrm{Gu}$ et al., 2005), Casamento de Contorno e Movimento (Yu \& Zhang, 2004), dentre outras aplicações.

O neurônio em uma rede PCNN (Figura 2.6) possui três partes distintas: a árvore dendrítica, o modulador e um gerador de pulsos, descritos a seguir. 
A árvore dendrítica é composta por duas regiões: entradas de alimentação $F_{j}$ e entradas de enlace $L_{j}$ apresentadas abaixo pelas Equações (2.15) e (2.16) respectivamente. A entrada de enlace é representada pela soma ponderada de todos os sinais gerados por neurônios vizinhos ao neurônio $j$. A entrada de alimentação é uma soma ponderada de todos os pulsos provenientes da vizinhança acrescida de um sinal de entrada $I_{j}$.

As sinapses deste neurônio podem ser visualizadas como circuitos $\mathrm{RC}^{2}$ que são carregadas pelos pulsos provenientes da vizinhança de acordo com um fator de ganho e decaem de forma exponencial de acordo com a constante de decaimento de cada sinapse (decaimento das sinapses de alimentação: $\alpha_{k j}^{F} \mathrm{e}$ decaimento das sinapses de enlace: $\alpha_{k j}^{L}$ ).

Na maioria das implementações cuja finalidade é o processamento de imagens, o carregamento das sinapses é realizado em um único passo definido por uma constante, isto é, quando um pulso de algum neurônio vizinho atinge a sinapse deste neurônio, ela é configurada instantaneamente com este valor definido e então passa a ser descarregada exponencialmente de acordo com a constante de decaimento. Este comportamento dinâmico das sinapses é responsável por prolongar o efeito pós-sináptico de cada pulso que chega até o neurônio, transformando assim um pulso em um sinal persistente (Broussard et al., 1999).

As constantes de decaimento $\alpha^{F}$ e $\alpha^{L}$ e o fator de ganho caracterizam os sinais. As sinapses de alimentação possuem uma constante de decaimento menor que a constante de decaimento das sinapses de enlace. Isto torna as entradas de alimentação mais persistentes que as entradas de enlace.

As entradas de alimentação e de enlace são descritas respectivamente pelas seguintes equações:

$$
F_{j}=\sum_{k} F_{k j}=\sum_{k}\left[m_{k j} \exp \left(-\alpha_{k j}^{F} t\right)\right] * Y_{k}(t)+I_{j}
$$

$\mathrm{e}$

$$
L_{j}=\sum_{k} L_{k j}=\sum_{k}\left[w_{k j} \exp \left(-\alpha_{k j}^{L} t\right)\right] * Y_{k}(t)
$$

onde $m_{k j}$ e $w_{k j}$ são os pesos das sinapses de alimentação e enlace, respectivamente. $Y_{k}(t)$ é um sinal de entrada (pulso - spike) proveniente do $k$-ésimo neurônio da vizinhança, $\alpha_{k j}^{F}$ e $\alpha_{k j}^{L}$ são as constantes de decaimento das sinapses de alimentação e das sinapses de enlace respectivamente, $I_{j}$ é um sinal de entrada externo (geralmente contém informações proveniente do pixel da imagem) e $*$ é o operador de convolução (Johnson, 1994).

O Modulador (Link Modulation), é responsável por gerar o nível total de

\footnotetext{
${ }^{2} \mathrm{RC}$ - Resistor-Capacitor
} 
ativação do neurônio $U_{j}$. O nível de ativação $U_{j}$ do neurônio é descrito por:

$$
U_{j}=F_{j}\left(1+\beta_{j} L_{j}\right)
$$

onde $\beta_{j}$ descreve o parâmetro de enlace que define a força de ligação entre as duas unidades de entrada que compõem o neurônio $j$.

De acordo com Broussard et al. (1999) as entradas de alimentação são moduladas pelas entradas de enlace. Isto significa que o nível de ativação $U_{j}$ é aumentado a um valor maior que o nível adquirido pelas entradas de alimentação sempre que um pulso chega as entradas de enlace (Johnson, 1994). As entradas de enlace forçam neurônios pertencentes a mesma vizinhança e com sinais de entrada semelhantes a pulsarem em sincronia. Esta característica do sinal de enlace é responsável pelo sincronismo observado neste modelo de rede neural.

O Gerador de Pulsos é composto por um "circuito RC" responsável por criar um limiar de disparo dinâmico $\theta_{j}$ que decai exponencialmente de acordo com uma constante $\alpha_{j}^{\theta}$ (Equação (2.19)). Guando o nível de ativação $U_{j}$ excede o limiar de disparo $\theta_{j}$, o neurônio emite um pulso (dispara um potencial de ação - spike). Este disparo, representado pela variável $Y_{j}$, é definido pela seguinte equação:

$$
Y_{j}=H\left(U_{j}-\theta_{j}\right)
$$

onde $H$ é a função Heaviside. Este disparo imediatamente carrega o "circuito RC" $\left(\theta_{j}\right)$ com uma constante $V_{\theta}$. A dinâmica de $\theta_{j}$ é definida pela seguinte equação:

$$
\theta_{j}=\left[V_{\theta} \exp \left(-\alpha_{j}^{\theta} t\right)\right] * Y_{j}(t)
$$

onde $\alpha_{j}^{\theta}$, descrita acima, é uma constante que determina a velocidade de decaimento do limiar $\theta_{j}$. Este incremento de $\theta_{j}$ a um valor constante elevado evita que o neurônio dispare imediatamente após a geração de um pulso. Do ponto de vista biológico, este fenômeno pode ser caracterizado como o período refratário absoluto do neurônio, no qual este fica temporariamente incapacitado de disparar novos pulsos (Kandel et al., 2000).

\subsection{Atenção Visual}

A sensação de perceber os diversos detalhes de uma cena instantaneamente é uma mera ilusão criada por nosso sistema de visão. Em um dado instante do tempo, apenas uma pequena parte de toda informação visual disponível em uma cena atinge um nível consciente e é analisada em detalhes 
pelo cérebro (Pashler, 1998). O mecanismo de percepção responsável por selecionar qual parte do estimulo visual é realmente tratado pelo cérebro é denominado Atenção Visual. A atenção visual é um mecanismo de fundamental importância para a sobrevivência de um organismo permitindo que este consiga analisar cenas complexas de forma eficiente (Desimone \& Duncan, 1995; Pashler, 1998; Yantis, 1998).

De uma forma geral, a atenção visual está dividida em dois mecanismos principais (Yantis, 1998). O primeiro, atenção bottom-up, é representado por processos involuntários de baixa ordem atuando sobre os estímulos visuais provenientes da cena (atenção guiada por estímulos - stimulus-driven). Nesta fase, características visuais simples são extraídas paralelamente e a segmentação da cena e a definição de regiões relevantes são obtidas de forma préatentiva. Geralmente, a atenção bottom-up é associada ao conceito de saliência resultante do contraste de características visuais. Por exemplo, quando uma cena composta por um único objeto de cor vermelha e diversos objetos de cor verde é analisada, obtém-se a sensação de que o objeto vermelho está se destacando da cena. Este fenômeno é resultante do alto contrate no atributo cor entre os objeto favorecendo a seleção do objeto vermelho durante o processo de competição por atenção. O segundo, atenção top-down, é responsável por uma seleção voluntária de atributos visuais e está associada aos objetivos do indivíduo (atenção guiada por metas - goal-driven). Por exemplo, se uma pessoa está procurando por um objeto com uma forma geométrica específica, como um lápis, aspectos de mais alto nível podem guiar o processo seletivo de atenção durante a busca, ignorando outras características visuais que não façam parte do objetivo. Este processo, pode inclusive, moderar o processamento da atenção bottom-up. De uma forma geral, o processamento top-down envolve regiões do cérebro externas ao córtex visual, como por exemplo o córtex pré-frontal, uma memória de trabalho responsável por manter uma meta guiando o processo de busca, dentre outros (Deco \& Rolls, 2005).

Os modelos de atenção visual podem ser divididos em duas teorias principais de acordo com o mecanismo de seleção visual adotado (Pashler, 1998). A primeira é baseada na localização visual do estímulo (location-based attention) e a segunda baseada na seleção de objetos como unidade de atenção (object-based attention) (para uma ampla revisão ver (Egeth \& Yantis, 1997; Pashler, 1998; Yantis, 2000)). Os modelos baseados em localização podem ser comparados a um holofote (spotlight) que se desloca por uma superfície não iluminada. Desta forma, o foco de atenção pode ser representado pela região iluminada pelo holofote. Por outro lado, os modelos baseados em objetos sugerem que a seleção é realizada em nível de objeto definido como unidade básica de percepção. Neste caso, uma vez que a atenção é direcionada a uma 
parte qualquer de um objeto, as demais partes deste também se beneficiam do processo atentivo.

Recentes evidências comportamentais e neuropsicológicas têm demonstrado que a seleção de objetos estabelece um papel importante na visão de primatas (Roelfsema et al., 1998; O’Craven et al., 1999; Wang et al., 2005; Martinez et al., 2007; Richard et al., 2008; Shinn-Cunningham, 2008). Sugere-se que processos pré-atentivos realizados de forma inconsciente pelo cérebro, como uma organização perceptual, são responsáveis pela segregação objetofundo e segmentação da cena visual em um conjunto de objetos. Desta forma, os objetos, representando unidades de percepção, são selecionados integralmente durante o processo de competição por atenção (Desimone \& Duncan, 1995). A Organização Perceptual tem sido extensivamente estudada na psicologia da Gestalt onde é enfatizado que o mundo visual é percebido como um aglomerado de objetos bem estruturados e não como uma coleção de pontos desorganizados (ver Figura 2.7 para ilustração). A formação de objetos é governada por regras de agrupamento gestaltianas tais como conectividade, proximidade e similaridade. Vale observar que, embora tais processos possam ser caracterizados como bottom-up, eles também podem ser influenciados por mecanismos top-down de acordo com algum objetivo definido (Yantis, 2000). Acredita-se que tais mecanismos evoluíram para aumentar a velocidade do processamento visual e liberar recursos computacionais de mais alto nível do cérebro para realização de tarefas como planejamento e tomada de decisão (Yantis, 2000).

Inspirados por descobertas experimentais, diversos pesquisadores têm desenvolvido modelos de atenção visual em duas frentes principais: neurociência computacional e visão computacional. Os pesquisadores da área de neurociências buscam desenvolver modelos que possuam o maior grau de plausibilidade biológica necessário para a compreensão do processo de atenção visual presente nos seres vivos. Tais modelos visam simular de forma quantitativa os dados psicofísicos obtidos experimentalmente. Como por exemplo, em (Corchs \& Deco, 2001a,b) foi proposto um modelo neurodinâmico com objetivo de estudar e simular experimentos de busca visual. Este modelo é composto por diversos osciladores modelados por neurônios I\&D. Outro trabalho foi proposto em (Deco \& Rolls, 2005) onde um arcabouço foi desenvolvido para compreender as relações existentes entre diversas funções cerebrais. Este modelo apresenta como os processos bottom-up e top-down interagem nos aspectos cognitivos da visão além de outros mecanismos envolvidos no processamento da atenção visual.

Por outro lado, o desenvolvimento de modelos de atenção visual como ferramentas computacionais tem por objetivo imitar, de forma qualitativa, o com- 
portamento observado nos sistemas biológicos. Desta forma, um sistema de atenção pode atuar como um estágio primário em sistemas de visão mais complexos, como sistemas de reconhecimento de objetos, auxiliando na redução da quantidade de dados processadas por este. Assim, o modelo de atenção tem como objetivo aumentar a eficiência do um sistema permitindo que os recursos computacional disponíveis sejam utilizados para processar apenas regiões de interesse na cena (Carota et al., 2004; Walther et al., 2005; Bonaiuto \& Itti, 2006; Li \& Itti, 2008; Siagian \& Itti, 2008). Além disso, em um estudo recente realizado por Elazary \& Itti (2008) foi demonstrado que a seleção de objetos em uma cena é altamente influenciada por processos bottom-up. Este resultado corrobora com os fatos mencionados acima, onde apenas as regiões mais salientes da imagem precisam ser analisadas, descartando-se as demais.

Devido a natureza competitiva do processo de seleção visual, grande parte dos modelos computacionais de atenção são formados por redes winner-takeall (WTA) (Koch \& Ullman, 1985; Tsotsos et al., 1995; Itti et al., 1998; Itti \& Koch, 2001a). Através do processo competitivo realizado pelos neurônios, a rede WTA seleciona um neurônio, denominado vencedor, com base na resposta gerada por um dado estímulo de entrada (Arbib, 2003). Desta maneira, um ponto, representado pelo neurônio, é selecionado, mas não um objeto como um todo. Em (Itti et al., 1998), por exemplo, quando um neurônio vence a competição, um circulo com raio fixo e centro na posição do neurônio vencedor é considerada como a região recebendo a atenção do sistema. Este forma de entrega da atenção é denominada como holofote de atenção. Geralmente, esses modelos fazem uso de um mapa de duas dimensões que codifica a conspicuidade da cena visual em análise (Koch \& Ullman, 1985; Itti \& Koch, 2001a). Este mapa de saliência é utilizado para direcionar o foco de atenção (Koch \& Ullman, 1985; Gottlieb et al., 1998; Itti \& Koch, 2001a). Entretanto, tais modelo computacionais representam apenas características da teoria de atenção baseada em localização negligenciando aspectos relacionados à seleção de objetos.

Considerando modelos de atenção com fins computacionais, a incorporação de características provenientes da teoria baseada em objetos juntamente com os aspectos da seleção espacial podem trazer diversas vantagens (Sun \& Fisher, 2003). Dentre as principais, as seguintes vantagens podem ser destacadas:

- a busca visual é mais eficiente. Diferentes atributos visuais que compõem um objeto podem estar localizados em uma mesma região do espaço. Uma vez que o objeto é selecionado como um todo, não há necessidade de mudanças no foco de atenção para recuperar esses atributos;

- objetos são selecionados ao invés de regiões vazias da cena. Uma vez que 
a cena é pré-organizada em objetos através da organização perceptual, pode ser evitado que o foco de atenção seja direcionado a regiões de fundo da cena;

- a seleção hierárquica é possível. Neste caso, a cooperação entre os mecanismo de atenção baseada em objeto e em localização pode beneficiar a seleção hierárquica de objetos complexos movendo o foco de atenção entre suas partes constituintes.

Para desenvolver um modelo neural de atenção visual que implemente aspectos baseados em objetos, um mecanismo para agrupar elementos simples da cena visual em um conjunto de objetos coerentes deve ser considerado. Este problema relacionado a maneira como os elementos sensoriais de uma cena são combinados para formar objetos perceptíveis é conhecido como o Problema da Integração (binding problem) (von der Malsburg, 1981; Revounsuo \& Newman, 1999).

Conforme detalhado na Seção 2.2, von der Malsburg propôs a teoria da correlação temporal como uma forma para resolver o problema integração (von der Malsburg, 1981). Esta teoria afirma que objetos são representados pela correlação temporal das atividades de disparo de neurônios codificando diferentes propriedades de um mesmo objeto. Uma maneira natural de codificar a correlação temporal é através da sincronização de osciladores neurais onde cada oscilador codifica alguma característica de um objeto (von der Malsburg \& Schneider, 1986; Terman \& Wang, 1995; Wang, 2005). Esta forma de correlação temporal é denominada correlação oscilatória onde osciladores que codificam diferentes características de um mesmo objeto são sincronizados e aqueles que codificam diferentes objetos são dessincronizados. Desta forma, uma maneira de simular o processo de organização perceptual está na implementação de um modelo de correlação oscilatória. Isto é, representar os atributos da cena visual através de osciladores neurais.

Embora modelos computacionais de atenção visual baseados em osciladores tenham sido estudados há vários anos (Niebur et al., 1993), a primeira tentativa de desenvolver um modelo de atenção para seleção de objetos foi apresentada em (Wang, 1999). Este estudo resultou em um modelo capaz de selecionar objetos com base em seus tamanhos, onde objetos maiores são considerados mais salientes. Este modelo é baseado em uma rede LEGION (ver Seção 2.2.1) acrescida de um mecanismo de inibição lento. A dinâmica do modelo pode ser entendida da seguinte maneira: dado uma cena composta por diversos objetos como entrada, o modelo seleciona o maior objeto enquanto os demais são inibidos. Este fenômeno de seleção é observado devido ao comportamento competitivo entre os objetos segmentados pela rede LEGION. Sempre que um segmento se torna ativo na rede (os neurônios que os representam 
estão disparando), o mecanismo de inibição lento, definido por um termo de inibição, é configurado com o valor referente ao tamanho do objeto ativo. Desta forma, apenas objetos com tamanho superior ao objeto previamente ativo são capazes de superar o mecanismo de inibição se tornando ativos. Por sua vez, este último objeto ativo reconfigura o inibidor com um novo valor referente ao seu tamanho. Como consequência, após um número de ciclos, apenas o maior objeto sobrevive ao processo competitivo e continua ativo na rede. Entretanto, este modelo considera como atributo de saliência visual apenas o tamanho do objeto, o que restringe sua aplicação como um modelo geral de seleção visual. Seleção de objetos baseada em tamanho usando correlação oscilatória também foi abordada por Kazanovich \& Borisyuk (2002) onde a frequência e a amplitude dos osciladores são utilizadas para determinar a seleção. Pelos resultados apresentados em (Kazanovich \& Borisyuk, 2002) pode ser observado que o modelo proposto é capaz de realizar seleção consecutiva de objetos, porém, apenas imagens sintéticas foram utilizadas nos experimentos. Este último modelo foi estendido em (Borisyuk \& Kazanovich, 2004) onde o mecanismo de detecção de novidades utilizando uma memória de trabalho foi incorporado. Embora este modelo tenha como objetivo solucionar um problema cognitivo mais complexo, a aplicabilidade deste está restrita a imagens sintéticas simples. Em (Wang \& Liu, 2002), um sistema com múltiplas camadas para análise de cenas foi proposto. Neste modelo, uma rede LEGION é utilizada para realizar uma segmentação primária da cena. Após, camadas superiores do modelo são responsáveis por analisar cada um dos segmentos gerados pela rede LEGION isoladamente. Embora este modelo incorpore certos mecanismos de atenção, onde um objeto é analisado por vez em um dado instante do tempo, outros aspectos de atenção bottom-up não são consideradas. Um modelo de correlação oscilatória também foi utilizado no desenvolvimento de um modelo de atenção para seleção auditiva (Wrigley \& Brown, 2004).

Outro modelo de atenção aplicado a visão computacional incorporando aspectos de seleção baseada em objetos foi proposto em (Sun \& Fisher, 2003). Embora este modelo realize a seleção visual de objetos baseada em uma arquitetura que incorpora tanto aspectos bottom-up quanto top-down, é assumido que o processo de organização perceptual já foi realizado por algum outro mecanismo externo ao modelo. Em (Walther \& Koch, 2006), um modelo de atenção para seleção de regiões, denominadas proto-objetos, é proposto. Neste modelo, primeiramente um mapa de saliência baseado no modelo proposto em (Itti et al., 1998) é criado. Uma vez definidos o ponto de mais alta saliência, um processo de propagação da atenção sobre região (proto-objeto) que contém este ponto é realizada através de um mecanismo de crescimento de regiões. Este processo, através de um mecanismo de inibição por retorno, é repetido 
para várias regiões da imagem. Entretanto, tais modelos não são construídos sob a arquitetura de redes de osciladores, que é foco de investigação desta tese.

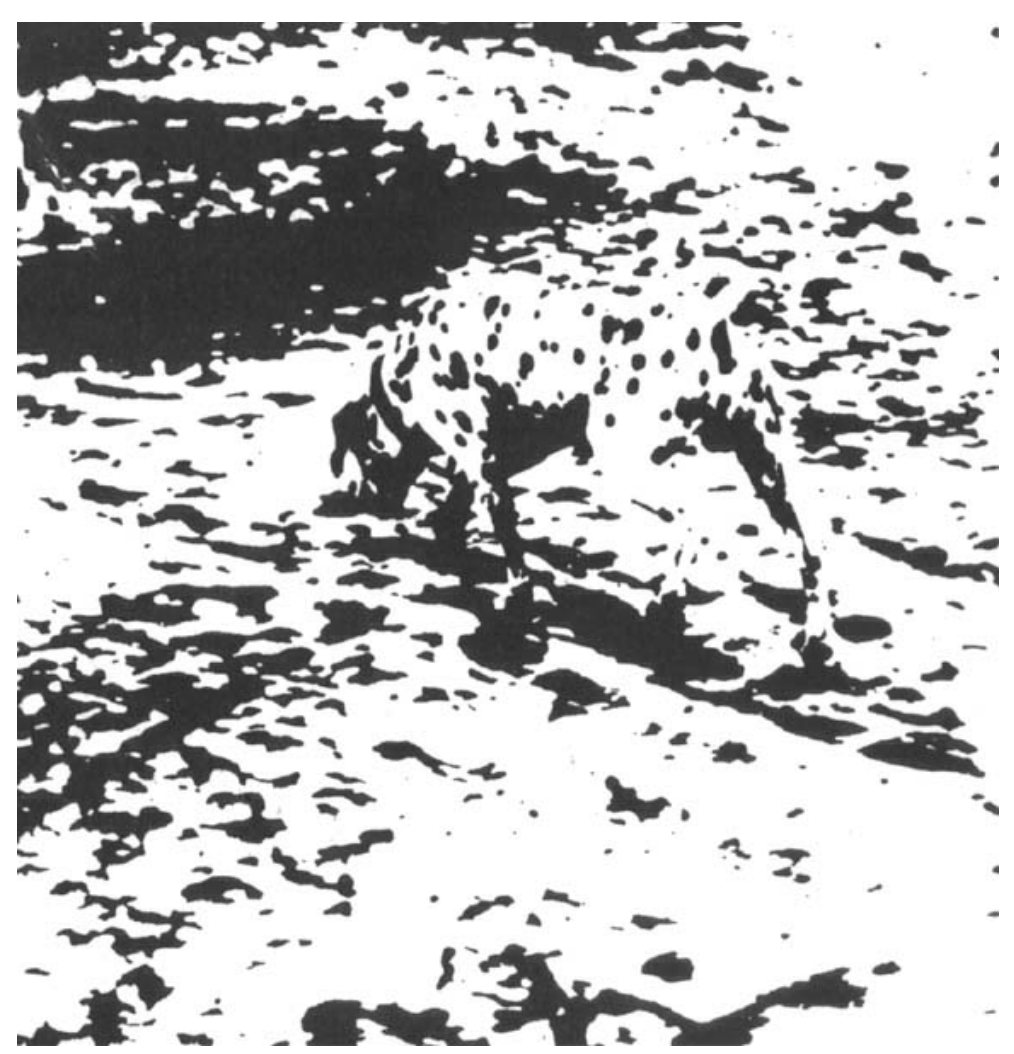

Figura 2.7: Ilustração da organização perceptual (Gestalt). A forma de um cachorro pode ser observada no centro da cena.

Como mencionado anteriormente, a maioria dos modelos de atenção bottomup utiliza o conceito de um mapa de saliência, inclusive o modelo proposto e apresentado na Seção 3.5. Por esta razão, o mapa de saliência proposto por Itti et al. (1998) é detalhado a seguir.

\section{O Mapa de Saliência: Itti et al. (1998)}

O mapa de saliência apresentado nesta seção foi proposto por Itti et al. (1998) como uma implementação do modelo de atenção bottom-up baseada em mapa de saliência desenvolvido por Koch \& Ullman (1985). Este mapa simula as propriedades de baixo nível da visão em primatas e é baseado na ideia de que um único mapa é usado pelo cérebro para controlar a entrega da atenção (Koch \& Ullman, 1985; Gottlieb et al., 1998; Itti \& Koch, 2001a).

O mapa de saliência é explicitamente definido por um mapa de duas dimensões responsável por codificar a saliência sobre todos os pontos da cena visual. Ele se baseia na ideia de que a atenção é guiada pelo contraste local de atributos visuais (Itti et al., 1998; Itti \& Koch, 2001a). Mesmo sendo constituído de uma arquitetura simples, este modelo tem demonstrado um 


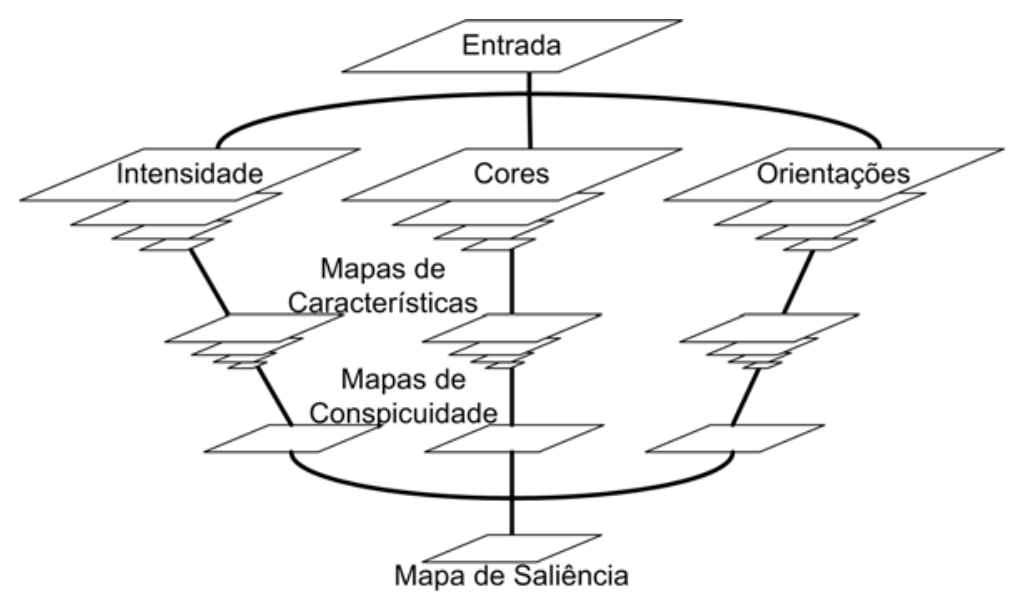

Figura 2.8: Fluxograma de geração do mapa de saliência (Itti et al., 1998).

desempenho robusto mesmo na análise de cenas complexas. Além disso, os resultados obtidos por este são qualitativamente semelhantes a aqueles obtidos por humanos realizando inspeção visual (Itti \& Koch, 2000).

De uma forma geral, o mapa de saliência proposto por Itti et al. (1998) é produzido da seguinte maneira. Primeiro, um conjunto de mapas primários, tais como cores e orientação, são extraído da cena. Na sequência, para simular os campos receptivos de centro-vizinhança ${ }^{3}$ (center-surround), operações sobre diferentes escalas espaciais destes mapas são realizadas. Este processo é seguido por um operador de normalização resultando em um novo conjunto de mapas denominados mapas de características. Os mapas de características, por sua vez, são combinados formando os mapas de conspicuidade. Por fim, o mapa de saliência é gerado através de uma combinação linear dos mapas de conspicuidades. Este processo é ilustrado na Figura 2.8.

Formalmente, dada uma imagem de entrada definida por $\Upsilon$, uma pirâmide gaussiana composta por nove níveis é criada através da convolução de um filtro gaussiano seguido de uma redução da imagem em um fator de $1 / 2$. O resultado é um conjunto de $\Upsilon(i), i \in\{0,1,2, \ldots, 8\}$, que correspondem aos nove níveis de $\Upsilon(0)=\Upsilon$ (imagem original) até $\Upsilon(8)$ (nono nível da pirâmide com resolução de $1 / 256$ da imagem original).

Cada $\Upsilon(i)$ é composto por três canais representados por $r, g$ e $b$, que representam os canais vermelho, verde e azul, respectivamente. O mapa de intensidade (tons de cinza), $I$, para cada nível é calculado pela seguinte equação:

$$
I(i)=\frac{r(i)+g(i)+b(i)}{3}
$$

com $i \in\{0,1,2, \ldots, 8\}$.

\footnotetext{
${ }^{3}$ São campos receptivos circulares com zonas de excitação central e inibição na vizinhança ou com excitação na vizinhança e inibição central.
} 
A partir dos canais $r, g$ e $b$ são obtidos os mapas vermelho-verde $(R G)$ and azul-amarelo $(B Y)$ para cada um dos níveis da pirâmide. A extração desses mapas (color opponencies) apresentados a seguir, difere do modelo original proposto em (Itti et al., 1998). Aqui, a definição proposta em (Walther, 2006; Walther \& Koch, 2006) é utilizada por apresentar resultados superiores aos obtidos pelo modelo original. Porém, vale observar que o conceito geral, bem como o mapa de saliência resultante é qualitativamente idêntico ao proposto em (Itti et al., 1998). Os mapas $R G$ e $B Y$ são definidos pelas equações:

$$
R G=\frac{r-g}{\max (r, g, b)}
$$

$\mathrm{e}$

$$
B Y=\frac{b-\min (r, g)}{\max (r, g, b)}
$$

Além disso, para evitar a instabilidade numérica quando o nível de intensidade aproxima zero, $R G$ e $B Y$ assumem valor zero quando $\max (r, g, b)<1 / 10$.

Os mapas de orientação são criados através da convolução do mapa $I$ com filtros de Gabor para quatro orientações $\theta \in\left\{0^{\circ}, 45^{\circ}, 90^{\circ}, 135^{\circ}\right\}$ :

$$
O_{\theta}=\left\|I * G_{0}(\theta)\right\|+\left\|I * G_{\pi / 2}(\theta)\right\|
$$

onde $G(\theta)$ representa um kernel de Gabor com orientação $\theta$ e o subscrito de $G$ indica a fase do kernel.

Após extraídos os mapas de intensidade $(I)$, cores $(R G$ e $B Y$ ) e orientações $\left(O_{\theta}\right)$, os mapas de característica são gerados através de operações de subtração inter-escala, $\ominus$, entre diferentes níveis de um mesmo mapa. O operador $\ominus$ imita o mecanismo implementado pelos campos receptivos centro-vizinhança encontrados no córtex visual. As seguintes equações definem os mapas de características:

$$
\begin{gathered}
F_{I}(c, s)=|I(c) \ominus I(s)| \\
F_{R G}(c, s)=|R G(c) \ominus R G(s)| \\
F_{B Y}(c, s)=|B Y(c) \ominus B Y(s)|
\end{gathered}
$$

$\mathrm{e}$

$$
F_{\theta}(c, s)=\left|O_{\theta}(c) \ominus O_{\theta}(s)\right|
$$

onde $c \in\{2,3,4\}$ representa o nível do mapa simulando o centro e $s \in\{c+3, c+4\}$ 
representa os mapas no nível de vizinhança. A seguir, esses mapas são combinados para formar os mapas de conspicuidade. O mapa de conspicuidade para intensidade $\left(C_{I}\right)$ é calculado através da seguinte equação:

$$
C_{I}=\oplus_{c=2}^{4} \oplus_{s=c+3}^{c+4} \mathcal{N}\left(F_{I}(c, s)\right)
$$

onde $\oplus$ é um operador de adição inter-escala e $\mathcal{N}$ é um operador de normalização responsável por aumentar a representatividade dos mapas que apresentam poucas regiões ativas (com altos valores) e suprimir os mapas que apresentam atividade homogênea (Itti \& Koch, 2001b).

O mapa de conspicuidade para as cores $\left(C_{H}\right)$ é gerado pela seguinte equação:

$$
C_{H}=\oplus_{c=2}^{4} \oplus_{s=c+3}^{c+4}\left[\mathcal{N}\left(F_{R G}(c, s)\right)+\mathcal{N}\left(F_{B Y}(c, s)\right)\right]
$$

O mapa de conspicuidade para a orientação é gerado em dois passos. Primeiro, um mapa intermediário é calculado para cada uma das orientações consideradas:

$$
C_{\theta}=\oplus_{c=2}^{4} \oplus_{s=c+3}^{c+4} \mathcal{N}\left(O_{\theta}(c, s)\right)
$$

após, esses mapas são combinados em um único mapa, o mapa de conspicuidade para orientação, representando todas as orientações:

$$
C_{O}=\sum_{\theta \in\left\{0^{\circ}, 45^{\circ}, 90^{\circ}, 135^{\circ}\right\}} \mathcal{N}\left(C_{\theta}\right)
$$

Por fim, o mapa de saliência, representado por $m^{s}$, é obtido através de uma combinação linear dos mapas de conspicuidade:

$$
m^{s}=\frac{1}{3}\left[\mathcal{N}\left(C_{I}\right)+\mathcal{N}\left(C_{H}\right)+\mathcal{N}\left(C_{O}\right)\right]
$$

Normalmente, o mapa de saliência é obtido utilizando o quarto nível da pirâmide, isto é, o tamanho do mapa de saliência é $1 / 16$ do tamanho da imagem de entrada. Uma vez gerado o mapa de saliência, $m^{s}$, a região da imagem que deve ser primeiramente selecionada (receber a atenção) é representada pelo ponto do mapa com maior valor de saliência. No modelo de atenção bottomup proposto por Itti et al. (1998), uma rede neural composta por neurônios Integra e Dispara, denominada rede de saliência, é utilizada para representar o mapa de saliência, onde a estimulação externa de cada neurônio é definida pelo valor de saliência dos respectivos pontos no mapa. Como consequência, os neurônios representando regiões mais salientes têm seus potenciais aumentados mais rapidamente. É importante observar que os neurônios desta rede não emitem pulsos, atuando apenas como neurônios integradores (cir- 
cuitos RC).

Os neurônios da rede de saliência alimentam neurônios de outra rede neural do tipo WTA, denominada rede de seleção (Itti et al., 1998). A rede de seleção, por sua vez, é responsável por selecionar apenas um dos neurônios como vencedor, neste caso, o neurônio que corresponde a região de mais alta saliência do mapa. Uma vez selecionado, o foco de atenção do modelo é direcionado para a região onde este se encontra, sendo os demais neurônios da rede inibidos. Além disso, o neurônio vencedor emite um sinal (Inibição por Retorno - IoR) inibindo o neurônio da rede de saliência que o alimenta e também os neurônios vizinhos a este. Desta forma, a região do mapa de saliência, que representa a primeira localização atendida pelo sistema, é inibida permitindo que outras regiões possam ser selecionadas, isto é, recebam o foco de atenção. Como nenhuma característica top-down é considerada neste modelo, a região selecionada como foco de atenção é definida por uma região circular de raio fixo com centro definido pelo neurônio vencedor.

\subsection{Redes Complexas e Detecção de Comunidades}

O início dos estudos relacionados da teoria de redes pode ser atribuído a Leonhard Euler que em 1736 provou uma série de teoremas referentes ao problema do caminho pelas pontes de Königsberg (Barabási, 2003). Este problema consistia na possibilidade de cruzar as sete pontes que ligavam as regiões da cidade de tal forma a não passar mais de uma vez pela mesma ponte. Motivado por este problema popular entre os habitantes da cidade, Euler abstraiu as regiões da cidade por uma representação denominada vértice e as ligações entre estas por arestas. Então, formalmente, demonstrou a inexistência de um caminho cruzando por todas as pontes uma única vez. Este estudo realizado por Euler é considerado o berço de uma área da matemática denominada teoria dos grafos.

Embora o estudo da teoria dos grafos tenha sido desenvolvido ao longo dos séculos seguintes a publicação de Euler, a linha de pesquisa principal desta disciplina sempre esteve voltada ao estudo das propriedades de grafos regulares. Apenas por volta da metade do século XX é que esta teoria sofreu uma grande mudança, no qual os matemáticos e físicos passaram a questionar não apenas sobre as propriedades dos grafos, mas sim, como estes são formados (Barabási, 2003).

Em 1959, Erdös \& Rényi (1959), utilizando métodos probabilísticos em conjunto com a teoria de grafos, propuseram um modelo de rede, denominado redes aleatórias. Em tal modelo, os vértices são ligados aleatoriamente. As propriedades dessas redes (grafos) foram amplamente estudadas na última 
metade do século XX. Entretanto, o estudo mais recente de redes reais começou a apresentar dados mostrando que as conexões em redes sociais e biológicas, por exemplo, não acontecem ao acaso. Dentre os estudos que motivaram a revisão do modelo de formação de redes aleatórias está o estudo realizado por Stanley Milgram (Barabási, 2003). Milgram, na época pesquisador em sociologia em Harvard, desenvolveu um experimento no quais diversas cartas foram enviadas aleatoriamente a várias pessoas nos Estados Unidos. Dentro destas cartas estavam informações sobre pessoas consideradas alvos de tal forma que o leitor deveria enviar a carta a um destes alvos, caso o conhecesse, ou então encaminhar esta carta a algum conhecido que fosse julgado mais provável de conhecer um dos alvos.

A partir deste experimento ficou demonstrado que quaisquer duas pessoas nos Estados Unidos estavam ligadas, na media, por uma distância de aproximadamente 6 pessoas. Este fato resultou no descobrimento de uma propriedade denominada mundo pequeno (small world). Esta propriedade está relacionado ao fato de que mesmo em uma rede formada por uma grande quantidade de vértices, a distância média entre quaisquer dois pontos é relativamente pequena (Milgram, 1967). Entretanto, mesmo sendo um tanto quanto inesperado, na época este resultado não causou um grande impacto nas teorias de redes.

Na última década do século XX, com a publicação de novos descobertas relacionadas ao conceito de redes, um novo tema de pesquisa, denominado redes complexas, foi estabelecido e desde então tem revolucionado não apenas as teorias de redes (grafos) mas também diversas ciências. Dentre os trabalhos que precederam esta revolução no estudo de redes, dois podem ser destacados: 1) o trabalho proposto por Watts \& Strogatz (1998) no qual foi mostrado que a média dos caminhos mais curtos em uma rede pode ser reduzida se algumas ligações de uma rede regular forem aleatoriamente alteradas. Deste trabalho surgiu um modelo de rede chamado redes de mundo pequeno. 2) A descoberta de que muitas redes reais têm a distribuição de grau dos vértices obedecendo uma lei de potencia, $P(k) \sim k^{\gamma}$, na qual $k$ é o numero de conexões de um vértice escolhido aleatoriamente e $\gamma$ é o expoente de escala (Barabási \& Albert, 1999). Esta distribuição heterogênea representa a existência de um pequeno conjunto de vértices que possui um grande numero de ligações (hubs) e um grande número de vértices com poucas arestas. Estas redes são denominadas Redes Livre de Escala (Scale-free Networks).

A seguir, alguns conceitos sobre comunidades e detecção de comunidades em redes complexas são abordados. 


\subsection{Detecção de Comunidades}

Uma característica notável observada em diversas redes complexas é a presença de estruturas modulares locais, conhecidas como comunidades (Newman, 2004a; Danon et al., 2005, 2007). Tais comunidades podem ser definidas como grupos de vértices da rede densamente conectados, enquanto conexões entre vértices pertencentes a grupos (comunidades) diferentes são esparsas (Newman \& Girvan, 2004; Palla et al., 2005). Essas comunidades representam padrões de interação entre vértices da rede, e sua identificação é importante no entendimento dos mecanismos de crescimento e formação da rede (Clauset, 2005). Além disso, um fator importante referente a estrutura das comunidades está na similaridade das características dos vértices que as compõem. Desta forma, por meio da identificação e estudo das comunidades é possível obter informações pertinentes ao domínio da rede. Por exemplo, observando-se a estrutura de ligações entre páginas da world wide $w e b$ é possivel constatar que páginas descrevendo tópicos relacionados tendem a ser mais densamente conectadas entre si do que com o restante da rede (Flake et al., 2002). Esta propriedade também é compartilhada por redes reais provenientes de outros domínios, como redes biológicas (Jeong et al., 2000), rotas de transporte aéreo (Guimerà et al., 2003), redes metabólicas (Guimerà \& Amaral, 2005), dentre outras.

O processo de detecção de comunidades em uma rede não é computacionalmente trivial. Por exemplo, o problema de dividir um grafo em duas partes de mesmo tamanho de tal forma que número de arestas ligando estas partes seja mínimo é definido como um problema NP-Completo (Danon et al., 2005). Para complicar ainda mais este problema, que pode ser visto como um caso simples da tarefa de detecção de comunidades, as redes reais podem ser compostas por um número não conhecido de comunidades e não apenas duas como no caso anterior. Além disso, as comunidades por si só podem ser definidas por estruturas hierárquicas no qual uma comunidade é formada por outras sub-comunidades aninhadas (Ravasz \& Barabasi, 2003; Danon et al., 2005). Devido a importância do problema e a dificuldade computacional em sua solução, diversos autores têm proposto modelos computacionais para realizar de forma automática a detecção de comunidades em redes complexas.

Recentemente, diversos métodos para detecção de comunidades têm sido propostos e aplicados em diversos domínios (Zhou, 2003; Newman \& Girvan, 2004; Newman, 2004b; Reichardt \& Bornholdt, 2004; Boccaletti et al., 2007). Para um recente estudo comparativo, ver (Danon et al., 2005). Dada a grande quantidade de modelos proposto e seus distintos mecanismo computacionais, uma forma de compará-los que tem sido bastante utilizada por diversos autores é através do uso de redes randômicas clusterizadas (Newman, 2004b; 
Danon et al., 2005). Tais redes são compostas por $N$ vértices divididos em $M$ grupos (comunidades). A rede é formada pela seguinte regra: um par de vértices é conectado com probabilidade $p_{i n}$ se eles pertencem a uma mesma comunidade. Por outro lado, dois vértices pertencentes a comunidades distintas são conectados com probabilidades $p_{\text {out }} \cdot p_{\text {in }}$ e $p_{\text {out }}$ são escolhidos de tal forma a controlar o número de intra-conexões $z_{\text {in }}$ e o número de inter-conexões $z_{\text {out }}$ para um dado grau médio de conexão definido $<k>$. Com base nestes parâmetros, a fração de intra-conexões $z_{i n} /<k>$ e a fração de inter-conexões $z_{\text {out }} /<k>$ da rede são definidas, onde $\left(z_{\text {in }} /<k>+z_{\text {out }} /<k>\right.$ ) $=1$. Em (Danon et al., 2005), assim como em diversos outros trabalhos, para testar e comparar a precisão das técnicas de detecção de comunidade, redes com $N=128$ vértices divididos em $M=4$ comunidades iguais e $\langle k\rangle=16$ são utilizadas. Assim, partindo-se de redes com $z_{\text {out }} /\langle k\rangle=0$, isto é, não existem ligações entre comunidades distintas, até $z_{\text {out }} /\langle k\rangle=0.5$, no qual em média metade das arestas de um vértice estão ligadas a vértices da mesma comunidade e o restante são ligadas a vértices de outras comunidades, é possível estudar de forma controlada a capacidade dos algoritmos. Exemplos de duas redes descritas acima para distintos valores de $z_{\text {out }} /<k>$ são apresentadas na Figura 2.9 .

Em (Danon et al., 2005), um estudo comparativo de diversas técnicas utilizando a metodologia descrita acima foi realizado. Na Figura 2.10, uma sequência de gráficos obtidos em (Danon et al., 2005) avaliando a precisão, representada por $\phi$, na tarefa de detecção de comunidades de diversos modelos é apresentada. As siglas referentes aos modelos apresentados na Figura 2.10 estão definidas na Tabela 2.2. Nesta figura pode ser observado que, para redes com estrutura de comunidades bem definidas, ou seja $z_{\text {out }} /<k>$ é um valor próximo a zero, a precisão de todos os algoritmos estudado por Danon et al. (2005) é alta. Entretanto, conforme a proporção de ligações entre vértices de comunidades distintas aproxima o número de ligações intra-comunidade, a precisão dos algoritmos é reduzida, no qual apenas alguns são capazes de obter um acerto superior a $80 \%$.

De uma forma geral, os algoritmos que apresentam uma maior precisão no processo de detecção de comunidades expõem como desvantagem um maior custo computacional. Por outro lado, os algoritmos mais eficientes geralmente não apresentam alta precisão, principalmente quando as comunidades não estão bem definidas. Na Tabela 2.2, obtida em (Danon et al., 2005), é apresentado um quadro comparativo de diversos algoritmos segundo sua complexidade computacional.

A seguir, dois dos principais algoritmos referenciados na literatura são descritos. Esses algoritmos são geralmente utilizados como base de comparação 
para novos algoritmos.

(a)

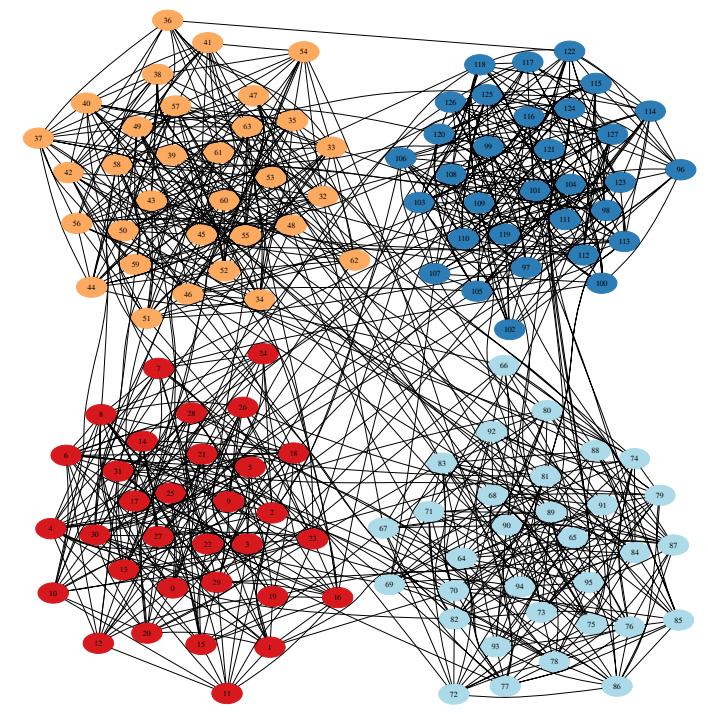

(b)

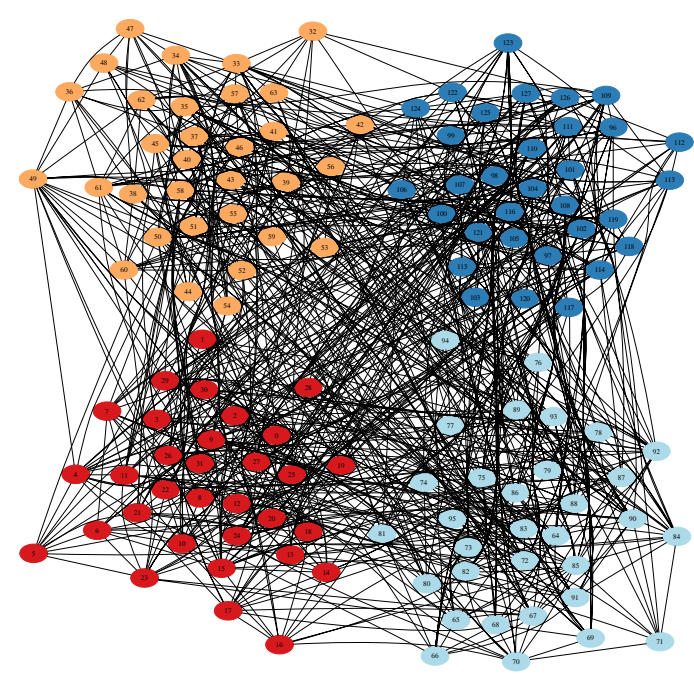

Figura 2.9: Exemplo de rede randômica clusterizada com $N=128, M=4 \mathrm{e}$ $<k>=16$. (a) $z_{\text {out }} /<k>=0,1$. (b) $z_{\text {out }} /<k>=0,5$.

\subsubsection{Algumas Técnicas}

Nesta seção, duas técnicas amplamente utilizadas como critério de avaliação para o desenvolvimento de novos modelos são brevemente apresentadas.

\section{Técnica Baseada em Betweenness (GN)}

Em (Girvan \& Newman, 2002; Newman \& Girvan, 2004) foi proposta uma técnica para detecção de comunidades baseada no conceito de betweenness. De uma forma geral, o betweenness para uma aresta é definido como o valor do número de caminhos mais curtos entre quaisquer dois vértices que passa por esta aresta. Desta forma, a medida favorece arestas localizadas entre comunidades ao mesmo tempo em que desfavorece arestas ligando vértices de uma mesma comunidade. Isto é, quando uma aresta está ligando vértices de comunidades distintas, a probabilidade de um caminho qualquer entre essas duas comunidades passar por esta aresta é alta, resultando assim em um alto valor de betweenness para esta aresta. No método proposto, a cada passo a aresta que apresenta um maior valor de betweenness é removida reduzindo assim a quantidade de ligações entre as comunidades. Consequentemente, como o número de arestas inter-comunidades é menor que o número de ligações dentro de uma comunidade, após a remoção de um conjunto de arestas que apresentam um alto valor de betweenness, espera-se que as comunidades se tornem isoladas possibilitando assim sua identificação. 


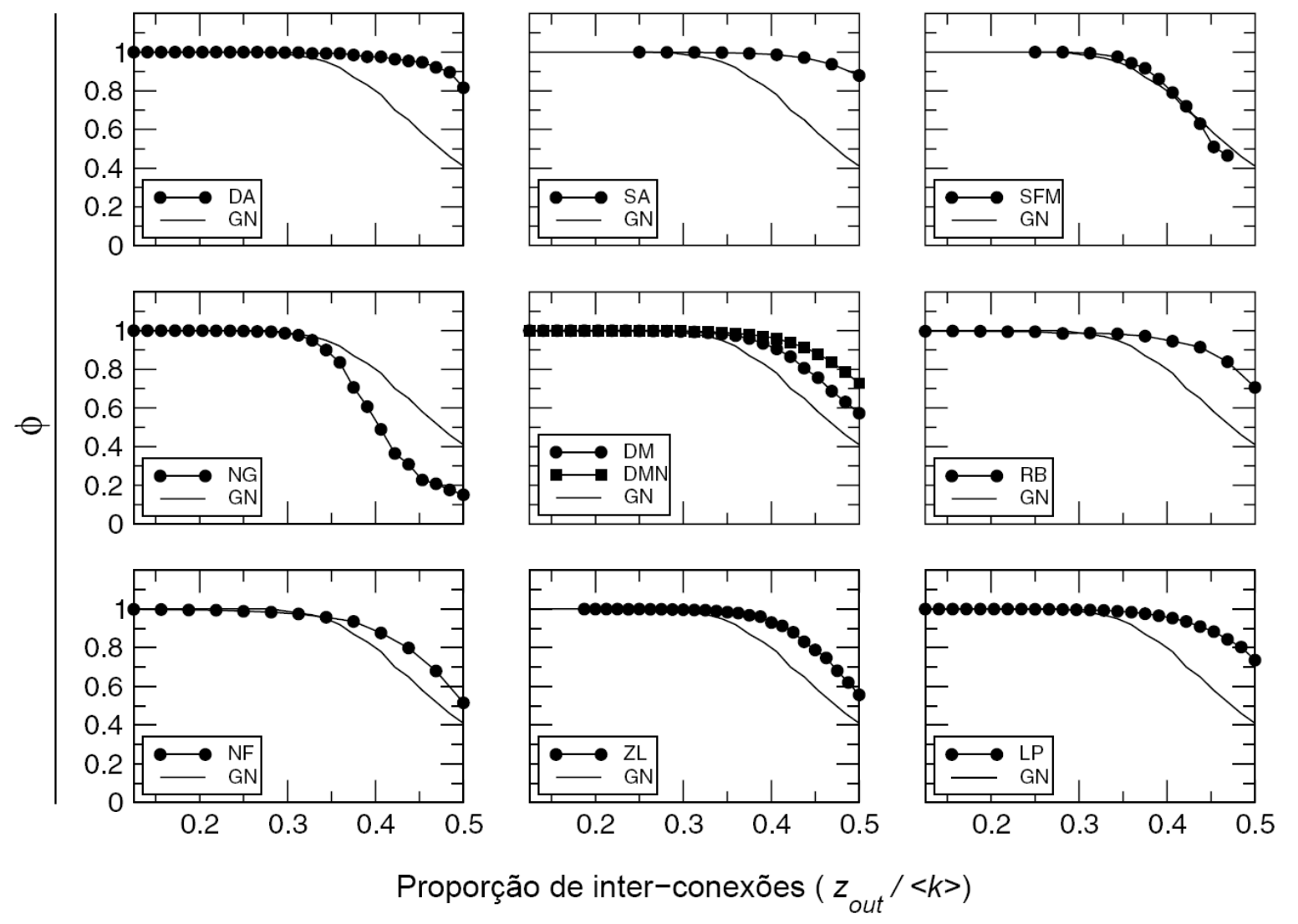

Figura 2.10: Comparação de diversos algoritmos para detecção de comunidades em redes (Obtido em (Danon et al., 2005)). $\phi$ (eixo vertical) representa a precisão no processo de detecção de comunidades e $z_{\text {out }} /<k>$ é representado pelo eixo horizontal. As siglas utilizada nos gráficos são definidas na Tabela 2.2 .

Tabela 2.2: Complexidades computacionais apresentadas por alguns modelos de detecção de comunidades. Esta tabela foi obtida em (Danon et al., 2005).

\begin{tabular}{l|l|l}
\hline \hline Referência & Abreviação & Complexidade \\
\hline \hline Eckmann \& Moses (2002) & EM & $O\left(m<k^{2}>\right)$ \\
\hline Zhou \& Lipowsky (2004) & ZL & $O\left(n^{3}\right)$ \\
\hline Pons \& Latapy (2006) & LP & $O\left(m n^{2}\right)$ \\
\hline Newman (2004b) & NF & $O\left(n \log ^{2} n\right)$ \\
\hline Newman \& Girvan (2004) & NG & $O\left(m^{2} n\right)$ \\
\hline Girvan \& Newman (2002) & GN & $O\left(n^{2} m\right)$ \\
\hline Guimerà et al. (2004) & SA & Dependente de parâmetros \\
\hline Duch \& Arenas (2005) & DA & $O\left(n^{2} \log n\right)$ \\
\hline Fortunato et al. (2004) & FLM & $O\left(n^{4}\right)$ \\
\hline Radicchi et al. (2004) & RCCLP & $O\left(n^{2}\right)$ \\
\hline Donetti \& Muñoz (2004, 2005) & DM/DMN & $O\left(n^{3}\right)$ \\
\hline Bagrow \& Bollt (2005) & BB & $O\left(n^{3}\right)$ \\
\hline Capocci et al. (2004) & CSCC & $O\left(n^{2}\right)$ \\
\hline Wu \& Huberman (2004) & WH & $O(n+m)$ \\
\hline Palla et al. (2005) & PK & $O(\exp (n))$ \\
\hline Reichardt \& Bornholdt (2004) & RB & Dependente de parâmetros \\
\hline \hline
\end{tabular}


Sumarizando, o mecanismo para detecção de comunidades utilizando o conceito de betweenness é dado da seguinte forma. Primeiro, o valor de betweenness para uma das arestas da rede é calculado. Na sequência, a aresta com maior valor de betweenness é removida. Este processo é repetido até que as comunidades sejam separadas.

\section{Técnica Baseada em Modularidade (NF)}

Outra técnica para detecção de comunidades é proposta por Newman (2004b). Neste trabalho, um algoritmo baseado no conceito de modularidade é desenvolvido. A modularidade é uma medida utilizada para qualificar determinado particionamento da rede em comunidades. De modo geral, o objetivo do algoritmo está na otimização da função de modularidade.

Considere uma divisão qualquer da rede em $M$ comunidades. A partir desta suposição defini-se uma matriz simétrica $C_{k \times k}$ de tal forma que o elemento $c_{i j}$ corresponda à fração das arestas da rede que conectam vértices de uma comunidade $i$ a uma comunidade $j$. Já os elementos da diagonal principal, por exemplo, $c_{i i}$, correspondem as arestas ligando vértices de uma mesma comunidade, no caso a comunidade $i$. Assim, a soma dos elementos da diagonal principal da matriz (traço) corresponde a fração de todas as arestas da rede ligando vértices pertencentes as comunidades mas não entre comunidades $\left(\sum_{i} c_{i i}\right)$. Desta forma, se as comunidades encontram-se totalmente isoladas, isto é, não existem inter-conexões, o traço da matriz $C$ é igual a 1 . Consequentemente, quanto maior o valor do traço da matriz, melhor dividida em comunidades a rede se encontra. Porém, esta medida de forma isolada não representa um bom índice sobre a divisão da rede em comunidades, pois, no caso trivial, onde todos os vértices pertencem a uma mesma comunidade, o valor do traço da matriz também é 1 .

Para solucionar esta limitação, Newman (2004b) propôs um índice de modularidade definido por :

$$
Q=\sum_{i}\left(c_{i i}-a_{i}^{2}\right)
$$

onde $a_{i}$ define a fração das arestas que ligam os vértices da comunidade $i$ aos vértices de outras comunidades da rede $\left(a_{i}=\sum_{j} c_{i j}\right)$. Assim, o índice de modularidade definido na Equação (2.33) apresenta um valor baixo ou mesmo zero quando o número de ligações dentro de uma comunidade não supera um valor por ligações definidas aleatoriamente. Por outro lado, dada uma divisão da rede no qual as intra-conexões superam as inter-conexões, $Q$ assume um valor alto. Segundo Newman (2004b), valores $Q>0.3$ indicam uma suposta existência de uma estrutura de comunidades na rede. 
Para aplicar o conceito de modularidade na tarefa de detecção de comunidades, procede-se da seguinte maneira. No início, cada vértice da rede é considerado uma comunidade $i$ independente. Na sequência, os vértices (comunidades) são repetidamente agrupados de tal forma a maximizar o índice de modularidade. A variação obtida pela fusão das comunidades $i$ e $j$ é obtida pela seguinte equação:

$$
\Delta Q=c_{i j}+c_{j i}-2 a_{i} a_{j}=2\left(c_{i j}-a_{i} a_{j}\right)
$$

onde $\Delta Q$ representa a variação na modularidade. 


\section{- 3 \\ Redes de Osciladores Acoplados Aplicados à Atenção Visual}

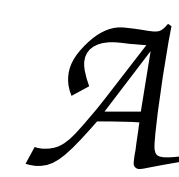

atenção visual pode ser definida como um mecanismo de seleção responsável por reduzir a quantidade de informações provenientes ambiente. Desta forma, é possível otimizar a análise visual concentrando a capacidade de processamento do cérebro em regiões bem definidas no campo visual. O processo de seleção dos estímulos é baseado tanto no conceito de saliência e organização perceptual resultante da análise de baixo nível da cena (bottom-up) quanto em um conhecimento prévio da cena ou metas de busca pré-estabelecidas (top-down) (Desimone \& Duncan, 1995; Pashler, 1998; Itti \& Koch, 2001a).

De uma forma geral, as teorias por trás dos modelos de atenção visual estão agrupadas em dois grandes grupos: seleção visual baseada em localização e seleção visual baseada em objetos (Egeth \& Yantis, 1997; Pashler, 1998; Yantis, 2000).

Este capítulo apresenta as minhas principais contribuições provenientes do desenvolvimento de modelos computacionais de redes de osciladores neurais aplicadas à atenção visual. A elaboração dos modelos que serão apresentados nas próximas seções levou em conta três pontos principais: a utilização de osciladores neurais como base dos modelos; a seleção de objetos como unidade de atenção (object-based attention); e a sincronização entre osciladores e dessincronização de grupos para representação temporal dos objetos (teoria da correlação oscilatória). É importante observar que, embora a arquitetura dos modelos seja motivada por estudos experimentais da atenção visual, não é objetivo destes simular dados psicofísicos de forma quantitativa. 
Diversos modelos de redes de osciladores neurais têm sido propostos. Neste trabalho, os seguintes modelos foram estudados e adaptados como mecanismos de atenção visual: redes PCNN (Johnson, 1994), redes de osciladores Wilson-Cowan caóticos (Zhao et al., 2000), redes de neurônios Integra e Dispara (Koch, 1998; Izhikevich, 2004) e o modelo LEGION composto por osciladores de relaxamento (Terman \& Wang, 1995; Wang, 1999).

Ao longo deste capítulo, seguindo a ordem cronológica no qual foram desenvolvidos, cada modelo é descrito e as respectivas simulações computacionais são apresentadas. As simulações têm como objetivo principal testar a capacidade dos modelos segundo as seguintes características:

- segmentação da imagem em um conjunto coerente de objetos (segmentos);

- seleção temporal de um dos objetos em um dado instante do tempo (entrega do foco de atenção);

- mudança do foco de atenção ao longo do tempo (inspeção visual);

- resistência a mudança nos parâmetros do modelo (robustez do modelo);

- capacidade de atuar em imagens reais (aplicabilidade).

Uma característica comum a todos os modelos está na forma de organização dos osciladores neurais na rede. Dada uma cena visual qualquer, para

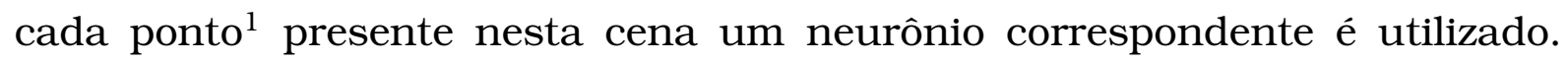
Assim, para uma cena $2 \mathrm{D}$ com $n \times m$ pontos, uma rede com $n \times m$ neurônios/osciladores é utilizada. Ainda vale observar que, embora para indexar um elemento em um reticulado 2D seja necessário dois índices (linha,coluna), em toda a extensão deste trabalho os osciladores serão indexados por apenas um índice cujo objetivo é simplificar a notação matemática utilizada.

A seguir, os modelos desenvolvidos são apresentados.

\section{1 Modelo de Atenção Baseado em PCNN - I}

Nesta seção, um modelo de atenção visual baseado na rede PCNN é apresentado.

\section{1. 1 Descrição do Modelo}

Como descrito na Seção 2.2.3, o modelo PCNN tem como característica principal a sincronização de neurônios vizinhos alimentados por sinais externos semelhantes. Embora a sincronização entre os osciladores seja facilmente

\footnotetext{
${ }^{1}$ Neste texto, um ponto se refere a um pixel da imagem e não a uma forma geométrica "ponto"
} 
obtida, a dessincronização entre grupos que é um requisito da correlação oscilatória não é tratada na formulação original do modelo. Desta forma, com o objetivo de adaptar a rede PCNN como um modelo de atenção visual, onde um dos diversos objetos presentes na imagem é selecionado em um dado instante do tempo, algumas modificações no modelo original foram realizadas (Quiles et al., 2006).

O modelo original PCNN pode ser brevemente representado pelas seguintes equações (apresentadas na Seção 2.2.1):

$$
\begin{gathered}
F_{j}=\sum_{k} F_{k j}=\sum_{k}\left[m_{k j} \exp \left(-\alpha_{k j}^{F} t\right)\right] * Y_{k}(t)+I_{j} \\
L_{j}=\sum_{k} L_{k j}=\sum_{k}\left[w_{k j} \exp \left(-\alpha_{k j}^{L} t\right)\right] * Y_{k}(t) \\
U_{j}=F_{j}\left(1+\beta_{j} L_{j}\right) \\
Y_{j}=H\left(U_{j}-\theta_{j}\right)
\end{gathered}
$$

$\mathrm{e}$

$$
\theta_{j}=\left[V_{\theta} \exp \left(-\alpha_{j}^{\theta} t\right)\right] * Y_{j}(t)
$$

representando, respectivamente, as entradas de alimentação, de enlace, o modulador de sinal, o gerador de pulsos e a equação de decaimento do limiar de disparo (para uma completa descrição do modelo, ver Seção 2.2.3). A seguir, as modificações realizadas são descritas:

- as entradas (sinapses) de alimentação do modelo original são simplificadas e passam a responder apenas ao sinal externo $I$ e não mais aos sinais provenientes dos acoplamentos com os neurônios vizinhos. Assim, a Equação (3.1) é re-escrita da seguinte forma:

$$
F_{j}=w_{I} I_{j}
$$

onde $w_{I}$ é uma constante utilizada para ponderar o sinal de entrada proveniente da cena;

- a matriz $W$ que define o peso dos acoplamentos da árvore de enlace entre os neurônios vizinhos é definida pela seguinte equação:

$$
w_{i j}=\left\{\begin{array}{ccc}
\frac{1}{r_{i j}} & \text { se } & r_{i j} \leq R \\
0 & \text { se } & r_{i j}>R
\end{array}\right.
$$


onde $r_{i j}$ representa a distância entre os neurônios $i$ e o neurônio $j$ na rede e $R$ o distância máxima na qual um neurônio $i$ pode influenciar um neurônio $j$;

- o limiar do gerador de pulsos é configurado por uma constante $V_{\theta}$ sempre que um pulso é gerado. Desta forma, o processo de recarga do limiar é instantaneamente configurado em $V_{\theta}$;

- para auxiliar o processo de dessincronização entre grupos (objetos), o limiar $\theta$ passa a receber influência dos pulsos que chegam às sinapses de enlace. Assim, para cada pulso que as entradas de enlace recebem, o limiar é decrementado por um fator $\gamma \in[0,1]$ de acordo com a seguinte equação:

$$
\theta_{i}=\gamma \theta_{i}
$$

desta forma, um neurônio que possui uma grande vizinhança composta por neurônios ativos, isto é, emitindo pulsos, tem sua frequência disparos aumentada.

O modelo resultante, denominado PCNN-I, apresenta os seguintes parâmetros que precisam ser configurados:

- $\beta$, define a força do acoplamento de enlace. Quando $\beta=0$, o acoplamento de enlace é nulo e o potencial do neurônio é gerado apenas pela alimentação externa proveniente da imagem. Neste caso a sincronização entre neurônios alimentados por valores próximos, porém distintos, não acontece. Por outro lado, para valores altos de $\beta$, a sincronização é observada até mesmo entre neurônios alimentados com padrões distintos;

- $\alpha^{L}$, define o decaimento do sinal nas sinapses de enlace, quando um valor pequeno é adotado, os pulsos recebidos pela sinapses de enlace persistem por um longo tempo. Conforme $\alpha^{L}$ é incrementado, a influência dos sinais recebidos pelas sinapses de enlace no potencial do neurônio se tornam menos persistentes;

- $\alpha^{\theta}$, controla o decaimento do limiar de disparo definindo a frequência de disparos do neurônio. Quanto maior $\alpha^{\theta}$, maior a frequência de disparos do neurônio;

- $w_{I}$, é uma constante que define a influência do sinal externo $I$ no potencial do neurônio;

- $R$, define o raio da vizinhança máximo de acoplamento de um neurônio; 
- $V_{\theta}$, representa o valor inicial e valor de retorno do limiar de disparo $\theta$ do neurônio;

- $\gamma$, é uma constante responsável por aumentar a frequência de disparos dos neurônios conforme o padrão de atividades exibidas por seus neurônios vizinhos.

Com base no modelo descrito acima, diversos experimentos computacionais foram realizados e serão apresentados a seguir.

\subsubsection{Simulações Computacionais}

Dado a quantidade de parâmetros livres que necessitam ajustes, diversos testes empíricos foram realizados a fim de se estabelecer um conjunto de valores adequados à tarefa de seleção visual. Para isto, partindo-se de um conjunto de imagens sintéticas foram realizados testes visando obter as seguintes características dinâmicas na rede: atividade síncrona, sincronização entre grupos de osciladores alimentados por valores semelhantes e separação de grupos de osciladores distintos (objetos).

Com base nestes testes realizados, os seguintes valores foram obtidos e mantidos constantes em todos os experimentos: $\beta=0,1, \alpha^{L}=0,40, \alpha^{\theta}=0,20$, $w_{I}=0,25$ e $\gamma=0,99$. Entretanto, os parâmetros $R$, e $V_{\theta}$ precisam ser ajustados conforme a imagem de entrada utilizada. Quando uma imagem binária é utilizada como entrada, ou seja, os neurônios são alimentados por 1 ou 0 , os valores $R=4$ e $V_{\theta}=5$ se mostraram adequados. Por outro lado, quando imagens em tons de cinza são utilizadas, os parâmetros $R$ e $V_{\theta}$ precisam ter seus valores reduzidos a fim de possibilitar a segmentação de objetos na rede, caso contrário a separação de objetos definidos por tons de cinza próximos não é alcançada. Para estas imagens, os seguintes valores foram adotados: $R=2$ e $V_{\theta}=3$.

Na Figura 3.1(a) é apresentada uma imagem composta por uma dupla espiral. O problema em distinguir em um plano bidimensional se o padrão apresentado é uma simples espiral conectada ou uma dupla espiral desconectada, denominado Problema da Espiral, tem sido utilizado como meio de validação da capacidade de um modelo em tratar padrões não separáveis linearmente (Chen \& Wang, 2001). O aprendizado de problemas não lineares tem atraído a atenção de pesquisadores da área de redes neurais desde a publicação do livro Perceptrons por Minsky \& Papert (1969). Neste contexto, a Figura 3.1(a) é utilizada como entrada do modelo PCNN-I para verificar a capacidade deste em distinguir (segmentar) os dois padrões não separáveis linearmente presentes na imagem de entrada. 


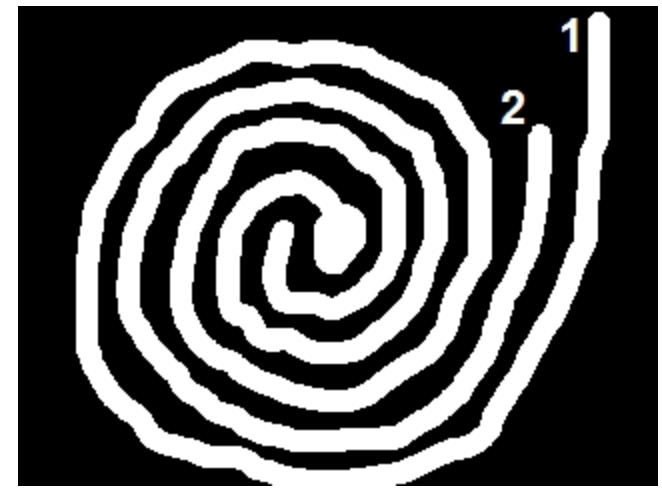

(a)

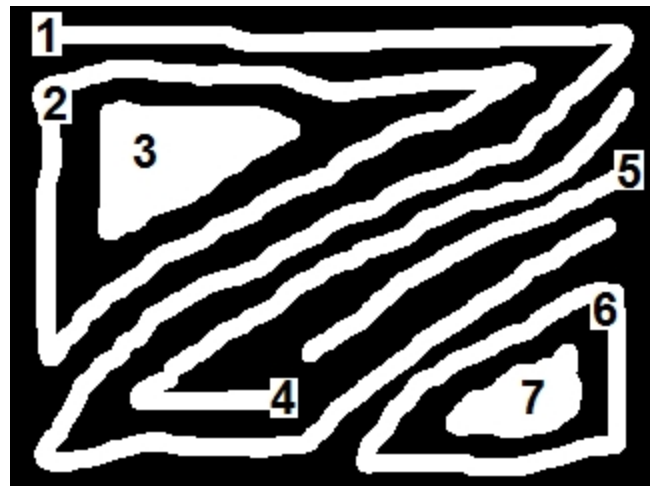

(b)

Figura 3.1: Imagens binárias utilizadas em simulações com o modelo PCNN-I $(320 \times 240$ pontos). (a) Imagem composta por uma dupla espiral. (b) Imagem composta por 7 objetos distintos.

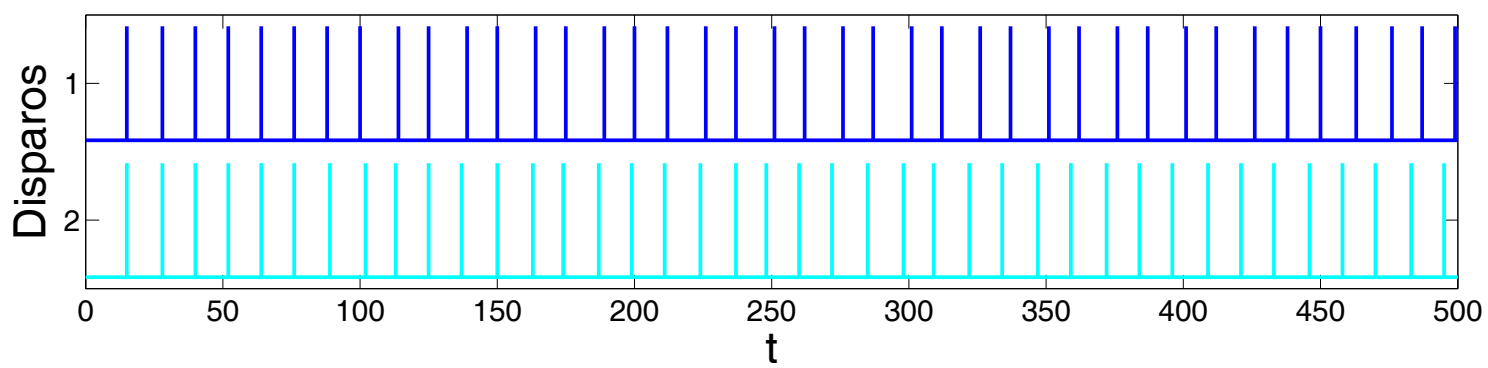

Figura 3.2: Atividade temporal de disparo dos neurônios representando as duas espirais apresentadas na Figura 3.1(a) (a atividade de um neurônio é apresentada por objeto). Os índices no eixo $y$ identificam os objetos presentes na imagem. 
Na Figura 3.2 é possível observar que, no início da simulação, os trens de pulsos representando as duas espirais estão sincronizados. Entretanto, devido a dinâmica do modelo gerado pelo acoplamento irregular entre os neurônios, a diferença na quantidade de pontos representando cada padrão e pela Equação (3.8), as duas trajetórias se dessincronizam e a passam a apresentar fases distintas. Como consequência, os dois padrões podem ser separados temporalmente. Desta forma, pode-se assumir que o sistema está entregando a atenção a cada uma delas alternadamente ao longo do tempo. Vale observar que, em alguns instantes, as trajetórias voltam a coincidir.

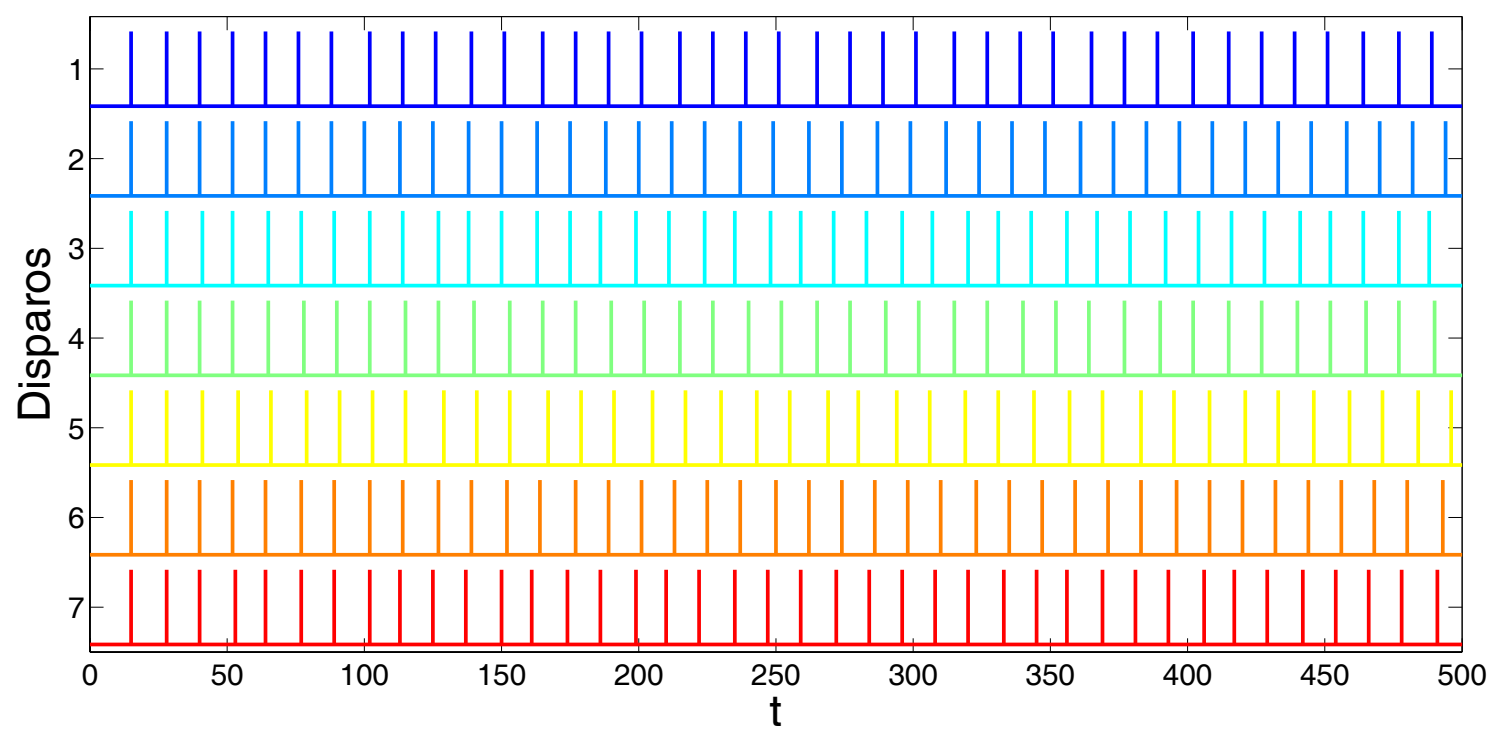

Figura 3.3: Atividade temporal de disparo dos neurônios representando os sete objetos apresentados na Figura 3.1(b) (a atividade de um neurônio é apresentada por objeto). Os índices no eixo $y$ identificam os objetos presentes na imagem.

Nesta simulação, apresentada pela Figura 3.3, o modelo também foi capaz de separa os 7 padrões que compõe a imagem de entrada. Entretanto, a separação temporal dos padrões é observada em apenas alguns instantes da simulação, pois em diversos momentos, como pode ser observado na Figura 3.3, os trens de pulsos representando alguns dos objetos coincidem. Uma ilustração desse fenômeno é apresentada na Figura 3.6 onde é possível observar algumas formas de agrupamentos referentes aos objetos 7, 8, 9 e 10 .

A Figura 3.4 apresenta uma imagem composta por objetos em tons de cinza. Como pode ser observado na Figura 3.5, o modelo também é capaz de segmentar imagens sintéticas em tons de cinza. Além disso, outra observação constatada nos experimentos está no agrupamento e desagrupamento de partes de um objeto. Por exemplo, em um dado instante do tempo, o objeto formado pelas partes 7, 8, 9 e 10 da Figura 3.4 é considerado pela rede como um único objeto. Contudo, em outros instantes, cada objeto é sinalizado 


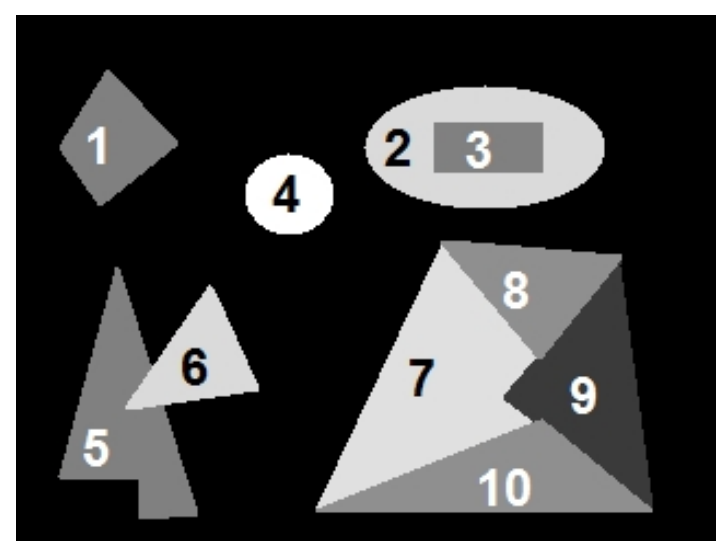

Figura 3.4: Imagem em tons de cinza composta por 10 objetos (imagem com $320 \times 240$ pontos).

pelo sistema como um objeto independente. Mesmo sendo uma limitação do sistema relacionado a quantidade de objetos que podem ser segmentados, tal fenômeno é biologicamente plausível, pois, por exemplo, quando um ser humano observa o objeto "mão", este pode ser constatado tanto como um único objeto quanto como suas partes independentes "dedos" e "palma". A Figura 3.6 mostra alguns exemplos de agrupamentos de objetos observados durante a simulação utilizando a Figura 3.4.

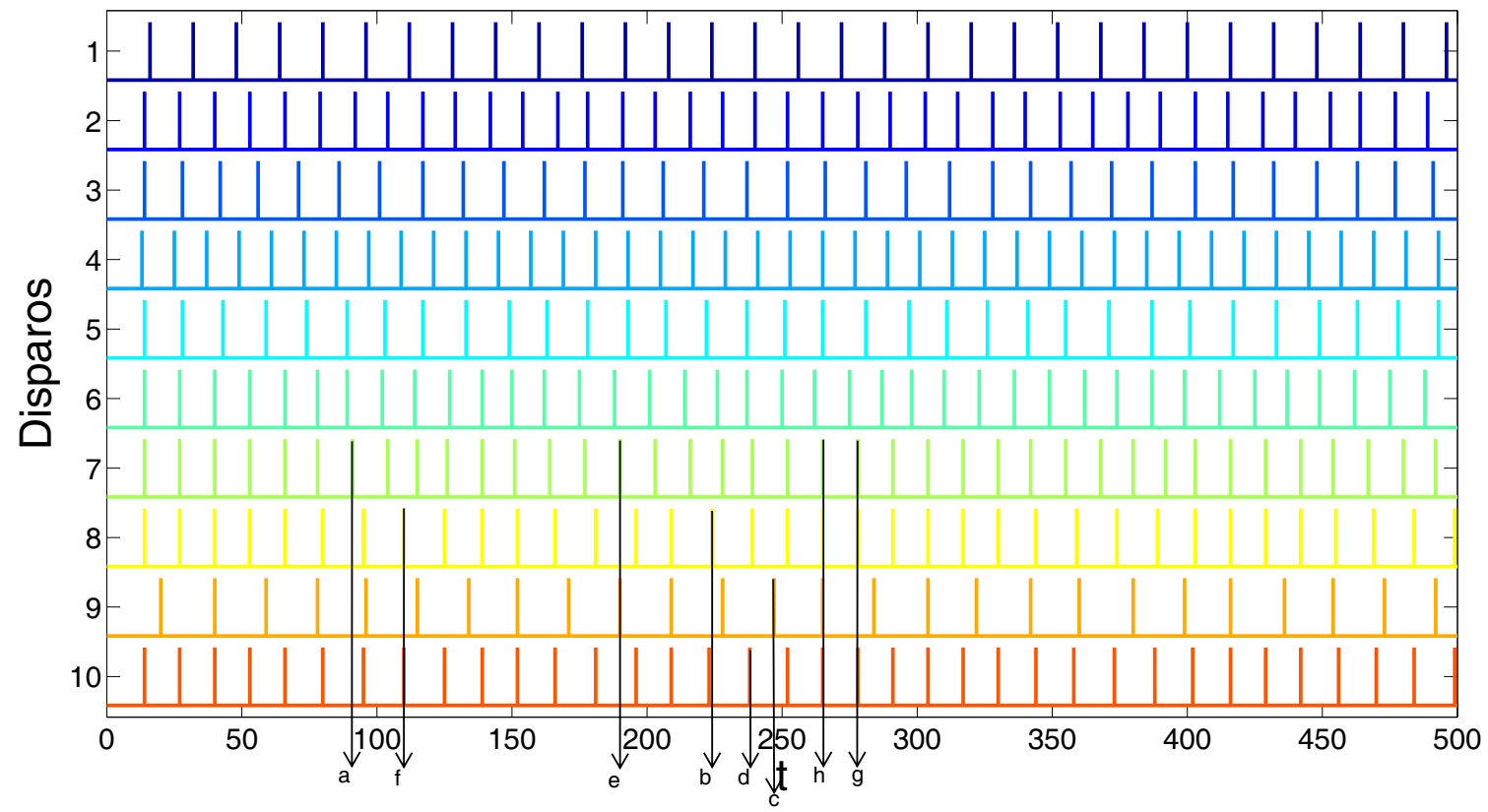

Figura 3.5: Atividade temporal de disparo dos neurônios representando os 10 objetos apresentados na Figura 3.4 (a atividade de um neurônio é apresentada por objeto). Os índices no eixo $y$ identificam os objetos presentes na imagem. Os marcadores no eixo $x$ representam alguns dos possiveis padrões de agrupamentos de objetos que podem ser obtidos. Os marcadores correspondem aos padrões apresentados na Figura 3.6.

Experimentos utilizando outras imagens sintéticas foram realizados com 


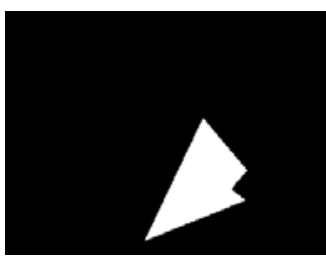

(a)

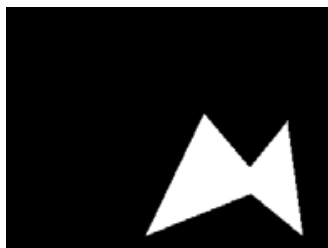

(e)

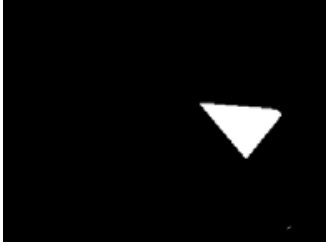

(b)

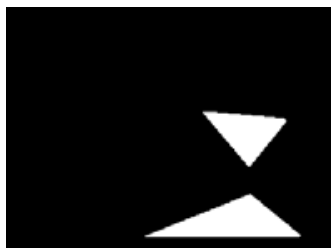

(f)

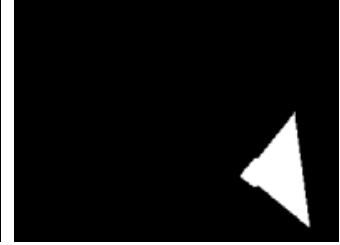

(c)

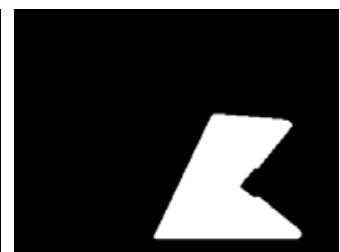

(g)

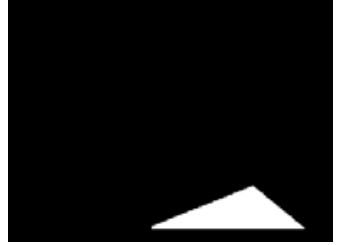

(d)

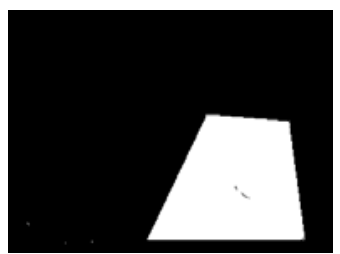

(h)

Figura 3.6: Exemplo de padrões de agrupamentos de objetos formados na rede alimentada pela Figura 3.4. Ver as séries temporais correspondentes na Figura 3.5.

o modelo PCNN-I e os resultados obtidos foram semelhantes aos apresentados acima. Porém, mesmo o sistema sendo capaz de segmentar uma imagem em diversos segmentos e a atividade dos neurônios podendo representar o processo de entrega da atenção, o modelo ainda apresenta as seguintes limitações:

- grande número de parâmetros livres. Embora tenham sido encontrado valores adequados aos parâmetros do modelo, uma pequena variação em um desses parâmetros da rede pode acarretar em resultados insatisfatórios, como falhas na segmentação dos objetos e supressão da dinâmica oscilatória dos neurônios. Desta forma, a automatização do ajuste dos parâmetros para uma dada imagem não é um processo trivial e um conjunto de testes empíricos se faz necessário a fim de encontrar valores adequados aos parâmetros do modelo;

- capacidade de segmentação limitada. Esta deficiência é observada tanto no número de segmentos que podem ser separados ao longo do tempo, quanto na qualidade de segmentação. Esta limitação pode ser observada na Figura 3.5, onde é possível verificar que em apenas alguns instantes do tempo os objetos são realmente segmentados;

- mecanismo de atenção inadequado. Embora a atividade dos neurônios possa ser abstraída como a entrega da atenção a um objeto, esse mecanismo não se mostra totalmente adequado, pois, uma vez que um objeto recebe a atenção, isto é, é selecionado, os demais deveriam ser efetivamente inibidos;

- limitação no tratamento de imagens reais. Diversos testes foram realiza- 
dos na tentativa de aplicar o modelo PCNN-I a imagens reais. Entretanto, os resultados obtidos não foram satisfatórios;

- falha na segmentação de padrões idênticos. Quando dois padrões idênticos são apresentados, ou seja, dois padrões com mesmo tamanho, intensidade de cinza e forma geométrica, a rede não consegue separá-los. Esta limitação pode ser amenizada inserindo um termo de ruído. Esta abordagem já foi adotada em outros modelos de redes neurais para segmentação de imagens (Terman \& Wang, 1995; Wang \& Terman, 1997; Zhao et al., 2000).

Assim, com o objetivo de melhorar o modelo PCNN-I reduzindo algumas de suas deficiências, em (Quiles et al., 2007b) foi proposto um novo modelo baseado no modelo PCNN para a tarefa de seleção visual de objetos. O modelo proposto em (Quiles et al., 2007b) é apresentado a seguir.

\subsection{Modelo de Atenção Baseado em PCNN - II}

Nesta seção, um segundo modelo de atenção visual baseado na rede PCNN é apresentado.

\subsubsection{Descrição do Modelo}

De forma geral, em comparação com o modelo PCNN original (Johnson, 1994) e com o modelo PCNN-I, as seguintes extensões podem ser destacadas: 1) a implementação de um mecanismo de seleção do objeto mais saliente com base no aumento da frequência de disparo dos osciladores e diminuição da frequência dos osciladores representando os demais objetos da cena; 2) um mecanismo de inibição por retorno (IoR - Inhibition of Return) para possibilitar a mudança do foco de atenção entre os objetos. Estas mudanças satisfazem os seguintes requerimentos de um sistema de seleção visual:

- com base em uma indicação de saliência formada por características extraídas da cena, a rede neural deve selecionar o objeto mais saliente, isto é, direcionar o foco de atenção a este objeto;

- em quanto a atenção é direcionada a uma determinada região (objeto) da imagem, todas as outras áreas da cena devem ser ignoradas;

- outros objetos da cena também devem receber a atenção. Isto é, devido ao mecanismo de inibição por retorno, a atenção previamente alocada a um objeto deve ser inibida possibilitando a mudança do foco para um outro objeto. 
A frequência de disparo dos neurônios em uma rede de pulsos acoplados pode ser controlada através da velocidade de decaimento do limiar do gerador de pulsos $\theta_{j}$. Este controle pode ser implementado transformando a constante de decaimento $\alpha_{j}^{\theta}$ em uma função dependente do tempo e da ativação dos neurônios.

$$
\alpha_{j}^{\theta}(t)=\alpha_{j}^{\theta}(t-1)\left[1+C_{E} Y_{j}(t-1)\right]
$$

onde $C_{E}>0$ é uma constante que define quão rápido a frequência de disparo dos neurônios é aumentada. Com base nesta modificação em $\alpha_{j}^{\theta}(t)$, cada vez que um neurônio $j$ dispara, sua frequência de disparo é aumentada. Consequentemente, o grupo de neurônios sincronizados representando o objeto mais saliente assumirá uma maior frequência de disparo. Ao mesmo tempo em que a frequência dos neurônios são aumentadas de acordo com suas atividades, um mecanismo de inibição responsável por diminuir a frequência de disparo de grupos de neurônios representando objetos menos salientes também é implementado.

O mecanismo de inibição altera a constante de decaimento do limiar $\alpha_{j}^{\theta}$ pela seguinte equação:

$$
\alpha_{i}^{\theta}(t)=\alpha_{i}^{\theta}(t-1) C_{I}^{\left|N_{j}(t-1)-N_{i}(t-1)\right|}
$$

onde $C_{I} \in[0,1)$ é uma constante que controla a força de inibição e $N_{i}(t)$ representa o número de pulsos que um neurônio $i$ disparou até o instante $t$. Desta forma, toda vez que um neurônio $j$ dispara, um sinal inibitório é enviado a todos os demais neurônios $i$ da rede. Através da Equação (3.10), este sinal de inibição reduz a frequência de disparo de todos os neurônios $i$ cuja frequência seja diferente da frequência de disparo do neurônio $j$.

O mecanismo de inibição (Equação 3.10) juntamente com o mecanismo de cooperação (Equação 3.9) são responsáveis por destacar o objeto mais saliente enquanto os demais objetos são inibidos. Este processo pode ser visto como um mecanismo de seleção, semelhante ao observado em sistemas biológicos, no qual apenas parte do estímulo visual atinge um nível consciente. Aqui, o objeto que recebe a atenção do sistema é definido pelo conjunto de neurônios cujas atividades de disparo permanecem ativas.

Com base nas Equações (3.9) e (3.10) apresentadas acima, a equação que descreve a dinâmica do limiar de disparo dos neurônios pode ser re-escrita como:

$$
\theta_{j}(t)=\left[V_{\theta} \exp \left(-\alpha_{j}^{\theta}(t) t\right)\right] * Y_{j}(t)
$$


Como mencionado anteriormente, para evitar que o foco de atenção do sistema permaneça sobre um único objeto da cena permitindo que outras regiões possam receber a atenção do sistema, um mecanismo de inibição por retorno é introduzido. Este mecanismo é responsável por inibir os neurônios da rede que representam o objeto que detém o foco de atenção. No modelo proposto, os neurônios que representam o objeto sobre o foco de atenção são bloqueados de tal forma a não conseguirem pulsar antes que todos os demais objetos da imagem tenham tido a chance de obter a atenção do sistema. Este bloqueio é implementado através da interrupção do decaimento do limiar $\theta_{j}$ assumindo $\alpha_{j}^{\theta}(t)=0$. Após todos os objetos presentes na cena terem sido selecionados uma vez, todos os neurônios da rede são reiniciados e podem participar do processo de competição novamente.

Com o objetivo de normalizar os sinais recebidos pelas sinapses de enlace e de alimentação dos neurônios de tal forma que estes recebam a mesma quantidade de informação, as Equações (3.1) e (3.2) que modelam tais sinapses de entrada também foram modificadas de acordo com a seguintes equações:

$$
\begin{gathered}
F_{j}=\frac{K^{F}}{P_{j}} \sum_{k}\left[w_{k j} \exp \left(-\alpha_{k j}^{F} t\right)\right] * Y_{k}(t)+w_{I} I_{j} \\
L_{j}=\frac{K^{L}}{P_{j}} \sum_{k}\left[w_{k j} \exp \left(-\alpha_{k j}^{L} t\right)\right] * Y_{k}(t)
\end{gathered}
$$

onde $w_{I}, K^{F}$ e $K^{L}$ são constantes, $P_{j}$ é um fator de normalização definido como segue:

$$
P_{j}=\sum_{k} w_{k j}
$$

onde $W$ é a matriz de pesos do modelo a qual é considerada a mesma para as sinapses de enlace e de alimentação dos neurônios. A matriz $W$ é definida segundo a Equação (3.15) que é uma função baseada na similaridade entre os sinais externos recebidos pelos neurônios vizinhos e a distância entre estes.

$$
w_{i j}=\exp \left(-T r_{i j}\left|I_{j}-I_{i}\right|^{\frac{3}{2}}\right)
$$

onde $T$ é uma constante, $I_{i} \in[0,1]$ é o sinal de entrada proveniente da imagem e $r_{i j}$ é a distância entre os neurônios $i$ e $j$ definida pela seguinte equação:

$$
r_{i j}=\frac{\max \left(\left|x_{i}-x_{j}\right|,\left|y_{i}-y_{j}\right|\right)}{R_{\max }}
$$

onde $x_{i}$ e $y_{i}$ são respectivamente a posição horizontal e vertical do neurônio $i$ no reticulado que representa a rede. max é uma função que retorna o valor máximo entre dois valores e $R_{\max }$ define o valor máximo absoluto de distância 
entre dois neurônios que são considerados vizinhos. Neurônios cuja distância esteja acima de $R_{\max }$ não são considerados vizinhos e não interferem diretamente na evolução temporal um do outro.

De uma forma geral a dinâmica do modelo pode ser entendida da seguinte maneira. O processo de sincronização entre neurônios vizinhos alimentados por sinais semelhantes é responsável pela representação dos objetos na rede. Neste modelo, o conceito de saliência é representado pelo valor de intensidade obtido na imagem de entrada e o processo de seleção é definido através do aumento da frequência dos neurônios representando o objeto mais saliente enquanto os demais neurônios (objetos) são inibidos. Além disso, um mecanismo de inibição por retorno é utilizado para inibir um objeto previamente selecionado permitindo que o próximo objeto na escala de saliência receba a atenção.

$\mathrm{Na}$ próxima seção, algumas simulações computacionais com este modelo são apresentadas.

\subsubsection{Simulações Computacionais}

O modelo PCNN-II também possui diversos parâmetros que necessitam ajustes a fim de se obter um correto funcionamento do modelo. As constantes de decaimento $\alpha^{F}$ e $\alpha^{L}$; a variável do controle de decaimento do limiar de disparo $\alpha^{\theta}$; o peso relacionado ao padrão de entrada $w_{I}$; as constantes $C_{E}$, $C_{I}, K^{F}$, e $K^{L}$; a força do acoplamento de enlace $\beta$; a constante que define o limiar de disparo $V_{\theta}$; e a matriz dos pesos de acoplamento com os neurônios vizinhos $W$.

Assim, seguindo a mesma metodologia adotada no modelo PCNN-I, um conjunto de imagens sintéticas foi utilizado para estudar o comportamento do modelo e encontrar valores adequados aos seus diversos parâmetros. Nestes testes, para cada imagem apresentada a rede, manualmente um dos parâmetros foi gradualmente variado e o resultado desta variação analisado. Assim, após um conjunto de testes variando os diversos parâmetros do modelo, os seguintes valores foram obtidos e se mostraram adequados as simulações realizadas:

- $\alpha^{F}=0,05$ e $\alpha^{L}=1,5$;

- $\alpha^{\theta}=0,5$;

- $w_{I}=0,1, C_{E}=1,3, C_{I}=0,999, K^{F}=0,05$, e $K^{L}=5,0$;

- $\beta=0,1$;

- $V_{\theta}=1,0$; 
- $R_{\max }=2,0$;

- $T=20$

- a matriz de pesos $W$ é definida pela Equação (3.15).

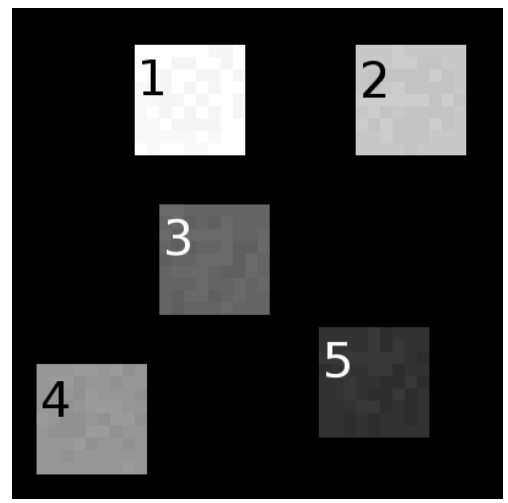

(a)

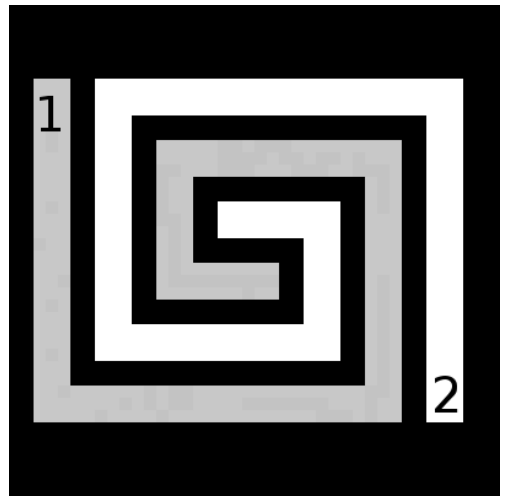

(b)

Figura 3.7: Imagens utilizadas em simulações com o modelo PCNN-II; (a) Imagem composta por cinco objetos com diferentes niveis de intensidade $(40 \times 40$ pontos); (b) Imagem composta por uma dupla espiral (40 $\times 40$ pontos).

Nas simulações, o conceito de saliência é representado pelo nível de cinza de cada ponto proveniente da imagem de entrada. Assim, pontos representados pela cor branca indicam o nível máximo de saliência, enquanto pontos de cor preta representam regiões não salientes.

O primeiro experimento foi conduzido para verificar o comportamento do sistema em uma cena composta por vários objetos. Para isto, a Figura 3.7(a) composta por cinco objetos com diferentes níveis de cinza foi utilizada. Além disso, para verificar o processo de sincronização, um sinal de ruído aleatório foi adicionado em cada objeto, ou seja, o nível de intensidade de cinza de cada ponto foi alterado aleatoriamente em $\pm 10 \%$. Na Figura 3.8, a atividade de disparo dos neurônios representando os cinco objetos pode ser observada. É possível verificar que, no inicio da simulação, os cinco objetos encontram-se ativos (pulsando). Entretanto, devido a dinâmica de competição do modelo onde o objeto mais saliente inibe os demais objetos e aumenta sua própria frequência, após um período de tempo, apenas um objeto permanece pulsando $(t \approx 2000)$. Quando o primeiro objeto recebe a atenção do sistema, o mecanismo de inibição por retorno é ativado e este objeto é inibido. Este mecanismo possibilita que o próximo objeto na escala de saliência receba a atenção, isto é, seja selecionado. Este processo é repetido até que todos os objetos tenham sido selecionados uma vez. Uma vez que o ciclo de seleção tenha terminado, os neurônios são reiniciados e um novo processo de competição por atenção é iniciado. 


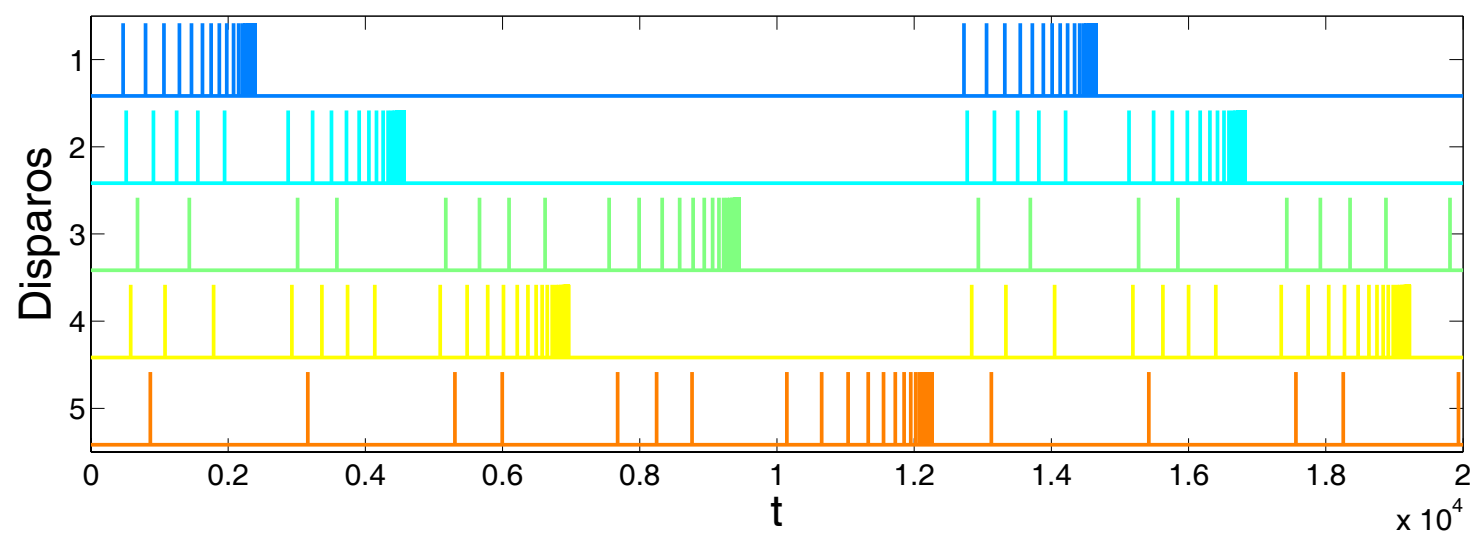

Figura 3.8: Atividade temporal de disparo dos neurônio da Rede PCNN-II alimentada pela Figura 3.7(a) (a atividade de um neurônio é apresentada por objeto). Os índices no eixo $y$ identificam os objetos presentes na imagem.

Na Figura 3.7(b), o problema da espiral é novamente considerado para verificar a capacidade do modelo na segmentação/seleção de objetos não separáveis linearmente. Para isto, duas espirais representadas por diferentes niveis de cinza (saliência) são utilizadas. Novamente para testar a capacidade de sincronização entre os neurônios que representam um determinado objeto, um sinal de ruído é adicionado a imagem. A Figura 3.9 apresenta a atividade dos neurônios representando as duas espirais. Aqui é possível verificar que, no início da simulação os dois objetos estão ativos. Devido a dinâmica do modelo, a espiral número 2 (mais saliente) é selecionada primeiro. Após o processo de inibição, a espiral representada pelo número 1 é selecionada. Este processo é repetido até que o sistema execução seja interrompido ou a cena seja alterada. A Figura 3.10 mostra a evolução temporal de dois neurônios representando as espirais 1 e 2 respectivamente. Nesta figura, a partir da observação dos sinais representando o potencial $U_{i}$ e o limiar de disparo $\theta_{i}$ dos dois neurônios, é possível compreender o mecanismo de geração de pulsos, no qual os neurônios disparam sempre que $U_{i}>\theta_{i}$.

A partir dos resultados apresentados acima é possivel verificar que o modelo é capaz de cumprir os objetivos esperados: 1) separar/segmentar os objetos presentes na cena; 2) selecionar o objeto mais saliente; e 3) inibir o objeto previamente selecionado deslocando o foco de atenção ao próximo objeto mais saliente.

Entretanto, com a formulação atual do modelo e utilizando apenas o nível de cinza como atributo de saliência, este não foi capaz de realizar seleção de objetos em imagens reais. Sendo que a principal deficiência observada foi a limitação da capacidade de segmentação devido ao ruído natural presentes nas imagens reais. Além disso, dado a grande quantidade de parâmetros do modelo, uma busca exaustiva se torna inviável, limitando a aplicação do mo- 


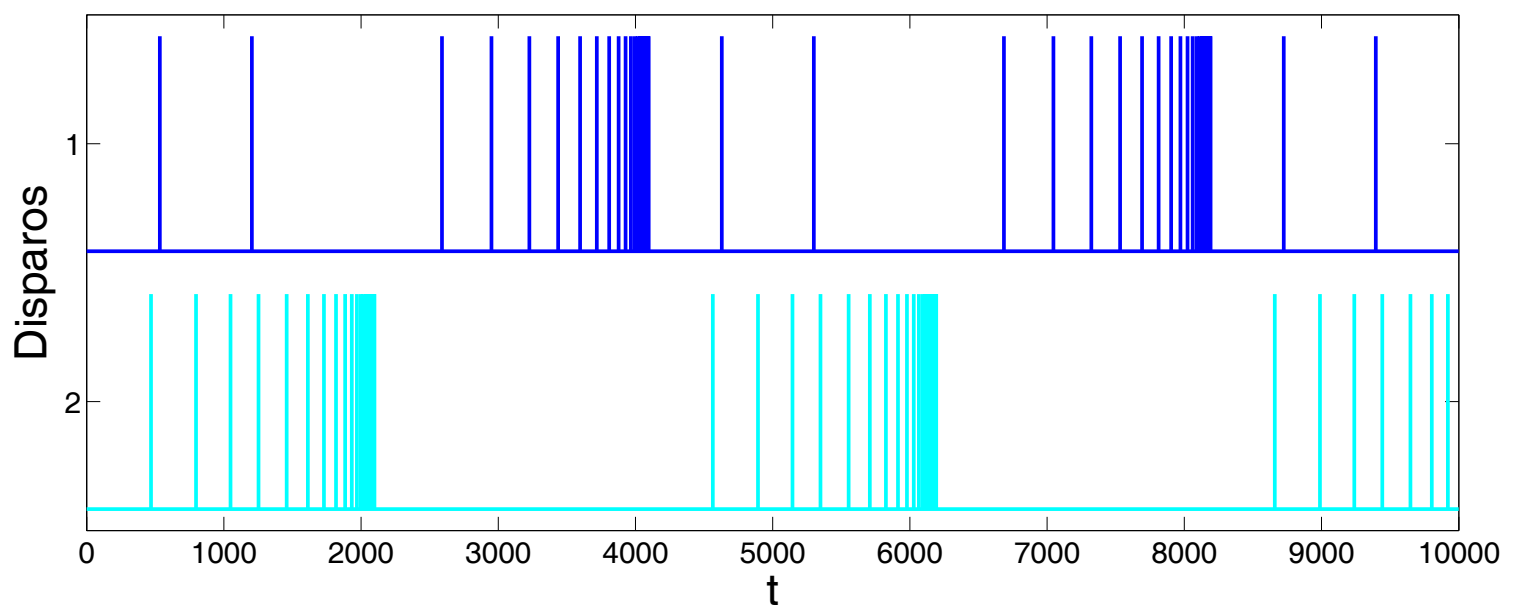

Figura 3.9: Atividade temporal de disparo dos neurônios da Rede PCNN-II alimentada pela Figura 3.7(b) (a atividade de um neurônio é apresentada por objeto). Os índices no eixo $y$ identificam os objetos presentes na imagem.

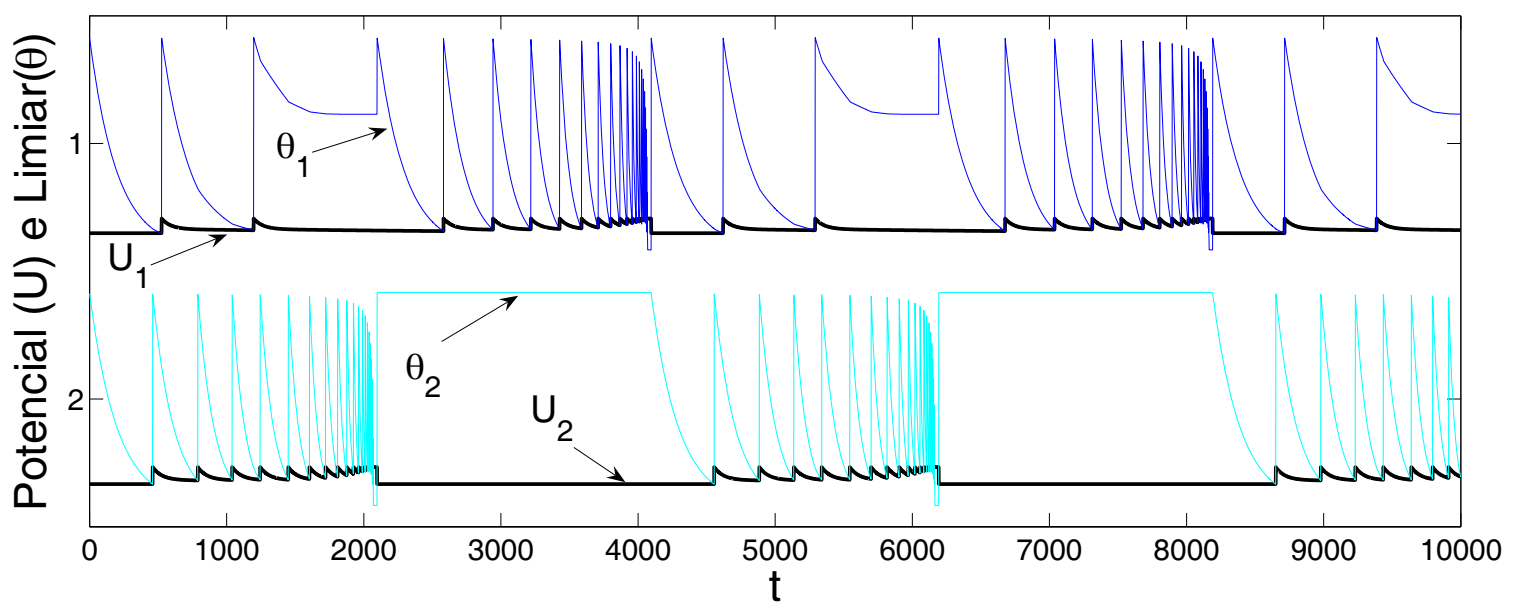

Figura 3.10: Evolução temporal do potencial dos neurônios $U$ e do limiar de disparo $\theta$ obtida através de simulação utilizando a imagem apresentada na Figura 3.7. As linhas em cor preta representam o limiar de disparo $(\theta)$ para as espirais número 1 e 2 conforme indicado no eixo $y$. As linhas em cor azul e ciano representam os potenciais $U$ para as espirais número 1 e 2 , respectivamente. 
delo proposto a imagens sintéticas. Mesmo assim, é sugerida como trabalho futuro uma re-estruturação do modelo visando simplificar a sua formulação e também a incorporação de novos atributos como cores e orientação.

\subsection{Modelo de Atenção Baseado em rede de Oscila- dores WCC}

Nesta seção é apresentado um modelo ${ }^{2}$ de seleção visual baseado no modelo de correlação oscilatória caótico proposto por Zhao et al. (2000). Primeiramente o modelo para segmentação de imagens proposto em (Zhao et al., 2000) é brevemente revisitado e, na sequência, o modelo proposto é apresentado.

\subsection{Rede de Osciladores Wilson-Cowan Caótico}

Os osciladores Wilson-Cowan têm sido amplamente utilizados na modelagem de redes neurais. Esses osciladores podem ser vistos como uma aproximação de campo médio da dinâmica de um grupo de neurônios (Wilson \& Cowan, 1972). O oscilador Wilson-Cowan (WC) é formado por um laço de realimentação entre uma unidade excitatória e uma unidade inibitória definido pela seguinte equação:

$$
\begin{aligned}
\dot{x} & =-x+G\left(x-\beta y+I-\theta_{x}\right) \\
\dot{y} & =-b y+G\left(\alpha x-\theta_{y}\right) \\
G(v) & =\frac{1}{1+e^{-(v / T)}}
\end{aligned}
$$

onde $\alpha$ e $\beta$ são parâmetros positivos que descrevem o acoplamento da unidade excitatória para a unidade inibitória e da unidade inibitória para a unidade excitatória, respectivamente. O sinal negativo junto ao termo $\beta$ representa o fator de inibição. $b$ é um parâmetro de decaimento. $\theta_{x}$ e $\theta_{y}$ representam limiares das unidades $x$ e $y$, respectivamente. I representa um estimulação externa ao oscilador. $G$ é uma função sigmoide com inclinação definida por $T$. Esta formulação pode ser vista como uma simplificação do modelo original proposto em (Wilson \& Cowan, 1972).

Entretanto, no modelo descrito acima, apenas as dinâmicas estacionária e periódica podem ser observadas considerando que o oscilador é definido por um sistema contínuo em duas dimensões. Com o objetivo de introduzir um comportamento caótico no oscilador WC, a constante $I$ que define a estimula-

\footnotetext{
${ }^{2} \mathrm{E}$ importante mencionar que a implementação deste modelo e a execução das simulações apresentadas nesta seção foram realizadas por Fabricio Aparecido Breve.
} 
ção externa ao oscilador foi redefinida como uma função periódica (Zhao et al., 2000):

$$
I(t)=A \cos (t)
$$

onde $A$ define a amplitude do sinal $I$.

Segmentação de Imagens Por Osciladores WCC

Para a tarefa de segmentação de imagens, a rede é definida como uma estrutura 2D cuja dinâmica é governada pelas seguintes equações:

$$
\begin{aligned}
\dot{x}_{i} & =-x_{i}+G\left(x_{i}-\beta y_{i}+I_{i}-\theta_{x}\right)+c \Delta x_{i} \\
\dot{y}_{i} & =-b y_{i}+G\left(\alpha x_{i}-\theta_{y}\right)+c \Delta y_{i} \\
G(v) & =\frac{1}{1+e^{-(v / T)}}
\end{aligned}
$$

onde $i$ é representa o índice de um osciladores presente na rede. $c$ é a força de acoplamento. $\Delta x_{i}$ e $\Delta y_{i}$ representam os termos de acoplamento entre o oscilador $i$ e seus vizinhos e é definido como segue:

$$
\Delta v_{i}=\sum_{j \in \Delta_{i}}\left(v_{j}-v_{i}\right)
$$

onde $v_{i}$ representa as variáveis $x_{i}$ e $y_{i}$ e $\Delta_{i}$ é o conjunto de todos os osciladores acoplados a $i$. A vizinhança de acoplamento é definida pelos 8 vizinhos imediatos (vizinhança 8-conectado) obedecendo à seguinte regra:

$$
\Delta_{i}=\left\{j|| A_{j}-A_{i} \mid<\theta_{v}\right\}
$$

onde $A_{i}$ é assumido como um parâmetro de bifurcação recebendo o nível de cinza de cada ponto correspondente da imagem de entrada e $\theta_{v}$ é um limiar de conexão configurado conforme a imagem apresentada a rede.

A estratégia de segmentação é descrita a seguir. Considere uma imagem contendo diversos objetos. A rede é organizada de tal forma que cada ponto da imagem seja representado por um oscilador na rede e a intensidade destes pontos utilizadas para codificar parâmetros dos osciladores. Conforme o sistema é executado, os osciladores se auto-organizam de acordo com o critério de similaridade adotado (Equações (3.20)-(3.21)). Desta forma, apenas osciladores alimentados com características similares permanecem conectados. Consequentemente, todos os osciladores pertencentes a um mesmo objeto (segmento) terão suas trajetórias sincronizadas. Dado as propriedades do caos, como por exemplo, a alta sensibilidade a condição inicial, em um curto 
espaço de tempo as trajetórias podem ser facilmente separadas, isto é, a imagem é segmentada. Uma completa descrição do processo de segmentação bem como uma análise do mecanismo de sincronização caótico pode ser obtido em (Zhao et al., 2000).

A seguir, um modelo de seleção visual baseada na rede composta de osciladores Wilson-Cowan caóticos apresentada acima é descrito (Quiles et al., 2007a; Zhao et al., 2007).

\subsubsection{Descrição do Modelo}

O modelo de seleção visual apresentado a seguir pode ser visto como uma extensão do modelo de segmentação descrito anteriormente com duas novas características.

- Um mecanismo para seleção de objetos. Este mecanismo é definido pelo aumento da frequência de disparo dos osciladores representando o objeto a ser selecionado ao mesmo tempo em que a frequência dos demais osciladores é reduzida;

- Um mecanismo de mudança de foco. Este mecanismo tem por finalidade capacitar o modelo a deslocar o foco de atenção entre os diversos objetos presentes na imagem;

A frequência de disparos em um oscilador Wilson-Cowan pode ser controlada pelo parâmetro $b$ da Equação (3.19). Analisando o diagrama de bifurcação de um oscilador Wilson-Cowan caótico variando $b$ é possivel observar que, para pequenos valores de $b \leq 0,005$, praticamente não são observadas oscilações. Conforme o valor de $b$ é aumentado, é possível observar janelas com comportamentos periódicos e caóticos. Para valores pequenos, o comportamento caótico é predominante, para valores maiores de $b$, a dinâmica periódica é mais comum.

Na Figura 3.12, cinco séries temporais variando $b$ são apresentadas. Nesta figura é possivel observar tanto o aumento da frequência de disparo dos osciladores quanto a mudança de comportamento dinâmico conforme o parâmetro $b$ é incrementado. Por exemplo, quando $b=0,1$, não apenas uma frequência mais alta é observada, mas também um comportamento aparentemente periódico pode ser visto.

Para realizar a seleção de objetos, primeiramente uma fase transiente de segmentação com o parâmetro $b$ constante é necessária. Durante esta fase, as trajetórias caóticas de cada um dos objetos é formada, isto é, a imagem inicial é segmentada. Após completada a fase de segmentação, sempre que um oscilador dispara, por exemplo, o oscilador $i$, dois sinais são gerados: 1) um 


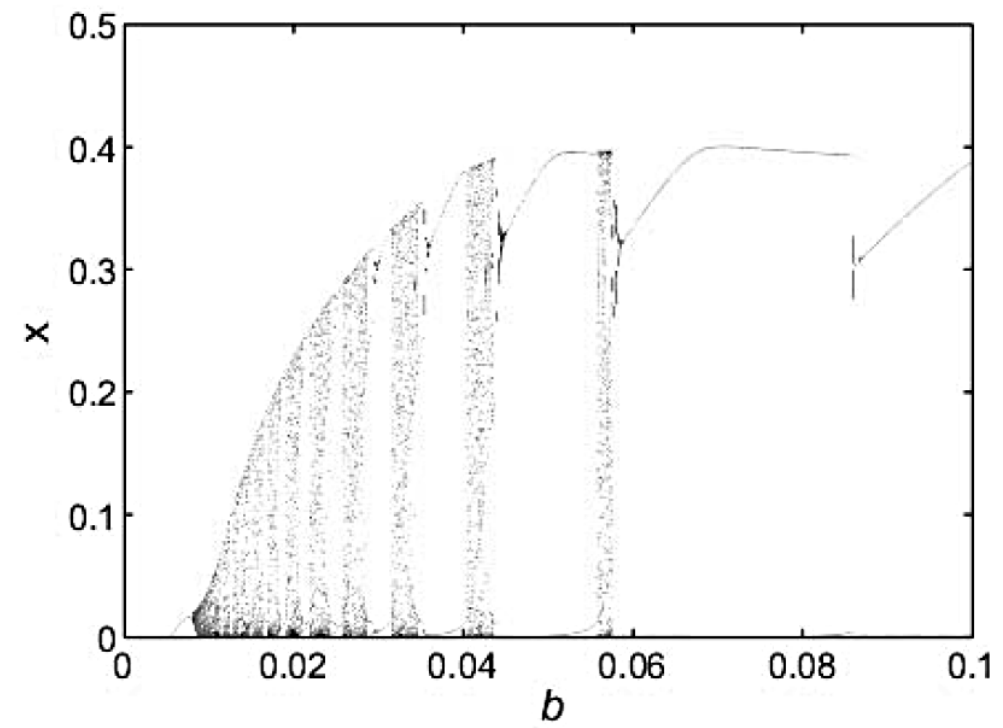

Figura 3.11: Diagrama de bifurcação de um oscilador Wilson-Cowan alimentado por um sinal periódico variando o parâmetro $b . \Delta b=0,0001$.

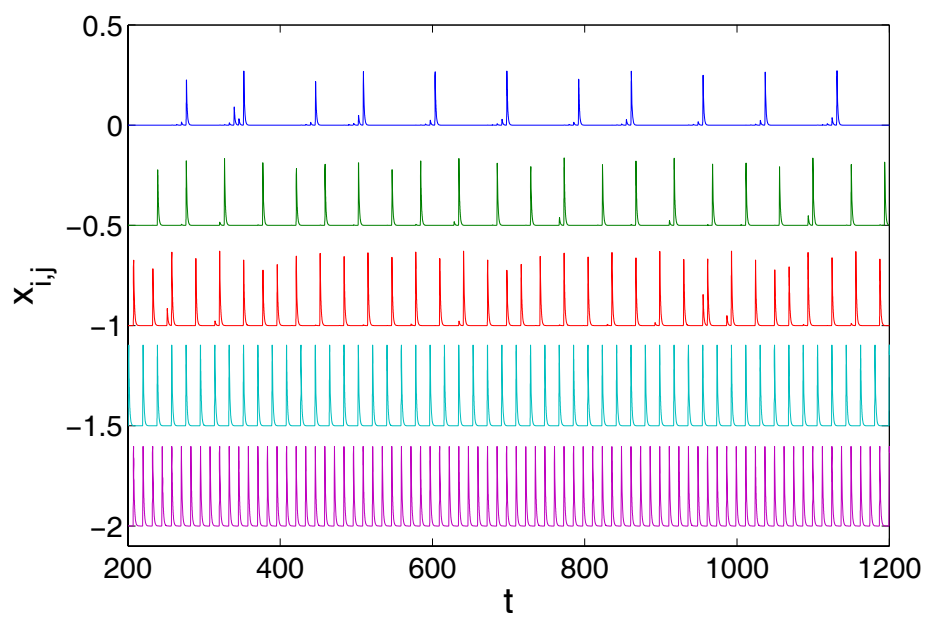

Figura 3.12: Atividade temporal de osciladores Wilson-Cowan $\operatorname{com} b=0,01$, $0,02,0,034,0,05$ e 0,1 , respectivamente. A escala vertical do segundo para o quinto oscilador estão deslocadas na vertical por 0,5 . 
sinal excitatório para o oscilador $i$ e para todos os osciladores sincronizados com $i$. 2) um sinal de inibição para os demais osciladores não sincronizados com $i$. Vale observar que neste modelo a saliência de um objeto é definida pelo seu nivel de cinza.

O sinal de reforço/inibição é modelado pelo parâmetro $b$ conforme a seguinte equação:

$$
\begin{gathered}
b_{i}(\tau)=b_{i}(\tau-1)+\frac{a}{M(\tau)} \sum_{j \in \Delta(\tau)} f\left(\left\|x_{j}-x_{i}\right\|\right) \\
b_{\min } \leq b_{i}(\tau) \leq b_{\max }
\end{gathered}
$$

onde $\tau$ representa o instante $t$ em que pelo menos um oscilador está disparando, $M(\tau)$ representa o número de osciladores no estado disparando no instante $\tau, \Delta(\tau)$ define o conjunto de osciladores disparando no instante $\tau$, $b_{\min }$ e $b_{\max }$ são constantes, $\|x\|$ é a norma Euclidiana de $x$, e $f(x)=a_{1} x+a_{2}$. Assumindo $a_{1}<0, f(x)$ define que cada neurônio, ao disparar, pode enviar um sinal positivo ou negativo a um outro oscilador dependendo da diferença entre seus estados. Desta forma, todo oscilador envia sinais positivos ao seu próprio grupo de osciladores enquanto um sinal negativo (inibitório) é enviado aos demais grupos (objetos).

Cada oscilador que recebe um sinal de reforço tem seu parâmetro $b$ aumentado, enquanto osciladores recebendo sinais de inibição têm o valor de $b$ reduzido segundo a Equação (3.22). O máximo valor que $b$ pode assumir é definido por $b_{\max }$ e o valor mínimo é definido por $b_{\min }$. Desta forma, após um certo instante de tempo, apenas o grupo de osciladores representando o objeto mais saliente (maior nível de cinza) continuará oscilando enquanto os demais serão inibidos. Como mencionado anteriormente, o objeto (grupo de osciladores) que permanece oscilando define o objeto que se encontra sob o foco de atenção.

Com o objetivo de permitir ao modelo realizar o deslocamento do foco de atenção a outros objetos, algumas modificações no modelo descrito acima foram realizadas. 1) foi introduzido um termo $\omega_{i}$ na Equação (3.22) com o objetivo de realçar o incremente gerado pelo sinal de reforço. Desta forma, a Equação (3.22) é re-escrita como:

$$
b_{i}(\tau)=b_{i}(\tau-1)+\frac{a}{M(\tau)} \sum_{j \in \Delta(\tau)} \omega_{j} f\left(\left\|x_{j}-x_{i}\right\|\right)
$$

onde $\omega_{j}$ codifica a intensidade do ponto $j$. Além disso, um mecanismo de inibição por retorno é ativado quando o parâmetro $b$ dos osciladores representando o objeto selecionado atingem $b=b_{\max }$. Desta forma, os osciladores previamente ativos são inibindo. Este mecanismo de inibição atua sobre o 
parâmetro $b$, o qual é reduzido a um valor baixo após a seleção do objeto, ou seja, quando o objeto ativo tem seu valor de $b=b_{\max }$. Desta forma, o próximo objeto mais saliente poderá ser selecionado pela rede como sendo o novo foco de atenção. Quando todos os objetos presentes na imagem são inibidos, isto é, já foram selecionados uma vez, seus osciladores são reiniciados e podem ser selecionados novamente. Este processo é repetido durante toda a execução do sistema.

Na próxima seção são apresentadas algumas simulações. Primeiramente são apresentadas duas simulações sem o mecanismo de mudança de foco. Em seguida, mais duas simulações ilustrando o processo de mudança de foco são exibidas.

\subsubsection{Simulações Computacionais}

Nas simulações apresentadas abaixo, os seguintes parâmetros são mantidos constantes. $\alpha=0,6, \beta=2,5, \theta_{x}=0,2, \theta_{y}=0,15, T=0,025, b_{\min } \in$ $\{0,002 ; 0,009\}, b_{\max }=0,1, a=0,001, a_{1}=-4$ e $a_{2}=1$. O valor inicial de $b$ é configurado em 0,02. A utilização de tais valores garantem que, inicialmente, todos os osciladores apresentam uma dinâmica caótica (Zhao et al., 2000).

Adotando esses parâmetros, algumas simulações são apresentadas utilizando imagens sintéticas como entrada. $A_{i, j}$ é definido com base no nível de cinza de cada ponto $i$ correspondente da imagem. Para as duas primeiras simulações, $b_{\min }=0,002$.

A primeira simulação é conduzida com a imagem sintética apresentada na Figura 3.13(a). Esta imagem é composta por duas espirais com diferentes níveis de cinza. Para esta simulação, a força de acoplamento $c=20$. Foi provado que cada grupo de osciladores pode ser sincronizado se um valor adequado para $c$ for utilizado (Zhao et al., 2000). A Figura 3.14 apresenta a atividade temporal dos osciladores representando as duas espirais, onde é possivel observar que o modelo é capaz de selecionar a espiral com nivel de cinza mais alto, denominada aqui como objeto saliente, enquanto a outra espiral é inibida. Vale observar que um período transiente (até $t=200$ ) é utilizado pelo processo de segmentação. Durante este período, o mecanismo de seleção de objeto não está ativado. Além disso, com base nesta simulação, pode-se constatar que o modelo além da capacidade de segmentação dos objetos e seleção do mais saliente, determinado pelo nível de cinza, também se mostra adequado na separação de problemas não lineares.

A Figura 3.13(b) apresenta a imagem utilizada na segunda simulação. Esta imagem é composta por cinco objetos com diferentes níveis de cinza. A força de acoplamento foi configurada em $c=5$. A atividade dos osciladores geradas pela alimentação da rede com a Figura 3.13(b) é apresentada na Figura 3.15. 


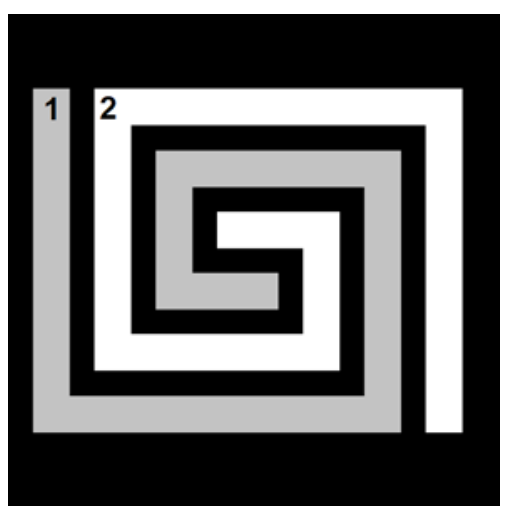

(a)

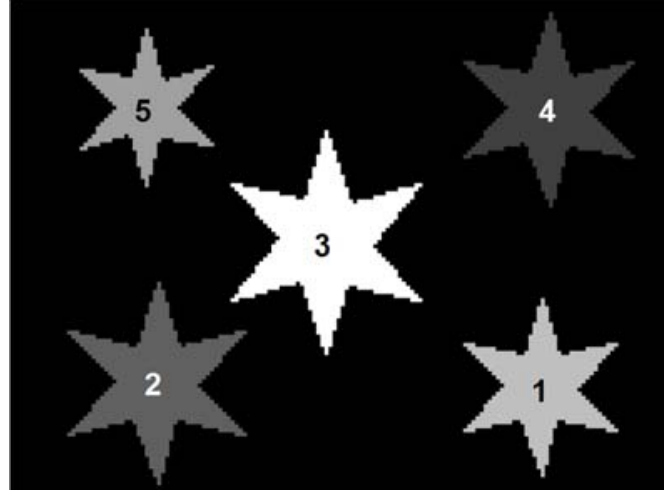

(b)

Figura 3.13: Imagens utilizadas em simulações sem o mecanismo de deslocamento de foco de atenção. (a) Imagem sintética composta por uma duplaespiral $(25 \times 25$ pontos). (b) Imagem sintética composta por cinco objetos $(160 \times 120$ pixels $)$.

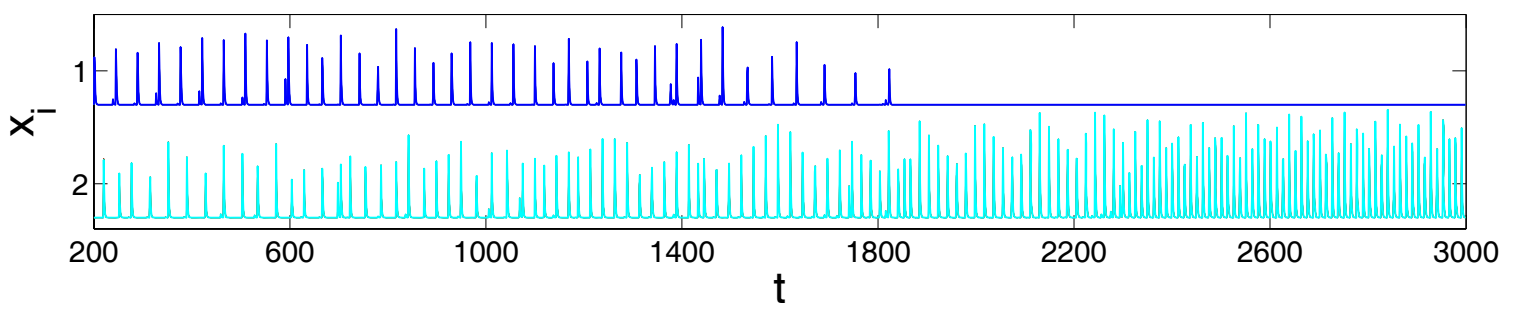

Figura 3.14: Atividade temporal dos osciladores em uma rede alimentada pela imagem apresentada na Figura 3.13(a). O período transiente utilizado pelo processo de segmentação dos objetos não é apresentado $t<200$. Os índices no eixo $y$ identificam os objetos presentes na imagem.

Novamente é possivel observar que, após um período de competição pela aquisição da atenção, apenas um grupo de osciladores permanece ativo (objeto número 3), enquanto os demais são inibidos.

As próximas duas simulações consideram o mecanismo de Inibição de Retorno utilizado para inibir o objeto previamente selecionado, possibilitando assim a mudança do foco de atenção a um próximo objeto. Nestas simulações a Equação (3.24) é utilizada.

A Figura 3.16(a) apresenta uma imagem composta por 4 objetos com diferentes niveis de cinza. Na Figura 3.17, a atividade temporal dos osciladores representando os 4 objetos é apresentada. Pode ser observado que, nesta simulação, o foco de atenção do sistema é sequencialmente alterado entre os objetos, cuja a ordem de seleção é definida pelo saliência dos objetos que compõem a cena.

A última simulação é conduzida com a imagem apresentada na Figura 3.16(b). A Figura 3.16(b) apresenta o resultado de simulação utilizando esta imagem. Novamente é possível observar que o modelo permite que todos os objetos sejam temporalmente selecionados com base na saliência definida pelo 


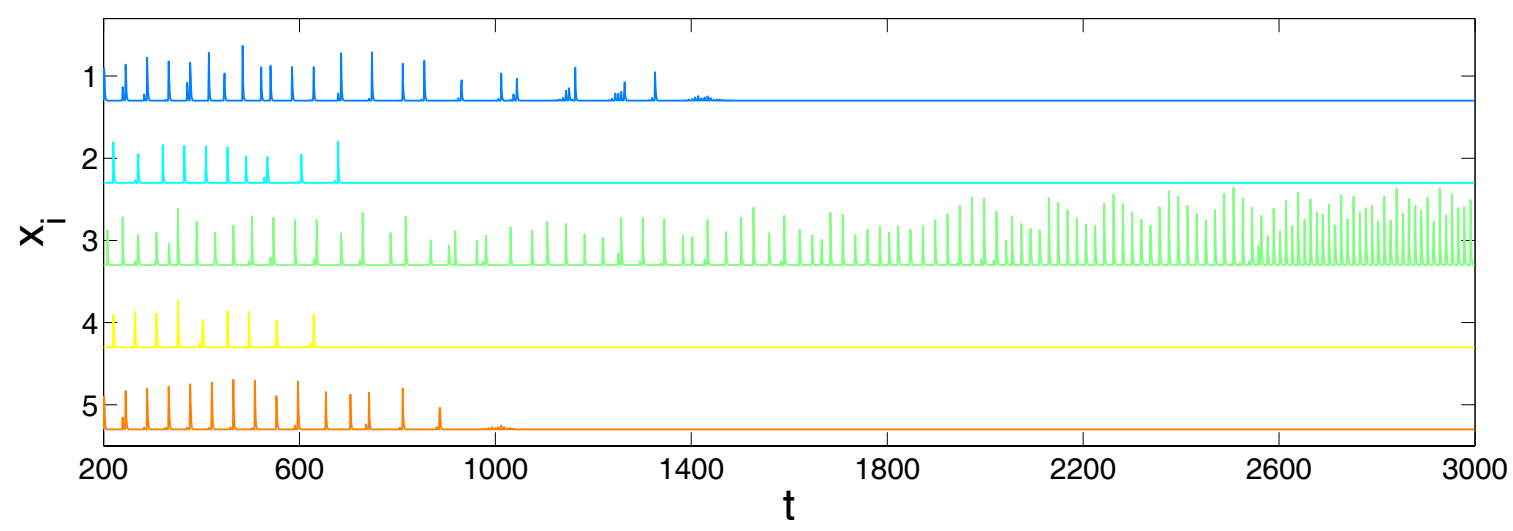

Figura 3.15: Atividade temporal dos osciladores em uma rede alimentada pela imagem apresentada na Figura 3.13(b). O período transiente utilizado pelo processo de segmentação dos objetos não é apresentado $t<200$. Os índices no eixo $y$ identificam os objetos presentes na imagem.

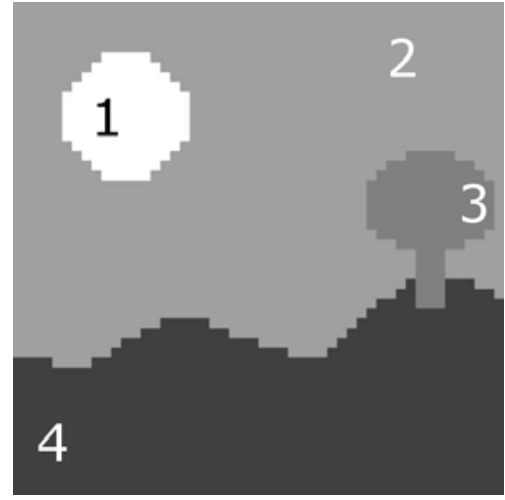

(a)

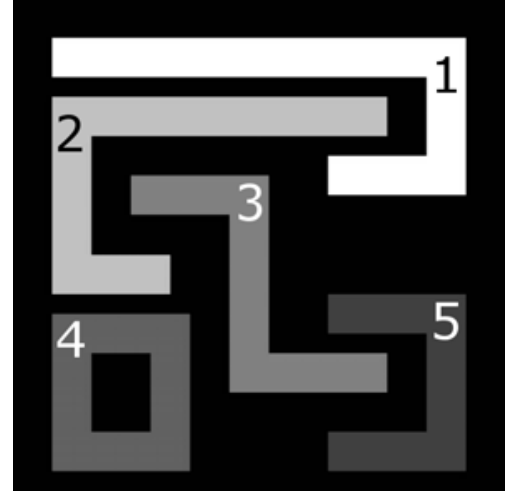

(b)

Figura 3.16: Imagens utilizadas em simulações sem o mecanismo de deslocamento de foco de atenção. (a) Imagem sintética composta por quatro objetos $(25 \times 25$ pontos). (b) Imagem sintética composta por cinco objetos ( $25 \times 25$ pixels).

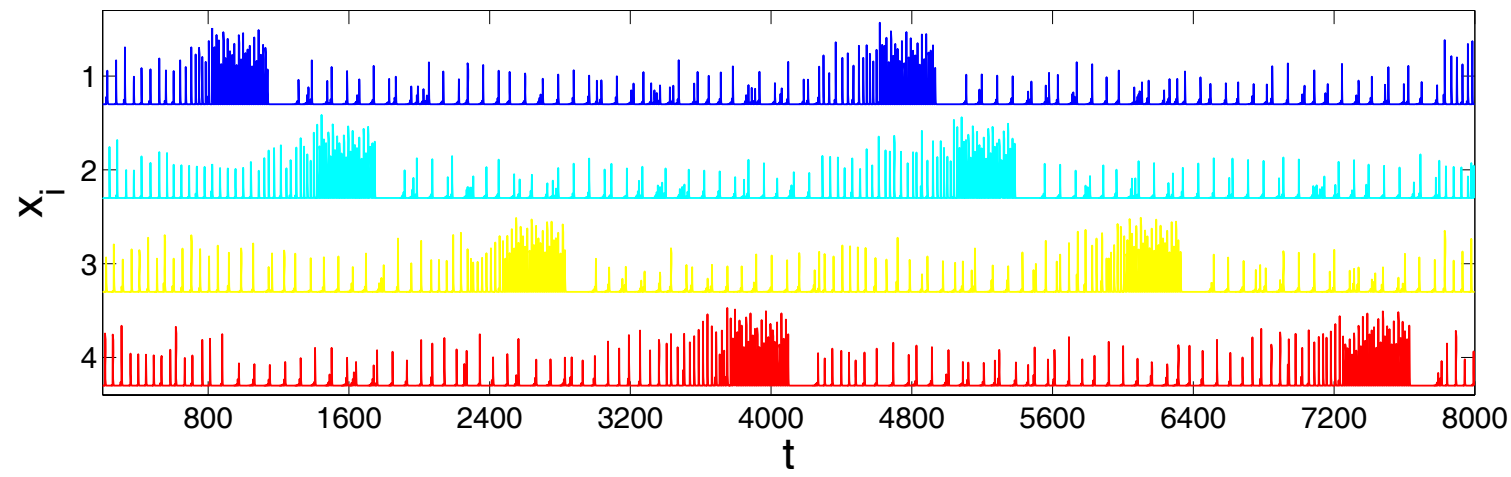

Figura 3.17: Atividade temporal dos osciladores em uma rede alimentada pela imagem apresentada na Figura 3.16(a). O período transiente utilizado pelo processo de segmentação dos objetos não é apresentado $t<200$. Os índices no eixo $y$ identificam os objetos presentes na imagem. 


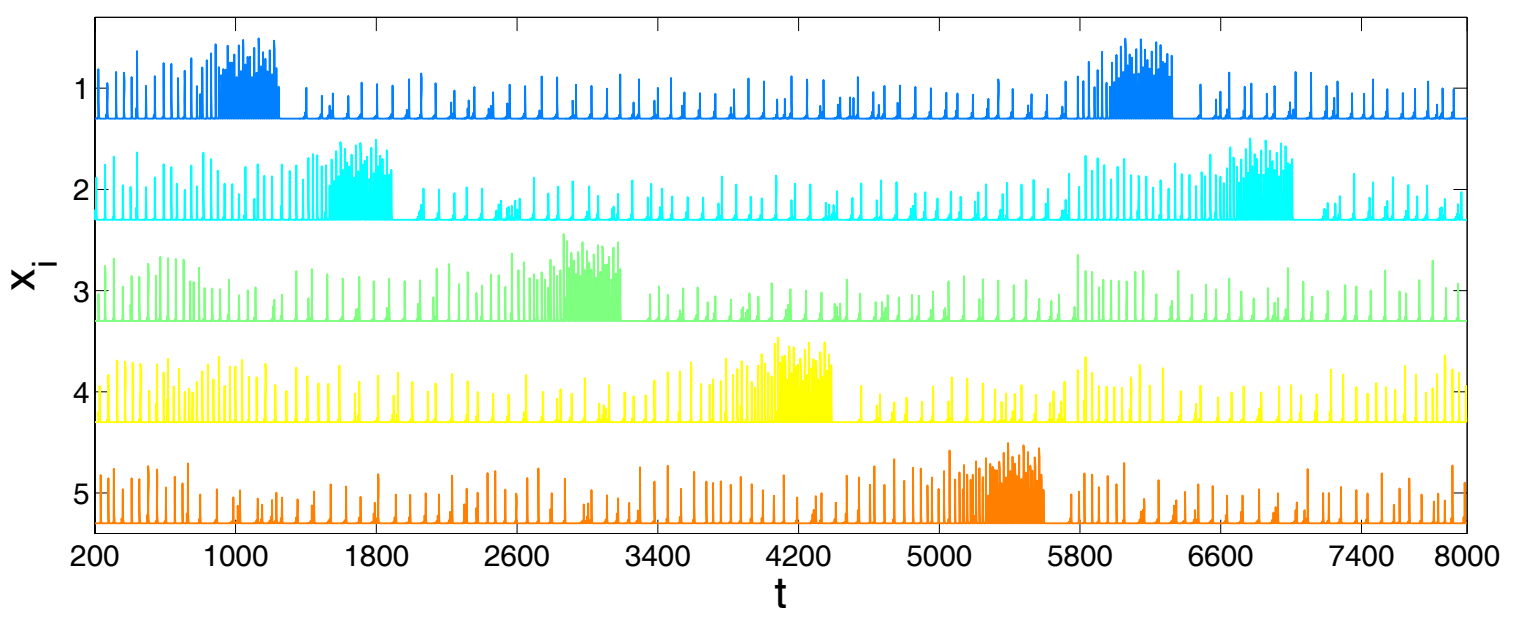

Figura 3.18: Atividade temporal dos osciladores em uma rede alimentada pela imagem apresentada na Figura 3.13(b). O período transiente utilizado pelo processo de segmentação dos objetos não é apresentado $t<200$. Os índices no eixo $y$ identificam os objetos presentes na imagem.

nível de cinza de cada objeto.

Com base nas simulações apresentadas acima, pode ser observado que o modelo proposto representa uma alternativa viável como um mecanismo de seleção de objetos. Tal afirmação tem como subsídio a capacidade do modelo na segmentação temporal dos objetos presentes na cena, capacidade de seleção de um dos objetos em um dado instante do tempo e mudança do foco de atenção. Entretanto, a utilização deste modelo com imagens reais, nos testes previamente realizados, não se mostrou adequada devido a limitação deste na segmentação de tais cenas. Além disso, em se tratando da seleção de objetos em imagens reais, para representação da saliência, outros atributos como cores e orientação devem ser considerados.

\subsection{Modelo de Atenção Baseado em Neurônios I\&D}

Nesta seção, um estudo sobre o processo de sincronização em redes de neurônios I\&D com crescimento de fase linear e um modelo de atenção baseado nesta rede é apresentado.

\subsection{Redes de Neurônios I\&D}

As redes neurais compostas por neurônios do tipo Integra e Dispara (I\&D) têm sido extensivamente utilizadas na construção de modelos neurocomputacionais e também aplicadas na solução de problemas computacionais, como segmentação de imagens (Campbell et al., 1999), clusterização de dados (Rhouma \& Frigui, 2001), dentre outros. O processo de sincronização em tais redes tam- 
bém tem sido investigado quantitativamente por diversos autores. O estudo teórico destes modelos tem como objetivo principal a análise do processo de sincronização entre os neurônios para uma dada topologia de acoplamento, como por exemplo, as redes globalmente acopladas (Mirollo \& Strogatz, 1990; Kuramoto, 1991), localmente acopladas, (Corral et al., 1995; Hopfield \& Herz, 1995; Díaz-Guilera et al., 1998; Campbell et al., 1999) e também em redes com topologia de acoplamento complexo (Timme et al., 2006).

Um neurônio do tipo I\&D é um dos modelos mais simples para simulação de dinâmica neural (Izhikevich, 2004) e pode ser definido pela seguinte equação:

$$
\dot{v}=I+a-b v
$$

onde $v$ é uma variável que representa um valor análogo ao potencial da membrana de um neurônio biológico, $I$ é um valor de entrada e, $a$ e $b$ são parâmetros do modelo. A dinâmica do neurônio I\&D pode ser descrita como segue: se o potencial do neurônio (membrana) $v$ ultrapassar um limiar denominado $\theta_{v}$, o neurônio dispara e o potencial $v$ retorna ao valor 0 . Normalmente, para fins de simulação, o limiar $\theta_{v}$ é assumido como 1.

O modelo descrito pela Equação (3.25) pode ser simplificado como um oscilador com crescimento de fase linear (Guardiola et al., 2000). Este modelo, denominado aqui oscilador I\&D linear, é descrito pela seguinte equação:

$$
\dot{\phi}=I
$$

onde $\phi$ representa a fase do oscilador neural (análogo ao potencial da membrana $v$ do modelo com crescimento de fase não-linear). Desta forma, o potencial evolui linearmente no tempo com velocidade definida por $I$. Quando o potencial deste oscilador atinge o limiar de disparo, neste caso assumido como $\phi=1$, o neurônio dispara e seu potencial retorna a zero.

Em uma rede com $N$ neurônios I\&D lineares, a evolução da fase de cada neurônio é definida por:

$$
\dot{\phi}_{i}=I_{i}
$$

onde $i$ é o índice do oscilador na rede. Quando $N=2$, a rede é composta por apenas dois neurônios $i=\{1,2\}$. Quando um oscilador, denominado $O_{i}$ atinge o limiar de disparo $\left(\phi_{i}=1\right)$, sua fase e a fase do segundo oscilador acoplado a $O_{i}$ são atualizadas pela seguinte equação:

$$
\phi_{i}\left(t^{-}\right) \geq 1 \Rightarrow\left\{\begin{array}{l}
\phi_{i}\left(t^{+}\right)=0 \\
\phi_{j}\left(t^{+}\right)=\phi_{j}+\Delta\left(\phi_{j}\right)
\end{array}\right.
$$


onde $\phi_{j}$ representa a fase do oscilador $O_{j}$ acoplado ao oscilador $O_{i}, \Delta\left(\phi_{j}\right)$ define a mudança de fase ocorrida no oscilador $O_{j}$ devido ao pulso gerado pelo oscilador $O_{i}$ e, $t^{-}$e $t^{+}$representam, respectivamente, os instantes do tempo imediatamente antes e após a emissão do pulso pelo oscilador $O_{i}$. A mudança de fase $\Delta\left(\phi_{j}\right)$ é definida por:

$$
\Delta(\phi)=\epsilon \phi
$$

Em uma rede de neurônios I\&D lineares, quando um neurônio qualquer dispara, sua fase retorna a zero e um pulso gerado é enviado a todos os demais neurônios acoplados ao neurônio que disparou. Este pulso pode ser um pulso excitatório (positivo) ou um pulso inibitório (negativo) de acordo com o tipo de sinapse definida. Se o pulso é excitatório, o potencial do neurônio que recebe tal pulso é incrementado, caso contrário o potencial do neurônio que recebe o pulso é reduzido atrasando o próximo disparo deste neurônio. Normalmente, sinapses excitatórias produzem o efeito de sincronização entre um grupo de neurônios acoplados, já as conexões inibitórias tendem a prevenir a sincronização entre os neurônios.

Nas redes formadas pelos neurônios I\&D definidos pela Equação (3.27), a não-linearidade é observada apenas quando um pulso ocorre e altera a fase dos neurônios vizinhos. Caso contrário, quando não existe acoplamentos na rede, todos os neurônios evoluem linearmente no tempo de acordo com a Equação (3.27). Desta forma, o modelo contínuo apresentado pode ser definido como um mapa discreto representando apenas os instantes em que os pulsos ocorrem.

Diversos trabalhos têm demonstrado que redes de neurônios I\&D acoplados com sinapses excitatórias apresentam o fenômeno de sincronização quando o tempo tende ao infinito. Este fato ocorre independente de quão fraca for a força de acoplamento entre os neurônios (Mirollo \& Strogatz, 1990; Guardiola et al., 2000; Rhouma \& Frigui, 2001). A seguir, é apresentada uma análise demonstrando o processo de sincronização entre dois neurônios I\&D lineares conectados por uma sinapse excitatória. Na sequência, simulações numéricas ilustram o processo de sincronização para o caso de $N$ osciladores. O estudo apresentado a seguir tem como objetivo ilustrar e estimar o tempo necessário para atingir a sincronização entre dois neurônios com base na força de acoplamento entre estes.

\subsubsection{Sincronização em Redes de Neurônios I\&D}

Primeiramente é demonstrado que dois neurônios positivamente acoplados sincronizam conforme $t \rightarrow \infty$. Sejam $\phi_{1}$ e $\phi_{2}$ fases de dois osciladores $O_{1}$ e $O_{2}$, 
respectivamente. Sem perda de generalidade, as fases iniciais são assumidas como: $\phi_{1}(0)=0$ e $\phi_{2}(0)=\phi$. A análise examina as mudanças de fases que ocorrem a cada ciclo. Um ciclo do sistema é completado quando $O_{1}(0)=0$, inicialmente na origem, dispara e retorna a origem do sistema, isto é $O_{1}(1)=0$.

Conforme o sistema evolui, $O_{2}$ irá disparar quando atingir o limiar $\phi_{2}=1$. Após o disparo, $\phi_{2}=0$ e a fase de $O_{1}$ é definida por;

$$
\begin{aligned}
\phi_{1} & =0+(1-\phi)+(1-\phi) \epsilon \\
& =(1-\phi)(1+\epsilon) \\
& =(1-\phi) \mu
\end{aligned}
$$

onde $\epsilon(1-\phi)$ é a mudança de fase causada pelo disparado de $O_{2}$ e $\mu=1+\epsilon$.

(a)

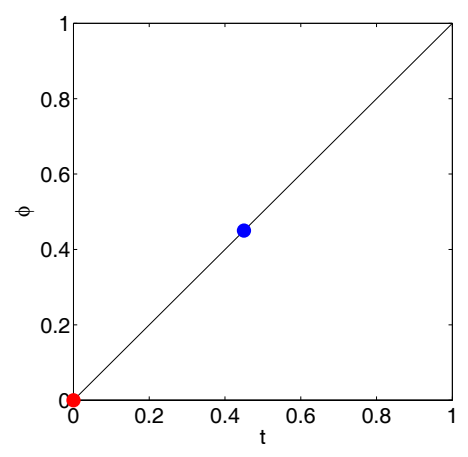

(d)

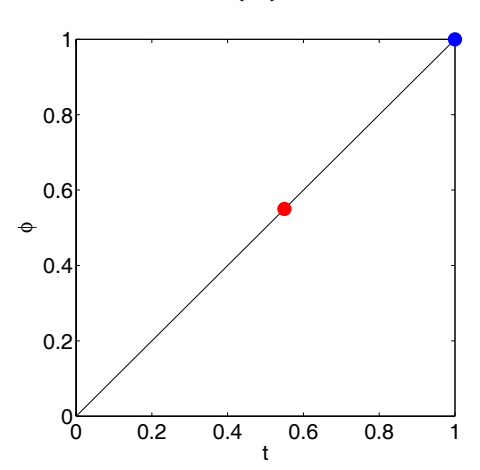

(b)

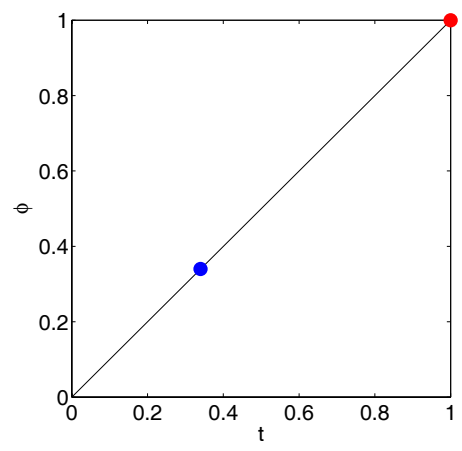

(c)

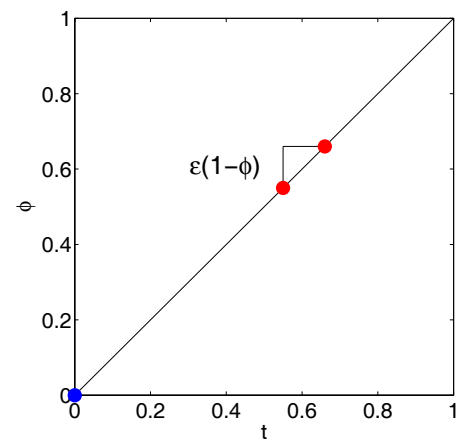

(e)

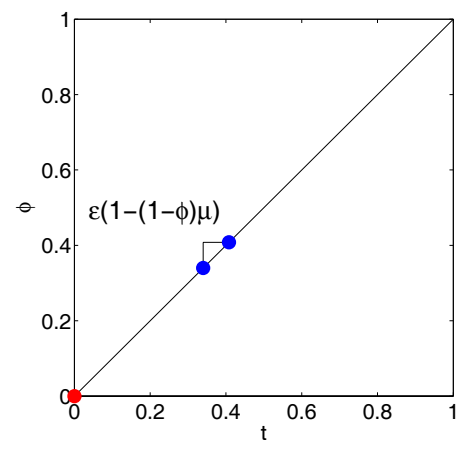

Figura 3.19: Evolução da fase em um ciclo completo com dois osciladores I\&D acoplados. Os pontos de cor vermelha e azul representam os osciladores $O_{1}$ e $\mathrm{O}_{2}$ respectivamente. (a) $\mathrm{O}_{1}$ encontra-se na origem e $\mathrm{O}_{2}$ é configura com uma fase inicial arbitrária definida por $\phi$. (b) $\mathrm{O}_{2}$ atinge o limiar. (c) $\mathrm{O}_{2}$ dispara e retorna instantaneamente a origem. Ao mesmo tempo, o pulsado gerado pelo disparo de $O_{2}$ atinge $O_{1}$. Como resultado, $O_{1}$ tem sua fase alterada por $\epsilon(1-\phi)$. (d) $O_{1}$ atinge o limiar de disparo. (e) $O_{1}$ dispara e imediatamente retorna a origem. Um pulso é enviado a $\mathrm{O}_{2}$ alterando sua fase em $\epsilon(1-(1-\phi) \mu)$.

Agora que $O_{2}$ está na origem, $O_{1}$ possui fase diferente de zero e é o próximo oscilador a disparar. Após um certo tempo $O_{1}$ atinge o limiar, dispara e retorna à origem $\left(\phi_{1}=0\right)$. Neste momento, o primeiro ciclo do sistema está completo e 
a nova fase de $\mathrm{O}_{2}$ é definida por:

$$
\begin{aligned}
\phi_{2} & =\left(1-\phi_{1}\right) \mu \\
& =(1-(1-\phi) \mu) \mu \\
& =\mu-\mu^{2}(1-\phi)
\end{aligned}
$$

Este ciclo de evolução é apresentado pela na Figura 3.19. Após o primeiro ciclo, as novas fases são $\phi_{1}(1)=0$ e $\phi_{2}(1)=\mu-\mu^{2}(1-\phi)$. Desta forma, pode-se obter as novas fases de $O_{2}$ após cada ciclo do sistema, isto é, a fase $\phi_{2}$ sempre que $O_{1}$ retorna a origem. O ponto fixo do sistema pode ser determinado por $\phi^{*}=\mu-\mu^{2}+\mu^{2} \phi^{*}$. Isolando $\phi^{*}$ nesta última equação, $\phi^{*}=\frac{\mu^{2}-\mu}{\mu^{2}-1}$ é obtido. Como a derivada de primeira ordem de $\phi^{*}=\mu-\mu^{2}+\mu^{2} \phi^{*}$ é $\mu^{2}$ e $\mu^{2}=(1+\epsilon)^{2}>1$ para um acoplamento excitatório, então $\phi^{*}$ é um ponto fixo instável. Assim, dado que o ponto fixo é instável, $\phi_{2}$ se distância de $\phi$ aproximando 0 ou 1 a cada ciclo e a sincronização entre os dois osciladores é obtida.

Tendo conhecimento de que a sincronização é obtida para um acoplamento excitatório $(\epsilon>0)$, o próximo passo está em obter o número de ciclos $T$ necessário para atingir está sincronização. Continuando os cálculos iniciados acima, os valores de $\phi_{2}(\mathrm{t})$ é obtido após cada ciclo do sistema, isto é, $t=0,1,2,3, \ldots, T$ :

$$
\begin{aligned}
\phi_{2}(0) & =\phi \\
\phi_{2}(1) & =\mu-\mu^{2}+\mu^{2} \phi \\
\phi_{2}(2) & =\mu-\mu^{2}+\mu^{3}-\mu^{4}+\mu^{4} \phi \\
\phi_{2}(3) & =\mu-\mu^{2}+\mu^{3}-\mu^{4}+\mu^{5}-\mu^{6}+\mu^{6} \phi \\
\vdots & \\
\phi_{2}(T) & =\mu-\mu^{2 T}+\mu^{2 T} \phi+\sum_{t=1}^{2 T-2}(-1)^{t} \mu^{t+1}
\end{aligned}
$$

O número de ciclos $T$ necessários para a sincronização depende da fase inicial de $O_{2}$, ou seja, $\phi_{2}(0)=\phi>\phi^{*}$ ou $\phi_{2}(0)=\phi<\phi^{*}$.

No primeiro caso, $\phi_{2}(0)=\phi>\phi^{*}$, $\phi_{2}$ é incrementado a cada ciclo até atingir 1. Quando isso acontece, o sistema está sincronizado. Podemos determinar $T$ resolvendo a seguinte equação:

$$
\mu-\mu^{2 T}+\mu^{2 T} \phi+\sum_{t=1}^{2 T-2}(-1)^{t} \mu^{t+1}=1
$$


Tabela 3.1: Comparação entre os resultados teóricos e de simulação obtidos: Número de ciclos necessários para sincronização entre dois neurônios com $\phi_{1}=0,0$ e $\phi_{2}=0,45$

\begin{tabular}{|c||c|c|}
\hline \hline$\epsilon$ & Resultado teórico & Resultado de Simulação \\
\hline \hline 0,01 & 113,51 & 114 \\
0,02 & 56,003 & 56 \\
0,03 & 36,87 & 37 \\
0,04 & 27,32 & 28 \\
0,05 & 21,61 & 22 \\
\hline
\end{tabular}

Resolvendo a equação acima, o seguinte valor de $T$ é obtido:

$$
T \approx \frac{\ln \left(\frac{1}{\mu \phi-\mu+\phi}\right)}{2 \ln (\mu)}
$$

No segundo caso, $\phi_{2}(0)=\phi<\phi^{*}$, a fase de $O_{2}$ é reduzida a cada ciclo até atingir o valor zero (sincronia). Desta forma, a seguinte equação pode ser utilizada para obter $T$ :

$$
\mu-\mu^{2 T}+\mu^{2 T} \phi+\frac{\mu^{2 T-\mu^{2}}}{\mu+1}=0
$$

Resolvendo a equação acima, obtemos:

$$
T \approx \frac{\ln \left(\frac{-\mu}{\mu \phi-\mu+\phi}\right)}{2 \ln (\mu)}
$$

Assim, além da garantia da sincronização entre os dois neurônios, também é possível estimar a quantidade de ciclos necessários para a aquisição da sincronia entre estes. A Tabela 3.1 apresenta o número de ciclos necessários para atingir a sincronização entre dois neurônios variando a força de acoplamento $\epsilon$. Pelos valores apresentados na tabela, é possível observar que os resultados teóricos obtidos aproximam com alta precisão os resultados de simulação.

A seguir, é apresentado o resultado de simulação para a sincronização de redes com $N$ osciladores e diversas topologias de conexão. A Figura 3.20 mostra que todos os neurônios podem sincronizar quando um acoplamento positivo é utilizado. Além disso, a sincronização é obtida mais rapidamente quando cada neurônio da rede é acoplado a um maior número de vizinhos, isto é, conforme o grau médio de conexões da rede aumenta, o número de ciclos necessários para atingir a sincronização global na rede diminui. 
(a)

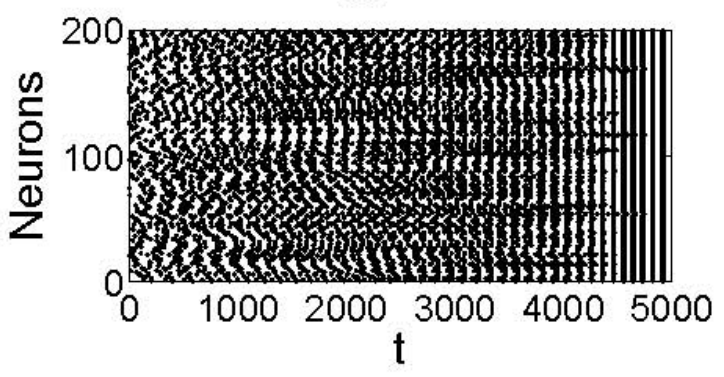

(c)

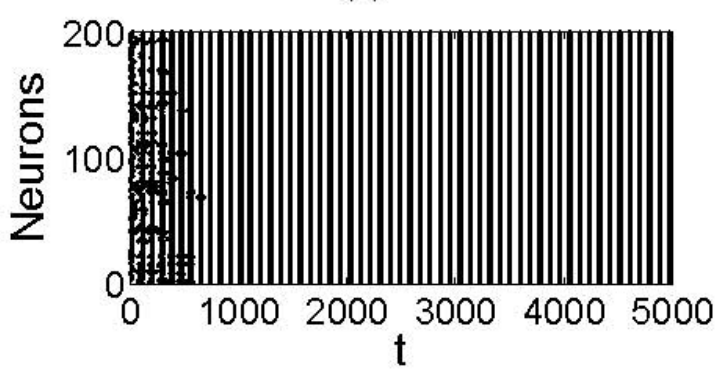

(b)

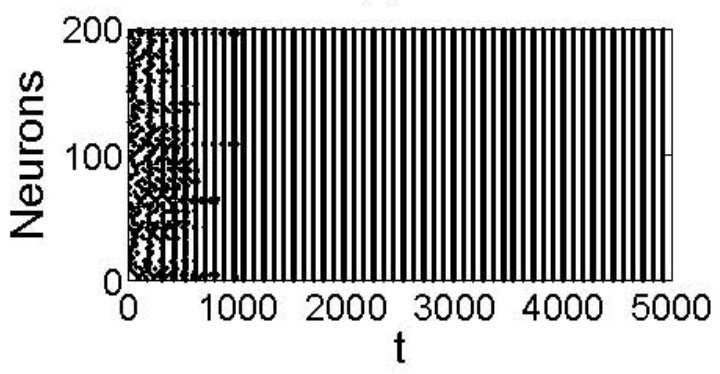

(d)

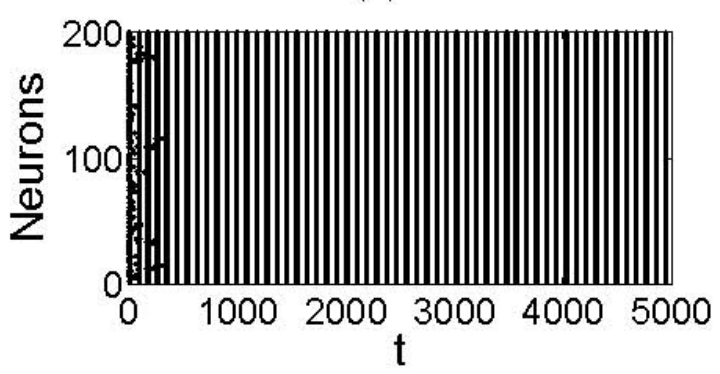

Figura 3.20: Atividade temporal de um rede de neurônios positivamente acoplada. $N=200$ e $\epsilon=0,1$. Cada ponto no gráfico representa o instante de disparo de um neurônio. (a) Grau médio da rede $\langle k\rangle=2$, cada neurônio está, em média, aleatoriamente acoplado a dois outros neurônios; (b) $\langle k\rangle=4$; (c) $<k>=6$; (d) $<k>=8$.

\subsubsection{Descrição do Modelo}

Com base no modelo linear apresentado acima, um modelo de atenção visual para seleção de objetos foi elaborado (Quiles et al., 2009). O modelo é formado por uma rede $2 \mathrm{D}$ composta por neurônios $\mathrm{I} \& \mathrm{D}$ com dois tipos de conexões: conexões excitatórias locais e conexões inibitórias estendidas. As conexões excitatórias formam um mecanismo cooperativo responsável por sincronizar grupos de neurônios que representam um mesmo objeto (segmento). Por outro lado, as conexões de inibição têm por finalidade segregar os diversos objetos presentes no estimulo visual de tal forma que cada objeto seja representado por um trem de pulso único. Além disso, as conexões inibitórias, competitivas, também têm como objetivo inibir objetos de fundo permitindo que apenas o objeto mais saliente seja selecionado.

A rede de neurônios I\&D é definida pela seguinte equação:

$$
\frac{d \phi_{i}}{d t}=C_{i}(t)+E_{i}(t)-Y_{i}(t)
$$

onde $i$ é o índice do neurônio. $\phi_{i}$ é a fase do neurônio $i, C_{i}$ define a velocidade de crescimento da fase cuja finalidade é controlar a frequência de disparo do neurônio $i, E_{i}(t)$ define o acoplamento excitatório e $Y_{i}(t)$ representa o acoplamento inibitório entre os neurônios. Removendo os termos de acoplamento 
$E_{i}(t)$ e $Y_{i}(t)$; e assumindo $C_{i}(t)$ como uma constante, a Equação (3.37) representa o neurônio linear definido pela Equação (3.27) na Seção 3.4.1.

O termo de acoplamento excitatório $E_{i}(t)$ é definido pela seguinte equação:

$$
E_{i}(t)=\epsilon \phi_{i}(t) \sum_{j \in \Delta_{i}} \delta\left(t-t_{j}\right)
$$

onde $\delta$ é a função delta de Dirac, $t_{j}$ representa o instante em que o neurônio $j$ dispara, $\Delta_{i}$ define a vizinhança cooperativa do neurônio $i$. Especificamente, o neurônio $i$ é conectado ao neurônio $j$ caso $j$ pertença a vizinhança 8-conectado do neurônio $i$ e a diferença entre os atributos que alimentam suas entradas sejam inferiores a um determinado limiar (definido posteriormente). $\epsilon$ é uma constante que define a força de acoplamento entre os neurônios $i$ e $j$.

O termo de acoplamento inibitório é definido por:

$$
Y_{i}(t)=\phi_{i}(t) \sum_{j \in \Lambda_{i}} \sigma_{i j} \delta\left(t-t_{j}\right)
$$

onde $\Lambda_{i}$ define a vizinhança de competição do neurônio $i$ e $\sigma_{i j}$ é a força inibitória de acoplamento entre os neurônios $i$ e $j$ definida pela seguinte equação:

$$
\sigma_{i j}=c_{Y} \exp \left(-\sum_{k} c_{i j}^{k} f_{i j}^{k}\right)
$$

onde $c_{Y} \in[0,1]$ é uma constante, $f_{i j}^{k}$ e $c_{i j}^{k}$ representa o contraste para o atributo $k$ (intensidade, cor ou orientação) e seus respectivos pesos, respectivamente. O contraste é definido como a diferença absoluta entre os atributos ( $k$ ) que alimentam os neurônios $i$ e $j$ :

$$
f_{i j}^{k}=\left|f_{i}^{k}-f_{j}^{k}\right|
$$

Para implementar a tarefa de seleção visual de objetos, um mecanismo para controlar a velocidade de disparo de cada neurônio é implementado. De forma geral, tal mecanismo pode ser definido como segue: se o neurônio é parte do objeto que apresenta maior contraste (objeto mais saliente), este neurônio tem sua frequência de disparo aumentada; caso contrário, isto é, o neurônio pertence a algum objeto de fundo, sua frequência de disparo é reduzida. Este mecanismo é modelo através do controle da variável $C_{i}(t)$.

Desta forma, cada vez que um neurônio $i$ dispara, sua frequência de disparo é aumentada pela seguinte equação:

$$
C_{i}(t)=C_{i}(t-1)+\eta\left(C_{\max }-C_{i}(t-1)\right)
$$

onde $\eta$ e $C_{\max }$ são constantes que definem o ganho de potencial e o valor máximo assumido por $C_{i}(t)$, respectivamente. 
Para reduzir a frequência de disparo, isto é reduzir o valor de $C_{i}(t)$, a seguinte equação é utilizada:

$$
C_{j}(t)=C_{j}(t-1)+\epsilon \sigma_{i j}\left(C_{m i n}-C_{j}(t-1)\right)
$$

onde $C_{\min }$ é o valor mínimo assumido por $C_{j}(t)$. Desta forma, toda vez que um neurônio $j$ recebe um sinal de inibição proveniente de um neurônio $i, C_{j}(t)$ é reduzido de acordo com a Equação (3.43).

Assumindo o limiar de disparo $\theta_{\phi}=1$, quando $C_{j}(t)<1$, o neurônio $j$ não apresenta atividade oscilatória pois o valor de $\phi_{j}$ é sempre inferior ao limiar. Este fenômeno é observado devido à dinâmica interna do oscilador na qual o valor de $\phi_{j}$ sempre retorna a zero quando um ciclo de oscilação é completado, isto é, ou o oscilador atinge o limiar e dispara, ou a duração do ciclo, neste caso $t=1$ é atingida sem disparos. Desta forma, apenas os osciladores que representam o objeto saliente continuam disparando enquanto os demais osciladores têm suas frequências de disparo reduzidas até se tornarem inativos.

De um modo geral, o funcionamento da rede pode ser explicado da seguinte maneira. Dado uma imagem de entrada, a rede é definida de tal forma que cada oscilador representa um ponto da imagem. Com base neste estímulo definido pelo padrão visual apresentado, as conexões entre os osciladores pertencentes a uma mesma vizinhança são estabelecidas conforme a similaridade dos sinais que os alimentam. Desta forma, as conexões excitatórias são criadas se, para quaisquer dois osciladores $i$ e $j, f_{i j}^{k}=\left|f_{i}^{k}-f_{j}^{k}\right|<\theta^{k}$, onde $\theta^{k}$ é um limiar de corte. Caso contrário, o acoplamento excitatório não é definido entre $i$ e $j$. Conforme descrito anteriormente, estas conexões têm como função principal sincronizar a atividade de osciladores representando um mesmo objeto. As conexões inibitórias são determinadas com base no contraste entre atributos (Equação (3.40)). Desta forma, se dois osciladores $i$ e $j$ são alimentados por atributos semelhantes, isto é, o contraste entre eles é pequeno ou nulo, o termo $f_{i j}^{k}$ da Equação (3.40) aproxima zero e, devido a função exponencial negativa desta equação, o peso de acoplamento inibitório assume um alto valor. Por outro lado, quando os sinais que alimentais tais osciladores são definidos por atributos distintos, o peso da conexão inibitória entre eles é pequeno ou mesmo nulo.

Desta maneira, objetos com características semelhantes são mutuamente inibidos devido a competição gerada pelas conexões inibitórias, por outro lado, um objeto que apresenta um alto contraste com os demais não é inibido e permanece oscilando, isto é, representa o objeto sob o foco de atenção do sistema. 


\subsubsection{Simulações Computacionais}

Nesta seção são apresentados os resultados de simulação obtidos a partir da aplicação do modelo descrito acima com imagens sintéticas e reais.

Dado uma imagem como entrada do sistema, a intensidade do nível de cinza, as componentes da cor (RGB) e a orientação são extraídas. Todas os atributos são normalizados entre $[0,1]$. A intensidade é obtida como $I=$ $(r+g+b) / 3$. As orientações locais são extraídas a partir da aplicação de um filtro extrator de bordas Laplaciano seguido por quatro máscaras espaciais definidas pelas Equações (3.44)-(3.47):

$$
\begin{aligned}
& M_{0^{\circ}}=\left[\begin{array}{rrr}
-1 & -1 & -1 \\
2 & 2 & 2 \\
-1 & -1 & -1
\end{array}\right] \\
& M_{45^{\circ}}=\left[\begin{array}{rrr}
-1 & -1 & 2 \\
-1 & 2 & -1 \\
2 & -1 & -1
\end{array}\right] \\
& M_{90^{\circ}}=\left[\begin{array}{rrr}
-1 & 2 & -1 \\
-1 & 2 & -1 \\
-1 & 2 & -1
\end{array}\right] \\
& M_{135^{\circ}}=\left[\begin{array}{rrr}
2 & -1 & -1 \\
-1 & 2 & -1 \\
-1 & -1 & 2
\end{array}\right]
\end{aligned}
$$

Os atributos extraídos de cada ponto da imagem são utilizados como entrada de cada um dos respectivos osciladores da rede. Mais especificamente, nas simulações que serão apresentadas a seguir, as conexões excitatórias da rede são definidas com base no valor da intensidade (nível de cinza) de cada ponto da imagem. Já as conexões inibitórias são determinadas a partir do contraste do nível de cinza $(I)$, cores $(r, g$ e $b)$, e orientações $\left(0^{\circ}, 45^{\circ}, 90^{\circ} \mathrm{e}\right.$ $135^{\circ}$ ). Para cada uma desses atributos que formam as conexões inibitórias, os seguintes pesos, definidos empiricamente, são utilizados (Equação (3.40)): $c_{i j}^{I}=1,0, c_{i j}^{R}=1,0, c_{i j}^{G}=1,0, c_{i j}^{B}=1,0, c_{i j}^{0^{\circ}}=0,25, c_{i j}^{45^{\circ}}=0,25, c_{i j}^{90^{\circ}}=0,25 \mathrm{e}$ $c_{i j}^{135^{\circ}}=0,25$.

Os demais parâmetros do modelo foram ajustados manualmente através 


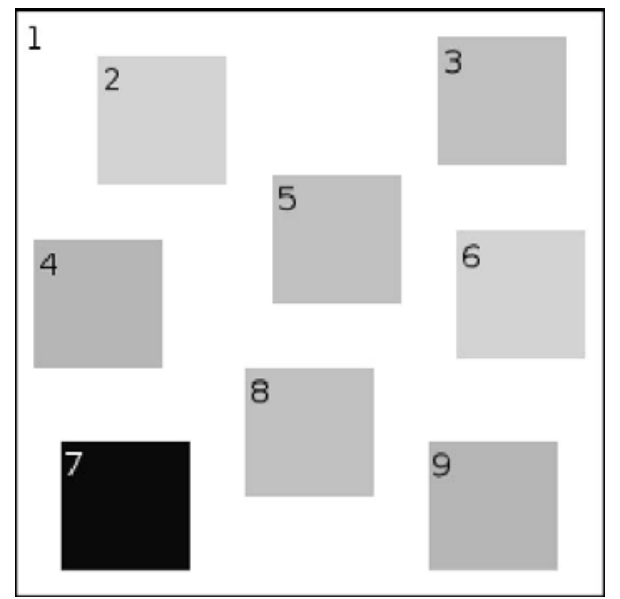

(a)

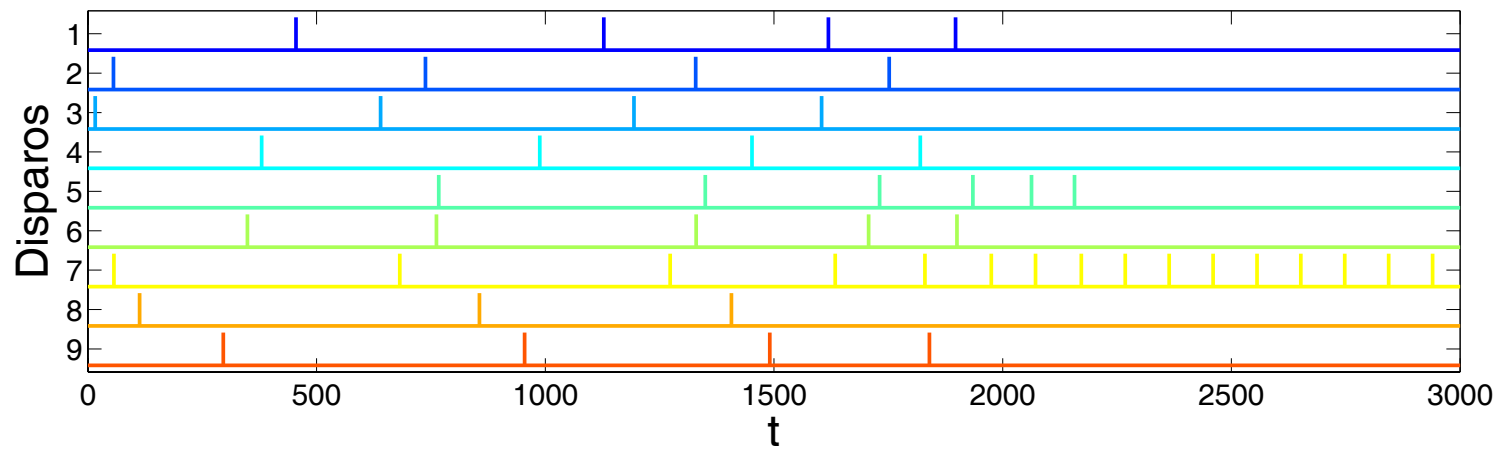

(b)

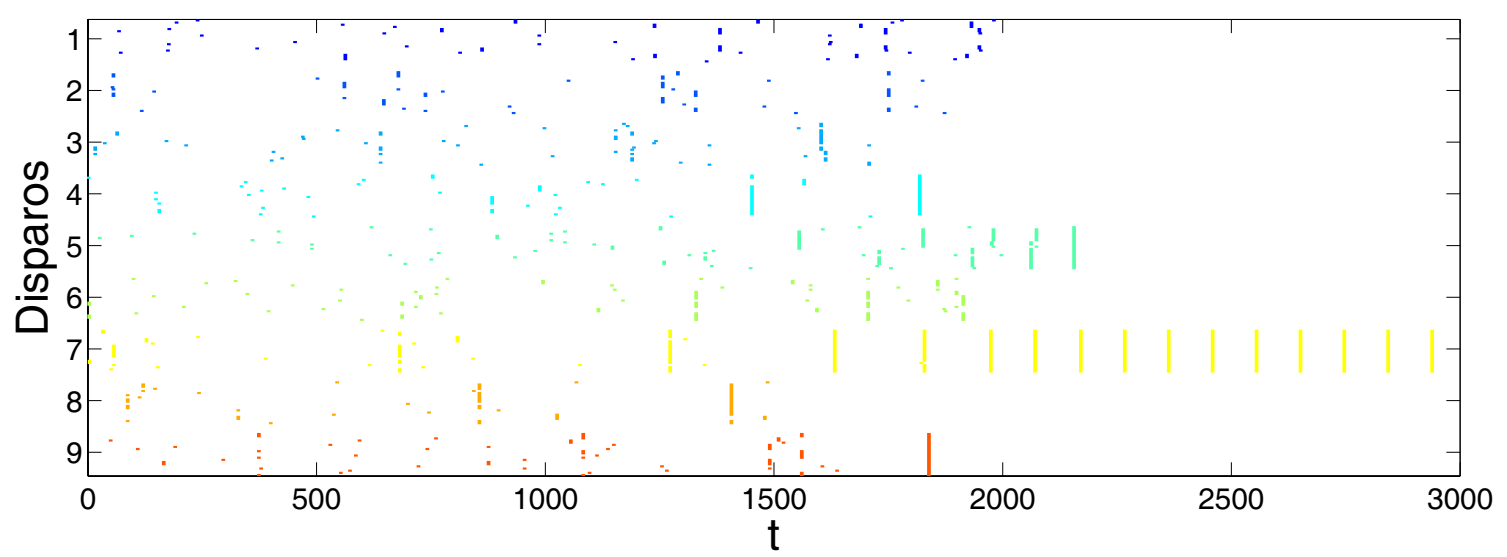

(c)

Figura 3.21: Simulação computacional utilizando uma imagem com nove objetos em tons de cinza; (a) Imagem de entrada com $64 \times 64$ pontos; (b) Atividade temporal de disparo dos neurônios representando os objetos (atividade de um neurônio por objeto). Os índices no eixo $y$ identificam os objetos presentes na imagem (a). (c) Ilustração do processo de sincronização/competição. A atividade de 20 neurônios aleatoriamente selecionados de cada objeto é apresentada. 
de simulações com imagens sintéticas. Com base nesses testes, os seguintes valores de parâmetros foram obtidos: $C_{0}=1,1, C_{\text {Min }}=0,0, C_{\text {Max }}=2,0, \epsilon \in$ $\{0,2 ; 0,4\}, c_{Y} \in\{0,3 ; 0,4 ; 0,5 ; 0,7\}$ e $\theta^{k}=0,1$.

Para todas as simulações tanto utilizando imagens sintéticas como reais, o objeto saliente é definido como sendo aquele que apresenta um maior contraste com os demais objetos presentes na cena, denominados aqui objeto saliente e objetos de fundo, respectivamente. Esta suposição recebe suporte direto de experimentos biológicos que têm demonstrado que o contraste dos objetos que compõem a cena analisada é mais importante que o nível absoluto de cada um dos atributos visuais em tarefas de inspeção visual (Wolfe \& Horowitz, 2004; Yantis, 2005).

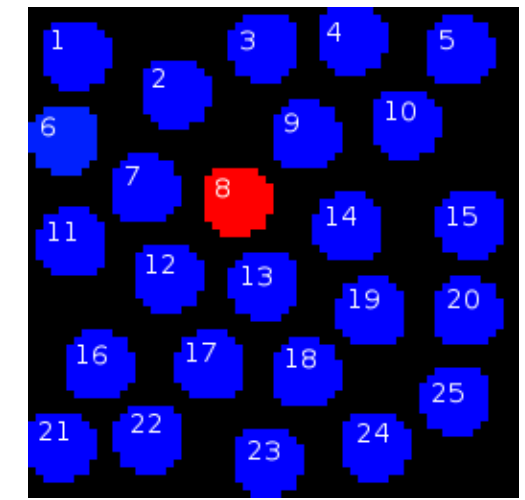

(a)

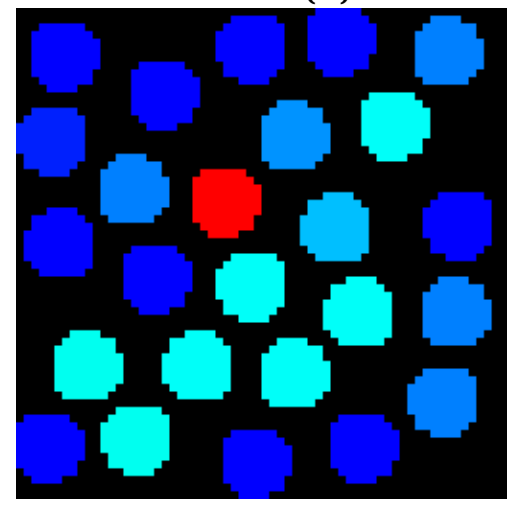

(c)

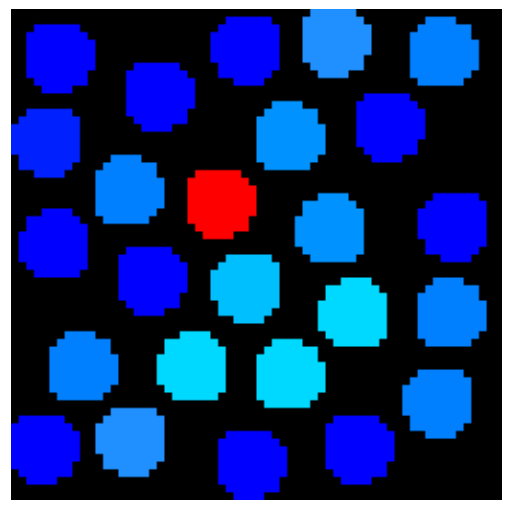

(b)

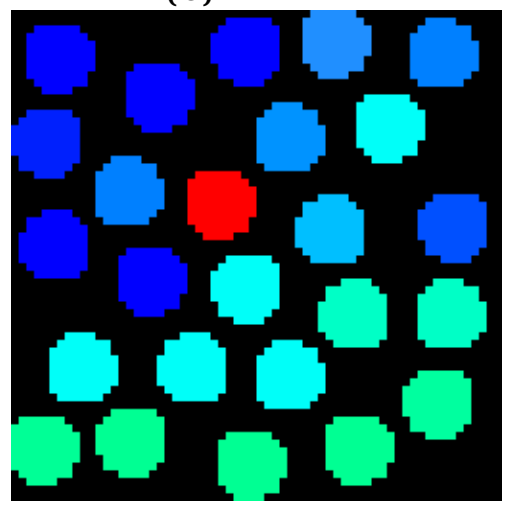

(d)

Figura 3.22: Simulação computacional variando a heterogeneidade dos distratores. (a), (b), (c) e (d) representam quatro níveis variando de um fundo contendo objetos homogêneos a um padrão de objetos distratores com cores heterogêneas (imagens com $64 \times 64$ pontos).

A Figura 3.21(a) apresenta uma imagem em tons de cinza no qual o objeto de cor preta, em uma inspeção visual por humanos, mostra-se como o objeto mais saliente. O resultado da aplicação do modelo nesta imagem é apresentado na Figura 3.21(b), onde são mostradas as séries temporais de disparos dos neurônios representando os nove objetos da Figura 3.21(a). Por este resultado é possível observar que, no início, todos os objetos se encontram ativos representados por neurônios disparando. Após esse processo competitivo por 
atenção, apenas um grupo de neurônios permanece ativo (número 7) enquanto os demais são inibidos. Este grupo é exatamente o que representa o objeto de cor preta, fato este que coincide com a percepção visual humana. Nesta simulação, como todos os objetos presentes na cena são representados por tons de cinza e caracterizados pela mesma forma geométrica, é importante ressaltar que o atributo intensidade (cinza) é única característica discriminativa responsável por conduzir o processo de competição pela atenção.

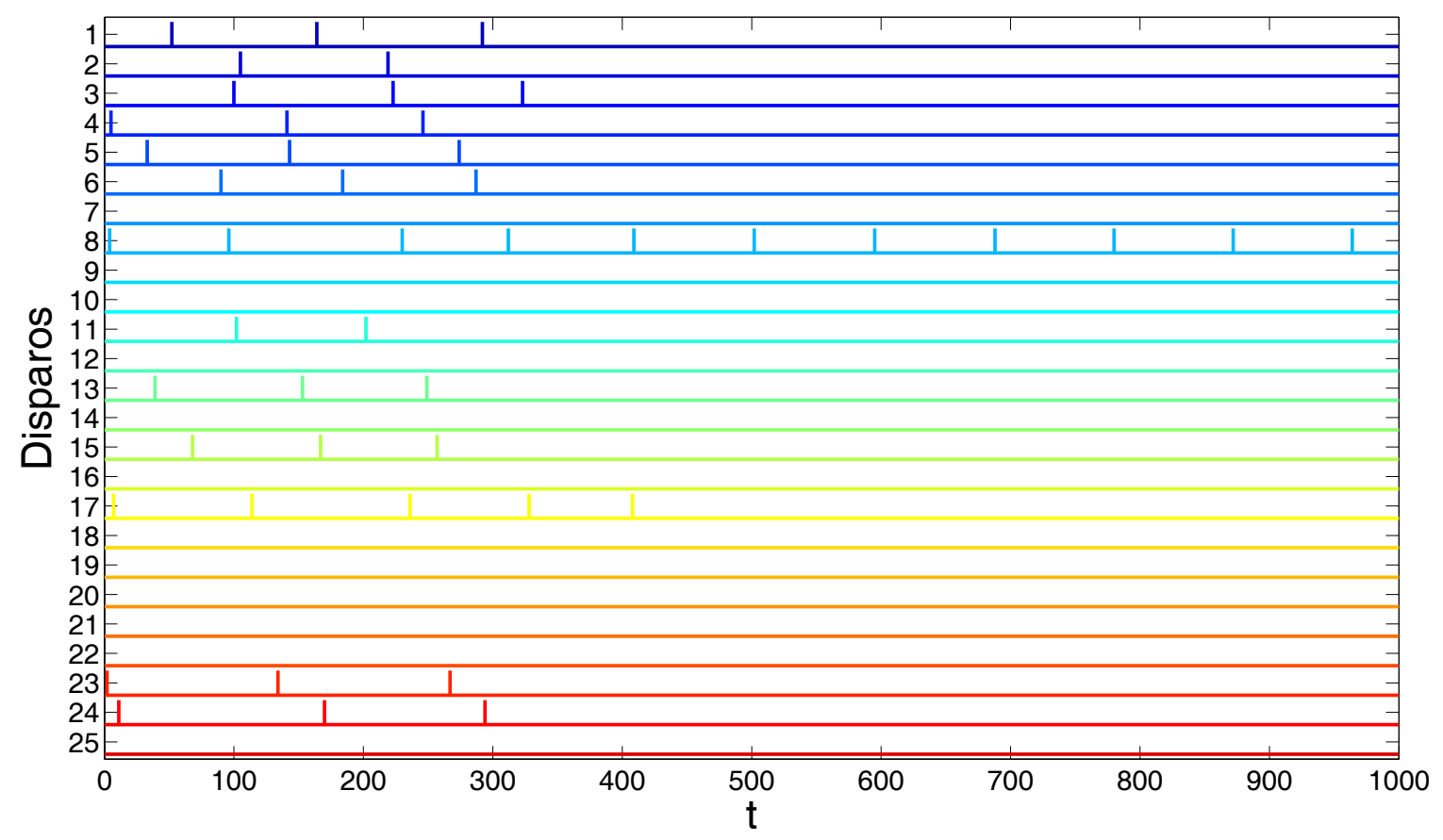

Figura 3.23: Resultado de simulação utilizando a imagem apresentada na Figura 3.22(a). Atividade temporal de disparo dos neurônios representando os objetos (atividade de um neurônio por objeto). Os índices no eixo $y$ identificam os objetos presentes na imagem.

A segunda simulação tem por objeto testar a capacidade de seleção do modelo considerando o contraste de cores. Nas Figuras 3.22(a)-(d) são apresentadas imagens contendo apenas um objeto saliente (objeto vermelho número 8), isto é, com alto contraste em relação aos objetos de fundo. Além disso, do item (a) até o item (d) da Figura 3.22, os objetos de fundo, representando os distratores, variam gradualmente de um padrão homogêneo até uma cena mais heterogênea. Os resultados obtidos utilizando estas imagens (a)-(d) são apresentados nas Figuras 3.23-3.26, respectivamente. A partir destes resultados é possível observar que, mesmo estando o objeto saliente inserido em uma cena com distratores heterogêneos, o modelo apresenta um resultado coerente, no qual o objeto vermelho (número 8) é selecionado em todas as simulações. Além disso, uma característica interessante desta simulação refere-se ao tempo necessário para realizar a seleção do objeto vermelho, onde o tempo 


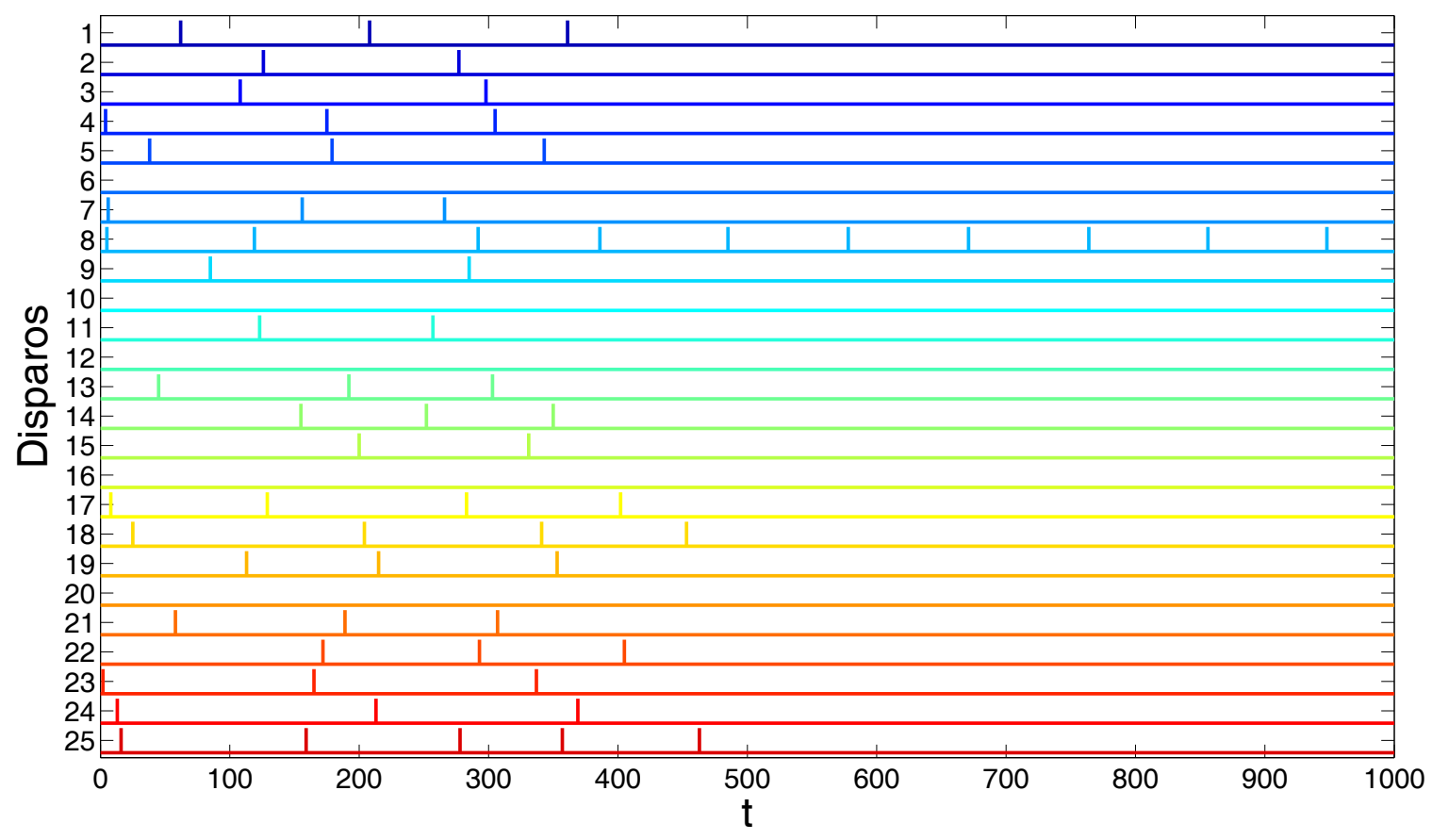

Figura 3.24: Resultado de simulação utilizando a imagem apresentada na Figura 3.22(b). Atividade temporal de disparo dos neurônios representando os objetos (atividade de um neurônio por objeto). Os índices no eixo $y$ identificam os objetos presentes na imagem.

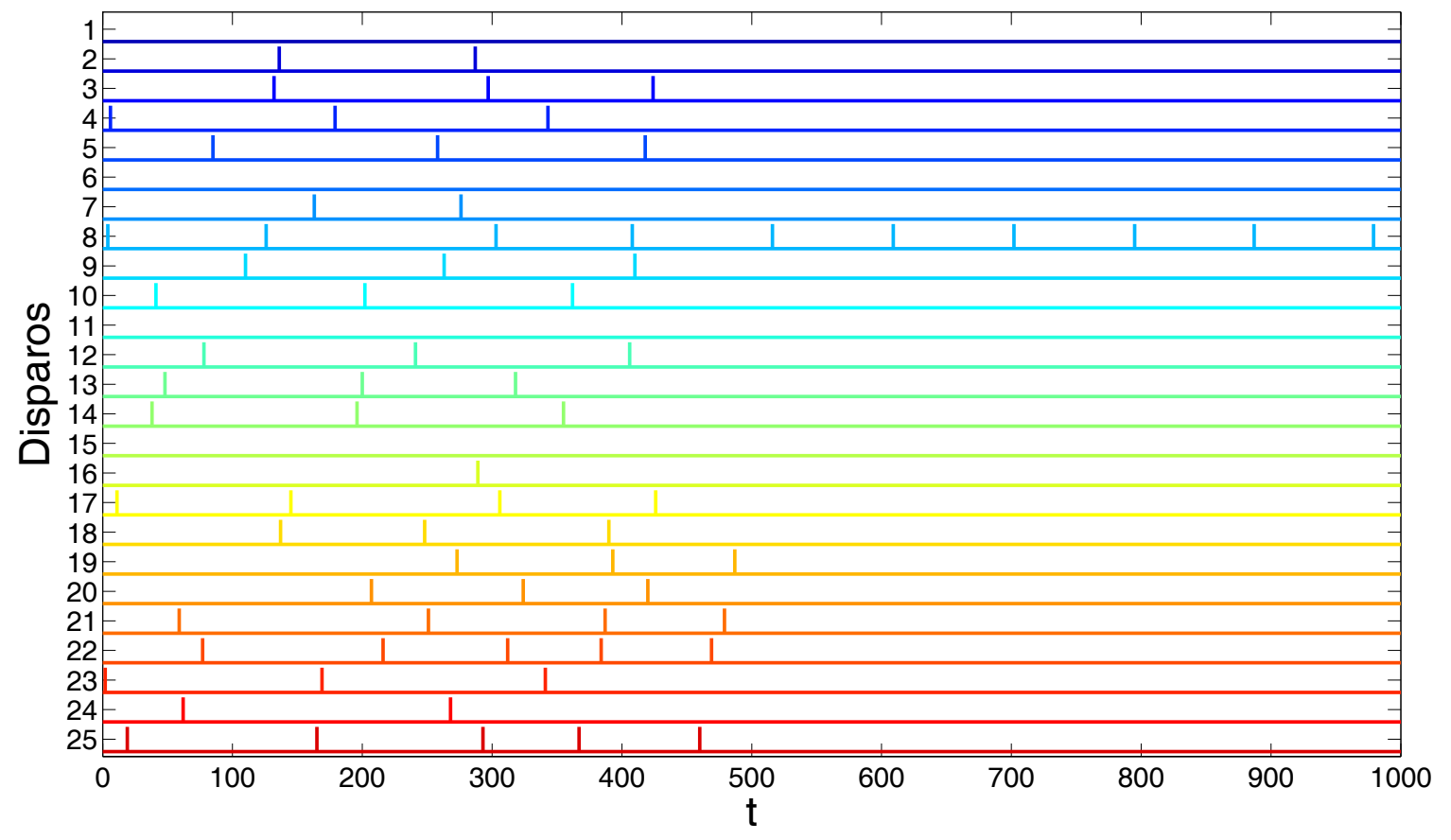

Figura 3.25: Resultado de simulação utilizando a imagem apresentada na Figura 3.22(c). Atividade temporal de disparo dos neurônios representando os objetos (atividade de um neurônio por objeto). Os índices no eixo $y$ identificam os objetos presentes na imagem. 


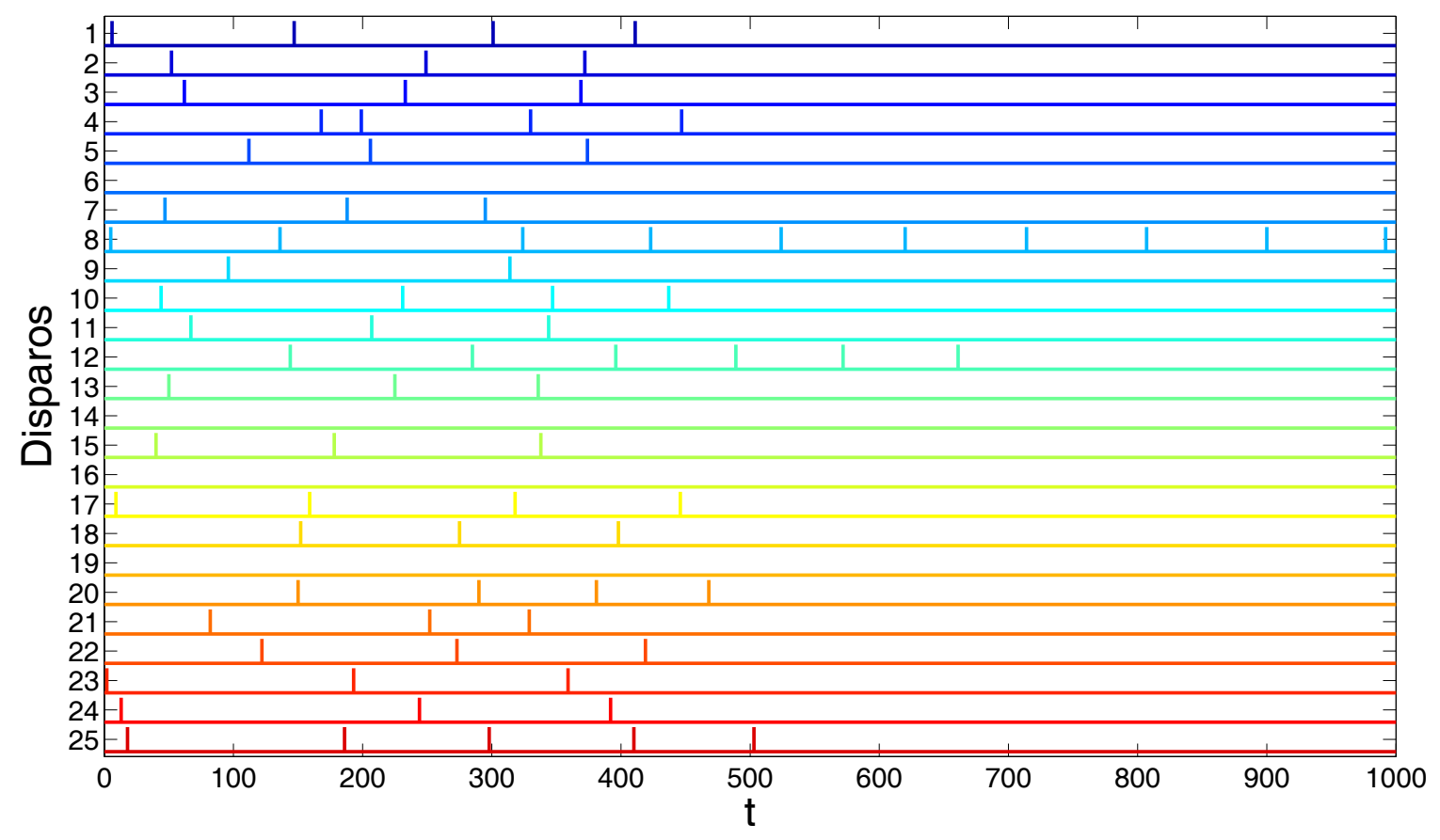

Figura 3.26: Resultado de simulação utilizando a imagem apresentada na Figura 3.22(d). Atividade temporal de disparo dos neurônios representando os objetos (atividade de um neurônio por objeto). Os índices no eixo $y$ identificam os objetos presentes na imagem.

gasto no processo aumenta conforme os distratores se tornam mais heterogêneo. Este fenômeno coincide com os resultados obtidos em experimentos de seleção visual com humanos (Wolfe \& Horowitz, 2004). Nestes experimentos, o tempo necessário para detectar um objeto alvo em uma dada cena é menor quando os objetos de fundo são homogêneos e apresentam um alto contraste com o objeto alvo. Por outro lado, se o fundo é representado por um padrão mais heterogêneo ou se o alvo apresenta um pequeno contraste com os demais objetos, o tempo de seleção é maior.

A Figura 3.27(b) apresenta o resultado da simulação utilizando a imagem apresentada na Figura 3.27(a). Nesta simulação é possível observar novamente que o modelo é capaz de selecionar o objeto mais saliente, representado pelo padrão "T" vermelho (objeto número 8), mesmo quando este encontra-se entre objetos de tamanhos variados.

A próxima simulação é responsável por testar a capacidade de seleção do modelo quando o atributo discriminativo é definido pela orientação. A Figura 3.28(a) mostra uma imagem composta por 25 objetos, sendo 24 representados pelo padrão “+” e um objeto da forma " $x$ ”. A partir das séries temporais apresentadas na Figura 3.28(b), pode ser constatado que o objeto "x" (número 9) recebe a atenção do sistema, sendo o único grupo de osciladores a permanecer ativo (disparando). 


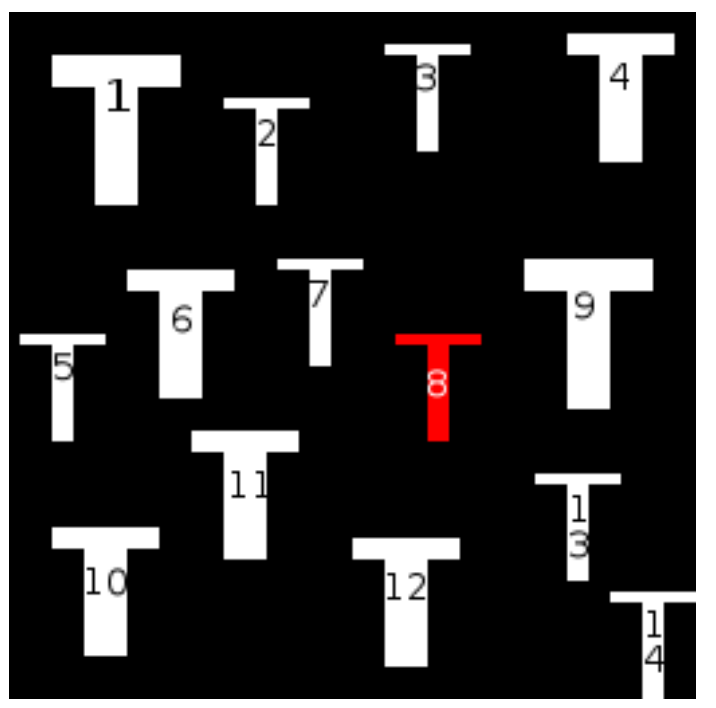

(a)

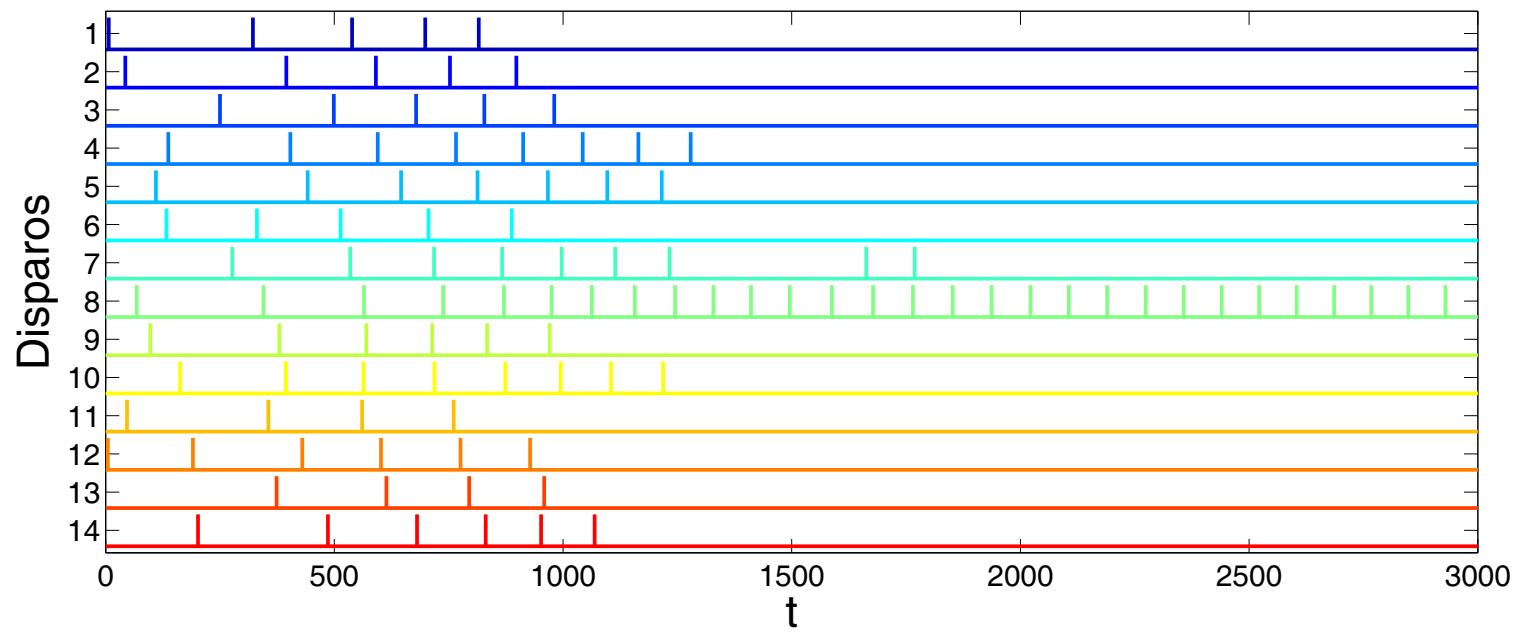

(b)

Figura 3.27: Simulação computacional utilizando uma imagem com 14 objetos variando a cor e o tamanho; (a) Imagem de entrada com $64 \times 64$ pontos; (b) Atividade temporal de disparo dos neurônios representando os objetos (atividade de um neurônio por objeto). Os índices no eixo $y$ identificam os objetos presentes na imagem (a). 


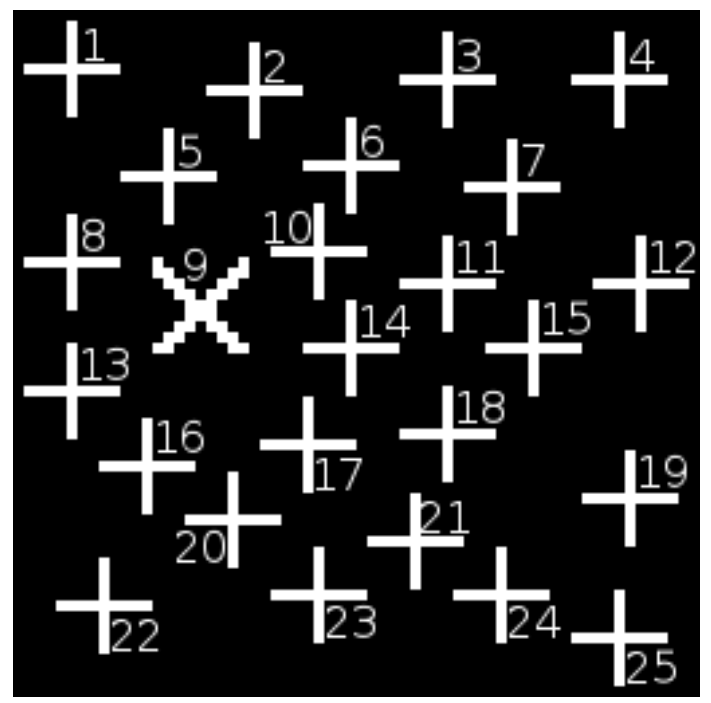

(a)

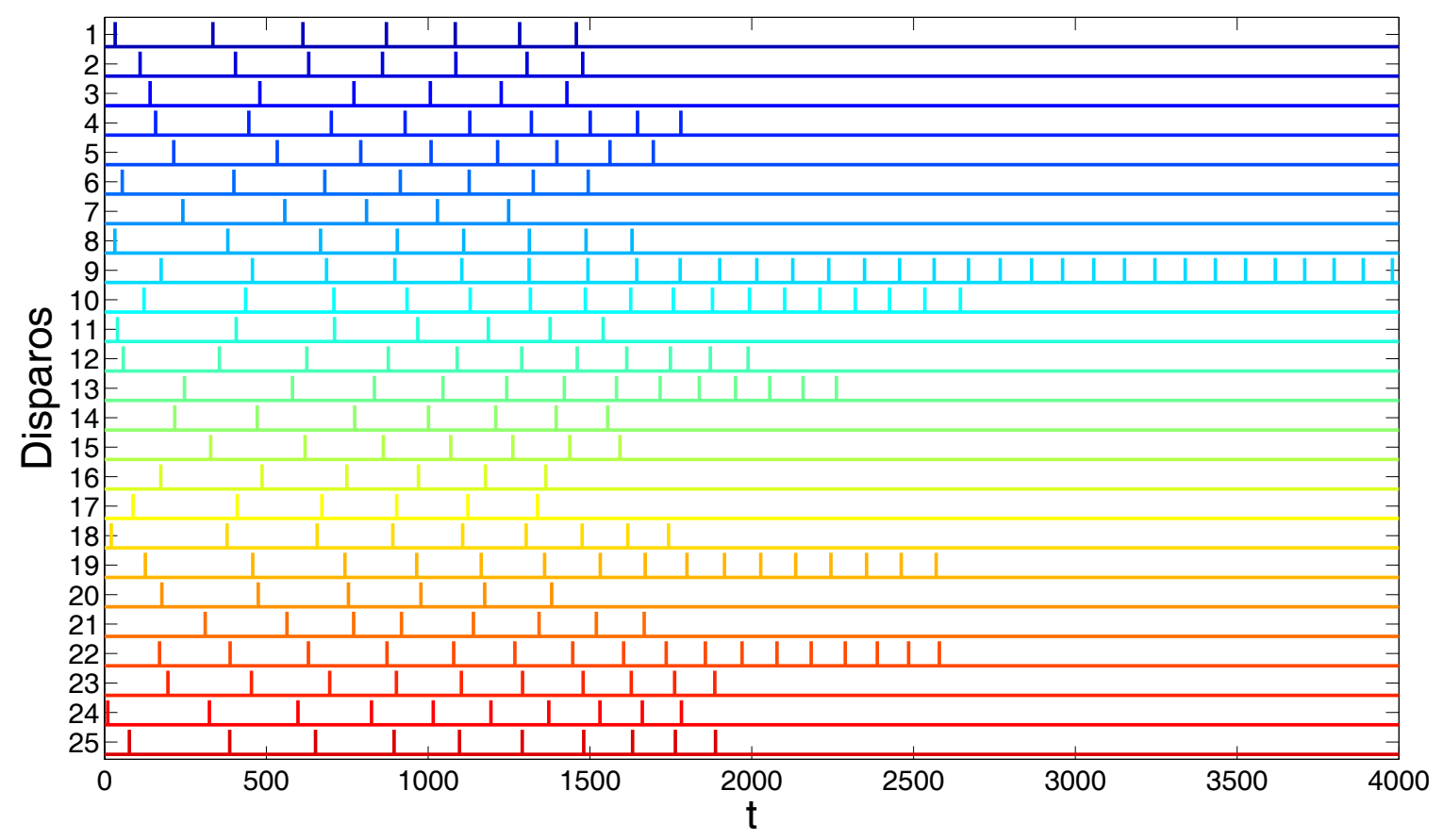

(b)

Figura 3.28: Simulação computacional utilizando uma imagem com 25 objetos variando a orientação; (a) Imagem de entrada com $64 \times 64$ pontos; (b) Atividade temporal de disparo dos neurônios representando os objetos (atividade de um neurônio por objeto). Os índices no eixo $y$ identificam os objetos presentes na imagem (a). 


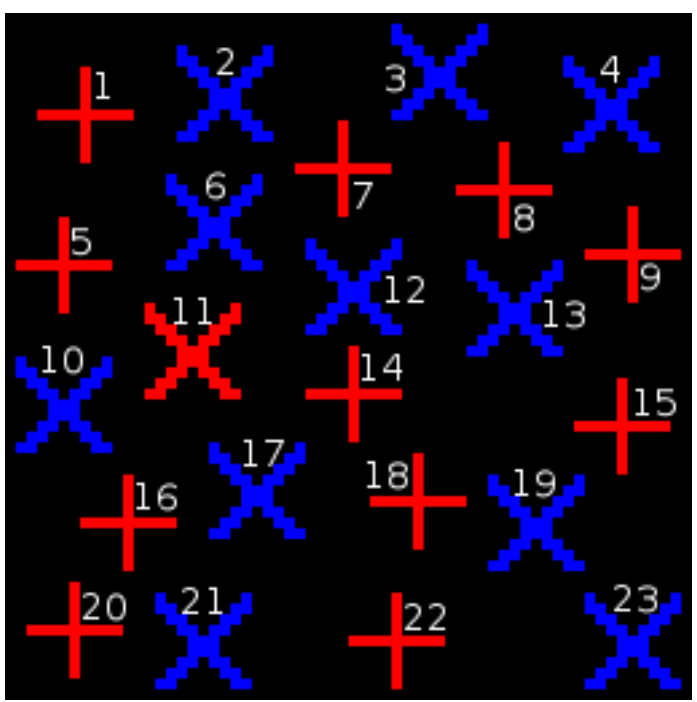

(a)

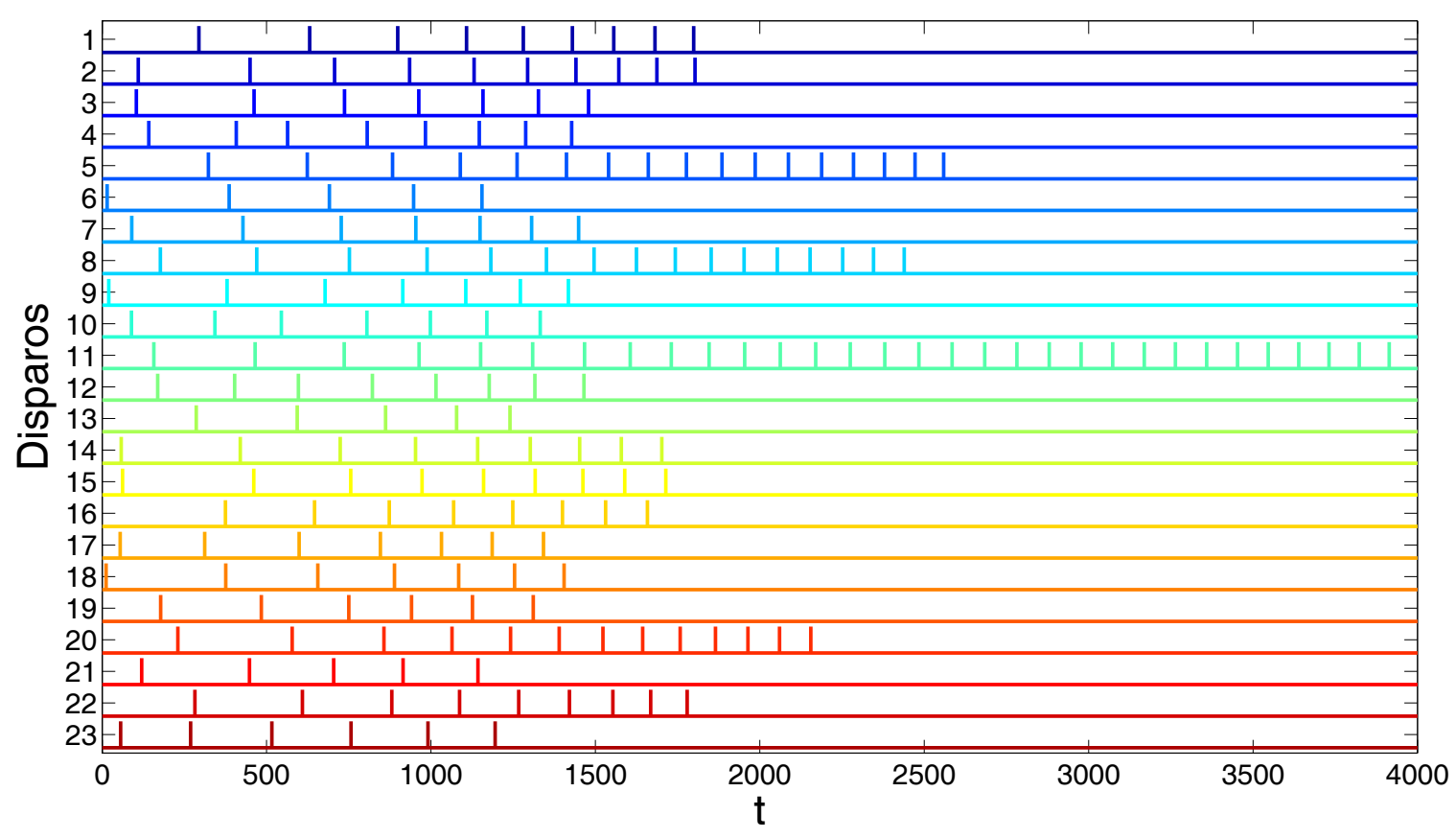

(b)

Figura 3.29: Simulação computacional utilizando uma imagem com 23 objetos variando a cor e a orientação; (a) Imagem de entrada com $64 \times 64$ pontos; (b) Atividade temporal de disparo dos neurônios representando os objetos (atividade de um neurônio por objeto). Os índices no eixo $y$ identificam os objetos presentes na imagem (a). 
A Figura 3.29(a) apresenta uma imagem cujo objeto saliente não se destaca dos demais pela análise de um simples atributo. Nesta cena, o objeto de interesse é identificado apenas quando um cruzamento dos atributos cor e orientação é realizado, esta forma de seleção visual baseada na análise de múltiplos atributos é denominada busca conjuntiva. Através do resultado de simulação apresentado na Figura 3.29(b), pode se observar que o modelo foi capaz de identificar o objeto " $x$ " vermelho (número 11) como sendo o objeto mais saliente. Este resultado coincide com a inspeção visual realizada por humanos.

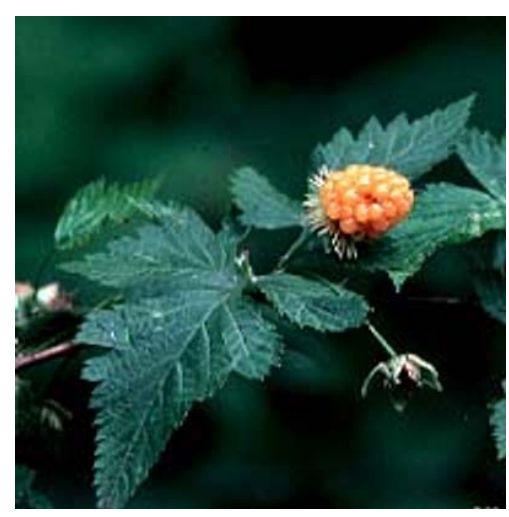

(a)

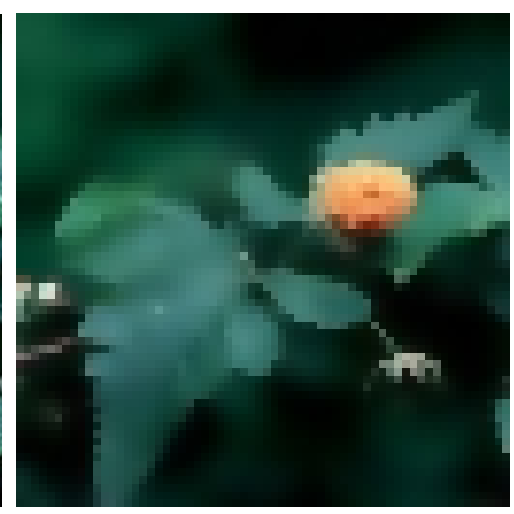

(b)

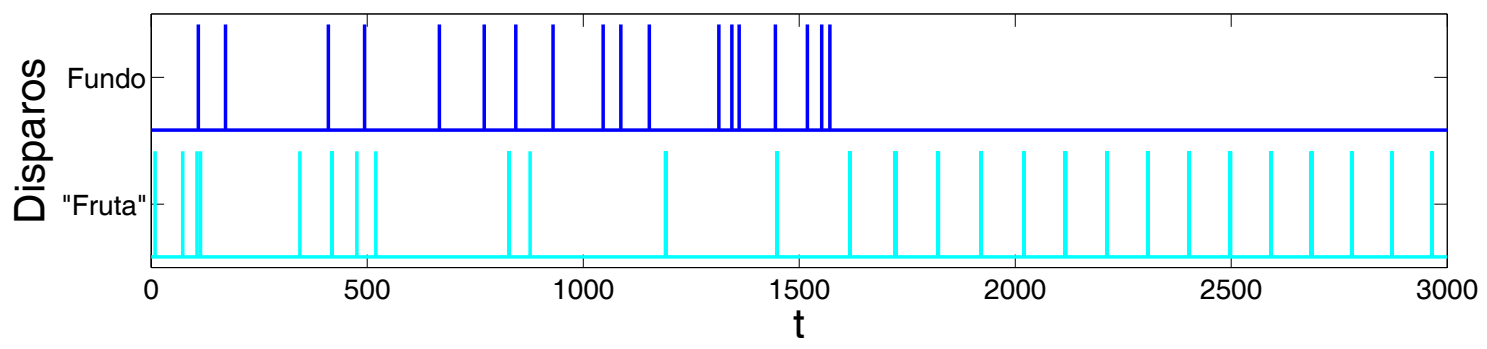

(c)

Figura 3.30: Simulação computacional com imagem real. (a) Imagem real original. (b) Imagem real tratada utilizada como entrada para rede (imagem com $64 \times 64$ pontos). (c) Atividade temporal de disparo dos neurônios representando os objetos ("fruta" e fundo) identificados pelo índice no eixo $y$ (atividade de dez neurônio aleatoriamente selecionados por objeto).

Por fim, um conjunto de simulações utilizando imagens reais apresentadas pelas Figuras 3.30(a)-3.32(a) é apresentado. No resultado apresentado na Figura 3.30(c), é possível observar que o modelo seleciona como objeto mais saliente a fruta de cor laranja, o que coincide com a inspeção visual realizada por humanos. Nas Figuras 3.31(c) e 3.32(c), o foco de atenção recai sobre os objetos "pássaro" e "rosa”, respectivamente, tais objetos são considerados os mais salientes por se destacarem do restante da cena. Vale observar que, para realização destas simulações, as imagens reais foram re-escalonadas e filtradas com o objetivo de facilitar o processo de segmentação tendo em vista que o modelo não conseguiu segmentar corretamente os objetos nas imagens ori- 


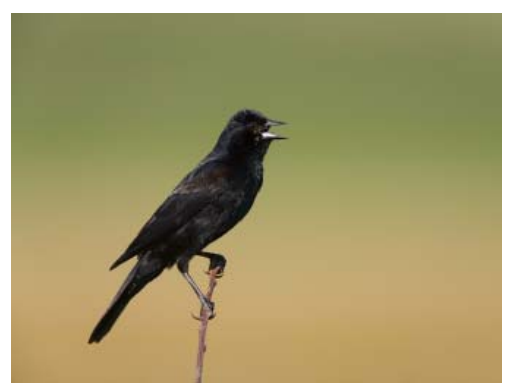

(a)

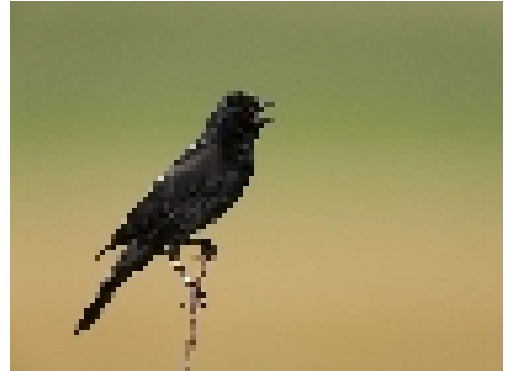

(b)

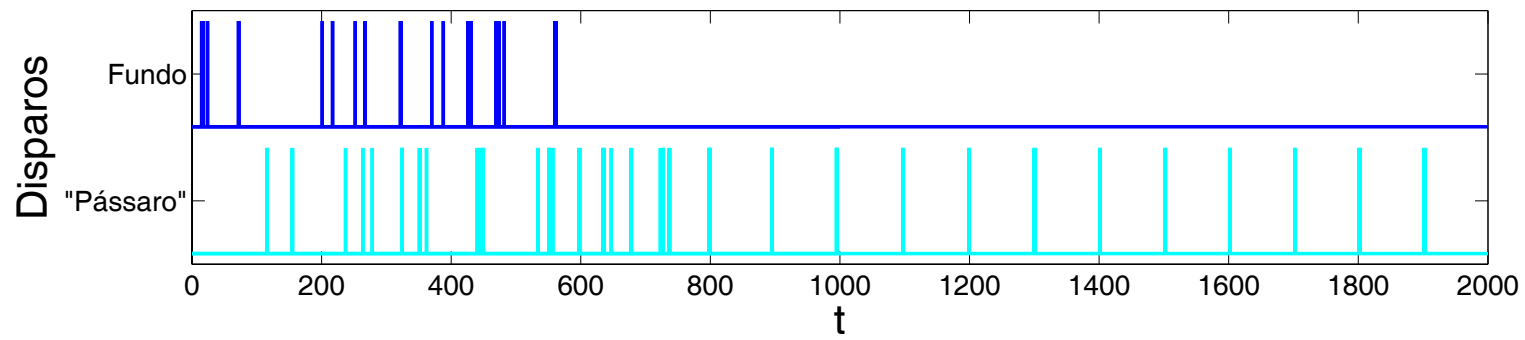

(c)

Figura 3.31: Simulação computacional com imagem real. (a) Imagem real original. (b) Imagem real tratada utilizada como entrada para rede (imagem com $93 \times 70$ pontos). (c) Atividade temporal de disparo dos neurônios representando os objetos ("pássaro" e fundo) identificados pelo índice no eixo y (atividade de dez neurônio aleatoriamente selecionados por objeto).

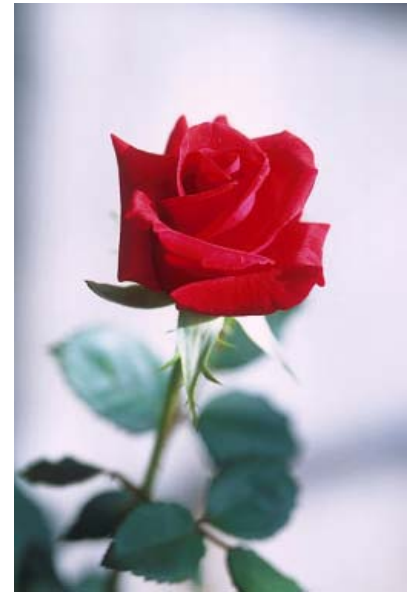

(a)

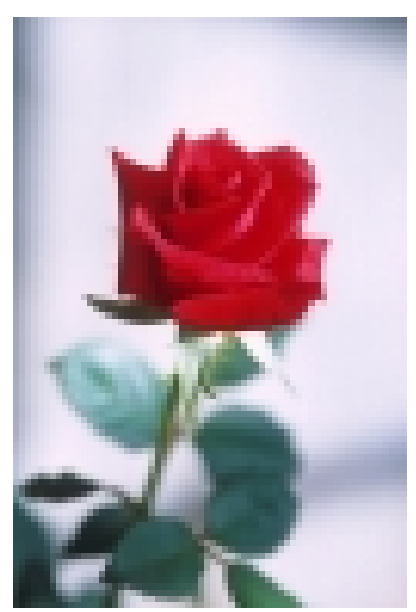

(b)

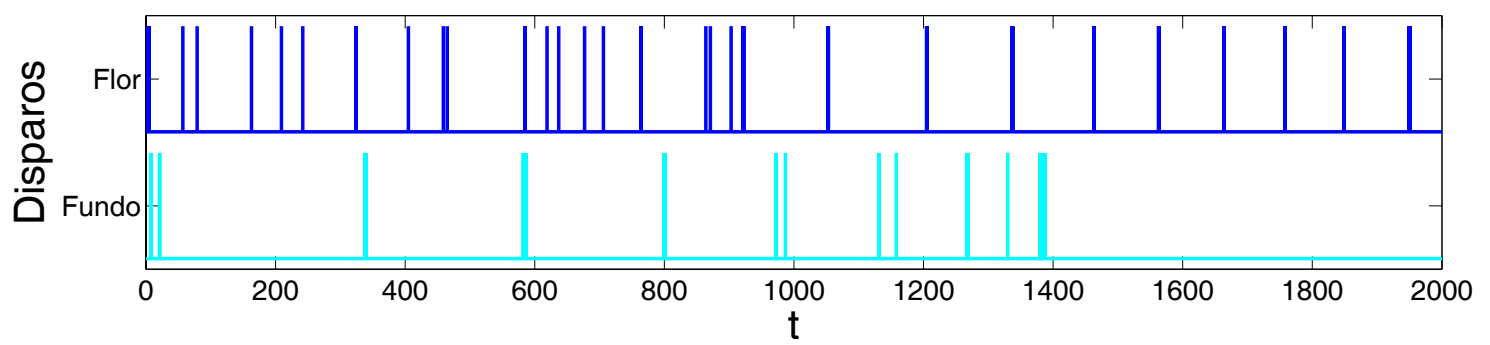

(c)

Figura 3.32: Simulação computacional com imagem real. (a) Imagem real original. (b) Imagem real tratada utilizada como entrada para rede (imagem com $64 \times 96$ pontos). (c) Atividade temporal de disparo dos neurônios representando os objetos ("flor" e fundo) identificados pelo índice no eixo y (atividade de dez neurônio aleatoriamente selecionados por objeto). 
ginais. As imagens utilizadas como entrada para o modelo são apresentadas nos itens (b) das Figuras 3.30-3.32.

Este modelo descrito acima também foi implementado utilizando-se neurônios I\&D com crescimento de fase não-linear e os resultados obtidos foram qualitativamente os mesmos (Quiles et al., 2008a).

\subsection{Modelo de Atenção Baseado em LEGION}

Nesta seção é apresentado um modelo de atenção visual baseado na arquitetura de correlação oscilatória implementada pelo modelo LEGION.

A Figura 3.33 apresenta um fluxograma do modelo de seleção visual de objetos proposto. Este modelo é composto por três módulos principais: modulo de segmentação de imagens, modulo do mapa de saliência e modulo de seleção de objetos. Primeiro, um mapa de saliência é utilizado para calcular a conspicuidade de cada ponto presente no padrão visual de entrada. Este mapa tem como função principal simular as características de atenção visual relacionadas a aspectos especiais e de atributos visuais como descrito na Seção 2.3. Segundo, uma rede LEGION é utilizada para realizar a segmentação da imagem. Este módulo tem como finalidade simular aspectos da organização perceptual do sistema de visão biológico organizando o estímulo visual em padrões (objetos/segmentos). Em terceiro, uma rede, baseada no modelo LEGION, realiza a seleção de objetos. Para guiar esta seleção, um mapa denominado mapa de objeto-saliência é proposto. Este mapa é resultado da integração de um mapa de saliência espacial com os segmentos gerados pela rede LEGION. Além disso, um mecanismo de inibição de retorno também é estabelecido na rede de seleção de objetos. Com este mecanismo, o modelo de atenção proposto é capaz de deslocar o foco de atenção entre os objetos presentes no campo visual.

O mapa de saliência usado neste modelo, definido no módulo do mapa de saliência, é o mesmo apresentado na Seção 2.3. Por esta razão ele não será reapresentado aqui. A seguir, o modelo LEGION para segmentação de imagens é revisitado e o módulo de seleção de objetos proposto é apresentado.

\subsection{O Modelo LEGION para Segmentação de Imagens}

O modelo de segmentação de imagens (Wang \& Terman, 1997) é uma extensão do modelo LEGION original proposto por Terman \& Wang (1995) e apresentado na Seção 2.2.1. A unidade básica do modelo LEGION (neurônio) é um oscilador de relaxamento definido como um laço de realimentação entre 


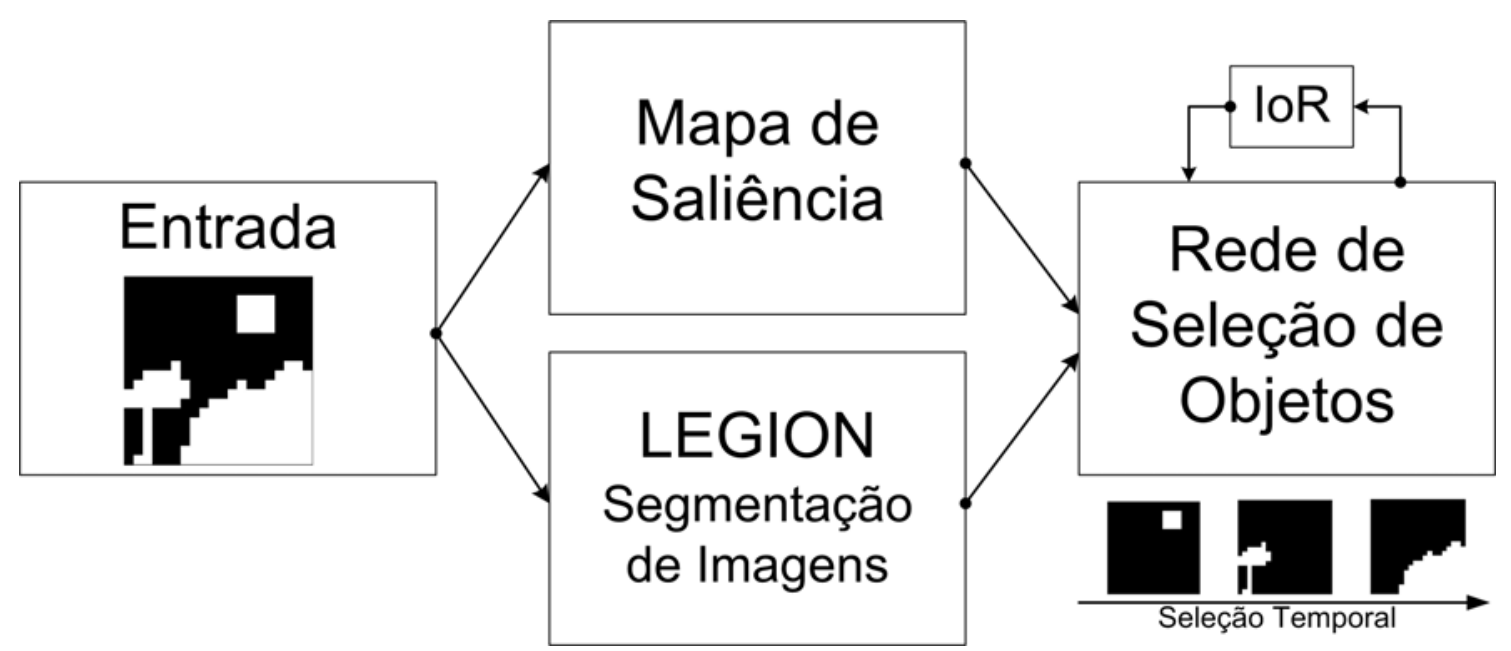

Figura 3.33: Diagrama de integração dos módulos que compõem o modelo proposto. O modelo é composto por um módulo para o cálculo do mapa de saliência; um módulo de segmentação de imagens (LEGION); e um módulo que implementa a rede de seleção de objetos, incluindo o mecanismo de inibição por retorno (IoR). As setas indicam o fluxo computacional do sistema. As imagens apresentadas abaixo da rede de seleção ilustra a sequência de seleção dos objetos.

uma variável excitatória $x_{i}$ e uma variável inibitória $y_{i}$ :

$$
\begin{aligned}
& \dot{x}_{i}=3 x_{i}-x_{i}^{3}+2-y_{i}+\mathcal{I}_{i}+S_{i}+\rho \\
& \dot{y}_{i}=\epsilon\left(\alpha\left(1+\tanh \left(x_{i} / \beta\right)\right)-y_{i}\right)
\end{aligned}
$$

onde $\mathcal{I}_{i}$ representa a estimulação externa, $S_{i}$ representa o sinal provenientes do acoplamento com os vizinhos, e $\rho$ define a amplitude do ruído Gaussiano. O parâmetro $\epsilon$ é uma pequena constante positiva.

Como descrito na Seção 2.2.1, o termo de ruído $\rho$ tem dois propósitos principais. Primeiro, é utilizado para testar a robustez do modelo. Segundo, tem a função de auxiliar o processo de segmentação. $\mathcal{I}_{i}$ representa a estimulação externa total recebida pelo oscilador $i$. No modelo LEGION original (Terman \& Wang, 1995), $\mathcal{I}_{i}$ é definido por uma constante. No modelo LEGION para segmentação de imagens, $\mathcal{I}_{i}$ é definido pela seguinte equação:

$$
\mathcal{I}_{i}=V_{i} H\left(p_{i}+\exp (-\alpha t)-\theta\right)
$$

onde $H$ é a função de Heaviside, $p_{i}$ define o potencial lateral do oscilador $i$. Este termo juntamente com a função Heaviside têm como finalidade principal distinguir entre regiões maiores e ruídos presentes na imagem (Wang \& Terman, 1997) e representam a principal diferença entre o modelo LEGION para segmentação e o modelo original proposto em (Terman \& Wang, 1995). De uma forma geral, este mecanismo pode ser entendido da seguinte maneira. Se um oscilador $i$ está localizado no centro de uma região homogênea, ele é capaz de receber uma grande estimulação de seus vizinhos. Neste caso, tal 
oscilador é denominado lider. Por outro lado, se o oscilador $i$ corresponde a um ruído ou um pequeno fragmento isolado na imagem, ele não recebe uma grande estimulação e não se torna um líder. Com base nesta ideia, apenas segmentos que possuem pelo menos um líder podem oscilar.

O potencial lateral é responsável por indicar se um oscilador $i$ é um líder e é definido pela seguinte equação:

$$
\dot{p}_{i}=\lambda\left(1-p_{i}\right) H\left[\sum_{k \in \Delta_{i}} T_{i k} H\left(x_{k}-\theta_{x}\right)-\theta_{p}\right]-\mu p_{i}
$$

onde $\lambda>0$ é um parâmetro, $T_{i k}$ define o peso permanente de conexão entre os osciladores $i$ e $k$; e $\Delta_{i}$ representa o conjunto de osciladores que compõem a vizinhança de $i . \theta_{x}$ é um limiar escolhido entre a fase de silêncio e a fase ativa do oscilador (ver a Figura 2.5) e tem por função indicar se o oscilador está na fase ativa ou na fase de silêncio. $\theta_{p}$ é um limiar que controla a dinâmica de $p_{i}$. Se o sinal total que o oscilador $i$ recebe de seus vinhos $k \in \Delta_{i}$ é superior a $\theta_{p}, p_{i}$ aproxima $1 \mathrm{com}$ velocidade $\lambda$ (normalmente definido com $\lambda \approx 1$ ). Por outro lado, se a soma é inferior a $\theta_{p}, p_{i}$ aproxima-se de zero com velocidade $\mu$ cujo valor é da ordem de $\epsilon$. Neste caso, se o valor de $p_{i}$ for superior a $\theta$ na Equação (3.49), a função Heaviside da Equação (3.49) assume 1 e $\mathcal{I}_{i}=V_{i}$, caso contrário, $\mathcal{I}_{i}=0$, exceto nos instantes iniciais da simulação onde, devido a presença do termo $\exp (-\alpha t)$ na Equação (3.49), a função Heaviside pode retornar 1 mesmo quando o valor de $p_{i}=0$. É importante observar que um oscilador $i$ irá receber um alto valor para o potencial lateral apenas se grande parte dos seus vizinhos estiverem na fase ativa $\left(x_{k}>\theta_{x}\right)$ no mesmo instante, isto é, eles devem estar sincronizados.

Para realizar segmentação de imagens uma rede LEGION 2D é utilizada. Tipicamente, cada oscilador está ligado aos seus quatro ou oito vizinhos imediatos (vizinhança 4 ou 8-conectado), exceto nas bordas. A Figura 2.4, apresentada na Seção 2.2.1, apresentou um exemplo da arquitetura desta rede.

O termo de conexão $S_{i}$ da Equação (3.48) é definido como segue:

$$
S_{i}=\sum_{k \in \Delta_{i}} W_{i k} H\left(x_{k}-\theta_{x}\right)-W_{z} H\left(z-\theta_{z}\right)
$$

onde $W_{i k}$ define o peso dinâmico de conexão do oscilador $k$ para o oscilador $i$ e $\Delta_{i}$ representa o conjunto de osciladores que compõem a vizinhança de $i$ (Wang \& Terman, 1997). As conexões dinâmicas $W$ são formadas com base nas conexões permanentes $T$ seguindo um processo de normalização cujo objetivo é assegurar que todos os osciladores recebam a mesma quantidade de sinal de sua vizinhança (Wang \& Terman, 1997).

$W_{z}$ na Equação (3.51) define o peso de inibição associado ao inibidor global 
z. A dinâmica de $z$ é definida por:

$$
\dot{z}=\phi\left(\sum_{k} H\left(x_{k}-\theta_{x}\right)-z\right)
$$

onde $\phi$ é um parâmetro que controla quão rápido o inibidor global reage as estimulações recebidas dos osciladores. Vale observar que $z$ aproxima o número de osciladores na fase ativa e será utilizado para representar o tamanho de cada bloco (objeto/segmento) de osciladores sincronizados.

Com base na dinâmica do modelo LEGION apresentada acima, Wang \& Terman (1997) desenvolveram um algoritmo computacional seguindo os aspectos principais da simulação numérica das Equações (3.48)-(3.52). Uma descrição detalhada deste algoritmo pode ser encontrada em (Wang \& Terman, 1997).

\subsubsection{Descrição do Modelo}

A seguir são apresentados o mapa de objeto-saliência e a rede de seleção de objetos proposta.

\section{Definição do Mapa de Objeto-Saliência}

O mapa de objeto-saliência, $m^{o}$, é responsável por indicar o nível de saliência de cada objeto presente na cena de entrada. Para geração deste mapa, tanto os dados provenientes do módulo do mapa de saliência quanto o resultado do módulo de segmentação são utilizados. Este mapa $\left(\mathrm{m}^{\circ}\right)$ difere do mapa de saliência $\left(m^{s}\right)$ apresentado na Seção 2.3 por representar a saliência de cada objeto ao invés da saliência de cada ponto da imagem. Como apresentado na Seção 2.3, o mapa de saliência proposto por Itti et al. (1998) é apresentado em uma dimensão inferior a imagem de entrada, geralmente 1/16 do tamanho da imagem original. Desta forma, com o objetivo de criar uma correspondência um-para-um entre o mapa da saliência gerado e a rede de segmentação LEGION, primeiramente o mapa de saliência é escalonado para o tamanho da imagem de entrada através de uma interpolação linear de pontos. Após este escalonamento, cada segmento produzido pelo modulo de segmentação tem sua média de saliência calculada pela seguinte equação:

$$
\overline{m_{i}^{o}}=\frac{\sum_{j \in O_{i}} m_{j}^{s}}{\left|O_{i}\right|}
$$

onde $\overline{m_{i}^{o}}$ é a saliência média de cada segmento contendo o ponto $i$; $O_{i}$ é o conjunto de todos os pontos agrupados ao ponto $i$ no mesmo segmento; $m_{j}^{s}$ é valor do ponto $j$ no mapa de saliência; e $\left|O_{i}\right|$ representa o tamanho do segmento contendo o ponto $i$. $\left|O_{i}\right|$ é obtido a partir da Equação (3.52), pois, como descrito anteriormente, $z$ aproxima o número de osciladores ativos em um dado 
instante o que representa o tamanho do segmento que se encontra na fase ativa. Após o cálculo da saliência média de cada segmento, o tamanho dos objetos é incorporado pela seguinte equação:

$$
m_{i}^{o}=\overline{m_{i}^{o}} \sqrt[5]{\frac{\left|O_{i}\right|}{\left|O_{\max }\right|}}
$$

onde a raiz quinta ${ }^{3}$ é usada para moderar o valor de saliência de objetos relativamente pequenos. $\left|O_{\max }\right|$ representa o tamanho do maior segmento presente na imagem. $m^{o}$ define o mapa de objeto-saliência usado para alimentar a rede de seleção.

Como mencionado anteriormente, para calcular o mapa de objeto-saliência os resultados gerados pelos módulos de segmentação e do mapa de saliência são necessários. Isto significa que o resultado do processo de segmentação deve ter sido concluído antes do calculo do mapa de objeto-saliência. Como descrito em (Wang \& Terman, 1997), o modelo LEGION para segmentação de imagens necessita de no máximo $T+1$ ciclos para segmentar a imagem, onde $T$ é o número de blocos principais. Entretanto, é importante ressaltar que o número de segmentos presentes na imagem não é conhecido a priori, o que inviabiliza este critério como meio de validação da conclusão do processo de segmentação. Desta forma, é necessária uma outra abordagem para indicar de forma automática a conclusão do processo de segmentação.

Foi relado na Seção 3.5.1 que Wang \& Terman (1997) desenvolveram um algoritmo extraído das equações do modelo LEGION que permite a segmentação de imagens reais de forma eficiente. Além disso, uma propriedade interessante deste algoritmo está no fato de que, para conclusão do processo de segmentação, é necessário esperar até que todo líder presente na rede salte para fase ativa uma vez. Desta forma, é possível obter, de forma automática, a indicação de que o processo de segmentação está concluído, bastando para isso esperar que cada líder tenha sido ativado uma única vez.

\section{Rede de Seleção de Objetos}

A rede de seleção de objetos proposta aqui pode ser vista como uma extensão do modelo LEGION seguindo as ideias previamente desenvolvidas em (Wang, 1999). A arquitetura desta rede é apresentada na Figura 3.34 no qual os inibidores globais rápido e lento são responsáveis pela dessincronização dos objetos e seleção de um deles, respectivamente.

Esta rede segue a dinâmica do modelo LEGION apresentado nas Seções 2.2.1 e 3.5.1. As principais diferenças entre a rede de seleção e a rede LEGION

\footnotetext{
${ }^{3} \mathrm{~A}$ função definida pela raiz quinta foi a que se ajustou melhor nos testes empíricos realizados.
} 
para segmentação de imagens são: 1) a presença do inibidor global lento; 2) a introdução do mecanismo de Inibição por Retorno; e 3) a definição da estimulação externa $\mathcal{I}$.

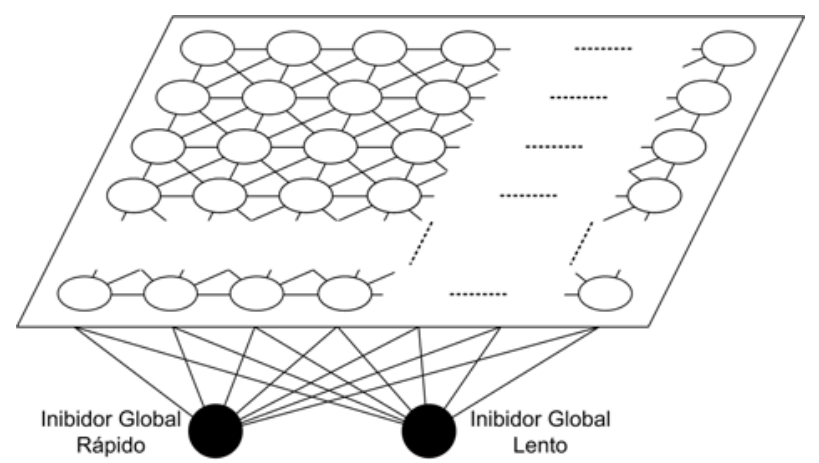

Figura 3.34: Arquitetura da rede de seleção. Círculos de cor branca representam osciladores com o mecanismo IoR incorporado. Os círculos em cor preta representam os inibidores globais lento e rápido.

Nesta rede, cada oscilador é conectado aos seus 8 vizinhos imediatos (vizinhança 8-conectado) respeitando a seguinte regra: Se dois osciladores vizinhos na rede de seleção possuem seus osciladores correspondentes no módulo de segmentação sincronizados, eles são conectados. Por outro lado, se os osciladores correspondentes no módulo de segmentação não pertencem ao mesmo objeto (estão desicronizados), a força de ligação entre eles é nula. Assim, pode se concluir que os objetos formados na rede LEGION do módulo de segmentação de imagens são diretamente transferidos para a rede de seleção.

A estimulação externa $\mathcal{I}_{i}$ é definida como:

$$
\mathcal{I}_{i}=V_{i} H\left(m_{i}^{o}-C z_{s}\right) H\left(r_{i}-\theta_{z}\right)
$$

onde $V_{i}$ assume um valor alto se o oscilador $i$ correspondente no módulo de segmentação está ativado. Caso contrário, $V_{i}$ assume um valor baixo. Desta forma, osciladores na rede de seleção correspondentes a um segmento (objeto) no módulo de segmentação assumem valores de $V$ altos, enquanto osciladores representando ruídos (fundo da imagem) recebem valores de $V$ baixos. $m_{i}^{o}$ representa o valor do mapa de objeto-saliência descrito anteriormente (Eq. (3.54)). $C$ é um parâmetro que controla o número de objetos que podem ser selecionados ao mesmo tempo (Wang, 1999). A variável $r_{i}$ modela o mecanismo de Inibição de Retorno de cada oscilador e é definido pela seguinte equação:

$$
\dot{r}_{i}=-\omega r_{i} H\left(x_{i}-\theta_{x}\right)
$$

Inicialmente, para cada oscilador $i, r_{i}=1$. Toda vez que um oscilador salta para fase ativa, isto é $x_{i}>\theta_{x}$, o valor de $r_{i}$ é reduzido de acordo com a Equação (3.56). Após um número de ciclos controlado pelo parâmetro $\omega, r_{i}$ aproxima 
zero. Assim, a segunda função Heaviside da Equação (3.55) retorna zero e o oscilador é inibido. Devido a presença do IoR, a rede de seleção é capaz de transferir o foco de atenção do primeiro objeto selecionado para um próximo objeto. Este mecanismo simula a mudança no foco de atenção presentes nos mecanismos biológicos de percepção visual (Itti \& Koch, 2001a).

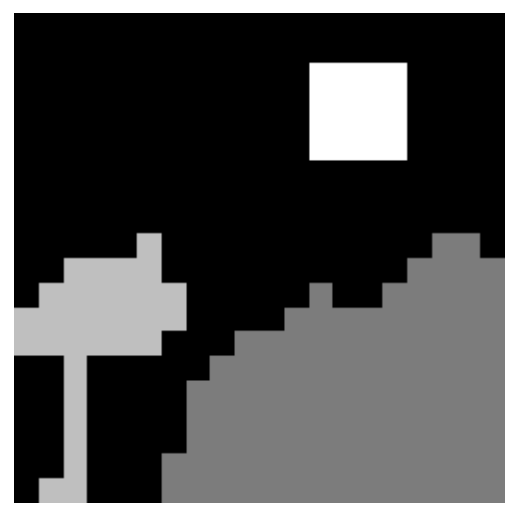

(a)

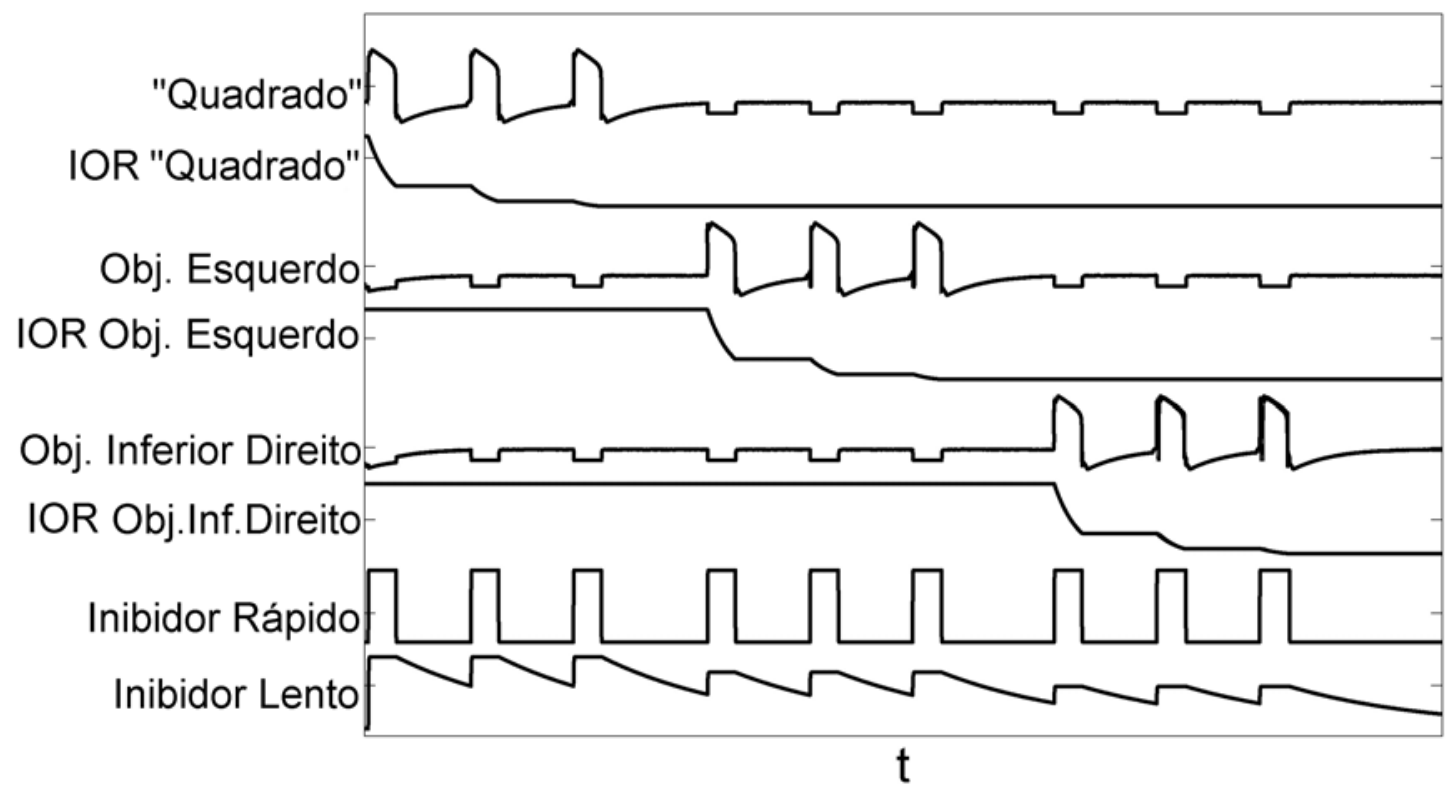

(b)

Figura 3.35: Ilustração do processo de seleção de objetos pela rede proposta. Para esta ilustração, os osciladores são integrados numericamente utilizando o método Runge-Kutta de quarta ordem. (a) representação ilustrativa de um mapa de objeto-saliência com 3 objetos: um quadrado, um objeto a esquerda e um objeto no canto inferior direto da imagem. (b) atividade de cada bloco de osciladores e seus respectivos valores de $r_{i}$. A atividade dos inibidores globais rápido e lento também são ilustradas.

A dinâmica do inibidor global lento presente na Equação (3.55) é definida por:

$$
\dot{z}_{s}=\psi\left[\sum_{k} \frac{m_{k}^{o} H\left(x_{k}-\theta_{x}\right)}{\left|O_{k}\right|}-z_{s}\right]^{+}-\mu \epsilon z_{s}
$$


onde a função $[v]^{+}=v$ se $v \geq 0$ e 0 caso contrário. Os parâmetros $\psi$ e $\mu$ são da ordem de 1. O inibidor lento é caracterizado por um rápido crescimento e por um lento decaimento devido ao baixo valor do parâmetro de relaxamento $\epsilon$. O processo de seleção é produzido pela função Heaviside e pelo inibidor global lento que permitem oscilar apenas osciladores com $m_{i}^{o} \geq z_{s}$. Desta forma, ajustando um valor adequado para $C$ como definido em (Wang, 1999), apenas o objeto com o maior valor de $m_{i}^{o}$ tem permissão para oscilar, isto é, ser selecionado.

O valor do mapa de objeto-saliência também é utilizado para configurar o estado inicial de cada oscilador da rede de seleção. Uma vez que a saliência de cada objeto é conhecida antes do processo de seleção, este valor pode ser utilizado para determinar qual objeto (bloco de osciladores) irá pulsar primeiro, evitando assim um gasto desnecessário de tempo que seria utilizado processo de competição pela seleção. Desta forma, pode-se configurar a rede de tal forma que o bloco de osciladores que representa o objeto mais saliente seja o primeiro a pulsar. Este comportamento é gerado configurando o valor inicial de $y_{i}$ da Equação (3.48) através da seguinte equação:

$$
y_{i}=2 \alpha\left(1-m_{i}^{o}\right)+V_{i}
$$

Com base na Equação (3.58), os osciladores da rede de seleção representando o objeto mais saliente têm seus valores iniciais de $y_{i}$ configurados na fase de silêncio próximo ao joelho esquerdo da isóclina nula cúbica. Por outro lado, os osciladores representando o objeto menos saliente têm seus valores iniciais de $y_{i}$ configuras na fase de silêncio, porém distantes do joelho esquerdo da nullcline cúbica (veja Figura 2.5). Um caso especial acontece quando dois ou mais objetos possuem a mesma saliência. Neste caso, a rede de seleção seleciona todos eles que permanecem oscilando até serem inibidos pelo IoR.

Na Figura 3.35 é apresentada uma ilustração do processo de seleção de objetos realizado pela rede de seleção. Como entrada para a rede de seleção, assume-se a imagem apresentada pela Figura 3.35(a) como um mapa de objeto-saliência. Neste mapa, o objeto "quadrado", que corresponde a região com maior intensidade, representa o objeto mais saliente, enquanto o objeto presente no canto inferior direito, menos intenso, representa o objeto menos saliente. Como descrito anteriormente, o valor de saliência possui duas funções. Primeiro, ele é usado como parâmetro da Equação (3.55) para definir qual objeto está apto a oscilar. Em segundo, ele é usado para definir o estado inicial de cada oscilador da rede (Eq. (3.58)). Como pode ser observado na Figura 3.35(b), o objeto "quadrado" é o primeiro a ser selecionado, enquanto os outros objetos permanecem inativos. Conforme os osciladores representando o objeto selecionado permanecem pulsando, o mecanismo de inibição 
de retorno é ativado e após alguns ciclos determinado pelo parâmetro $\omega$ (Eq. (3.56)), aqueles osciladores são inibidos permitindo que um próximo objeto seja selecionado, que neste exemplo é representado pelo objeto à esquerda. Este processo continua até que todos os objetos tenham sido selecionados uma vez.

De uma forma geral o comportamento do sistema pode ser descrito da seguinte forma. Uma imagem alimenta o mapa de saliência e o módulo de segmentação como ilustrado na Figura 3.33. O mapa de saliência calcula a saliência de cada ponto da imagem de entrada. Este processo incorpora o papel do contraste local de atributos visuais como guia do processo de atenção. Em paralelo, a rede LEGION do módulo de segmentação segrega a imagem de entrada em um conjunto de segmentos. Esta rede é caracterizada por produzir uma rápida sincronização entre osciladores representando um mesmo objeto e dessincronização entre blocos de osciladores representando segmentos distintos (Terman \& Wang, 1995; Wang \& Terman, 1997). Após a obtenção do mapa de saliência e do resultado do processo de segmentação, o mapa de objeto-saliência é gerado. Este mapa alimenta a rede de seleção de objetos. Na Equação (3.55), a primeira função Heaviside descreve o papel de seleção de objetos enquanto a segunda implementa o mecanismo de inibição por retorno. Se a primeira Heaviside retorna 0, por exemplo, a saliência do objeto não excede o nível do inibidor global lento, o oscilador se torna excitável e pode ser recrutado a oscilar por algum vizinho. Entretanto, considerando que osciladores de um bloco não são conectados a osciladores pertencentes a um outro bloco e que o valor de saliência para todo o bloco é o mesmo, se a primeira Heaviside de um oscilador retorna zero, a Heaviside de todos os osciladores que compõem o bloco também retornam zero. Desta forma, o objeto representado por este bloco é inibido. Por outro lado, se o valor do mapa de objeto-saliência do bloco ultrapassa o inibidor global lento, os osciladores podem oscilar e o objeto representado por estes é selecionado. Ao mesmo tempo, o inibidor global lento assume um novo valor segundo a Equação (3.57) que representa o valor de saliência do bloco ativo. Como resultado, objetos com saliência inferior ao objeto ativo não poderão ser selecionados.

Uma vez que um objeto é selecionado e os osciladores que o representam permanecem pulsando, o IoR é ativado e a variável $r_{i}$ de cada oscilador do bloco tem seu valor reduzido pela Equação (3.56). Após alguns ciclos controlado por $\omega, r_{i}$ aproxima zero. Como consequência, a segunda Heaviside da Equação (3.55) passa a retornar zero, o que representa a inibição do oscilador $i$ e consequentemente a inibição do objeto como um todo. Seguindo a inibição do objeto previamente selecionado, o inibidor global lento tem seu valor reduzido segundo a Equação (3.57) e o próximo objeto mais saliente é selecionado, 
assim como ilustrado pela Figura 3.35.

\subsubsection{Simulações Computacionais}

Nesta seção, os resultados obtidos a partir das simulações computacionais do modelo são apresentados. Antes da apresentação dos resultados, primeiramente são descritos os parâmetros usados na configuração dos módulos que compõem o modelo. No módulo do mapa de saliência, os mesmo parâmetros definidos em (Itti et al., 1998) foram utilizados, exceto a definição dos mapas de cores onde a abordagem definida em (Walther \& Koch, 2006) foi adotada.

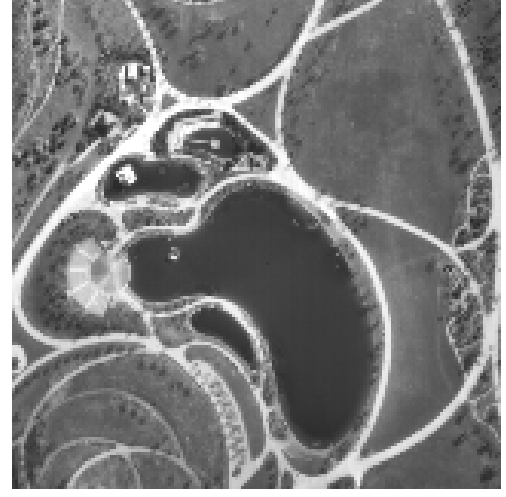

(a)

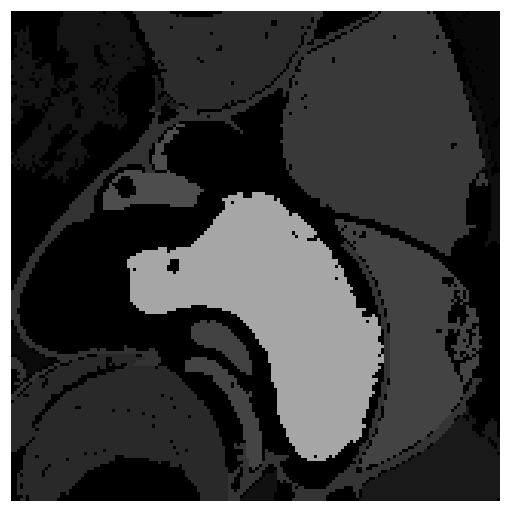

(d)

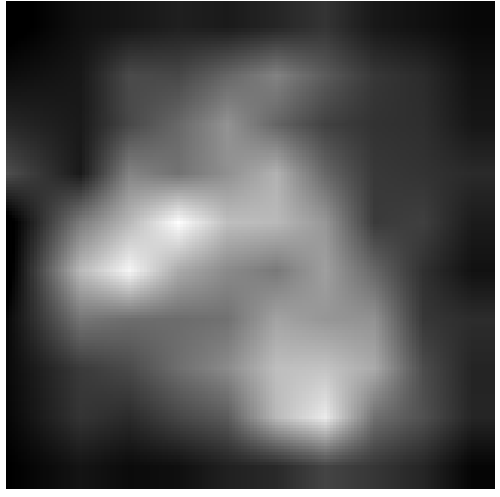

(b)

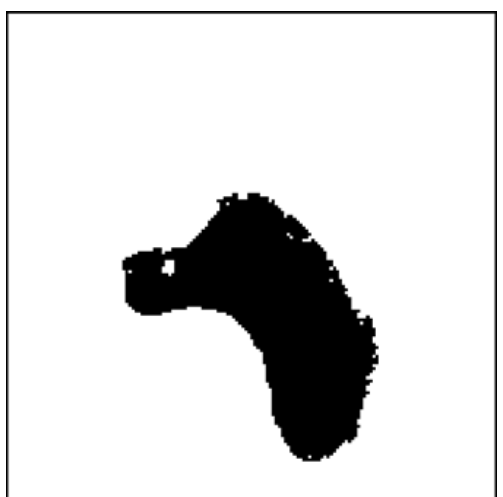

(e)

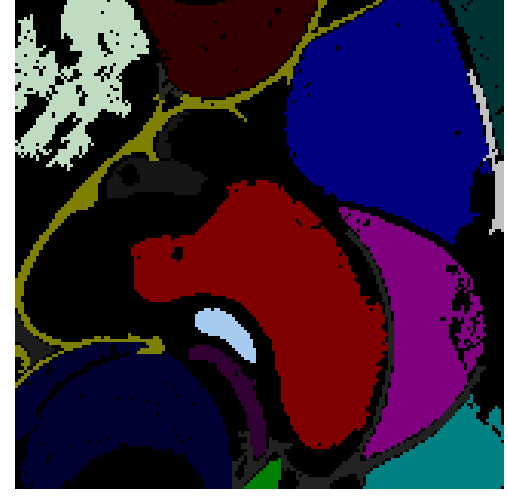

(c)

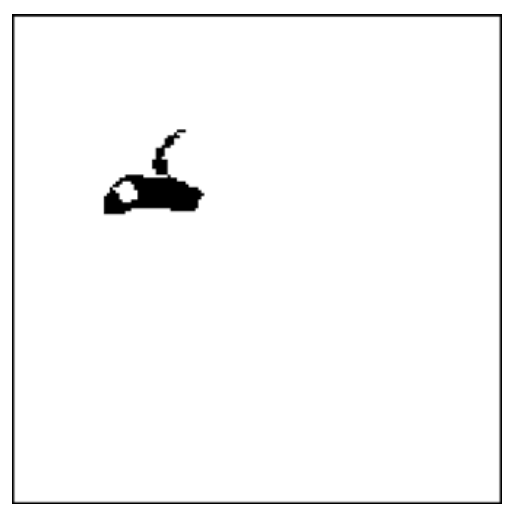

(f)

Figura 3.36: Resultado de simulação para uma imagem em nível tons de cinza. (a) Imagem de entrada. Esta figura representa uma cena aérea lago com definição de $160 \times 160$ pontos. (b) Mapa de saliência. (c) Resultado do processo de segmentação onde cada objeto é representado por uma cor distinta. (d) Mapa de objeto-saliência. (e) Primeiro objeto selecionado. (f) Segundo objeto selecionado.

O módulo de segmentação de imagens foi implementado segundo o algoritmo proposto em (Wang \& Terman, 1997). Para este algoritmo, o peso de ligação entre os osciladores vizinhos é definido segundo sua similaridade baseada nas seguintes regras: 
- para imagens em tons de cinza:

$$
W_{i j}=I_{M} /\left(1+\left|I_{i}-I_{j}\right|\right)
$$

- para imagens coloridas:

$$
W_{i j}=I_{M} /\left(1+\sum_{h \in\{r, g, b\}}\left|h_{i}-h_{j}\right|\right)
$$

onde $I_{M}$ represente o valor máximo assumido pelos canais: $I, r, g$ e $b$. Nas simulações apresentadas a seguir, $I_{M}=255$. $I_{i}$ representa o nível de intensidade do ponto $i$ da imagem de entrada. $h_{i}$ representa os canais de cores: $r, g$ ou $b$, do ponto $i$. O parâmetro $W_{z}$ é ajustado conforme a imagem de entrada utilizada de tal forma a se obter bons resultados para o processo de segmentação e será apresentado para cada uma das simulações.

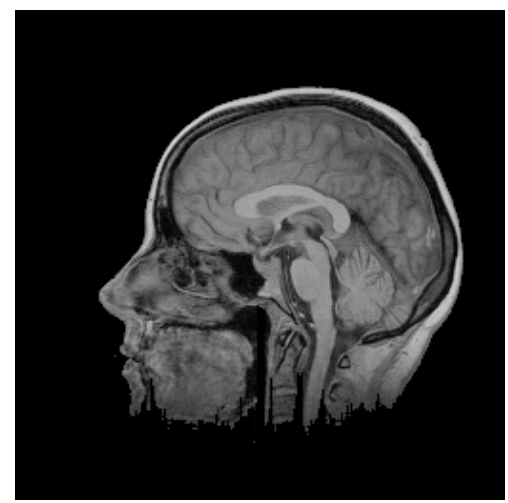

(a)

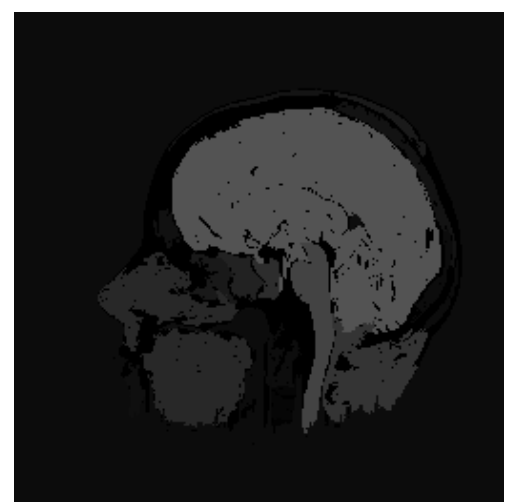

(d)

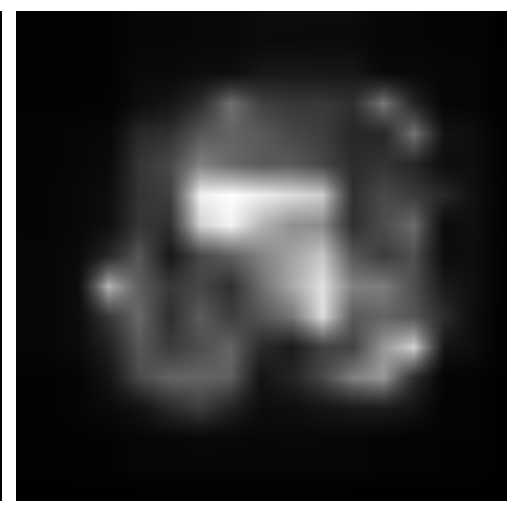

(b)

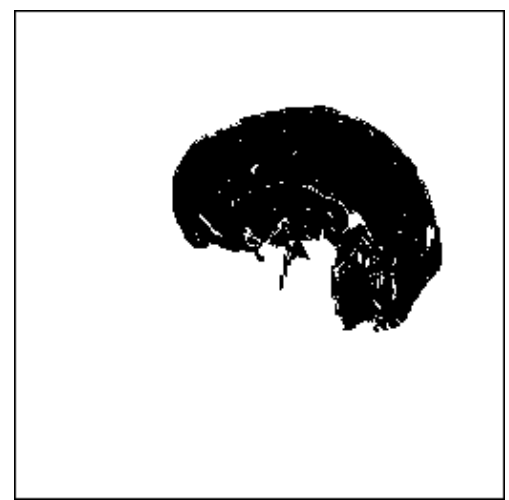

(e)

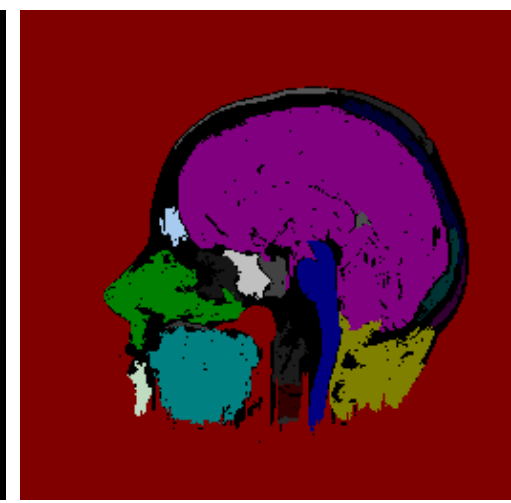

(c)

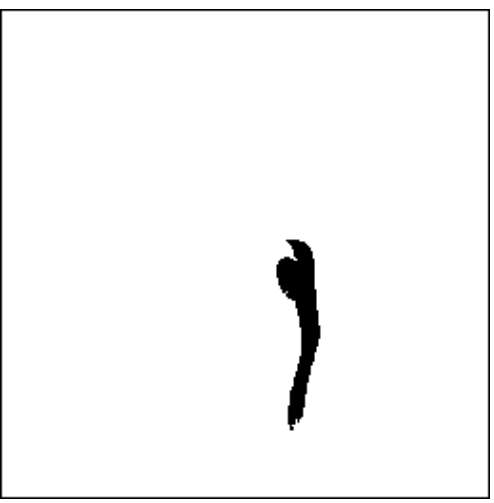

(f)

Figura 3.37: Resultado de simulação para uma imagem em nível tons de cinza. (a) Imagem de Ressonância Magnética do cérebro humano (257 × 257 pontos). (b) Mapa de saliência. (c) Resultado do processo de segmentação. (d) Mapa de objeto-saliência. (e) Primeiro objeto selecionado. (f) Segundo objeto selecionado.

A rede de seleção de objetos foi integrada utilizando o método numérico rápido proposto em (Linsay \& Wang, 1998). Utilizando este método é possível 
realizar a simulação de redes compostas por osciladores de relaxamento com grande número de osciladores. Além disso, uma outra vantagem deste método está na redução dos parâmetros da rede onde os seguintes parâmetros não são necessários: $\epsilon, \rho, \beta, \phi, \psi, \theta_{x}$ e $\theta_{z}$. Desta forma, apenas os parâmetros $\alpha=6,5$, $W_{z}=0,7, W_{T}=8,0$ e $\mu=0,125$ são suficientes para a simulação. A constante $C=1,65$ foi adotada em todas as simulações conforme especificado em (Wang, 1999).

Primeiramente, duas imagens em tons de cinza são utilizadas como entrada. Figura 3.36(a) apresenta a primeira imagem. A Figura 3.36(b) apresenta o mapa de saliência obtido a partir da Figura 3.36(a) onde os pontos mais claros representam pontos com maior saliência. Nesta simulação, adotando $W_{z}=20$, a rede LEGION (módulo de segmentação) produz 17 segmentos como pode ser observado na Figura 3.36(c). Com base nos resultados provenientes do mapa de saliência (Figura 3.36(b)) e da rede LEGION (Figura 3.36(c)), o mapa de objeto-saliência é gerado e mostrado pela Figura 3.36(d). Nesta figura, um objeto mais claro define um objeto com maior saliência. Este mapa alimenta a rede de seleção de objetos que primeiro seleciona o objeto mais saliente apresentado na Figura 3.36(e). Este objeto representa um lago presenta na região central da cena. Após a seleção do primeiro objeto, devido ao mecanismo de inibição de retorno descrito na Seção 3.5, os osciladores representando o primeiro objeto são inibidos permitindo ao sistema realizar a seleção de um outro objeto. Neste contexto, o segundo objeto mais saliente é selecionado pela rede e é apresentado na Figura 3.36(f). Em todas as simulações apresentadas a seguir, somente o primeiro e o segundo objeto selecionado pelo modelo são apresentado a fim de ilustrar o processo de seleção. A segunda simulação, apresentada pela Figura 3.37, utiliza uma imagem de ressonância magnética de um crânio humano como entrada (MRI - Magnetic Resonance Imaging). Assim como na simulação anterior, a Figura 3.37(a) apresenta a imagem de entrada e a Figura 3.37(b) o mapa de saliência. Para esta imagem, $W_{z}=20$ é adotado e a rede LEGION produz 21 segmentos (Figura 3.37(c)). A partir do mapa de objeto-saliência, apresentado na Figura 3.37(d), é possível observar que o cortex representa o objeto mais saliente, sendo desta forma o primeiro selecionado (Figura 3.37(e)). O segundo objeto selecionado pela rede é apresentado pela Figura 3.37(f) e corresponde a ponte de Varólio.

As próximas simulações são conduzidas com imagens coloridas apresentadas nas Figuras 3.38-3.41. Para todas as imagens coloridas, $W_{z}=20$ foi utilizado. Na Figura 3.38(a), devido ao alto contraste entre o inseto e o fundo da imagem composto em sua maioria por objetos de cores amarelas e verdes, o inseto, do ponto de vista de um observador humano, parece se destacar visualmente da cena. Esta observação visual é confirmada pelo mapa de objeto- 


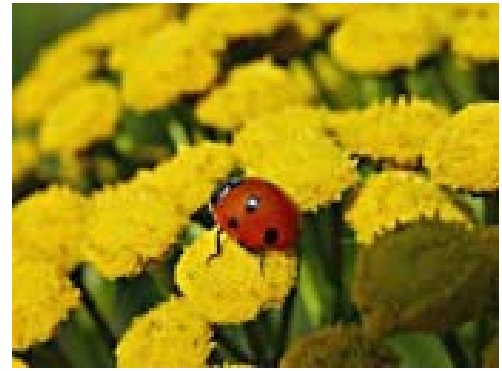

(a)

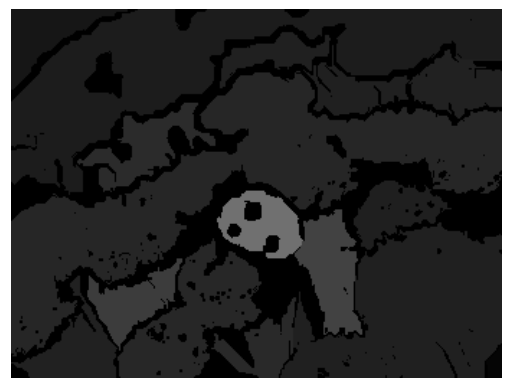

(d)

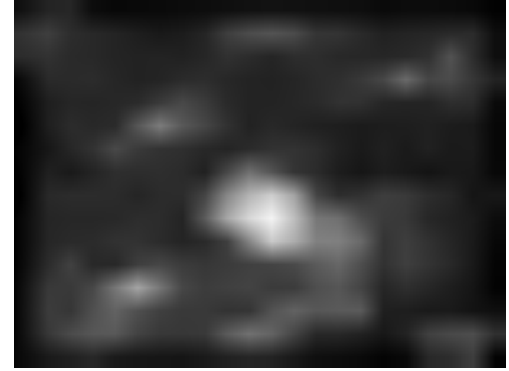

(b)

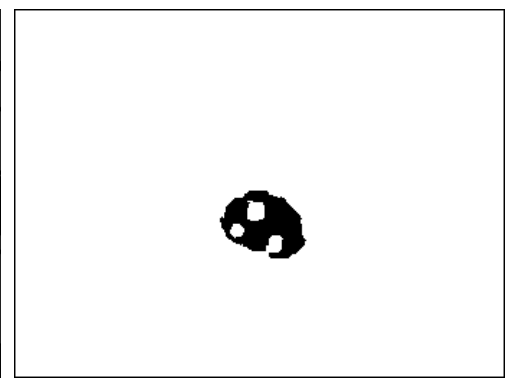

(e)

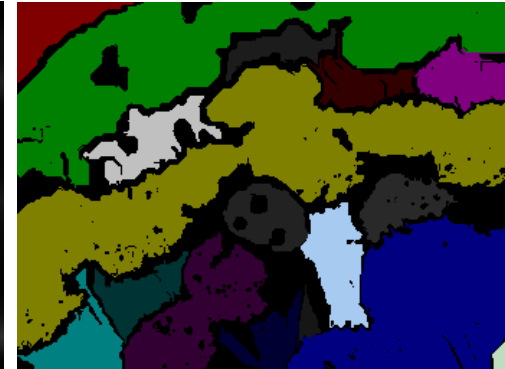

(c)

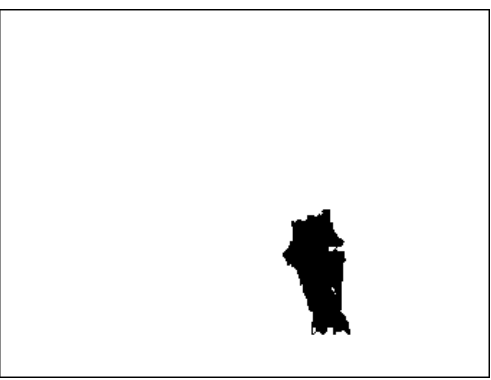

(f)

Figura 3.38: Resultado de simulação para uma imagem colorida. (a) Imagem natural com $351 \times 256$ pontos. (b) Mapa de saliência. (c) Resultado do processo de segmentação. (d) Mapa de objeto-saliência. (e) Primeiro objeto selecionado. (f) Segundo objeto selecionado.

saliência apresentado na Figura 3.38(d), onde o segmento que corresponde ao inseto é caracterizado por um nivel de cinza mais claro. Consequentemente, pode ser observado na Figura 3.38(e) que o inseto é o primeiro objeto a receber a atenção do sistema.

A Figura 3.39 apresenta uma simulação de uma cena onde o objeto mais saliente, segundo inspeção visual humana, representa um barco. Novamente, devido ao alto contraste entre o objeto e o fundo da cena, o objeto barco é selecionado primeiramente pelo sistema (Figura 3.39(e)). Parte de uma árvore de laranjas é apresentada na Figura 3.40. Para esta imagem, o sistema proposto seleciona as duas laranjas como o primeiro e segundo objetos resultantes do processo de competição por atenção. Este resultado é apresentado nas Figuras 3.40(e) e 3.40(f), respectivamente.

A Figura 3.41 mostra a cena de uma pessoa no Central Park em Nova York. Para esta imagem, o primeiro objeto selecionado é a parte superior do corpo da pessoa apresentado na Figura 3.41(e) e o segundo objeto selecionado corresponde a parte esquerda da cena mostrado na Figura 3.41(f).

Outras simulações utilizando imagens semelhantes foram conduzidas e os resultados com qualidade similar foram obtidos. Para todos os experimentos apresentados acima, a resposta do sistema parece coincidir com a percepção visual realizada por humanos referente a sequencia temporal de seleção dos objetos. 


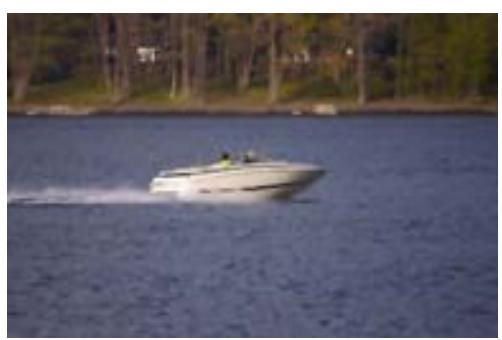

(a)

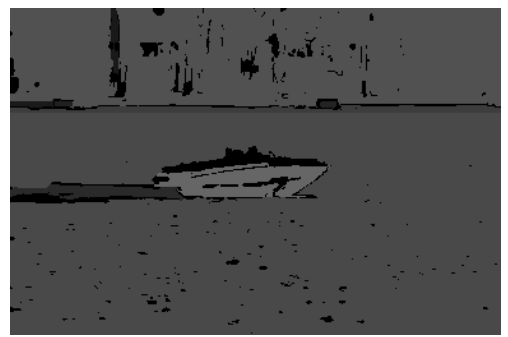

(d)

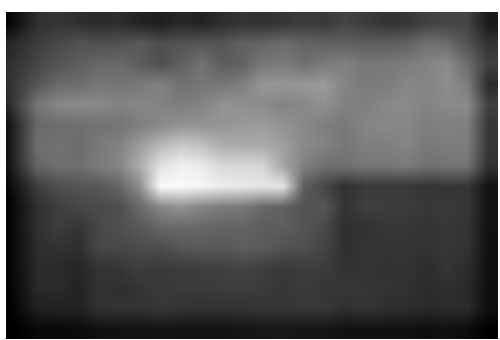

(b)

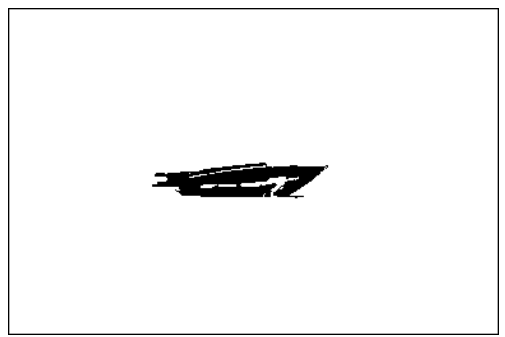

(e)

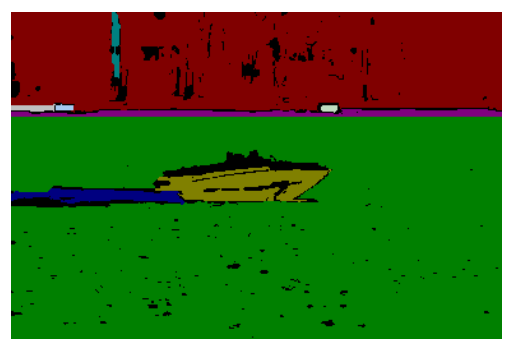

(c)

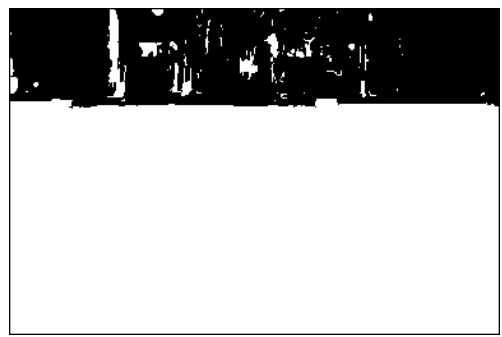

(f)

Figura 3.39: Resultado de simulação para uma imagem colorida. (a) Cena de um lago com $385 \times 256$ pontos. (b) Mapa de saliência. (c) Resultado do processo de segmentação. (d) Mapa de objeto-saliência. (e) Primeiro objeto selecionado. (f) Segundo objeto selecionado.

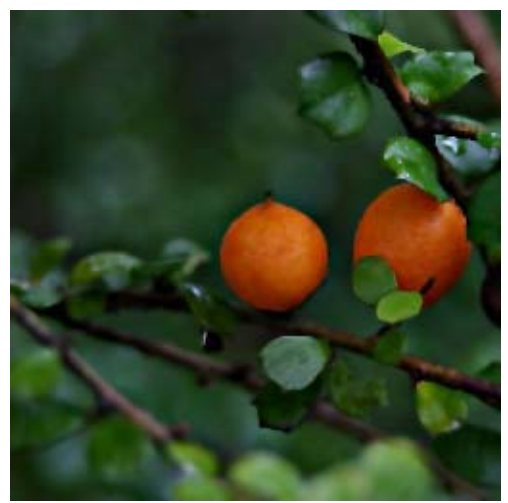

(a)

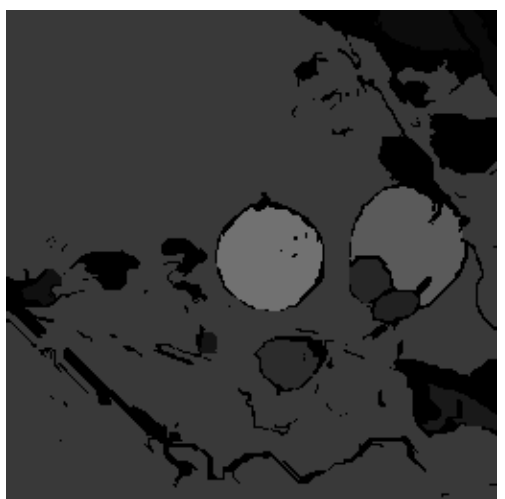

(d)

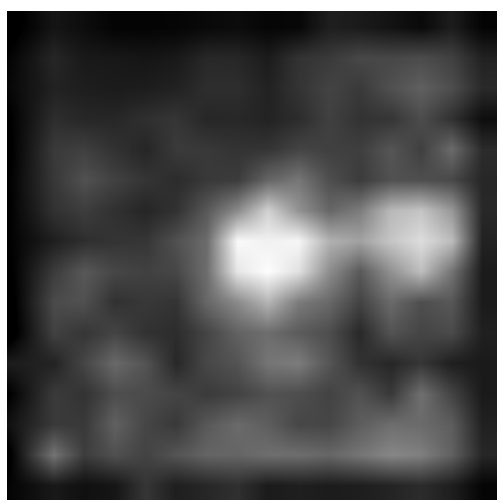

(b)

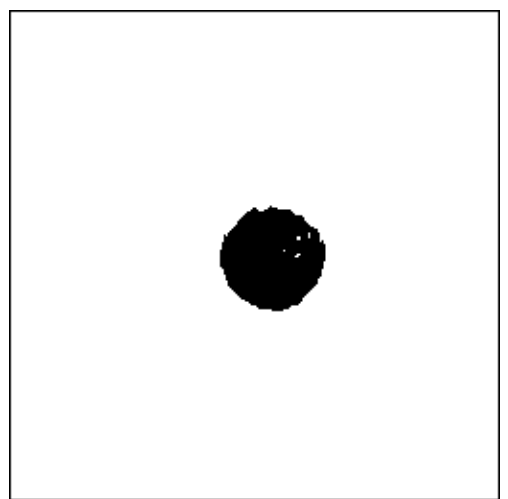

(e)

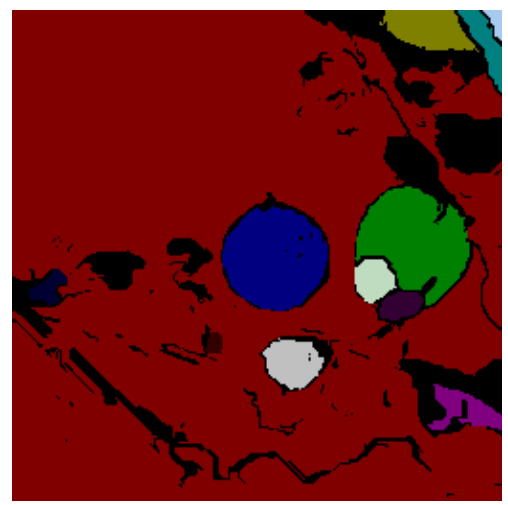

(c)

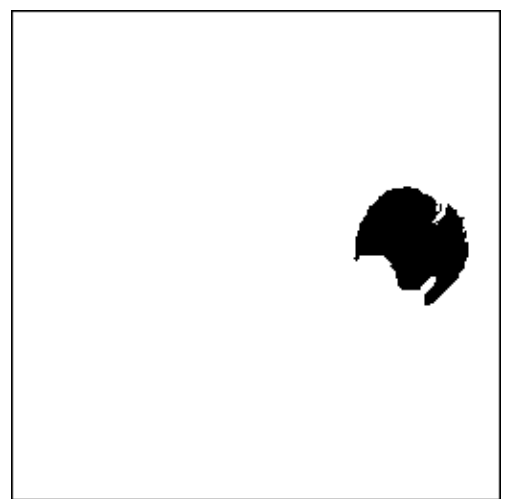

(f)

Figura 3.40: Resultado de simulação para uma imagem colorida. (a) Imagem natural com $256 \times 256$ pontos. (b) Mapa de saliência. (c) Resultado do processo de segmentação. (d) Mapa de objeto-saliência. (e) Primeiro objeto selecionado. (f) Segundo objeto selecionado. 
Dentre os modelos propostos e apresentados neste capítulo, este último se mostrou mais adequado a tarefa computacional de atenção visual devido as seguintes características principais. 1) realização de tarefas específicas em módulos individuais. Neste modelo, cada módulo é responsável por uma finalidade específica, facilitando a realização de tarefas como por exemplo a segmentação de imagens; 2) utilização de um mapa de saliência representando o papel do contraste local de atributos visuais como guia do processo de atenção. A utilização do mapa de saliência possibilitou o tratamento de imagens reais e também a seleção dos objetos com base em suas saliências; 3) organização perceptual da cena através da segmentação da imagem por uma rede LEGION. Ao contrário dos outros modelos, neste um módulo dedicado é utilizado na segmentação da cena o que facilita a tarefa de seleção de objetos; 4) seleção dos objetos com base em um valor definido por um mapa de objeto-saliência; e 5) implementação das redes LEGION através do algoritmo proposto em (Wang \& Terman, 1997) e integração da rede de seleção de objetos pelo método numérico proposto por Linsay \& Wang (1998). Neste modelo não houve a necessidade de integrar numericamente as equações diferenciais dos osciladores, resultando em uma maior eficiência computacional. Com base nestas característica, o modelo proposto se mostrou mais eficiente e capaz de atuar em imagens reais.

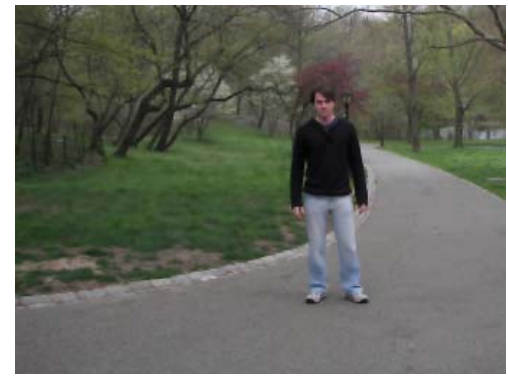

(a)

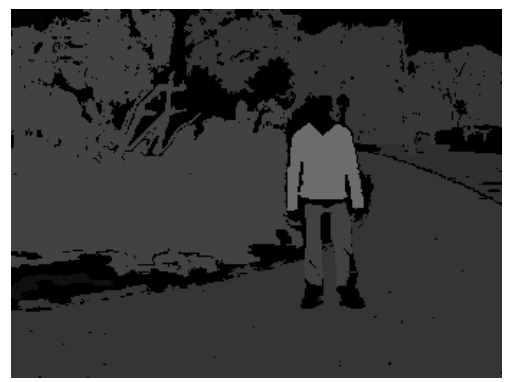

(d)

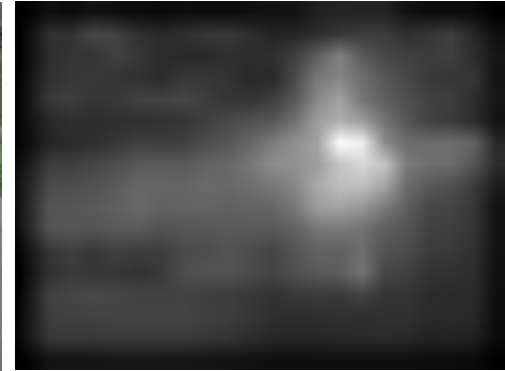

(b)

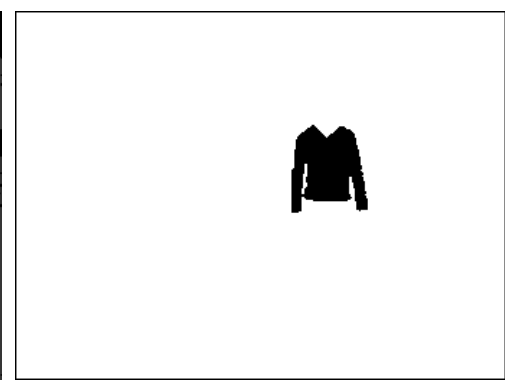

(e)

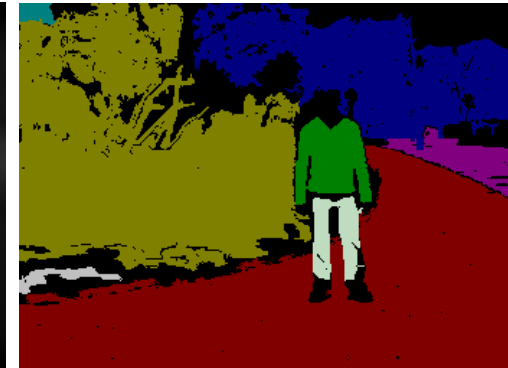

(c)

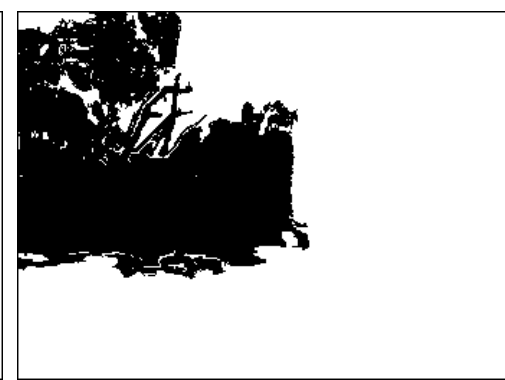

(f)

Figura 3.41: Resultado de simulação para uma imagem colorida. (a) Imagem real de uma pessoa no Central Park em Nova York ( $341 \times 256$ pontos). (b) Mapa de saliência. (c) Resultado do processo de segmentação. (d) Mapa de objetosaliência. (e) Primeiro objeto selecionado. (f) Segundo objeto selecionado. 
104 


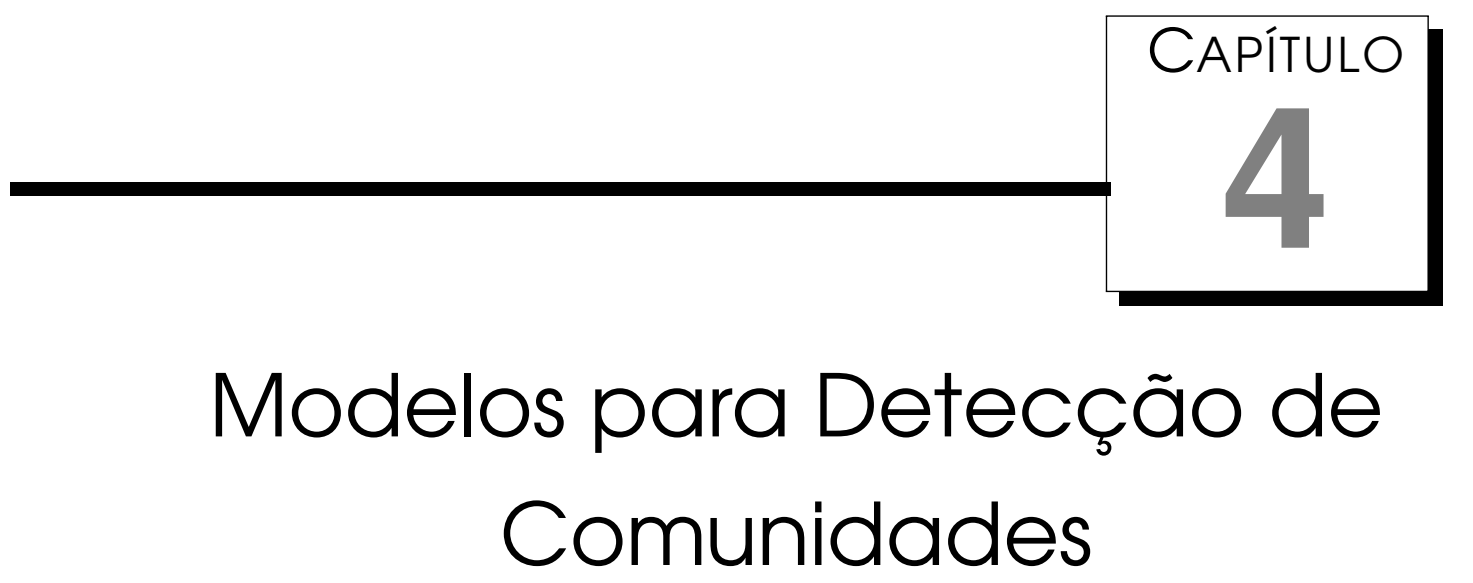

$\mathcal{U}$ ma importante característica observada em diversas redes complexas é a presença de estruturas modulares denominadas comunidades (Newman, 2004a; Danon et al., 2005). As comunidades podem ser definidas como um conjunto de vértices pertencentes a rede no qual a média de ligação entre estes é maior que o número de ligações com os demais vértices da rede.

Mecanismos para detecção de comunidades em redes complexas de forma automática têm se mostrado bastante atrativos em vários domínios de aplicação (Newman, 2004a; Danon et al., 2005). Isto se deve em fato a similaridade das características dos vértices que compõem uma mesma comunidade. Desta forma, por meio da identificação e estudo das comunidades é possível obter informações pertinentes ao domínio da rede. Por exemplo, em uma rede de interação social, uma comunidade pode identificar um conjunto de indivíduos com interesses comuns, relações de amizade ou profissionais, contágio de doenças, etc. De forma análoga, as comunidades também são importantes em redes de outros domínios como world wide web (WWW), redes neurais biológicas, redes metabólicas, dentre outras.

Como relatado na Seção 2.4.1, diversos modelos para detecção de comunidades em redes complexas têm sido propostos nos últimos anos. Entretanto, a precisão no processo de detecção das comunidades e a complexidade computacional desses algoritmos podem ser vistas como características antagônicas, no qual os modelos que apresentam alta eficiência computacional geralmente apresentam uma baixa precisão. Por outro lado, modelos com alta precisão 
demandam um alto custo de processamento (Danon et al., 2005). Com o objetivo de desenvolver técnicas mais precisas e eficientes, dois novos modelos inspirados em processos biológicos foram desenvolvidos e serão apresentados a seguir.

\section{1 Modelo de Competição de Partículas}

Nesta seção, um modelo de detecção de comunidades baseado em competição de partículas e suas respectivas simulações computacionais são apresentados. O modelo proposto envolve tanto mecanismos de competição quanto aspectos relacionados ao processo de tomada de decisão.

\subsubsection{Conceitos Iniciais}

A tomada de decisão em humanos pode ser vista como uma combinação de decisões randômicas e determinísticas (Lee, 2006; Daw et al., 2006). Quando uma pessoa possui um conhecimento completo sobre uma tarefa específica, uma decisão determinística é geralmente adotada; por outro lado, quando o oposto é observado pela completa falta de conhecimento sobre o assunto abordado, uma decisão randômica é tomada. Em situações reais, devido a algum conhecimento prévio adquirido, a tomada de decisão geralmente combina tanto aspectos randômicos quanto determinísticos.

A competitividade é um processo natural largamente observado em organismos vivos compartilhando recursos limitados, tais como água, comida, companheiros, território, reconhecimento, etc. A competição, para biólogos evolutivos, é um importante mecanismo de adaptação e evolução de espécies para sobreviver em um ambiente dinâmico com mudanças rápidas e recursos limitados. Acredita-se que a competição acontece até mesmo entre genes (Dawkins, 1990) e, desta forma, o comportamento das espécies é controlado por genes de modo a mantê-los dentro da população. Em alguns casos, os organismos podem até mesmo excretar alguns componentes químicos no ambiente com o objetivo de manter outros competidores distantes (Fredrickson \& Stephanopoulos, 1981). Como consequência, a espécie mais forte ou mais adaptada tende a forçar os outros a migrarem para outros territórios. Darwinismo Social sugere que a competição também serve como um mecanismo para determinar o grupo mais apto, politicamente, economicamente e ecologicamente (Burns, 1959). A competição também foi observada entre neurônios com o objetivo de refinar os circuitos neurais durante o desenvolvimento. É sugerido que a competição entre neurônios é importante na formação da memória, na qual neurônios são selecionados por sua atividade relativa durante o processo de aprendizado (Han et al., 2007). Esta descoberta está relacio- 
nada como o postulado de Hebb, o qual sugere que a atividade correlata entre neurônios é responsável pelas modificações sinápticas (Hebb, 1949). Tal postulado, denominado Aprendizado Hebbiano, tem sido largamente aplicado em redes neurais artificiais e aprendizado de máquina.

O aprendizado de máquina é um tópico de pesquisa importante no estudo de inteligência artificial (Mitchell, 1997). Ele se interessa pelo desenvolvimento de algoritmos que permitam que os computadores "aprendam". O aprendizado é essencial para sistemas computacionais inteligentes autônomos, como robôs móveis, os quais podem se adaptar a ambientes reais e desconhecidos (Pfeifer et al., 2007). O desenvolvimento de sistemas autônomos é uma tarefa desafiadora e, sem dúvidas, um mecanismo de aprendizagem é essencial e precisa estar presente no sistema.

Neste ponto é importante destacar que técnicas de aprendizado de máquina consistindo apenas de regras determinísticas não são suficientes (Quiles et al., 2008b). Isto se deve em parte ao grande número de regras que são necessárias para uma completa descrição até mesmo de um ambiente bastante restrito. Em ambientes dinâmicos, a situação se apresenta ainda mais complicada devido ao surgimento de novas regras e extermínio de outras devido a modificação constantes no ambiente. Desta forma, em um ambiente como o mencionado, o sistema deve ser capaz de continuar aprendendo ao longo do tempo. Assim, acredita-se que um certo nível de aleatoriedade ou caos é essencial para o processo de aprendizagem. Tal comportamento aleatório ou caótico pode ser definido como o estado "não sei como agir" gerado por um agente diante de uma situação não prevista na programação inicial. De certa forma, o comportamento aleatório ou caótico pode ser identificado como um detector de novidades e, no caso do modelo proposto aqui, auxiliar as partículas escaparem de mínimos locais presentes no domínio. Aqui um exemplo concreto é apresentado para mostrar que a aleatoriedade nem sempre é um estado de confusão, mas sim um estado útil para o processo de aprendizagem. Esta linha de raciocínio já foi adotada pela teoria da informação (Shannon, 1948), onde a aleatoriedade é considerada como novidade, por exemplo, quanto maior a entropia (incerteza) mais informação pode ser gerada.

A seguir, a descrição do modelo proposto e suas respectivas simulações computacionais são apresentadas.

\subsubsection{Descrição do Modelo}

Neste modelo diversas partículas caminham em uma rede competindo entre si para marcar vértices ao mesmo tempo em que rejeitam partículas intrusas em seu território. Após algum tempo de execução, cada partícula se 
isola permanecendo confinada dentro de uma comunidade da rede. Desta forma, os vértices da rede podem ser divididos em comunidades de acordo com suas partículas. O processo é similar a muitos processos naturais, tais como competição de recursos naturais entre animais, campanha eleitoral, etc. Além disso, as simulações computacionais apresentadas nesta tese mostram que o modelo tem bom desempenho na detecção de comunidades e, ao mesmo tempo, apresenta uma baixa ordem de complexidade (linear) (Quiles et al., 2008b).

A dinâmica do modelo é motivada pelo estudo da caminhada em rede por uma única partícula. Neste caso, era esperado que a partícula visitasse os vértices pertencentes a comunidades mais frequentemente do que vértices entre estas. Desta maneira, a frequência de visita aos nós poderia ser usado como um índice para determinar as comunidades. Entretanto, devido a propriedade de mundo pequeno das redes em estudo, a partícula tende a se movimentar entre as comunidades com uma alta frequência impossibilitando a identificação das comunidades. Por analogia, as comunidades podem ser comparadas a ilhas inabitadas e as ligações entre estas por pontes. Quando apenas uma partícula é utilizada, não é possível controlar a passagem desta entre as ilhas. Com base nesta observação, várias partículas são introduzidas na rede gerando um processo competitivo. Desta maneira, os vértices pertencentes a uma determinada partícula fixados em uma ilha têm como objetivo limitar a entrada de partículas provenientes de outras ilhas pela ponte, acarretando em um isolamento das partículas.

Para realizar esse mecanismo de competição, uma variável para representar o nível de domínio de cada vértice por uma partícula é introduzido (denominado potencial do vértice). Ao mesmo tempo, uma outra variável representando o nível de exploração de cada partícula, potencial da partícula, também é necessária. O potencial de uma partícula é aumentado sempre que esta visita seus próprios vértices e é reduzido quando a partícula visita vértices pertencentes a outra partícula. Da mesma maneira, quando um vértice é visitado por seu dono (partícula) seu potencial é aumentado representando um maior nível de domínio. Quando o vértice é visitado por uma partícula "intrusa", um choque é observado e o potencial do vértice é reduzido. Se um vértice é “atacado" diversas vezes, seu potencial pode ser reduzido a um valor mínimo ocasionando na mudança de seu domínio. A seguir, o modelo é formalmente apresentado.

O modelo considera dois tipos de dinâmica, a dinâmica das partículas e a dinâmica dos vértices. Cada partícula $\rho_{j}$ pode ser descrita por duas variáveis $\rho_{j}^{v}(t)$ e $\rho_{j}^{\omega}(t)$; a primeira usada para indicar o vértice $v_{i}$ em que a partícula esta visitando no instante $t$, e a segunda, $\rho_{j}^{\omega}(t) \in\left[\omega_{\min }, \omega_{\max }\right]$ é o potencial da 
partícula, que caracteriza a sua habilidade para explorar no instante $t$. Os valores $\omega_{\min }$ e $\omega_{\max }$ são os valores de mínimo e de máximo que o potencial dos vértices e partículas podem assumir. A dinâmica dessas partículas pode ser expressa pelas seguintes equações:

$$
\begin{gathered}
\rho_{j}^{v}(t+1)=v_{i} \\
\rho_{j}^{\omega}(t+1)=\left\{\begin{array}{clc}
\rho_{j}^{\omega}(t) & \text { se } & v_{i}^{\rho}(t)=0 \\
\rho_{j}^{\omega}(t)+\left(\omega_{\max }-\rho_{j}^{\omega}(t)\right) \Delta_{\rho} & \text { se } & v_{i}^{\rho}(t)=\rho_{j} \neq 0 \\
\rho_{j}^{\omega}(t)-\left(\rho_{j}^{\omega}(t)-\omega_{\text {min }}\right) \Delta_{\rho} & \text { se } & v_{i}^{\rho}(t) \neq \rho_{j} \neq 0
\end{array}\right.
\end{gathered}
$$

Na Equação (4.2) o parâmetro $\Delta_{\rho}$ controla a velocidade com que o potencial de cada partícula é alterado (aumenta ou diminui). De forma análoga, cada vértice $v_{i}$ também é caracterizado por duas variáveis $v_{i}^{\rho}(t)$ e $v_{i}^{\omega}(t)$, a primeira é usada para simplesmente registrar a qual partícula o vértice $i$ pertence no instante $t$; esta variável assume o valor $\rho_{j}$ se pertence ao território demarcado pela partícula $\rho_{j}$ ou 0 , se o vértice estiver no estado livre, i.e o vértice ainda não foi dominado por nenhuma partícula. A segunda variável $v_{i}^{\omega}(t)$, assim como $\rho_{j}^{\omega}(t)$, tem como objetivo armazenar o potencial do vértice $v_{i}$ no instante $t$. Este potencial é associado à força com que a partícula $\rho_{j}$ domina o vértice $v_{i}$, por exemplo, valores altos para $v_{i}^{\omega}(t)$ significa que o vértice $v_{i}$ é fortemente dominado pela partícula $\rho_{j}$, enquanto valores menores representam uma dominação mais amena. Especificamente se $v_{i}^{\omega} \leq \omega_{\text {min }}$ indica que o vértice $v_{i}$ está no estado livre, que pode ser dominado pela primeira partícula que o visitar. A dinâmica dos vértices pode ser resumida pelas seguintes equações:

$$
\begin{aligned}
& v_{i}^{\rho}(t+1)=\left\{\begin{array}{cll}
v_{i}^{\rho}(t) & \text { se } & v_{i}^{\gamma}=0 \\
\rho_{j} & \text { se } v_{i}^{\gamma}=1 & \text { e } v_{i}^{\omega}(t)=\omega_{\text {min }}
\end{array}\right.
\end{aligned}
$$

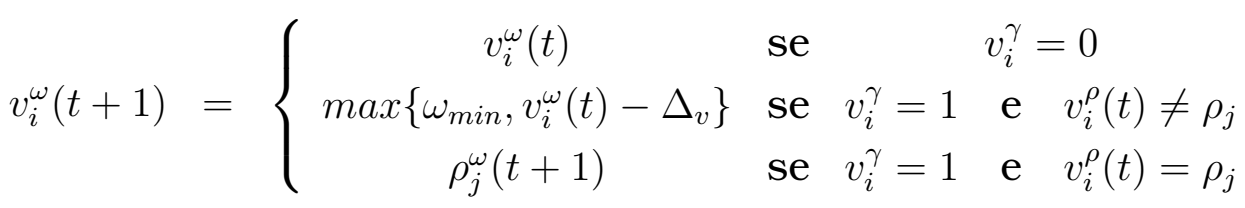

Na Equação (4.4), de maneira análoga a Equação (4.2), o parâmetro $\Delta_{v} \mathrm{e}$ utilizado para controlar a velocidade com que o potencial do vértice e alterado e $v_{i}^{\gamma}$ e um valor binário e simplesmente indica se o vértice esta sendo visitado no instante $t$ por alguma partícula. A aplicação do modelo no processo de detecção de comunidades pode ser descrito como segue. Inicialmente $k$ partículas são inseridas em $k$ vértices selecionados aleatoriamente. Cada uma 
dessas partículas e todos os vértices possuem um potencial inicial igual ao potencial mínimo. Ainda, no instante inicial todos os vértices encontram-se no estado livre, $v_{i}^{\rho}(t)=0$. Logo que o processo tem inicio, a cada instante, cada partícula escolhe um vértice vizinho para visitar. De maneira que cada partícula pode encontrar uma das três situações,

1. Se o vértice atual $v_{i}$ não pertence a nenhuma partícula $v_{i}^{\rho}(t)=0$, então o potencial da partícula não é alterado. O vértice é então marcado como pertencente à partícula $\rho_{j}$ com potencial igual ao da partícula.

2. Se o vértice atual já pertence à partícula corrente, o potencial desta partícula é aumentado e o potencial do vértice recebe o valor atual do potencial da partícula.

3. Se, no entanto, o vértice atual pertencer a uma partícula diferente da partícula que o está visitando, então ambos os potenciais são decrescidos. Se $\rho_{j}^{\omega}(t)$ for reduzido a valores menores que $\omega_{\text {min }}$, esta então é descartada e uma nova partícula com potencial igual a $\omega_{\min }$ é inserida em um vértice ainda não dominado por outra partícula ou no vértice com menor potencial assumindo que todos os vértices da rede já estão marcados. Se o potencial do vértice chegar a valores menores que $\omega_{\min }$ então sua pertinência retorna ao estado inicial 0 , indicando que este não pertence a nenhuma partícula.

Dessa forma, o grau de pertinência de um vértice é reforçado se este for visitado frequentemente pela mesma partícula, e reduzido ou mesmo alterado se visitado frequentemente por outras partículas distintas da partícula que o dominava inicialmente. O processo é continuado até o momento em que a maioria dos vértices não sofre mais mudanças com relação a seus domínios.

Outro ponto importante está na seleção do próximo vértice (vizinho) a ser visitado pela partícula. Primeiramente, duas regras são introduzidas representando os casos extremos da tomada de decisão abordada: movimento randômico e movimento determinístico. O primeiro supõe que a partícula não possui informações sobre a estrutura da rede, resultando em uma escolha aleatória do próximo vértice a ser visitado (o retorno imediato ao vértice visitado no instante $(t-1)$ não é permitido, exceto quando o grau do vértice é igual a um); Por outro lado, a regra determinística força a partícula a visitar um vértice que já está sob seu domínio.

A fim de estudar a combinação dos movimentos randômico e determinístico no processo de detecção de comunidades, uma probabilidade $0 \leq p_{\text {det }} \leq 1$ é definida. Desta forma, conforme $p_{\text {det }}$ é aumentado, a movimentação determinística se torna mais frequente. Em particular, a movimentação das partículas 
na rede é totalmente aleatória se $p_{\text {det }}=0$ e totalmente determinística quando $p_{\text {det }}=1$.

\subsubsection{Simulações Computacionais}

A Figura 4.1 apresenta uma ilustração do processo de detecção em uma rede randômica clusterizada composta por quatro comunidades como definido na Seção 2.4.1. A Figura 4.1(a) apresenta a condição inicial do processo onde apenas quatro vértices iniciais estão marcados com suas respectivas partículas associadas enquanto todos os demais vértices estão livres. Nas Figuras 4.1(b)-(d) pode ser observado que, devido ao processo de competição, cada partícula é confinada dentro de uma comunidade. Desta maneira, as quatro comunidades presentes na rede podem ser corretamente identificadas com base na partícula que a domina.

A Figura 4.2 apresenta a precisão do modelo na detecção de comunidades para diversos valores de $p_{\text {det }}$. Quando apenas a regra randômica é empregada $\left(p_{\text {det }} \approx 0\right)$, as partículas apresentam uma movimentação randômica constante entre os diversos vértices da rede, por esta razão, um processo de migração entre comunidades é bastante observado e as comunidades não são identificadas com uma alta precisão. Por outro lado, quando $\left(p_{\text {det }} \approx 1\right.$ ), as partículas permanecem confinadas em uma pequena região da rede dado que a característica de exploração implementada pela regra randômica não é utilizada. Desta forma, a precisão na detecção de comunidades também é baixa. Uma melhor precisão na detecção de comunidades é atingida quando $p_{\text {det }} \approx 0.6$ (Fig. 4.2), isto é, a regra de movimentação randômica é aplicada com probabilidade de $60 \%$ enquanto a regra de movimentação determinística é utilizada com probabilidade de $40 \%$. É importante observar que a Figura 4.2 apresenta a performance do modelo no caso em que as comunidades estão mal definidas, isto é $z_{\text {out }} /<k>=0,5$. A grande quantidade de ligações entre comunidades torna o processo de detecção difícil devido a alta probabilidade de migração inter-comunidades das partículas. Neste caso, a combinação adequada das regras de movimentação determinística/randômica auxiliam no processo aumentando a precisão de detecção do modelo. Por outro lado, quando as comunidades estão naturalmente isoladas, isto é, $z_{\text {out }} /\langle k\rangle$ é pequeno, o modelo proposto é capaz de obter bons resultados até mesmo quando apenas a regra de movimentação randômica é utilizada $\left(p_{\text {det }}=0\right)$.

Outra característica interessante que deve ser observada é que a regra determinística atuando de forma isolada $\left(p_{\text {det }} \approx 1\right)$ apresenta sempre os piores resultados. É exatamente a porção de aleatoriedade que proporciona uma melhor precisão no processo de detecção. Como já mencionado anteriormente, a regra de movimentação determinística tem por função manter as partículas 
(a)

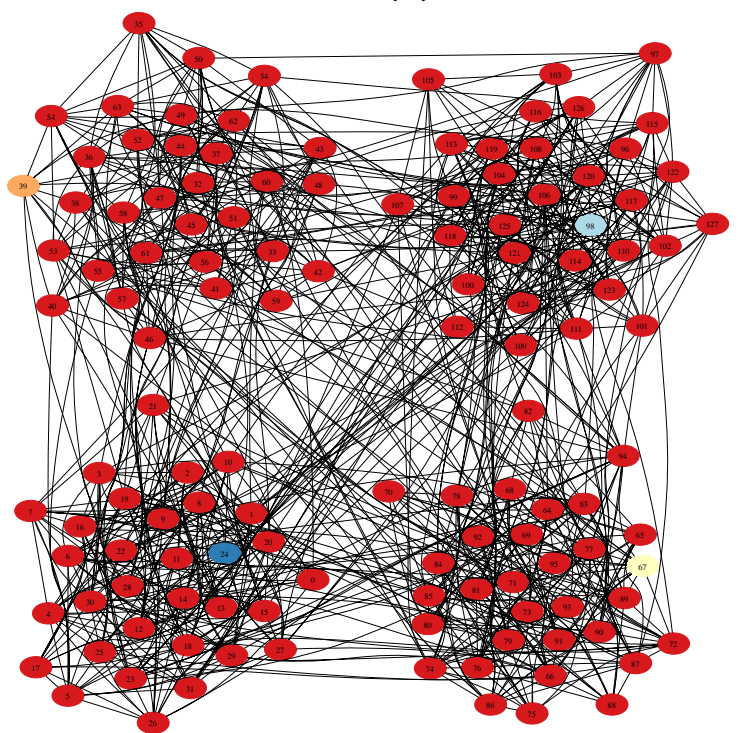

(c)

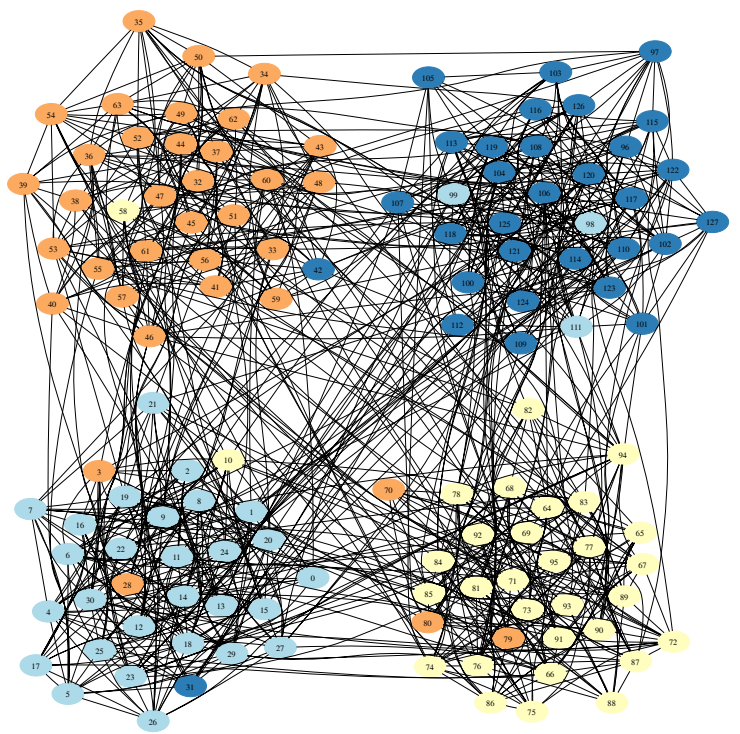

(b)

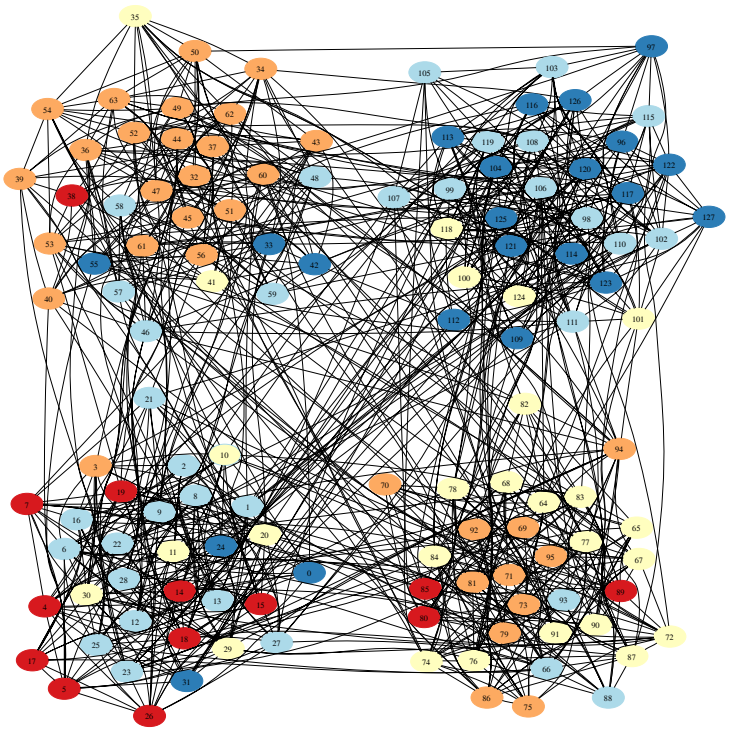

(d)

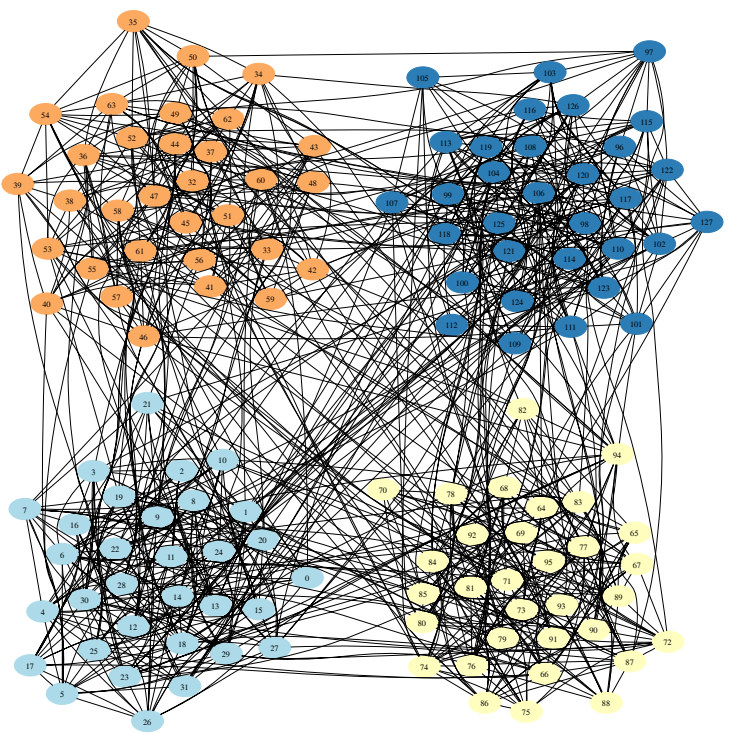

Figura 4.1: Ilustração do processo de detecção de comunidades via competição de partículas (Quiles et al., 2008b). (a) Estado inicial com 4 partículas randomicamente posicionadas na rede; (b) Resultado com 250 iterações (movimentos); (c) Resultado com 3500 iterações; (d) Resultado com 7000 iterações. 


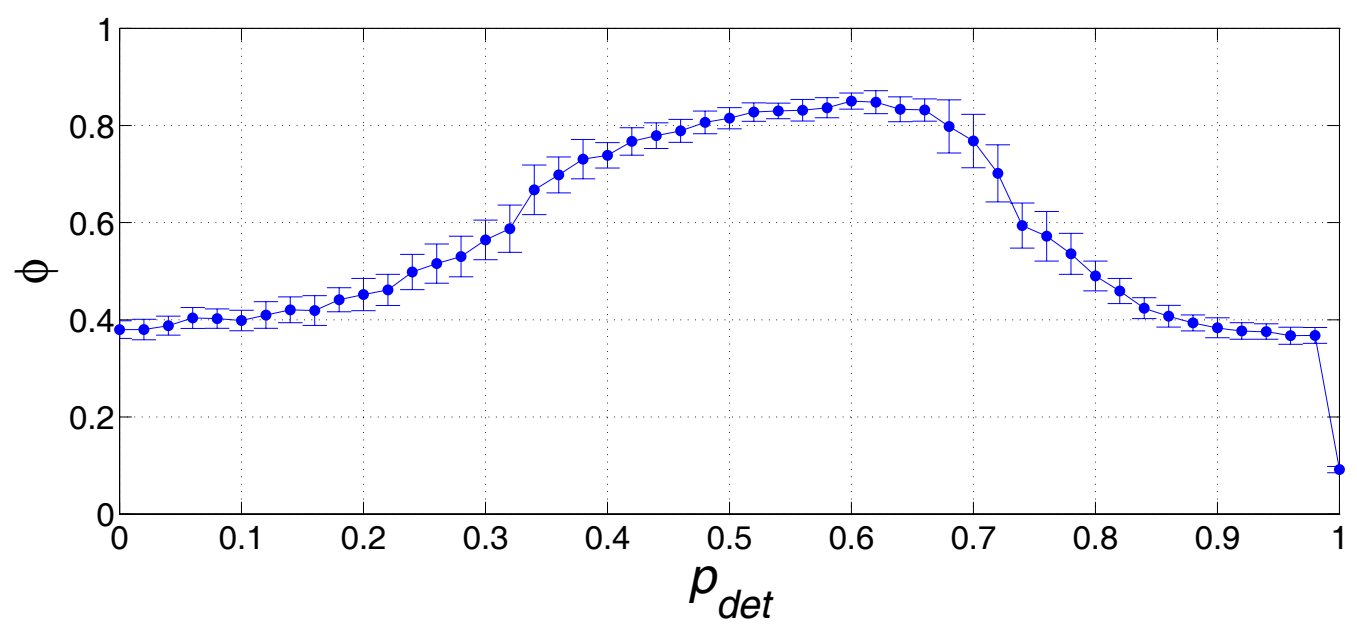

Figura 4.2: Taxa de detecção de comunidades correta $\phi$ versus probabilidade de movimentação determinística $p_{\text {det }}$. Nesta simulação, $N=128, M=4,\langle k\rangle=$ 16 e $z_{\text {out }} /<k>=0,5$. Cada ponto da curva é representado pela média de 200 execuções. A barra de erro representa o desvio padrão.

em seus territórios e a movimentação randômica é responsável por criar um comportamento de exploração. Este comportamento de exploração induz as partículas a se moverem livremente por vértices livres ou mesmo a competir por vértices da rede dominados por outras partículas. Neste caso, a aleatoriedade atua como um importante fator de adaptação das partículas ao meio (rede). Além disso, acredita-se que a aleatoriedade seja uma característica importante em aprendizado biológico e artificial.

A Figura 4.3(a) apresenta a evolução temporal do modelo com três valores de $p_{\text {det }} \in\{0,0 ; 0,6 ; 1,0\}$. Pode ser observado que a precisão tanto para $p_{\text {det }}=0$ quanto para $p_{\text {det }}=1$ é baixa. O melhor resultado é obtido quando $p_{\text {det }}=0,6$, reforçando o resultado apresentado pela Figura 4.2. As Figuras 4.3(b)-(c) apresentam a evolução temporal do potencial médio dos vértices e das partículas respectivamente, para os mesmos valores de $p_{\text {det }}$. Pode ser observado que a evolução da precisão do processo de detecção de comunidades apresenta um comportamento semelhante a evolução do potencial médio dos vértices. Esta semelhança também é observada com a evolução do potencial médio das partículas, exceto quando $p_{\text {det }}=1$. Neste caso, devido à restrição de movimento imposta pela regra determinística, as partículas permanecem presas a uma pequena região da rede e fenômeno de competição não é observado. Por esta razão, o potencial médio dos vértices atinge o valor máximo $\left(\omega_{\max }\right)$. Para redes onde a estrutura de comunidades não é conhecida a priori, o potencial médio dos vértices pode ser usado como um critério de parada para o processo de detecção.

O próximo experimento é utilizado para estudar como o número de partículas afeta o processo de detecção das comunidades. A Figura 4.4 mostra a 

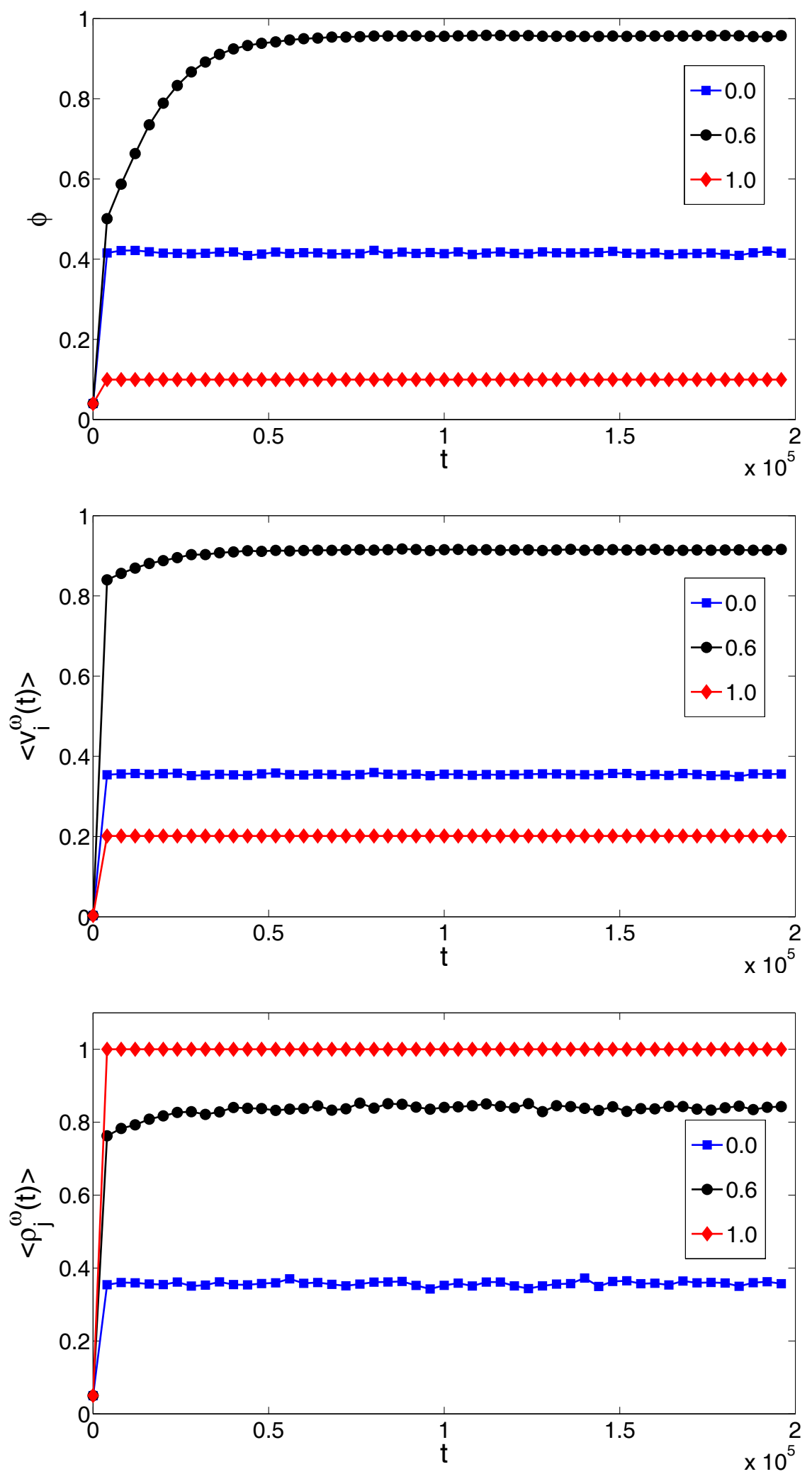

Figura 4.3: Séries temporais da evolução do modelo para diferentes valores de $p_{\text {det }}$. (a) Evolução da taxa de detecção de comunidades correta $\phi$; (b) Potencial médio dos vértices; (c) Potencial médio das partículas. Estas simulações foram realizadas com redes definidas pelos seguintes parâmetros: $N=128, M=4$, $z_{\text {out }} /\langle k\rangle=0,4 \mathrm{e}\langle k\rangle=16$. Cada ponto da curva é representado pela média de 200 execuções. 

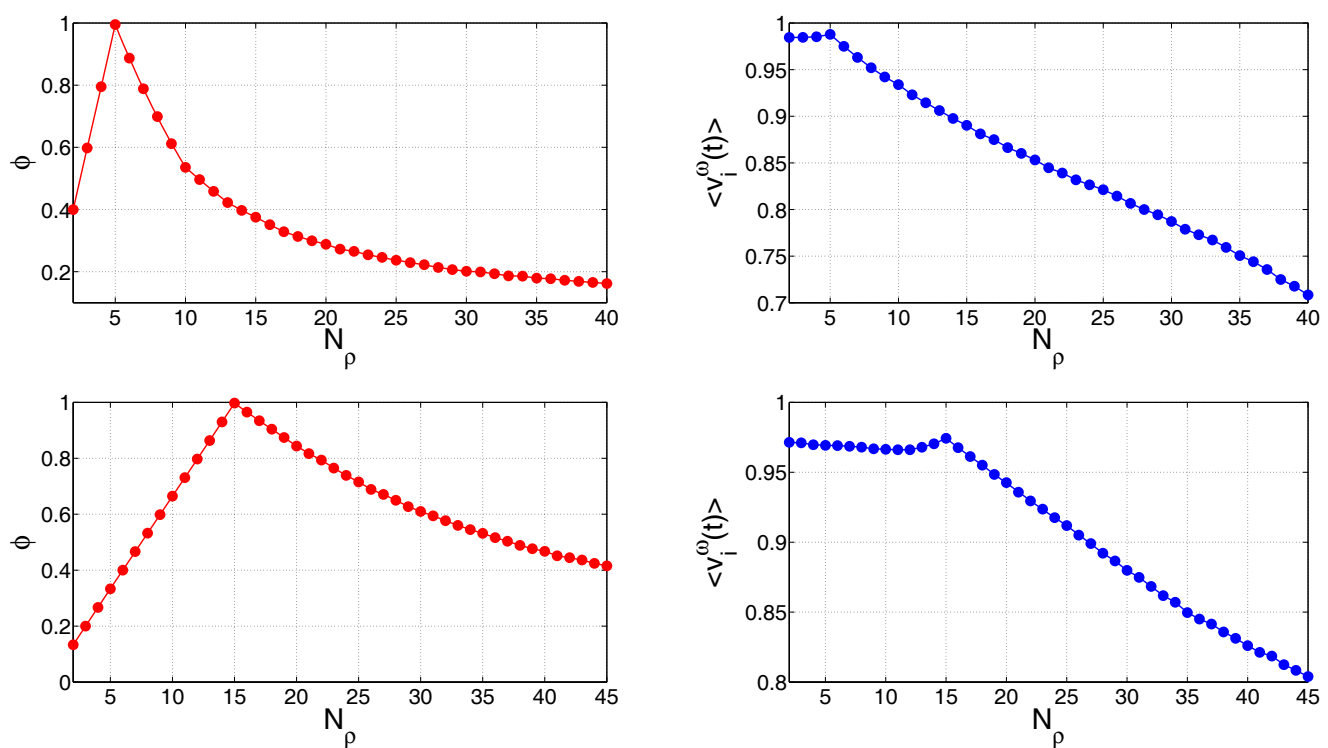

Figura 4.4: Resultados de simulação variando o número de partículas e o número de comunidades. (a) e (c) Taxa de detecção de comunidades correta $\phi$ versus número de partículas na rede $N_{\rho}$. (b) e (d) Potencial médio dos vértices $\left\langle v_{i}^{\omega}\right\rangle$ versus número de partículas na rede $N_{\rho}$. Nas simulações apresentadas nas Figuras (a) e (b), $N=160, M=5, z_{\text {out }} /<k>=0,3, z_{\text {in }} /<k>=0,7$, $<K>=16$ e $p_{\text {det }}=0,6$. Nas simulações apresentadas nas Figuras (c) e (d), $N=480, M=15, z_{\text {out }} /<k>=0,3, z_{\text {in }} /<k>=0,7$ e $p_{\text {det }}=0,6$.

precisão do processo de detecção de comunidades variando o número de partículas. Tanto na rede formada por cinco comunidades quanto na rede formada por quinze comunidades, o valor máximo é obtido quando 5 e 15 partículas são usadas, respectivamente. É intuitivo afirmar que o melhor resultado para o processo de detecção de comunidades é obtido quando o número de partículas coincide com o número de comunidades. Isto acontece porque se um número menor de partículas é utilizado, algumas comunidades podem ser agrupadas como uma única comunidade. Por outro lado, se quantidade de partículas excede o número de comunidades, uma comunidade pode abrigar mais de uma partícula ocasionando sua divisão. Ou ainda, devido a competição gerada pela partícula adicional, um desequilíbrio pode ser observado acarretando na migração contínua de partículas entre comunidades. A partir da Figura 4.4, é possivel observar a correspondência entre a taxa de detecção correta e o potencial médio dos vértices. Neste caso, quando o número de comunidades para uma dada rede não é conhecido, o potencial médio dos vértices pode ser utilizado como uma estimativa do número de comunidades desta rede.

As Figuras 4.5, 4.6 e 4.7 mostram a taxa de detecção de comunidades $\phi$ versus $\Delta_{v}$ e $\Delta_{\rho}$ para diferente valores de $z_{\text {out }} /\langle k\rangle$, tamanho da rede $N$ e grau médio da rede $\langle k\rangle$, respectivamente. A partir da Figura 4.5(a), pode ser observado que o modelo atinge bons resultados apenas para uma pequena região dos parâmetros $\Delta_{v}$ e $\Delta_{\rho}$ quando $z_{\text {out }} /<k>$ é grande, ou seja, quando a 
estrutura de comunidades da rede não é bem definida. Conforme $z_{\text {out }} /<k>$ é reduzido, as faixas de valores para parâmetros $\Delta_{v}$ e $\Delta_{\rho}$ onde um bom resultado é obtido são aumentadas (ver 4.5(b)-(e)). Quando $z_{\text {out }} /<k>$ é reduzido a valores próximos a 0,1 , boas taxas de detecção são obtidos para praticamente todas as combinações de valores dos parâmetros $\Delta_{v}$ e $\Delta_{\rho}$. Entretanto, quando $z_{\text {out }} /<k><0,1$, as comunidades se tornam bastante isoladas resultando na diminuição do processo migratório entre comunidades. Desta forma, para algumas condições iniciais e assumindo valores pequenos para $\Delta_{\rho}$, o modelo pode convergir para um mínimo local, onde mais de uma partícula pode permanecer confinada em uma mesma comunidade ou ainda, duas ou mais comunidades podem ser dominadas por uma mesma partícula. O caso extremo é observado na Figura 4.5(f) quando $\left.z_{\text {out }} /<k\right\rangle=0$. Neste caso, quando uma ou mais partículas são randomicamente iniciadas em uma mesma comunidade, a única forma de migração para uma outra comunidade ocorre quando o potencial da partícula é reduzido a $\omega_{\min }$ (partícula morre). Assim, a partícula é reiniciada e pode ser randomicamente posicionada em outra comunidade. Porém, se $\Delta_{\rho}$ é definido por um valor pequeno, o potencial das partículas é alterado de forma lenta, o que reduz a probabilidade desta forma de migração por morte da partícula ocorrer. Como consequência, para redes com valores de $z_{\text {out }} /<k><1$, um bom resultado do processo de detecção de comunidades é obtido apenas para valores maiores de $\Delta_{\rho}$ assim como apresentado na Figura 4.5(f).

Uma outra forma de evitar este problema é configurando $p_{\text {det }}$ com um valor menor. Neste caso, mesmo para valores pequenos de $\Delta_{\rho}$, a competição entre partículas é induzida devido a alta probabilidade de movimentação randômica. Assim, a chance de ocorrer migração das partículas é aumentada e bons resultados do processo de detecção podem ser atingidos.

As Figuras 4.6 e 4.7 mostram que a taxa de detecção de comunidades não é significativamente alterada variando-se o tamanho da rede ou o grau médio de conexões. Desta forma, analisando as Figuras 4.5, 4.6 e 4.7, pode ser observado que, para diferentes estruturas de redes, $\Delta_{v}$ e $\Delta_{\rho}$ podem ser mantidos praticamente constantes.

A Figura 4.8 apresenta a fração de vértices corretamente classificados como função da proporção de inter-conexões $z_{\text {out }} /<k>$. Os resultados apresentados por esta figura foram gerados utilizando-se redes randômicas clusterizadas com $N=128, M=4,<k>=16$, geradas conforme descrito na Seção 2.4.1. A partir da Figura 4.8 pode ser observado que o modelo proposto apresenta bons resultados de detecção de comunidades até mesmo para valores altos de $z_{\text {out }} /<k>$ no qual a estrutura de comunidades não é bem definida. Além disso, ao comparar os resultados obtidos com aqueles apresentado na 
(a)

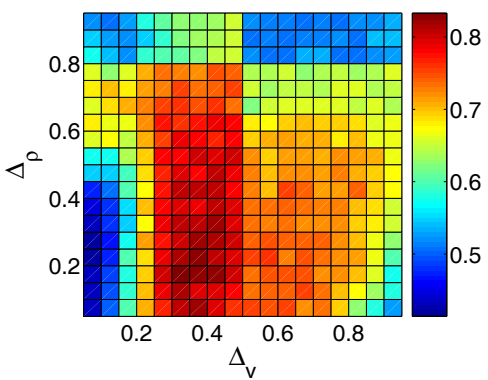

(d)

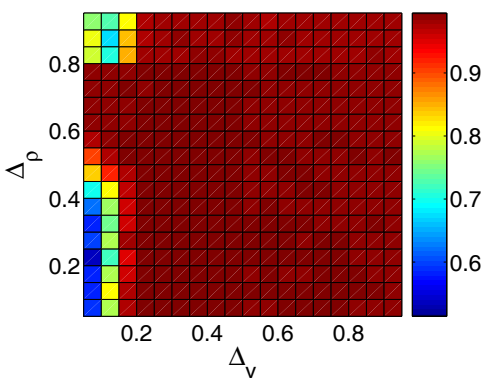

(b)

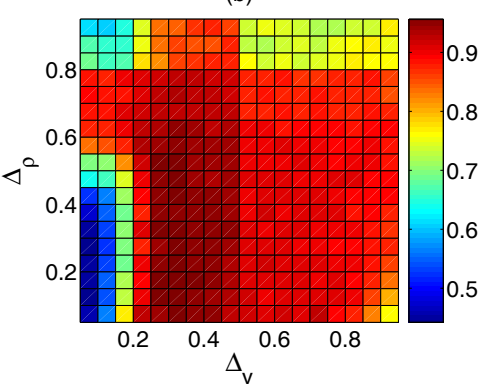

(e)

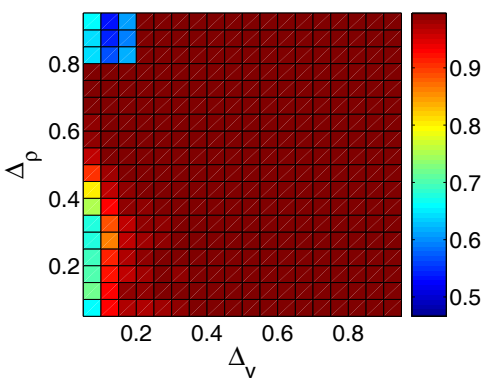

(c)

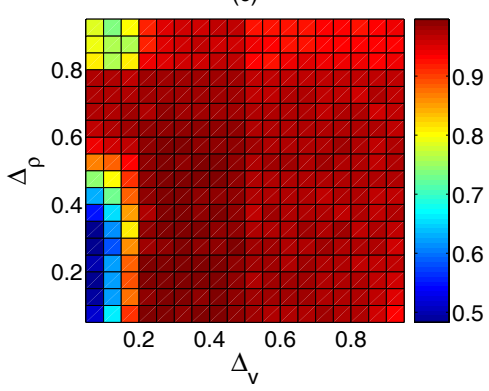

(f)

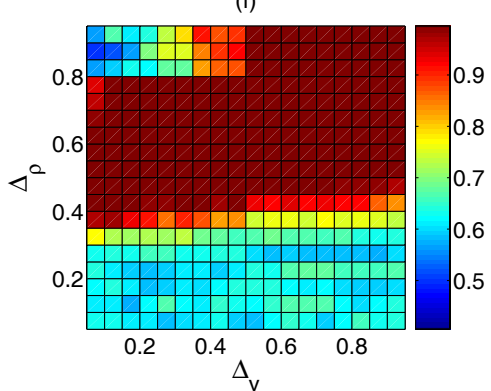

Figura 4.5: Taxa de detecção de comunidades correta $p h i$ versus $\Delta_{v}$ e $\Delta_{\rho}$ para diferentes valores de $z_{\text {out }} /\langle k\rangle$. As cores representam a taxa de detecção de comunidades. (a) $z_{\text {out }} /<k>=0,5$; (b) $z_{\text {out }} /<k>=0,4$; (c) $z_{\text {out }} /<k>=0,3$; (d) $z_{\text {out }} /<k>=0,2$; (e) $z_{\text {out }} /<k>=0,1$; (f) $z_{\text {out }} /<k>=0,0$. Nestas simulações, os seguintes parâmetros foram utilizados: $N=80, M=4, p_{\text {det }}=0,6 \mathrm{e}<k>=10$. Cada ponto na figura representa a média de 100 execuções.

Figura 2.10 da Seção 2.4.1, pode-se constatar que o modelo aqui proposto encontra-se entre aqueles que apresentam melhor precisão.

Para verificar a complexidade computacional do modelo de competição de partículas, alguns testes numéricos foram realizados com diversas redes com diferentes tamanhos. A Figura 4.9 mostra o número de iterações necessárias para atingir um alto valor para o potencial médio dos vértices $\left(<v^{\omega}>\geq 0,9\right)$, o que, na média, representa um bom resultado de detecção de comunidades. Pela figura pode ser observado que o número de passos necessários para atingir $\left\langle v^{\omega}\right\rangle \geq 0,9$ é incrementado linearmente conforme o tamanho da rede é aumentado. Esta complexidade linear obtida pode ser entendida pela seguinte explicação. Considere uma rede composta por comunidades completamente isoladas $\left(z_{\text {out }} /<k>=0\right)$ e com uma partícula cada. Neste caso, o domínio de cada vértice de rede/comunidade pode ser determinado por uma única visita da partícula, o que resulta em uma complexidade $O(N)=C N$, onde $C$ é uma constante positiva proporcional ao nivel de movimento randômico das partículas. Se as comunidades estão conectadas umas as outras por uma pequena quantidade de ligações, isto é, $z_{\text {out }} /<k>$ é um número pequeno, o domínio de cada vértice pode ser determinado por um pequeno número de visitas. Como resultado, a ordem de complexidade é novamente $O(N)=C N$. Pelo mesmo motivo, espera-se que a complexidade do modelo seja $O(N)=C N$ no qual a constante $C$ aumenta proporcional à $z_{\text {out }} /<k>$. Tal observação é apresen- 
(a)

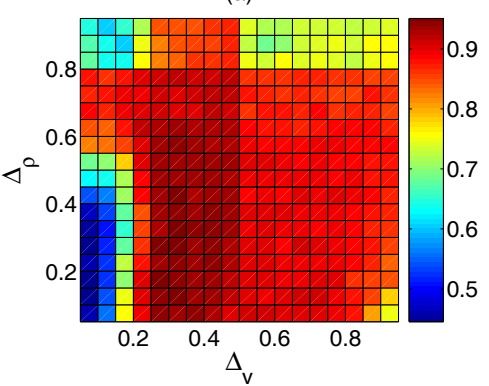

(d)

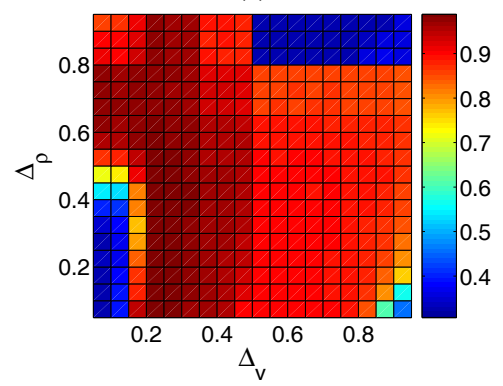

(b)

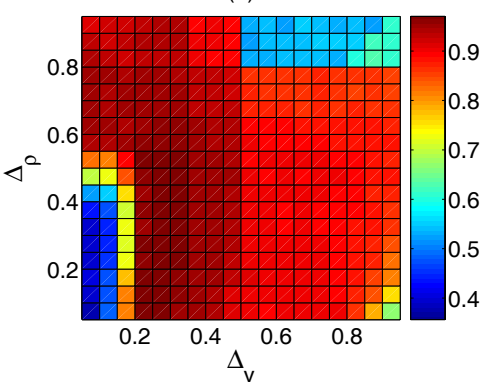

(e)

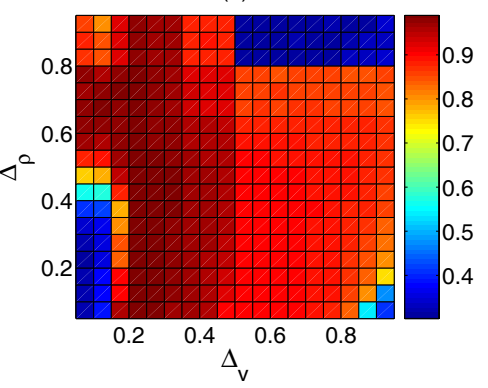

(c)

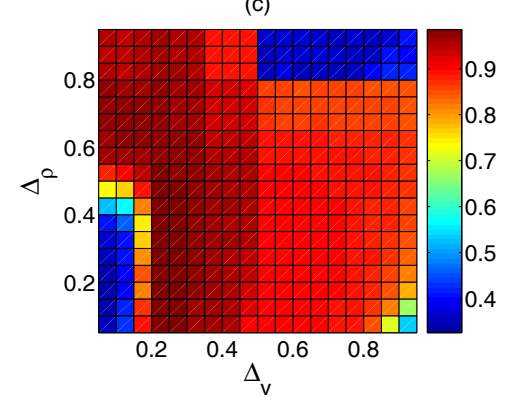

(f)

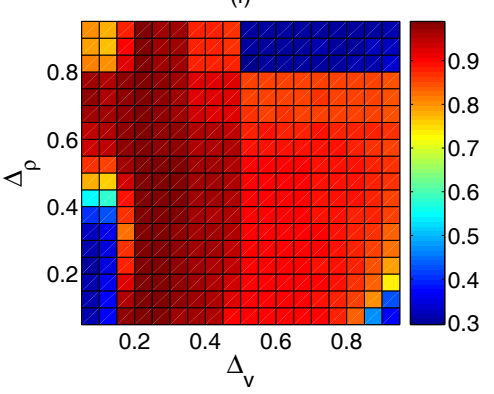

Figura 4.6: Taxa de detecção de comunidades correta $p h i$ versus $\Delta_{v}$ e $\Delta_{\rho}$ para diferentes valores de $N$. As cores representam a taxa de detecção de comunidades. (a) $N=80$; (b) $N=160$; (c) $N=320$; (d) $N=480$; (e) $N=640$; (f) $N=800$. Nestas simulações, os seguintes parâmetros foram utilizados: $\langle k\rangle=0,5 \mathrm{~N} / \mathrm{M}$, $M=4, p_{\text {det }}=0,6 \mathrm{e} z_{\text {out }} /\langle k\rangle=0,4$. Cada ponto na figura representa a média de 100 execuções.

(a)

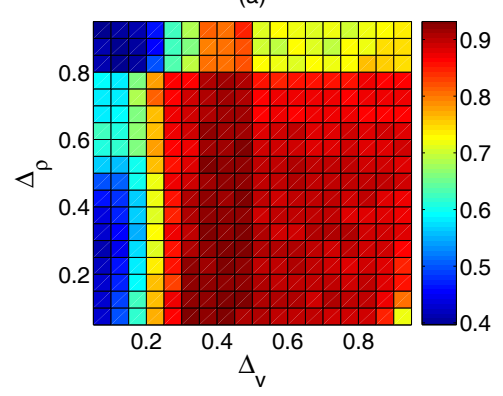

(d)

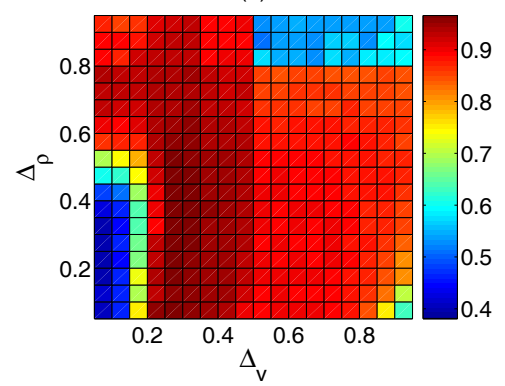

(b)

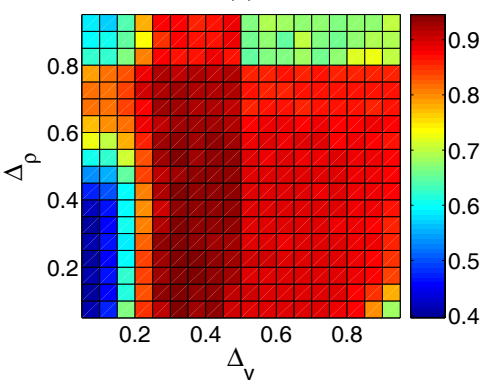

(e)

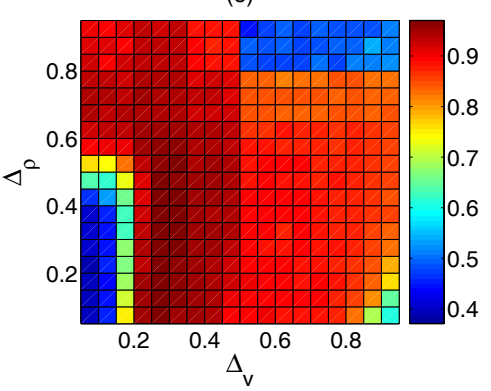

(c)

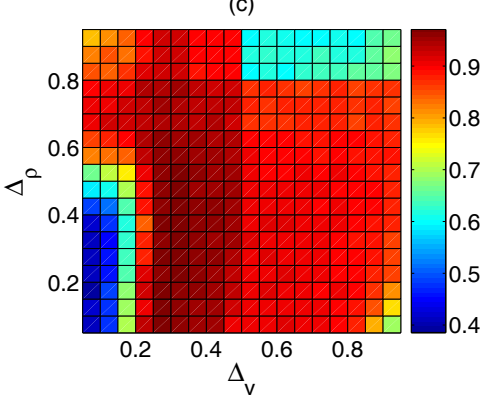

(f)

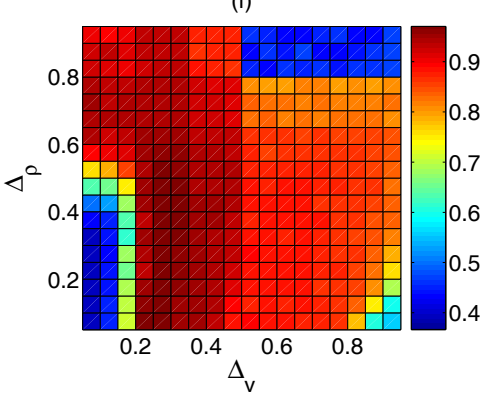

Figura 4.7: Taxa de detecção de comunidades correta phi versus $\Delta_{v}$ e $\Delta_{\rho}$ para diferentes valores de $\langle k>$. As cores representam a taxa de detecção de comunidades. (a) $<k>=8$; (b) $<k>=12$; (c) $<k>=16$; (d) $<k>=20$; (e) $<k>=24$; (f) $\langle k>=28$. Nestas simulações, os seguintes parâmetros foram utilizados: $N=128, M=4, p_{\text {det }}=0,6$ e $\left.z_{\text {out }} /<k\right\rangle=0,4$. Cada ponto na figura representa a média de 100 execuções. 


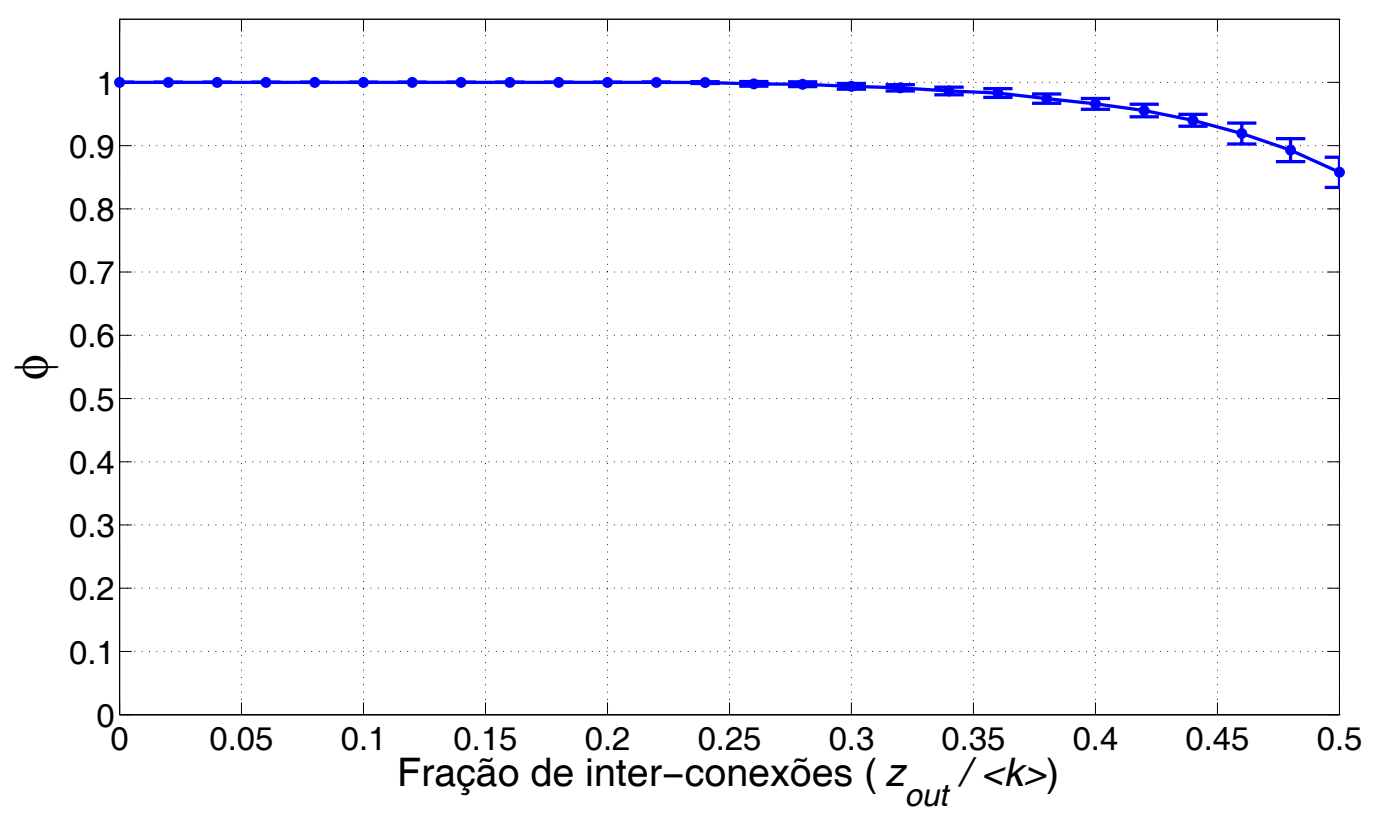

Figura 4.8: Taxa de detecção de comunidades correta $\phi$ aplicada a redes randômicas clusterizadas com $N=128, M=4 \mathrm{e}<k>=16$. O eixo $x$ representa a fração de inter-conexões $z_{\text {out }} /<k>$ e o eixo $y$ representa a proporção de vértices corretamente classificados. Cada ponto da curva é representado pela média de 200 execuções. As barras de erros representam o desvio padrão. $p_{\text {det }}=0,6$. Para $z_{\text {out }} /<k>\leq 0,1, \Delta_{\rho}=0,6$; Para $z_{\text {out }} /<k>>0,1, \Delta_{\rho}=0,4$.

tada pelas Figuras 4.9(a) e (b). A barra de erro da Figura 4.9 mostra que o número de iterações necessárias para realizar a detecção de comunidades em uma rede de tamanho $N$ é inferior a $O\left(N^{2}\right)$ mesmo no pior caso. Se compararmos a complexidade computacional estimada acima com as complexidades dos modelos apresentados na Tabela 2.2 apresentada na Seção 2.4.1, pode ser observado que a complexidade do modelo proposto também se encontra entre as melhores. Além disso, considerando que cada iteração consiste de apenas de uma movimentação da partícula entre o vértice atual e um de seus vizinhos, o modelo proposto pode ser considerado bastante eficiente computacionalmente.

Por fim, o modelo proposto é aplicado à tarefa de detecção de comunidades em duas redes reais. A Figura 4.10 apresenta o resultado de simulação utilizando uma rede formada pelas relações de amizade entre indivíduos em um clube de karate estudada em (Zachary, 1977). O resultado obtido e apresentado na Figura 4.10 difere em apenas um vértice (número 3) do resultado apresentado em (Newman \& Girvan, 2004). O segundo experimento é conduzido em uma rede de interação social entre golfinhos (Lusseau et al., 2003). Esta rede foi elabora com base na observação de laços sociais estabelecidos entre pares de golfinhos ao longo de vários anos. Uma característica interessante nesta rede é que, devido a partida de um dos membros principais do 


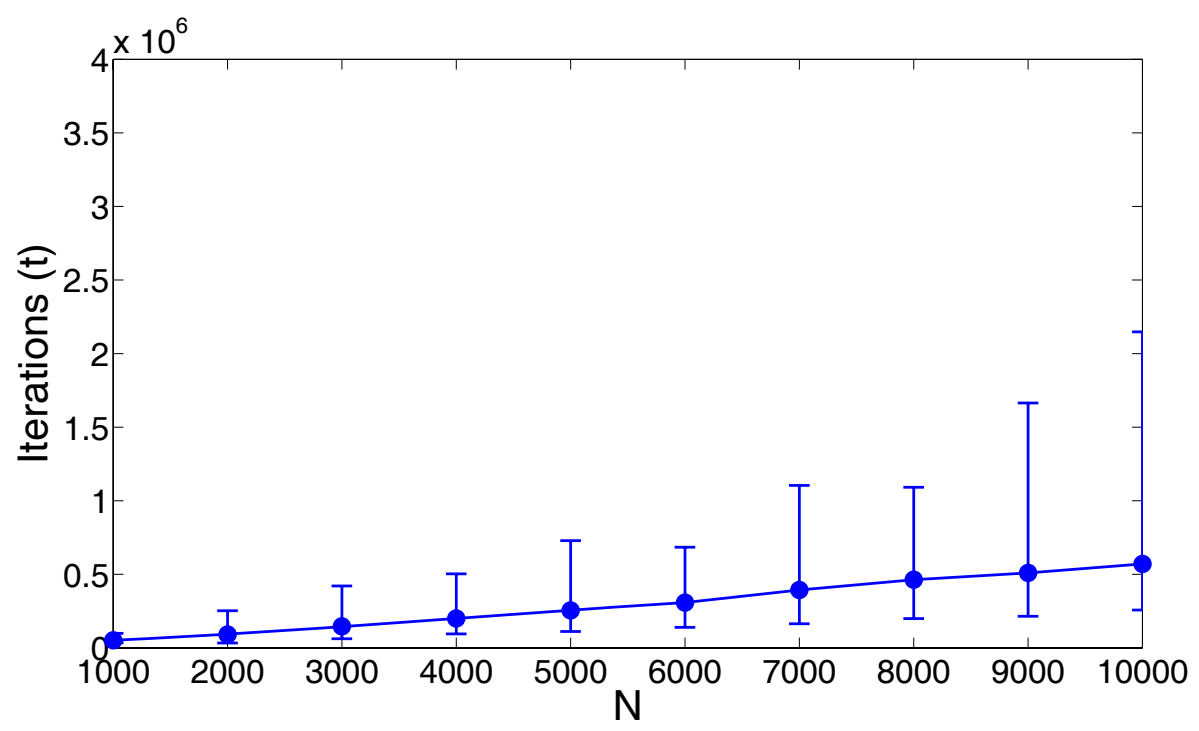

(a)

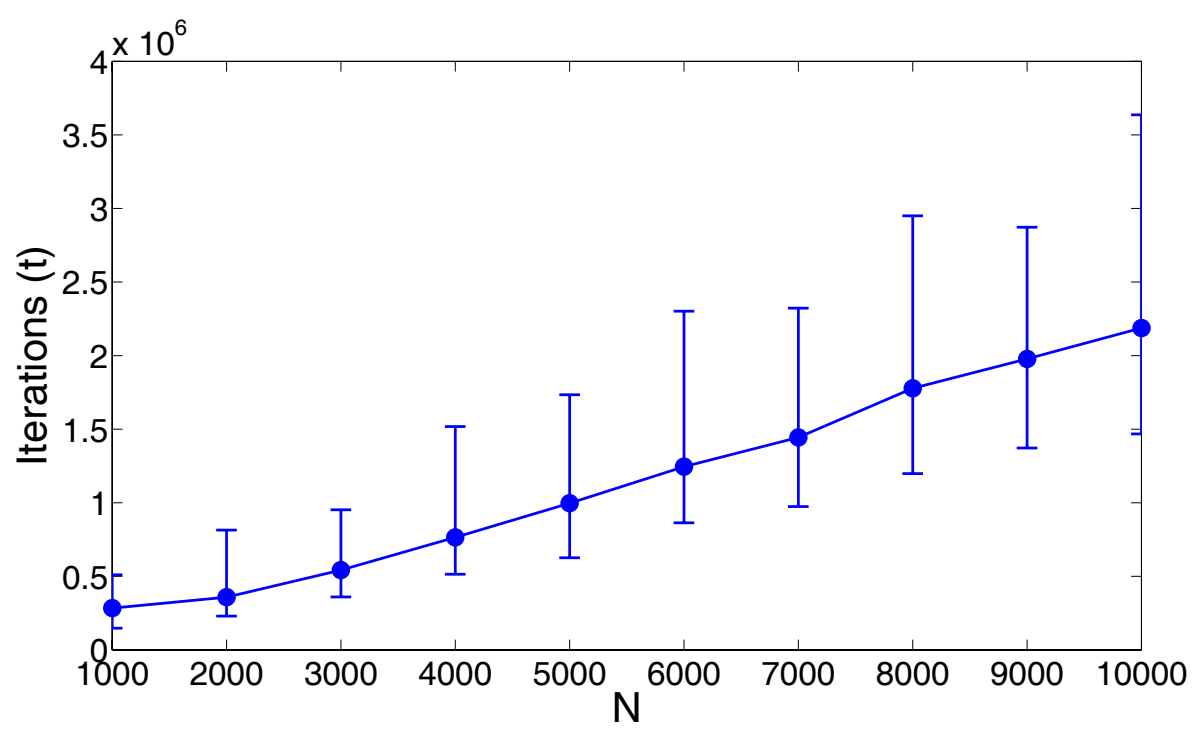

(b)

Figura 4.9: Número de iterações necessárias para detecção das comunidades versus tamanho da rede $N$. Nestas simulações os seguintes parâmetros foram utilizados: $M=4,\langle k\rangle=0.5 N / M$ e $p_{d e t}=0,6$. Cada ponto da curva é representado pela média de 200 execuções. As barras de erro representam os números mínimo e máximo de iterações necessárias para atingir $\left\langle v^{\omega}>\geq 0,9\right.$. (a) $\left.z_{\text {out }} /<k\right\rangle=0,2$. (b) $\left.z_{\text {out }} /<k\right\rangle=0,4$ 


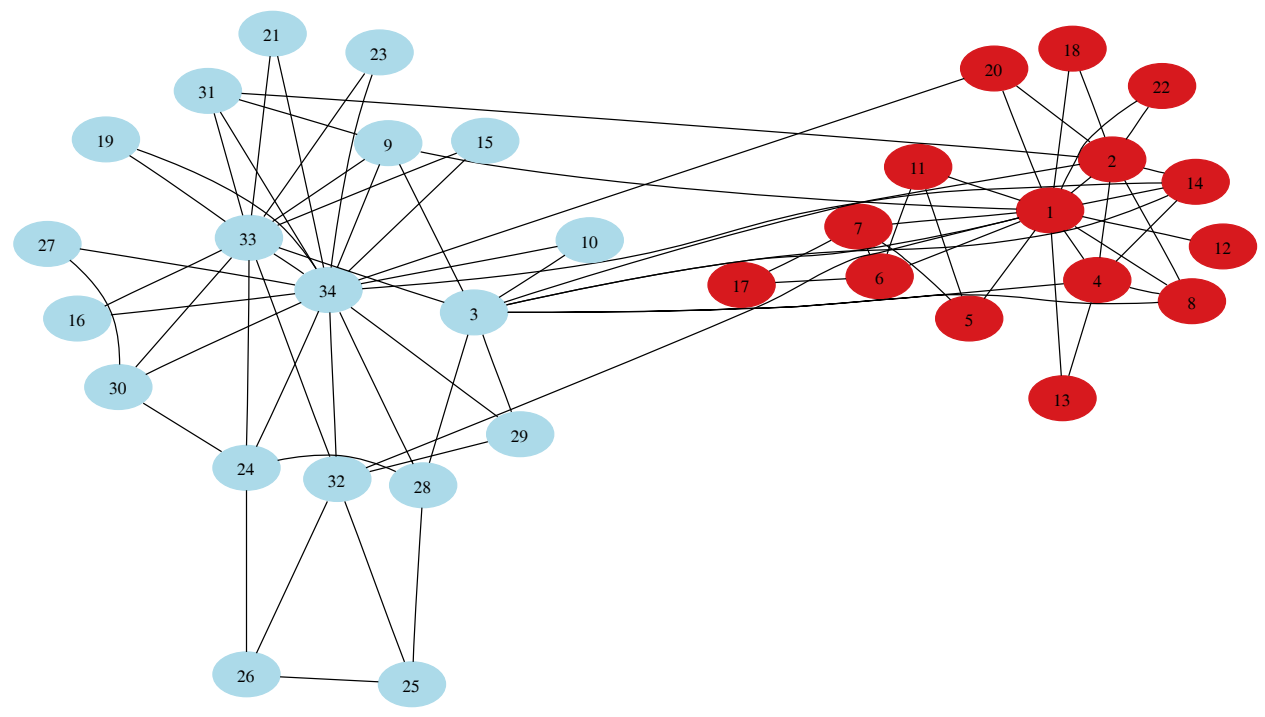

Figura 4.10: Resultado do processo de detecção de comunidades sobre a rede de interação social entre indivíduos pertencentes a um clube de karate (Zachary, 1977). $p_{\text {det }}=0,6$.

grupo (número 27), a população de golfinhos foi dividida em duas comunidades. O resultado obtido com a aplicação do modelo nesta rede, apresentado na Figura 4.11, demonstra exatamente divisão observada na população, onde os vértices de cor vermelha e azul representam essa duas comunidades.

Com base nos resultados apresentados acima, pode se observar que o modelo dinâmico para detecção de comunidades em redes complexas proposto é bastante promissor, tanto em aspectos de precisão quanto em eficiência computacional. A evolução do processo competitivo das partículas é bastante similar a vários processos naturais e sociais, tal como competição por recursos naturais, exploração de territórios por humanos e animais, etc. Além disso, com base no estudo da combinação de regras determinística e randômica para movimentação de partículas, foi observado que, o melhor resultado é obtido quando um equilíbrio destas é empregado no processo de detecção.

Na próxima seção, outro modelo de detecção de comunidades baseado na teoria da correlação oscilatória (von der Malsburg \& Schneider, 1986; Terman \& Wang, 1995) é apresentado.

\subsection{Modelo de Correlação Oscilatória: Neurônios I\&D}

Esta seção apresenta um modelo de detecção de comunidades baseado na teoria da correlação oscilatória implementada em uma rede composta por neurônios do tipo Integra e Dispara. Com detalhado na Seção 2.2, esta teoria descreve que um objeto é representados pela atividade síncrona de osciladores codificando diferentes propriedades deste, enquanto objetos distintos são 


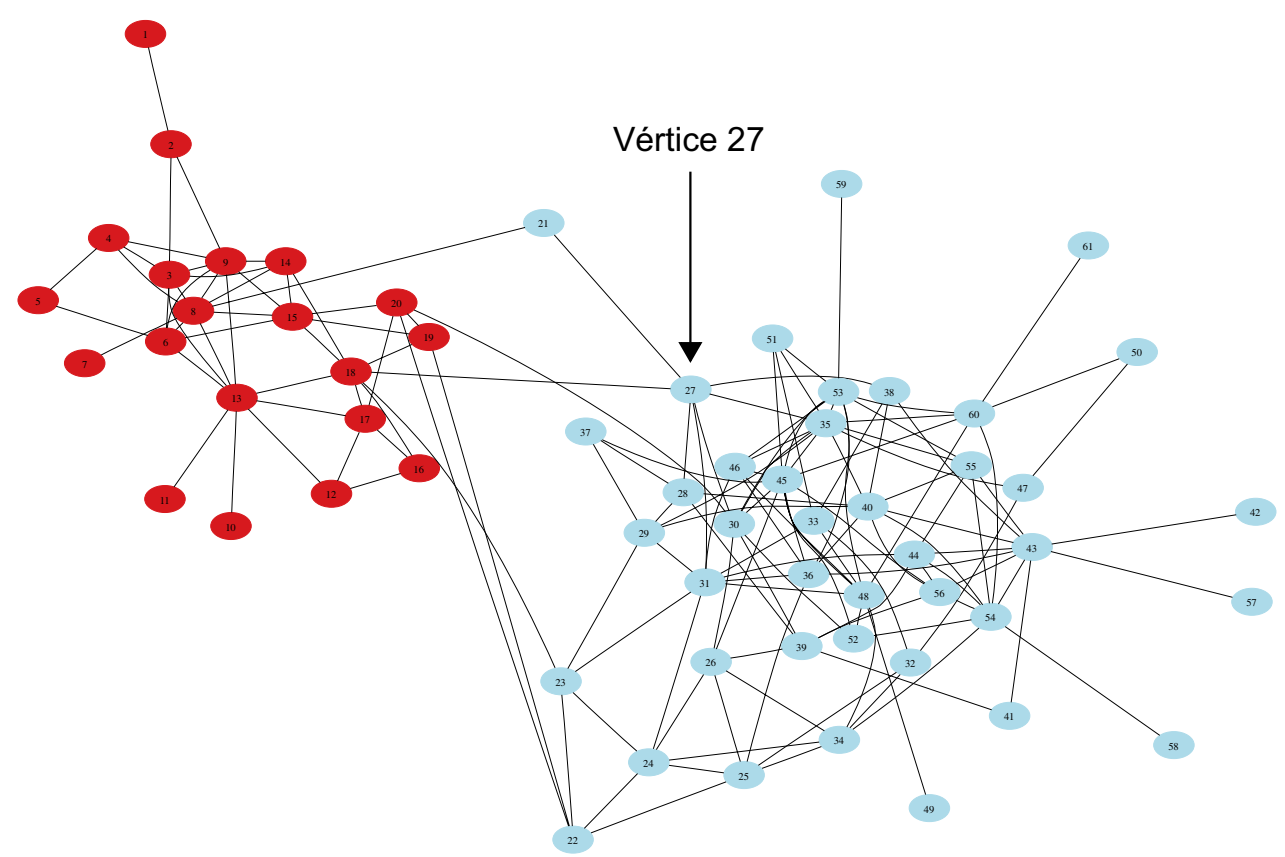

Figura 4.11: Resultado do processo de detecção comunidades sobre a rede interação social entre golfinhos ((Lusseau et al., 2003)). $p_{\text {det }}=0,6$.

representados por trajetórias não sincronizadas.

Neste modelo, cada oscilador representa um vértice da rede. Desta forma, grupo de osciladores densamente conectados, representando comunidades, têm seus atividades de disparo sincronizadas, enquanto comunidades distintas permanecem com trajetórias não correlacionadas.

\subsection{Descrição do Modelo}

Neste modelo, cada vértice da rede é modelado por um neurônio do tipo I\&D representado pela seguinte equação:

$$
\frac{d v_{i}}{d t}=-v_{i}+I_{i}+E_{i}(t)-Y_{i}(t)
$$

onde $v_{i}$ representa o potencial do neurônio, $I_{i}$ é uma constante que define a estimulação externa, $E_{i}(t)$ define o termo de acoplamento excitatório e $Y_{i}(t)$ o termo de acoplamento inibitório entre os neurônios. O neurônio $i$ dispara sempre que o potencial $v_{i} \geq \theta_{v}$, onde $\theta_{v}$ representa o limiar de disparo do neurônio.

O termo de acoplamento excitatório $E_{i}(t)$ é definido por:

$$
E_{i}(t)=\sum_{j \in \Delta_{i}} \omega_{i j} \delta\left(t-t_{j}\right)
$$

onde $\delta$ é a função delta de Dirac, $t_{j}$ representa o instante em que o neurônio $j$ dispara, $\Delta_{i}$ define a vizinhança de cooperação excitatória do neurônio $i$ de- 
finida com base nas ligações (arestas) presentes na rede. $\omega_{i j}$ define a força de acoplamento excitatório entre os neurônios $i$ e $j$ e é defina por:

$$
\omega_{i j}=\frac{c}{\left|\Delta_{i}\right|}
$$

no qual $c \in[0,1]$ é uma constante e $\left|\Delta_{i}\right|$ representa o grau do vértice $i$.

O termo de acoplamento inibitório é definido por:

$$
Y_{i}(t)=\frac{c}{N} \sum_{j=1 ; j \neq i}^{N} \delta\left(t-t_{j}\right)
$$

onde $N$ representa o número de vértices na rede.

De uma forma geral, a dinâmica do modelo apresentado acima pode ser descrita da seguinte maneira. Devido as conexões excitatórias, modelada pela Equação (4.6), grupos de neurônios (vértices) densamente conectados, representando comunidades, têm suas atividades de disparo sincronizadas. Por outro lado, devido a presença de um inibidor global (Equação (4.8)) aliado a menor probabilidade de conexões inter-comunidades, as atividades de disparos de comunidades distintas permanecem dessincronizadas. Por esta razão, o modelo proposto é capaz de detectar comunidades em redes.

A seguir, um conjunto de simulações computacionais utilizando redes sintéticas e reais é apresentado.

\subsubsection{Simulações Computacionais}

Esta seção apresenta um conjunto de simulações visando testar a capacidade do modelo como uma ferramenta computacional para detecção de comunidade. As redes sintéticas utilizadas nos próximos experimentos foram geradas conforme o procedimento especificado na Seção 2.4.1.

A Figura 4.12 apresenta uma ilustração do processo de detecção em uma rede randômica clusterizada composta por quatro comunidades. A partir da Figura 4.12(b) é possivel observar o processo de sincronização entre os grupos de neurônios representando as comunidades. Uma vez estabelecida a sincronização entre estes, as comunidades podem ser facilmente identificadas através da atividade de disparo de cada grupo. Isto se deve ao mecanismo da correlação temporal no qual cada grupo é representado por uma trajetória temporal distinta.

A Figura 4.13 apresenta a fração dos vértices corretamente classificados como função da proporção de inter-conexões $z_{\text {out }} /<k>$. Estes resultados foram gerados pela média de 200 execuções do modelo em redes randômicas clusterizadas com $N=128, M=4 \mathrm{e}\langle k\rangle=16$, geradas conforme descrito na Seção 2.4.1. A partir deste resultado pode ser constatado que o modelo 
apresenta bons resultados de detecção de comunidades para uma ampla faixa de $z_{\text {out }} /\langle k\rangle$, onde, na média, a precisão obtida para $z_{\text {out }} /\langle k\rangle=0,4$ é de aproximadamente 90\%. Embora os resultados obtidos por este modelo sejam inferiores a aqueles obtidos pelo modelo de competição de partículas apresenta na Seção 4.1, quando comparado a outros modelos encontrados na litetura, como por exemplo o modelo (GN) proposto em (Girvan \& Newman, 2002), o modelo baseado em correlação oscilatória apresenta uma precisão superior. Por exemplo, para a rede randômica clusterizada descrita acima, quando $\left.z_{\text {out }} /<k\right\rangle=0,4$, o modelo GN apresenta uma precisão de aproximadamente $80 \%$ contra aproximadamente $90 \%$ do modelo proposto aqui. Resultados ainda superiores são obtidos quando $z_{\text {out }} /\langle k\rangle=0,5$, neste caso, o modelo GN é capaz de obter uma precisão de aproximadamente $40 \%$ enquanto o nosso modelo apresenta uma precisão de $76 \pm 10 \%$ (ver Figura 2.10 da Seção 2.4.1).

Além disso, ao comparar os resultados obtidos com aqueles apresentado pela Figura 2.10, pode-se constatar que o modelo aqui proposto encontra-se entre aqueles que apresentam boa precisão.

Na Figura 4.14 é apresentado um estudo do modelo variando o grau médio da rede. Na Figura 4.14(a) uma rede com $N=128, M=4$ e $z_{\text {out }} /\langle k\rangle=0,3$ é utilizada onde $\langle K\rangle \in[4 ; 28]$. Nesta simulação é possível observar que a precisão do modelo é inferior quando $\langle K\rangle$ é pequeno, mas permanece alta quando valores maiores de $\langle K\rangle$ são adotados. Na Figura 4.14(b) a mesma simulação é repetida utilizando uma rede maior com $N=500, M=5$ e $z_{\text {out }} /<$ $k>=0,3$, neste caso, a taxa de acerto do modelo é praticamente constante para todos os valores de $<K>$ utilizados, exceto quando $<K><15$ onde uma pequena perda na precisão é observada.

A seguir, duas simulações utilizando as mesmas redes reais adotadas na Seção 4.1 são apresentadas. Na Figura 4.15 é apresentada as séries temporais de cada um dos osciladores representando os vértices da rede interação social entre indivíduos do clube de karate (Zachary, 1977). Nesta figura pode ser observado que, após um certo número de ciclos, as comunidades são formadas. Para auxiliar a visualização do processo de detecção de comunidades, na Figura 4.16, as séries temporais para algumas faixas de $t$ são apresentados em maior resolução temporal. Na Figura 4.16(a), pode ser observado que, com exceção dos osciladores número 9 e 10 o restante da rede se encontra divida em duas comunidades. Comparando esses resultado ao obtido pela técnica de competição de partículas (Figura 4.10), desconsiderando-se os vértices 9 e 10, apenas o vértice número 3 encontra-se agrupado em uma comunidade diferente da obtida pelo modelo de competição de partículas. Este resultado também é coerente com aquele obtido em (Newman, 2004a). Nas 
(a)

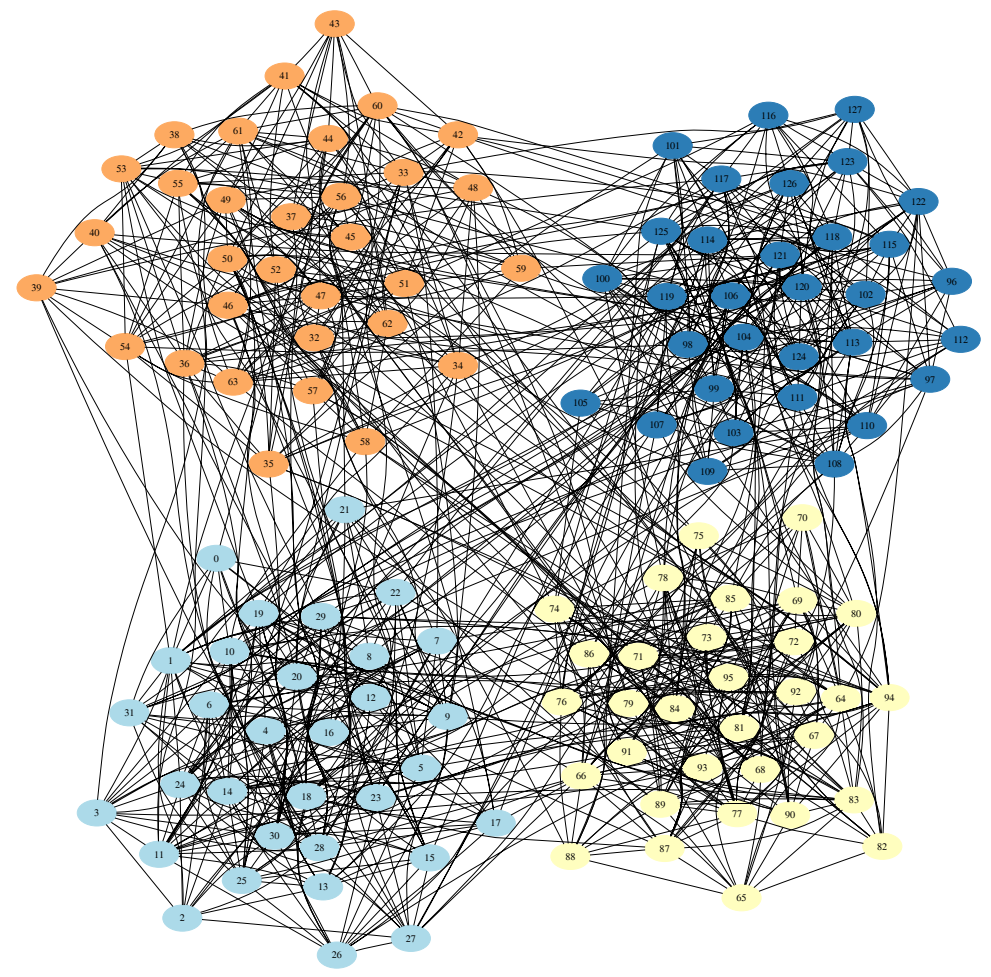

(b)

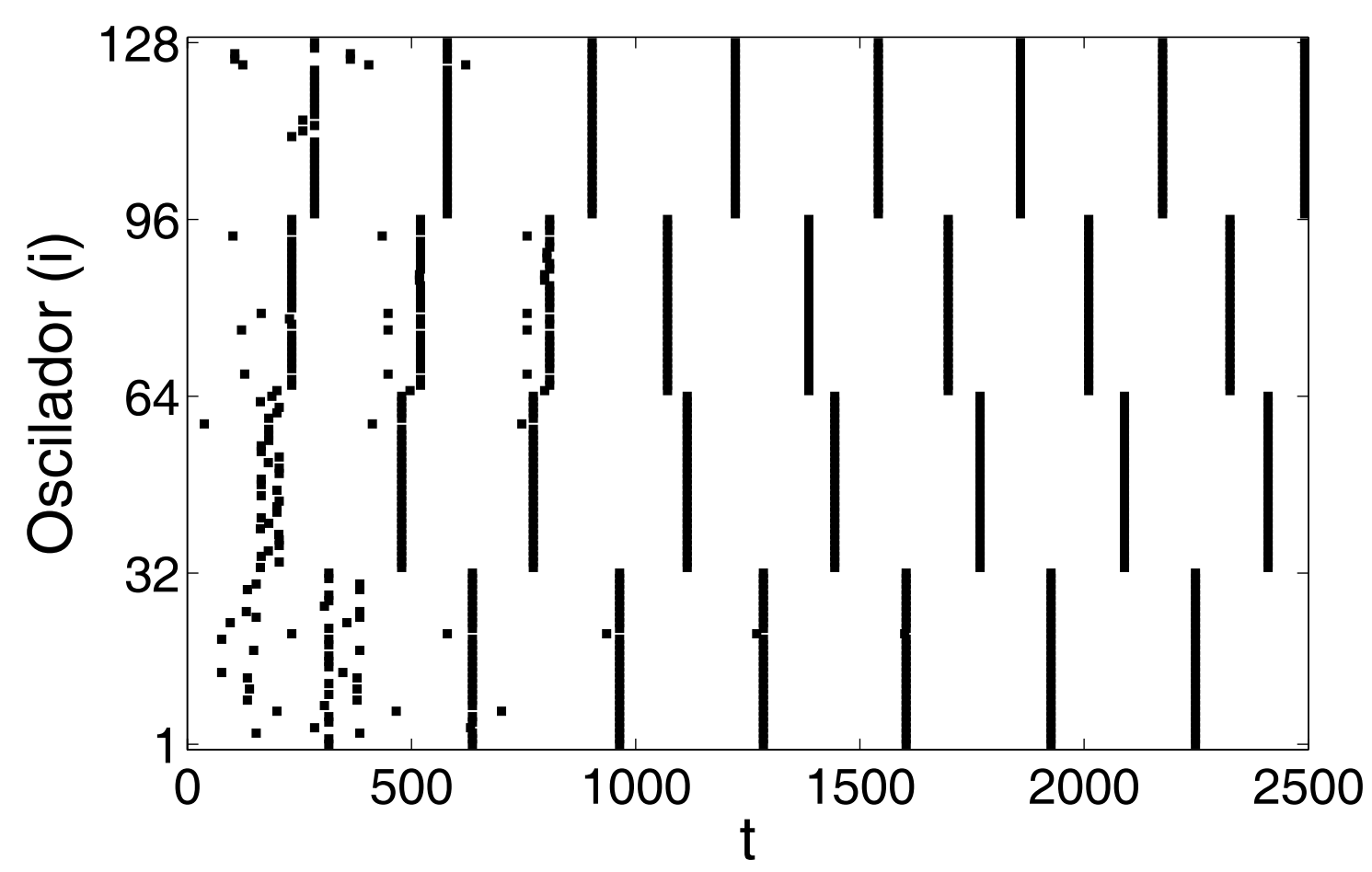

Figura 4.12: Ilustração do processo de detecção de comunidades usando o modelo proposto. Nesta simulação, $N=128, M=4,\langle k\rangle=16$ e $z_{\text {out }} /\langle k\rangle=$ 0,2 . (a) Rede randômica clusterizada. (b) Série temporal de disparo dos 128 neurônios. 


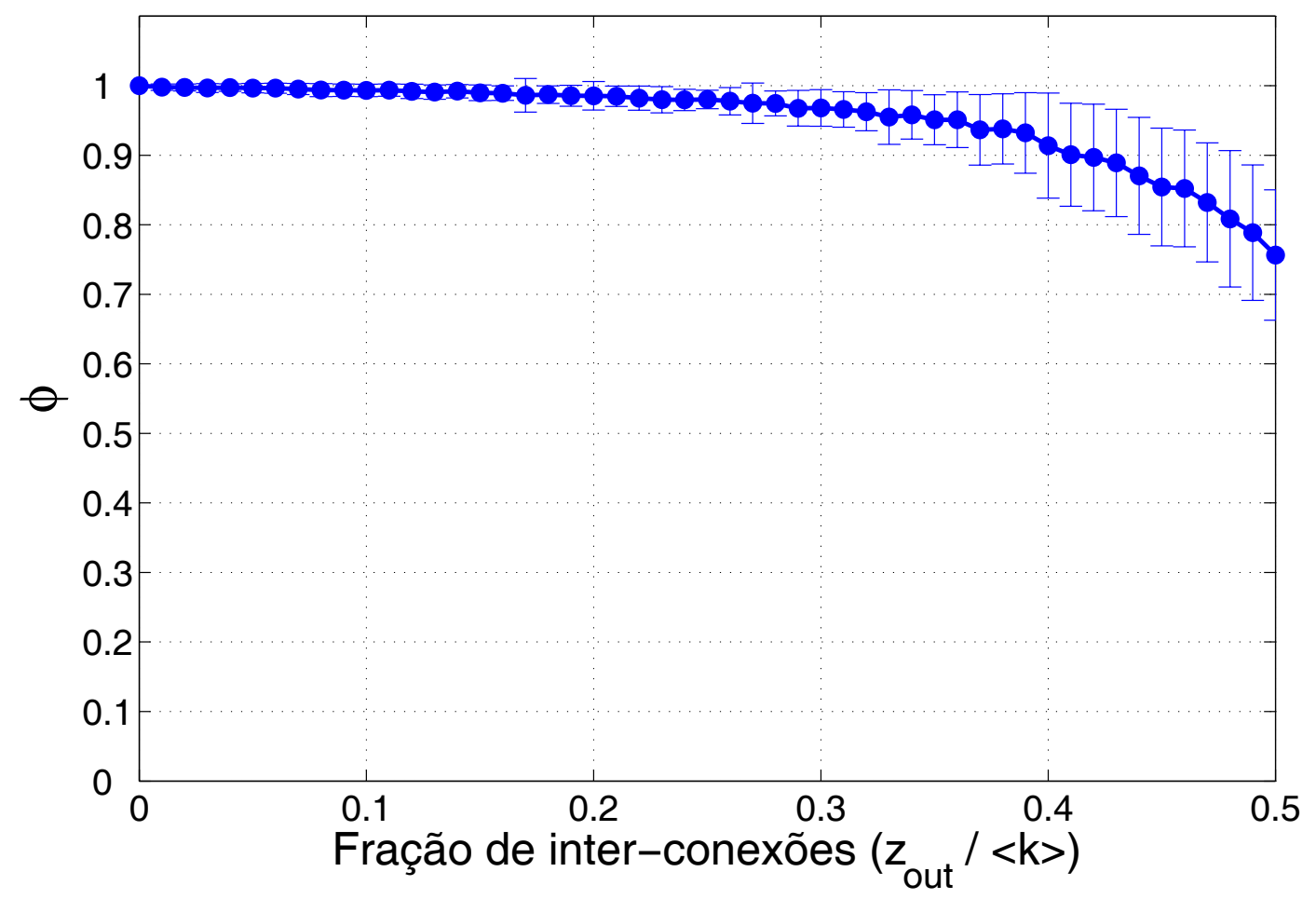

Figura 4.13: Precisão do processo de detecção de comunidades $\phi$ versus fração de inter-conexões $z_{\text {out }} /\langle k\rangle$. Nesta simulação, $N=128, M=4 \mathrm{e}\langle k\rangle=16$. Cada ponto da curva é obtido através da média de 200 execuções. A barra de erro representa o desvio padrão médio.

Figuras 4.16(b) e (c) outros dois instantes da simulação são apresentados. No item (c), em especial, três comunidades são obtidas no qual os vértices número 5, 6, 7, 11 e 17 são agrupados em uma terceira comunidade. A Figura 4.17 apresenta o resultado desta divisão. Esta resultado também foi observado no estudo apresentado em (Girvan \& Newman, 2002; Newman, 2004a). Diferente do modelo de competição de partículas, onde o número de comunidades é informado a priori, neste modelo, devido ao processo dinâmico de sincronização/dessincronização, o número de comunidades é obtido automaticamente, podendo ser controlado pela constante que define força de acoplamento $c$ (Equação (4.7)).

Nas Figuras 4.18-4.20, uma simulação utilizando a rede de interação social entre golfinhos (Lusseau et al., 2003) é apresentada. Seguindo a mesma metodologia utilizada na simulação anterior, aqui primeiramente é apresentada as séries temporais de todos os osciladores da rede (Figura 4.18), na sequência, três instantes do tempo são apresentados com uma maior resolução temporal (Figura 4.19) e o resultado final obtido com o modelo é apresentado na Figura 4.20. Nesta simulação também foi observado a detecção de uma terceira comunidade (vértices número $22,23,24,25,26,32,34,47$ e 50). Resultado semelhante também foi observado em (Newman \& Girvan, 2004; Newman, 2004a). 
(a)

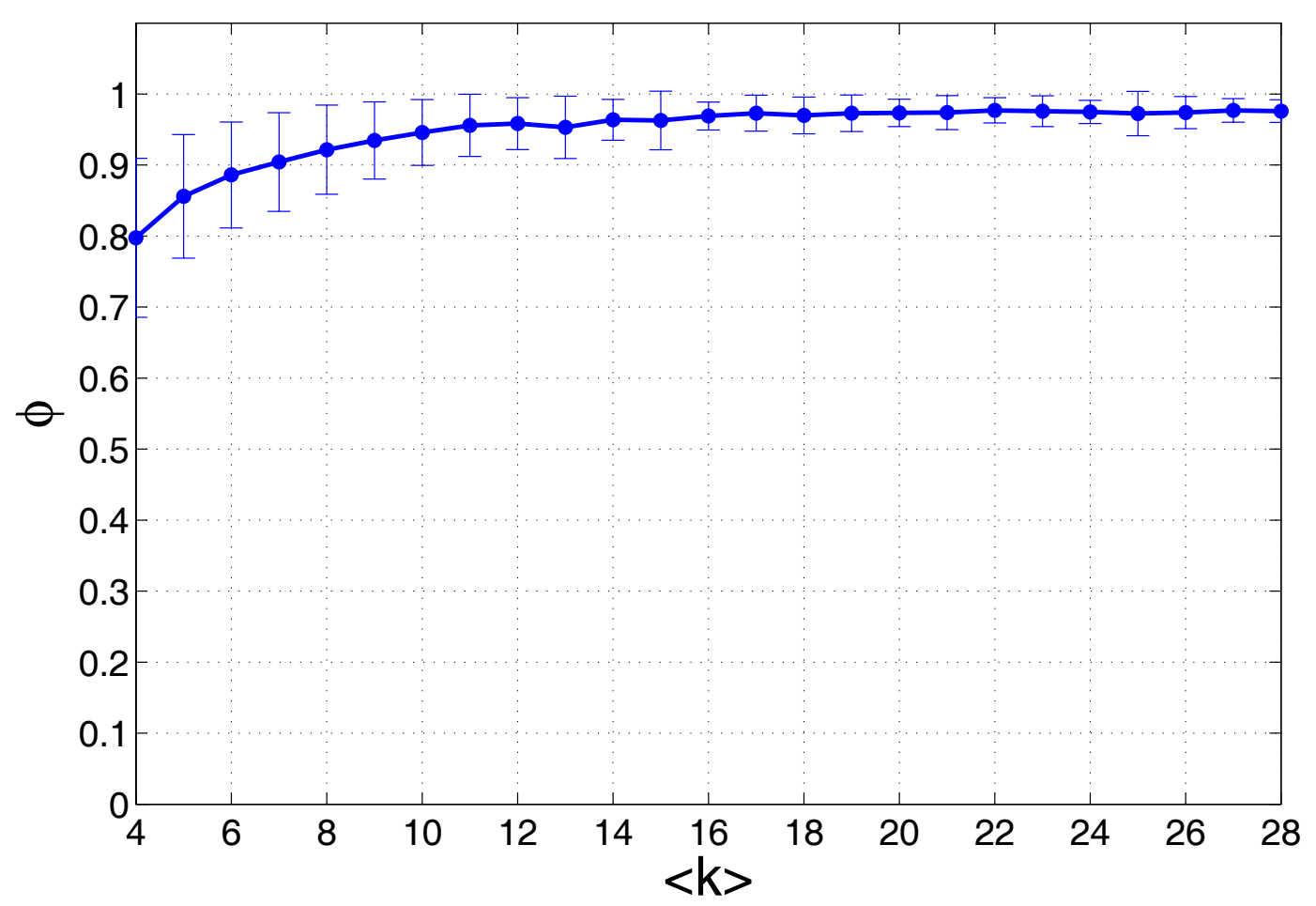

(b)

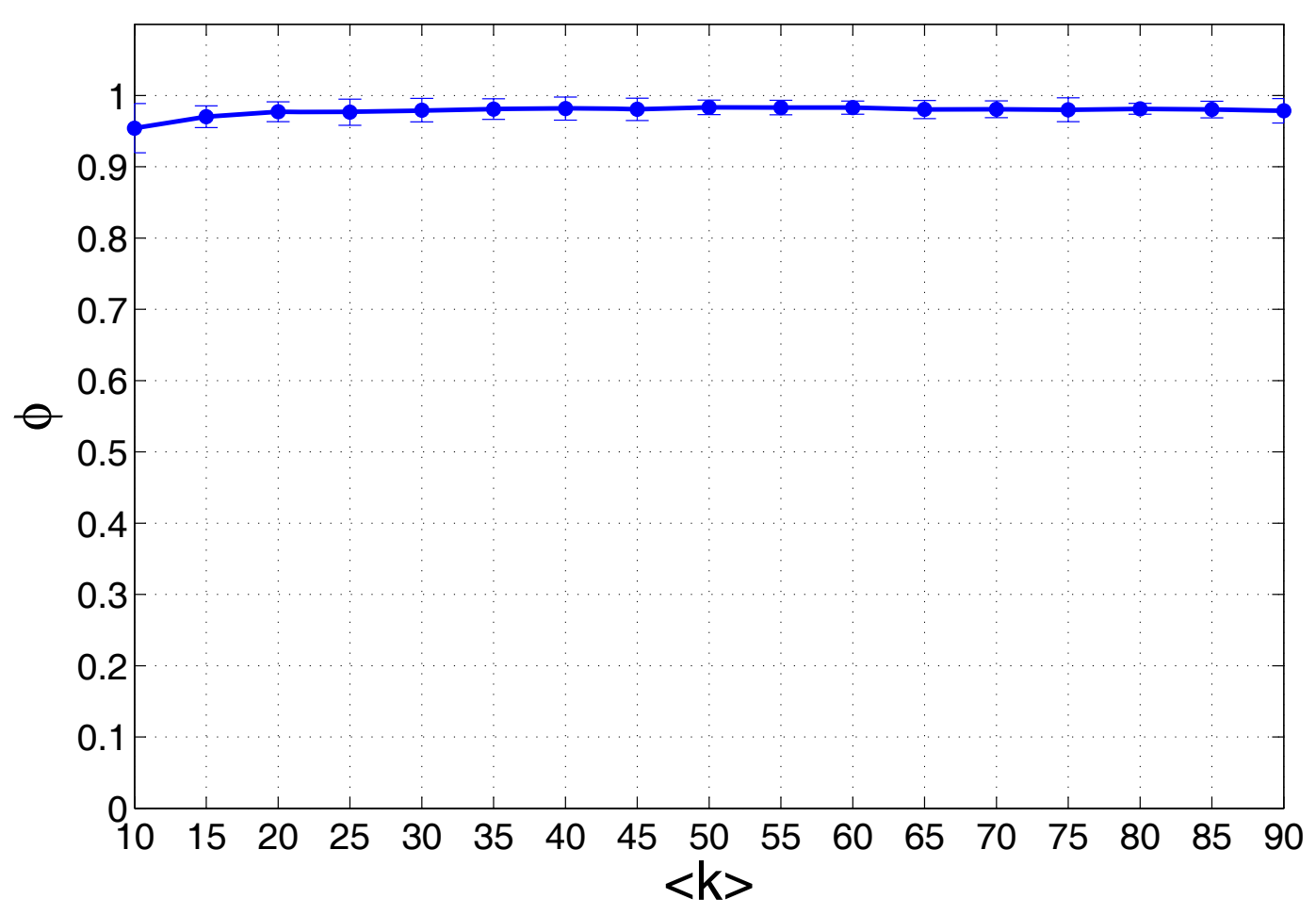

Figura 4.14: Precisão do processo de detecção de comunidades $\phi$ versus grau médio da rede $\left\langle k>\right.$. (a) $N=128, M=4$ e $z_{\text {out }} /\langle k\rangle=0,3$. (b) $N=500$, $M=5$ e $z_{\text {out }} /<k>=0,3$. Cada ponto da curva é obtido através da média de 200 execuções. A barra de erro representa o desvio padrão médio. 


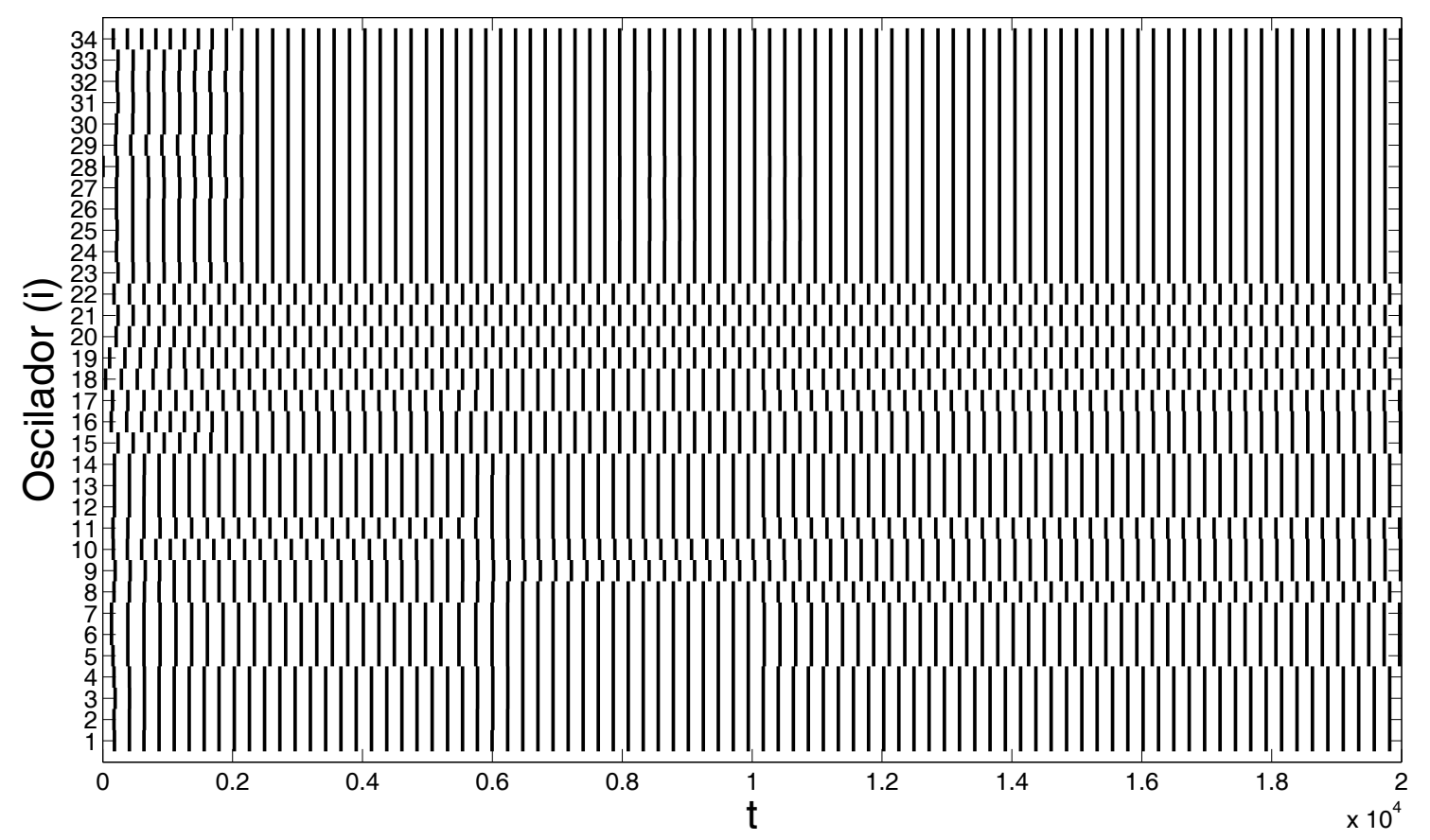

Figura 4.15: Séries temporais dos osciladores representando os vértices da rede de interação social entre indivíduos pertencentes a um clube de karate (Zachary, 1977). $c=0,1$.

(a)

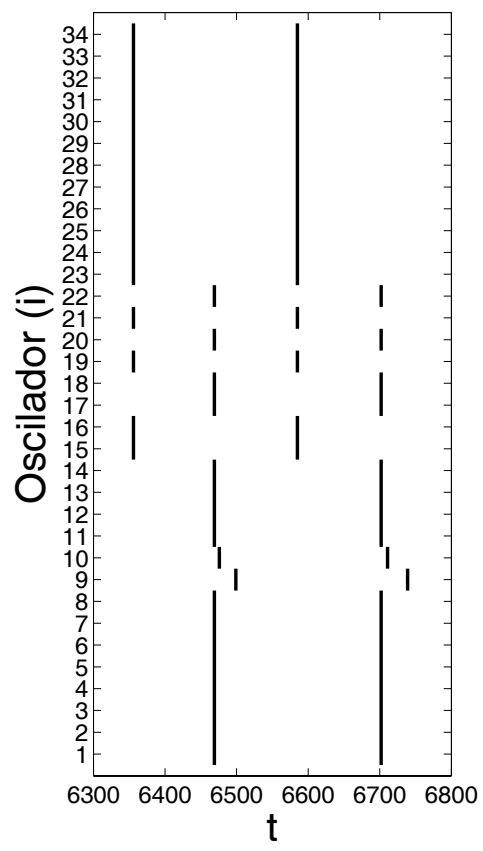

(b)

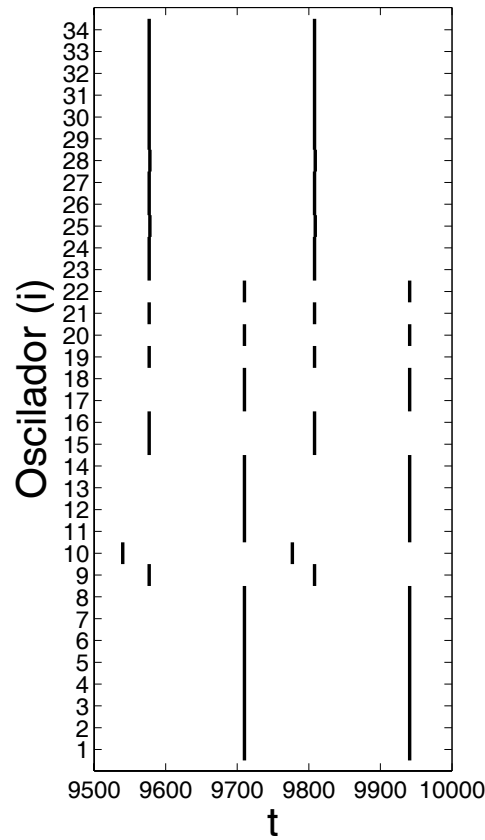

(c)

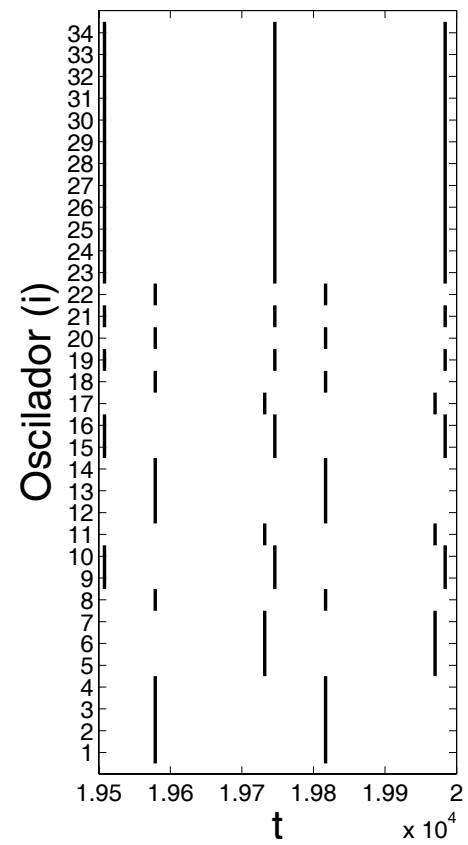

Figura 4.16: Representação em maior resolução temporal de algumas faixas de $t$ da simulação apresentada na Figura 4.15. 


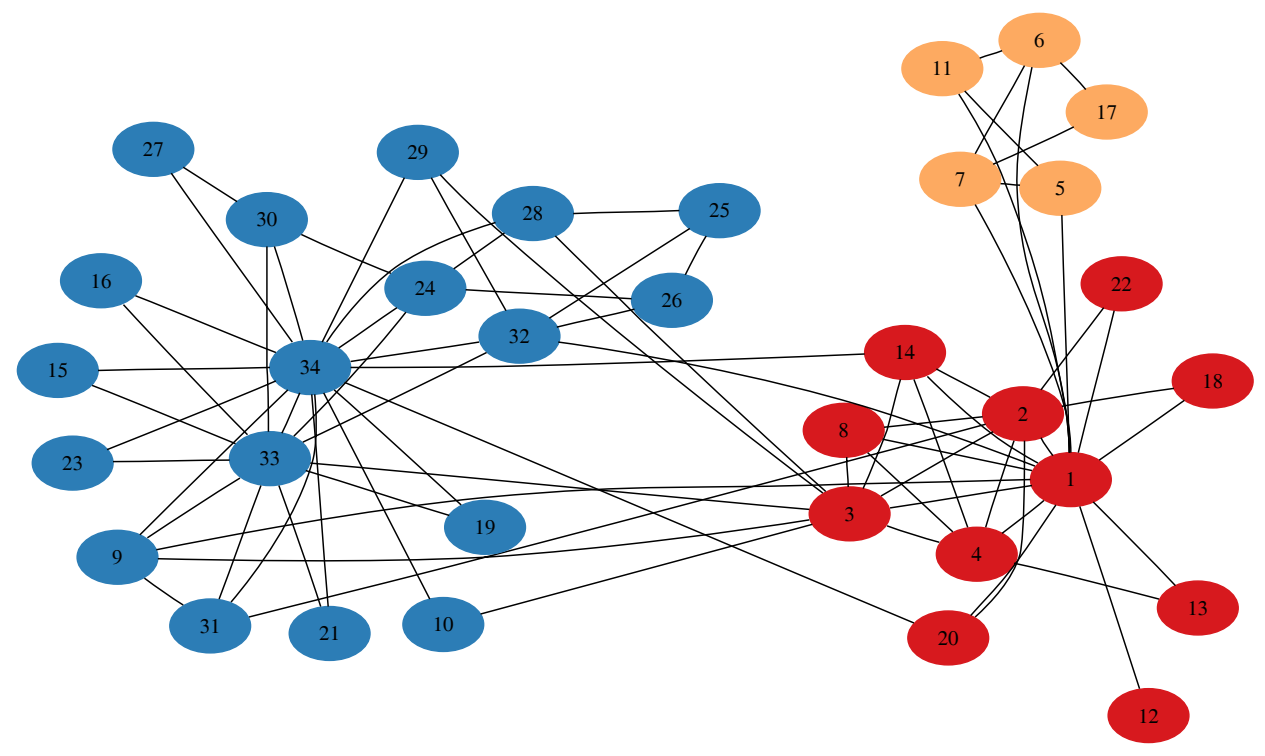

Figura 4.17: Resultado do processo de detecção de comunidades sobre a rede de interação social entre indivíduos pertencentes a um clube de karate (Zachary, 1977). $c=0,1$.

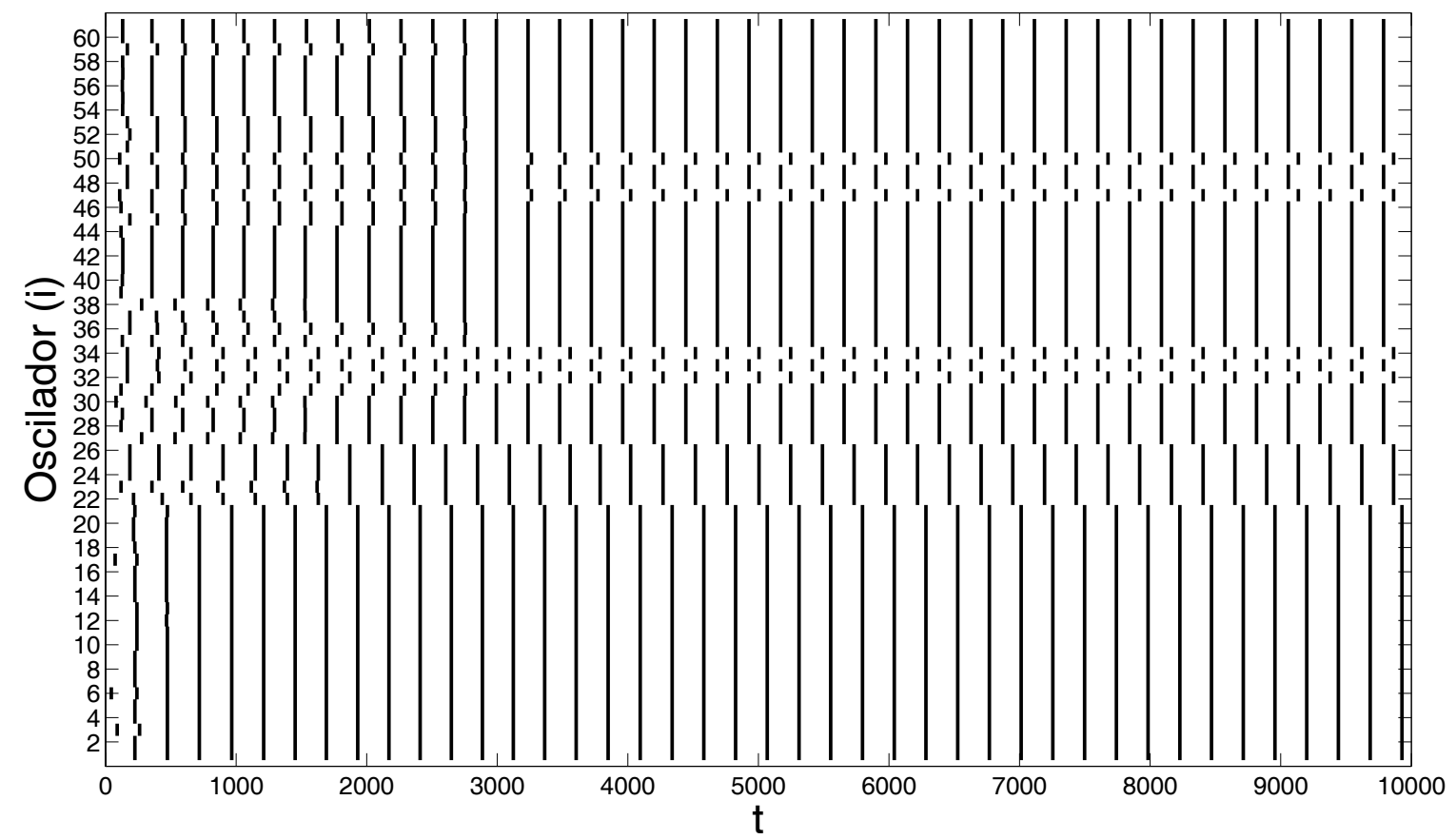

Figura 4.18: Séries temporais dos osciladores representando os vértices da rede de interação social social entre golfinhos ((Lusseau et al., 2003)). $c=0,3$. 
(a)

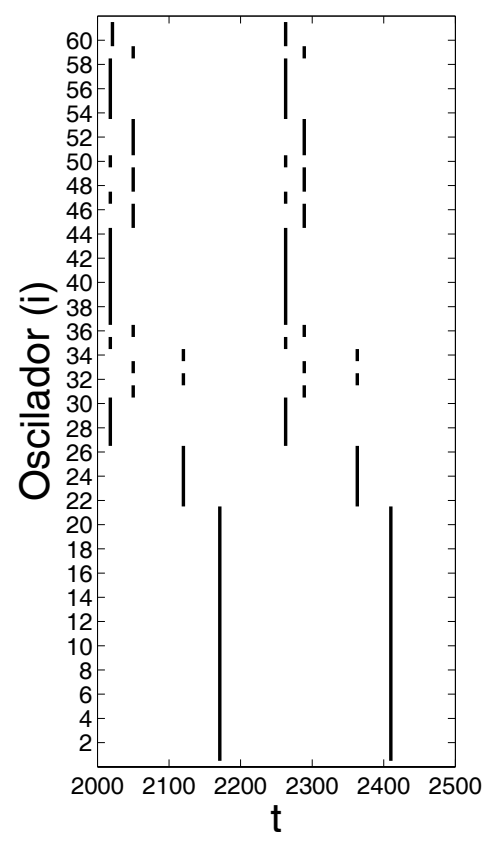

(b)

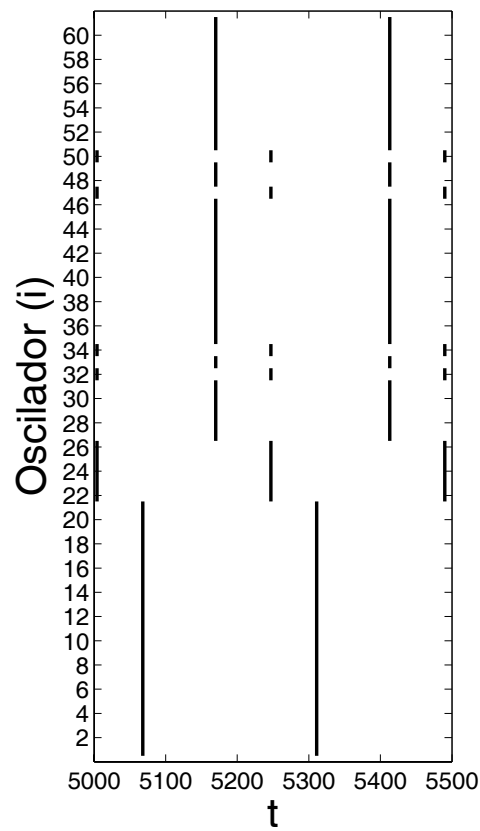

(c)

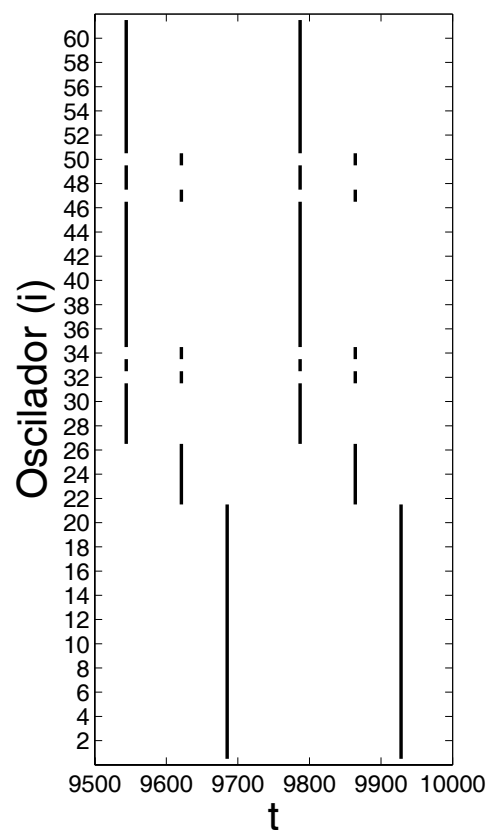

Figura 4.19: Representação em maior resolução temporal de algumas faixas de $t$ da simulação apresentada na Figura 4.18. 


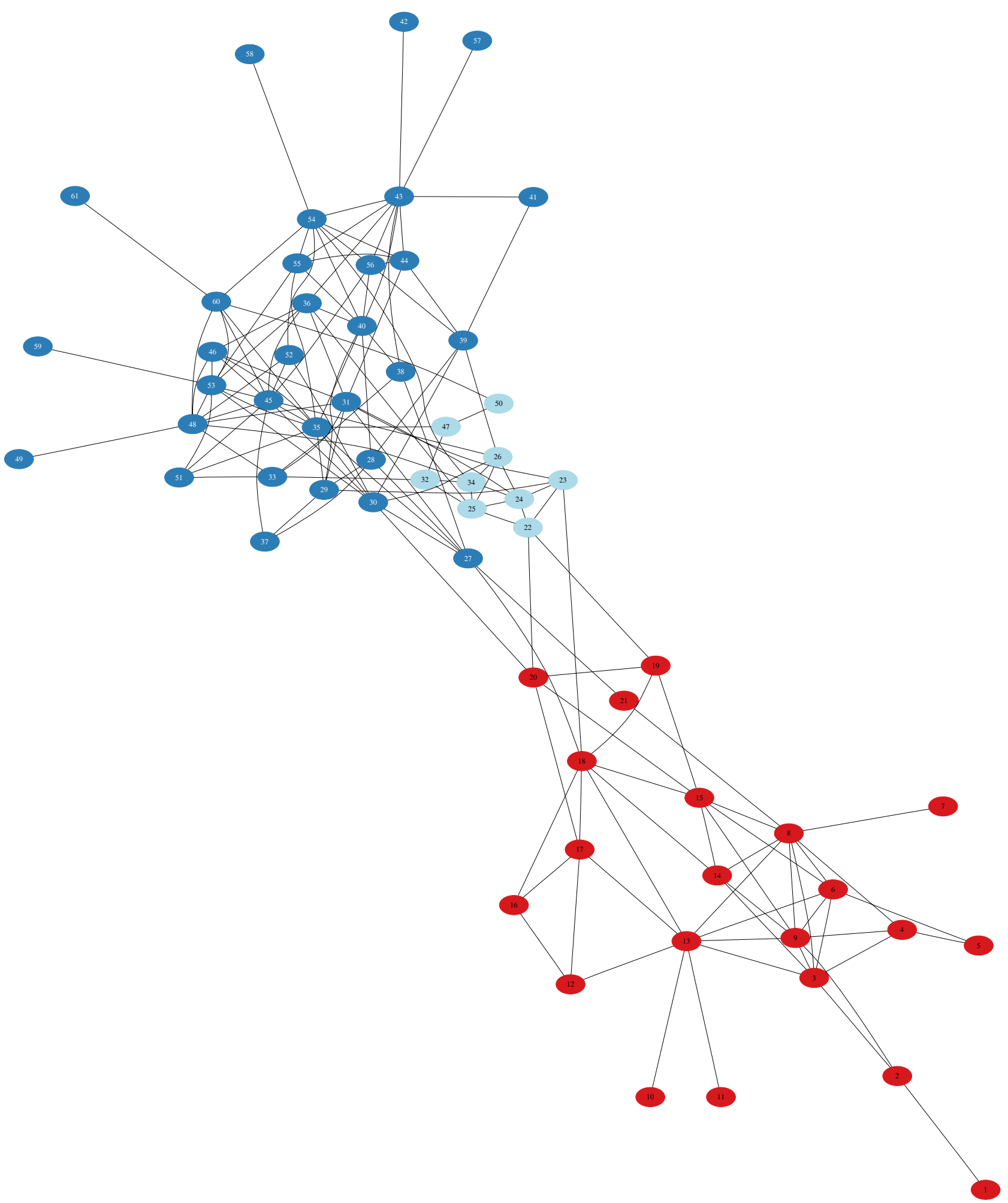

Figura 4.20: Resultado do processo de detecção comunidades sobre a rede interação social entre golfinhos ((Lusseau et al., 2003)). $c=0,3$. 


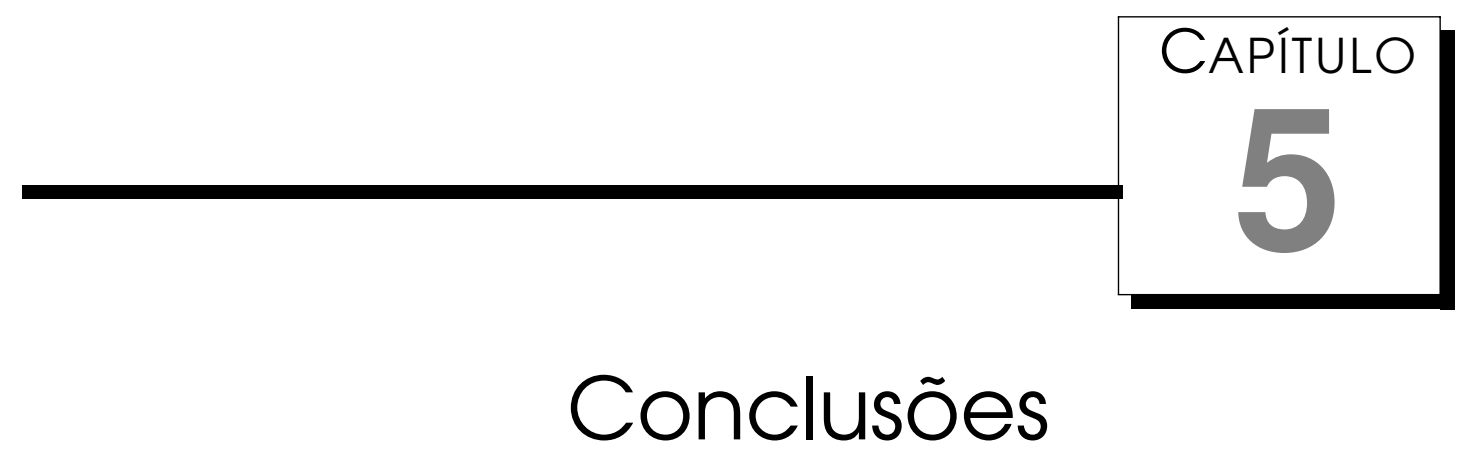

este trabalho, diversos modelos de redes formadas por unidades di-
nâmicas foram estudas. A partir do estudo destas redes, alguns mo-
delos com fins computacionais foram desenvolvidos em duas áreas de aplicação: modelos de atenção visual e detecção de comunidades em redes complexas. A seguir, uma breve apresentação cronológica do desenvolvimento deste programa de doutorado é apresentada. Na sequência, as principais contribuições, conclusões e trabalhos futuros são descritos.

No começo deste programa de doutorado foi dado início ao estudo da sincronização em redes neurais pulsadas, mais especificamente o estudo do modelo PCNN (Pulsed-Coupled Neural Network). Com base neste levantamento inicial e na análise de algumas aplicações relacionadas a sincronização encontradas na literatura, observou-se que a modelagem do fenômeno da atenção visual se apresentava como um tópico promissor.

Assim, com base na adaptação do modelo PCNN original, foi proposto um primeiro modelo de atenção (PCNN-I). Este modelo foi apresentado na Seção 3.1 (Quiles et al., 2006). Com este modelo algumas propriedades da atenção visual baseada em objetos foram observadas, como a segmentação da cena em um conjunto de objetos, a seleção temporal de um dos objetos (atenção) e o deslocamento do foco de atenção pela cena visual. Entretanto, ao considerar a fundo a forma de seleção desempenhada pelo sistema de atenção visual biológico, observou-se que o processo de seleção realizado pelo modelo PCNNI não estava adequado, pois, uma vez selecionado um dos objetos na cena, os demais deveriam ser inibidos de forma efetiva.

Considerando as limitações observadas no PCNN-I, outro modelo também baseado na rede PCNN, foi proposto (Quiles et al., 2007b) e apresentado na 
Seção 3.2. Neste modelo foi introduzido um processo de competição entre os objetos de tal forma que o objeto mais saliente fosse capaz de inibir os demais enquanto selecionado. Desta forma, a principal limitação do modelo PCNN-I referente ao processo de atenção foi solucionado. Para simular o conceito de saliência, a intensidade dos pontos provenientes da imagem de entrada foi utilizada no qual um maior nível de intensidade dos pontos que compõem o objeto na cena representa uma maior saliência. Contudo, este modelo baseado na rede PCNN apresentou uma grande limitação referente ao processo de segmentação de imagens o que limitou sua aplicação em imagens além daquelas sintéticas utilizadas nos primeiros experimentos. Outra limitação do modelo PCNN original está na grande quantidade parâmetros significativos que necessitam ser ajustados durante a simulação. Dada estas limitações, optou-se por estudar outros modelos de osciladores neurais.

Na sequência, o modelo Wilson-Cowan caótico foi abordado. Embora a dinâmica nas redes compostas por este oscilador seja bem distinta daquela observada nas redes PCNN, do ponto de vista qualitativo, os modelos se comportam de forma semelhantes e a mesma limitação no processo de segmentação de imagens mais complexas, como imagens reais, foi observada. Este modelo foi apresentado na Seção 3.3 (Quiles et al., 2007a; Zhao et al., 2007).

O oscilador neural Integra e Dispara foi o terceiro modelo de oscilador considerado neste estudo. Uma das razões desta escolha está na grande quantidade de trabalhos bem sucedidos utilizando este modelo, inclusive na tarefa de segmentação de imagens (Campbell et al., 1999). Considerando que a segmentação de imagens utilizando este oscilador é mais fácil de ser realizada quando comparado aos anteriores, partiu-se para uma nova fase no desenvolvimento de modelos de atenção visual nos quais outros atributos além da intensidade dos pontos foram considerados. Aqui o conceito de saliência foi representado pelo contraste dos seguintes atributos: cor, intensidade e orientação. Tal abordagem se mostrou adequada e alguns resultados interessantes foram obtidos e apresentados na Seção 3.4 (Quiles et al., 2008a, 2009).

Além disso, durante o estudo das redes compostas por neurônios Integra e Dispara, um tópico de pesquisa, denominado detecção de comunidades em redes complexas, mostrou-se bastante atrativo e relacionado aos conceitos utilizados no processo de segmentação da cena. Assim, nesta fase do doutorado ocorreu uma bifurcação na área de estudo.

Considerando este novo tópico abordado pelo projeto, detecção comunidades em redes complexas, uma nova revisão bibliográfica foi realizada a fim de se relacionar com as possiveis limitações observadas nos modelos existentes. Assim, além do processo de sincronização já utilizado pelos modelos de atenção, outras abordagens também foram consideradas. Dentre estas, a caminha 
de partículas em redes. Neste estudo inicial observou-se que a introdução de um processo competitivo entre várias partículas na rede ao invés de utilizar uma única partícula poderia ser interessante. Assim, um primeiro modelo de detecção baseado em competição de partículas foi proposto. Além disso, analisando o comportamento das partículas na rede foi notado que, devido à aleatoriedade do movimento, estas apresentavam dificuldade de isolamento dentro das comunidades, principalmente quando a rede utilizada não apresentava comunidades bem definidas. Assim, optou pela introdução de uma segunda forma de movimento denominado movimento determinístico. O movimento determinístico teve como finalidade forçar as partículas a permanecerem em regiões já dominadas por esta.

Em um primeiro instante, a seleção do tipo de movimento a ser executado pelas partículas foi definido aleatoriamente. Consequentemente, na média, as partículas realizam um movimento determinístico ou aleatório com probabilidade de 50\% cada. Com esta nova de dinâmica de movimento foi observado um grande ganho de precisão no processo de detecção de comunidades.

Considerando que a combinação da movimentação determinística-aleatória trouxe grandes benefícios para o processo de detecção de comunidades, optouse por realizar um estudo mais aprofundado desta combinação. Assim, uma nova regra foi introduzida para controlar a probabilidade de movimento determinístico realizado pela partícula. Com a utilização desta nova regra, alguns novos experimentos foram realizados a fim de se encontrar a melhor combinação dos movimentos. Este modelo para detecção de comunidades baseado em competição de partículas foi apresentado na Seção 4.1 (Quiles et al., 2008b).

No primeiro semestre de 2008, foi realizado um estágio de doutorado no exterior junto ao Departamento de Ciências da Computação e Engenharia da The Ohio State University, Columbus, OH, EUA, sob supervisão do Prof. Dr. DeLiang Wang. Neste estágio, analisando o que havia sido desenvolvido até momento, foi constatado que uma das limitações dos modelos de atenção estava na utilização de uma única camada responsável por realizar a organização perceptual (segmentação) e a seleção dos objetos. Desta forma, um novo modelo de atenção baseado na seleção de objetos composto por três módulos foi desenvolvido. Neste modelo, dois módulos iniciais são utilizados. O primeiro é responsável pelo cálculo de um mapa de saliência representando propriedades da atenção relacionada a seleção espacial e ao contraste de atributos visuais. O segundo módulo, implementado por uma rede LEGION, tem por finalidade segmentar a imagem em um conjunto de objetos. A partir destes resultados, um novo mapa, denominado mapa de objeto-saliência é proposto. Este mapa tem como objetivo indicar qual os objetos mais salientes da cena. Utilizando este mapa como entrada, um terceiro módulo, denominado módulo 
de seleção, tem por finalidade implementar a seleção do objeto mais saliente e também o mecanismo de inibição por retorno permitindo que diversos objetos sejam selecionados durante a inspeção visual. Este modelo foi apresentado em detalhes na Seção 3.5.

Por fim, nesta última etapa do doutorado, retornou-se ao tópico responsável pela bifurcação dos temas abordados. Isto é, a detecção de comunidades em redes através do mecanismo da correlação oscilatória. A partir deste estudo, um novo modelo de detecção de comunidades utilizando as propriedades de sincronização entre vértices e a dessincronização dos grupos por intermédio de um inibidor global foi proposto. Este modelo foi descrito na Seção 4.2.

A seguir, as principais contribuições desta Tese e as conclusões obtidas são sumarizadas.

\subsection{Principais Contribuições e Conclusões}

Com base nos desenvolvimentos realizados e descritos acima, as seguintes contribuições foram obtidas.

- exploração do uso da dinâmica espaço-temporal em redes na solução de alguns problemas computacionais. Este estudo focalizou-se em uma abordagem unificada dinâmica + estrutura, no qual a dinâmica se refere aos fenômenos produzido por elementos dinâmicos acoplados e a estrutura representa a organização desses elementos dinâmicos. Com base neste estudo, dois temas de aplicação foram selecionados: desenvolvimento de modelos de atenção visual e detecção de comunidades em redes complexas;

- desenvolvimento de novos modelos de atenção visual. Dentre as principais características desses modelos estão: a seleção baseada em objetos, a utilização da sincronização/dessincronização entre osciladores neurais como forma de organização perceptual e a competição entre objetos para aquisição da atenção. Ao comparar com outros modelos de seleção de objetos baseados em redes osciladores, os dois modelos apresentados nas Seções 3.4 e 3.5 mostram como principais vantagens a utilização de um maior número de atributos visuais e o tratamento de imagens reais. Além disso, no modelo baseado na rede LEGION (Seção 3.5), foi proposto um novo mapa, denominado mapa de objeto-saliência, que é o resultado da integração de um mapa de saliência e do resultado de segmentação realizado pela rede LEGION. Desta forma, tanto aspectos relacionados a atenção baseada em localização espacial e baseada em objetos são integradas. 
- desenvolvimento de uma nova técnica de detecção de comunidades baseada em competição de partículas:

- o processo de competição entre as partículas na rede é similar a diversos outros processos naturais, como por exemplo: exploração de territorial, competição entre animais por recursos naturais, etc. Desta forma, o modelo proposto também pode ser útil para simular tais processos naturais;

- foi introduzida uma regra para controlar o nível de aleatoriedade na movimentação das partículas na rede. Como resultado foi observado que a correta combinação determinística-aleatória na movimentação das partículas pode aumentar a precisão do modelo na tarefa de detecção de comunidades;

- devido a dinâmica simples do modelo, esse se mostrou capaz de atingir uma alta precisão na detecção das comunidades e, ao mesmo tempo, apresentar uma baixa complexidade computacional, o que é um ponto crítico de diversos modelos encontrados na literatura;

- a dinâmica proposta pelo modelo de partículas vai além de uma simples técnica de detecção de comunidades. O sistema de aprendizado empregado neste modelo pode ser visto como uma nova forma de aprendizado competitivo, e desta forma, uma nova contribuição para a área de aprendizado de máquina;

- desenvolvimento de um modelo de detecção de comunidades baseado na correlação oscilatória. Este modelo, através da sincronização entre osciladores neurais e a dessincronização através de um inibidor global apresentou uma alta precisão a um baixo custo computacional.

Como conclusões principais desta tese podem ser destacadas:

- A abordagem unificando dinâmica+estrutura como uma ferramenta computacional se mostrou bastante adequada ao tratamento dos problemas computacionais tratados nesta tese. Desta forma, acredita-se que esta abordagem deve ser continuamente explorada tanto na solução de problemas computacionais quanto em outras áreas de pesquisa envolvendo sistemas complexos;

- A utilização de redes de osciladores para modelagem de sistemas de atenção visual, além de ser biologicamente plausível, mostrou-se adequada ao problema, pois fornece diversas características importante, como a capacidade de segmentação dos objetos e a forma natural de criar a competição entre estes; 
- O desenvolvimento de técnicas para detecção de comunidades inspiradas em mecanismos naturais e biológicos se apresentou com uma importante alternativa aos modelos clássicos;

\subsection{Trabalhos Futuros}

Embora os modelos desenvolvidos apresentem diversas características interessantes, algumas limitações são observadas e podem ser desenvolvidas em trabalhos futuros.

- os modelos desenvolvidos consideram apenas aspectos de baixo nível (bottom-up) no processo de seleção. Desta forma, processos de alto nível (top-down) poderiam ser incorporados no sistema a fim de permitir que estes possam tratar casos mais gerais relacionados ao fenômeno da atenção visual. Por exemplo, busca por um alvo específico, entrega da atenção a objetos com sobreposição, dentre outros. Esses mecanismos de alto nível poderiam ser modelados com a inclusão de memórias de trabalho e/ou memórias associativas representando um conhecimento prévio de objetos presentes nas cenas analisadas;

- embora um mapa de saliência simulando características importantes da visão biológica como o contraste entre atributos já tenha sido considerado no modelo baseado em LEGION, a incorporação de outros atributos visuais como movimento, extração de contorno, visão estéreo para representar profundidade, dentre outros, poderiam contribuir para uma maior aplicabilidade do modelo;

- os modelos são aplicados apenas em cenas estáticas. Desta forma, a extensão dos modelos a fim de possibilitar sua aplicação em cenas dinâmicas (vídeos) é um ponto bastante interessante que pode ser investigado por trabalhos futuros;

- não foi objetivo desta Tese simular dados psicofísicos de forma quantitativa, porém, a abordagem utilizada poderia ser estendida de tal forma a simular esses dados. Por exemplo, os seguintes aspectos poderiam ser considerados: tempo necessário para a entrega da atenção, tempo que o foco permanece sob o objeto selecionado e implementação do mecanismo de inibição por retorno considerando a localização espacial dos estímulos, etc.

Com relação aos modelos de detecção de comunidades em redes complexas os seguintes pontos merecem ser mencionados: 
- Nas versões atuais, tanto do modelo de partículas quando do modelo baseado em correlação oscilatória, apenas redes sem peso foram consideradas. Assim, os modelos poderiam ser estendidos de tal forma a considerar outras formas de redes, como redes com pesos e redes direcionadas;

- Realizar um estudo para verificar como os modelos poderiam ser utilizados para detecção de comunidades hierárquicas;

- A dinâmica por trás do processo de detecção de comunidades em ambos os modelos é um fator bastante positivo, possibilitando que estes sejam aplicados em redes cuja a estrutura não seja estática, isto é, redes onde novas arestas ou vértices podem ser inseridos ou mesmo removidos ao longo do tempo. Porém, este fato ainda não foi comprovado por experimentos e será considerado nos próximos trabalhos;

- Considerações específicas do modelo de partículas (Quiles et al., 2008b):

- Apenas uma partícula é utilizada para definir cada comunidade. Um mecanismo de cooperação entre partículas poderia ser implementado de forma a melhorar a eficiência do processo de detecção de comunidade. Neste caso, ao invés de uma partícula atuando de forma isolada marcando sua comunidade, diversas partículas poderiam realizar o trabalho. De uma forma geral, acredita-se que a introdução de outras partículas não acarrete em um aumento da complexidade do sistema, pois a dinâmica de cada uma dessas é bastante simples envolvendo apenas um movimento (determinístico ou aleatório) na rede;

- O número de comunidades deve ser informado a priori. Embora o número de comunidades possa ser estimado através de aplicações sucessivas do modelo variando o número de partículas, este processo não é vantajoso computacionalmente. Desta forma, a geração do número automático de partículas (comunidades) representaria uma importante extensão do modelo original;

- Considerações específicas do modelo baseado em correlação oscilatória (Seção 4.2):

- Ainda não foi estabelecido um critério de parada adequado para o algoritmo. No estágio atual, o processo é executado por um número fixo de ciclos configurado empiricamente;

- Embora o modelo tenha se mostrado bastante eficiente no processo de detecção de comunidades, um estudo quantitativo dos parâme- 
tros ainda não foi realizado e deve ser investigado em trabalhos futuros; 


\section{Referências Bibliográficas}

Albert, R., Albert, I., \& Nakarado, G. L. (2004). Structural vulnerability of the north american power grid. Physical Review E, 69:025103(1-4).

Albert, R. \& Barabási, A.-L. (2002). Statistical mechanics of complex networks. Review of Modern Physics, 74:47-97.

Albert, R., Jeong, H., \& Barabási, A.-L. (1999). Diameter of the world wide web. Nature, 401:130-131.

Arbib, M. A. (2003). Handbook of brain theory and Neural Networks. MIT Press, Cambridge, MA, 2nd edition edition.

Axmacher, N., Mormann, F., Fernández, G., Elger, C. E., \& Fell, J. (2006). Memory formation by neuronal synchronization. Brain Research Reviews, 52:170-182.

Bagrow, J. P. \& Bollt, E. M. (2005). Local method for detecting communities. Physical Review E, 72:046108(1-10).

Bar-Yam, Y. (2003). Dynamics of complex systems. Westview Press.

Barabási, A.-L. (2003). Linked: How Everything Is Connected to Everything Else and What It Means. Plume.

Barabási, A.-L. \& Albert, R. (1999). Emergence of scaling in random networks. Science, 286:509-512.

Barahona, M. \& Pecora, L. M. (2002). Synchronization in small-world systems. Physical Review Letters, 89:054101(1-4).

Boccaletti, S., Ivanchenko, M., Latora, V., Pluchino, A., \& Rapisarda, A. (2007). Detecting complex network modularity by dynamical clustering. Physical Review E, 75:045102(1-4). 
Boccaletti, S., Kurths, J., Osipov, G., Valladares, D., \& Zhou, C. (2002). The synchronization of chaotic systems. Physics Reports, 366:1-101.

Bonaiuto, J. \& Itti, L. (2006). Using attention and spatial information for rapid facial recognition in video. Image and Vision Computing, 24(6):557-563.

Borisyuk, R. \& Kazanovich, Y. (2004). Oscillatory model of attention-guided object selection and novelty detection. Neural Networks, 17:899-915.

Broussard, R. P., Rogers, S. K., Oxley, M. E., \& Tarr, G. L. (1999). Physiologically motivated image fussion for object detection using a pulse coupled neural network. IEEE Transaction on Neural Networks, 10(3):554-563.

Buia, C. \& Tiesinga, P. (2006). Attentional modulation of firing rate and synchrony in a model cortical network. Journal of Computational Neuroscience, 20:247-264.

Burns, T. (1959). Darwinism and the study of society. Nature, 183:1562-1564.

Campbell, S. R. \& Wang, D. L. (1996). Synchronization and desynchronization in a network of locally coupled wilson-cowan oscillators. IEEE Transactions on Neural Networks, 7:541-554.

Campbell, S. R., Wang, D. L., \& Jayaprakash, C. (1999). Synchrony and desynchrony in integrate-and-fire oscillators. Neural Computation, 11:15951619.

Capocci, A., Servedio, V. D. P., Caldarelli, G., \& Colaiori, F. (2004). Communities detection in large networks. In Lecture Notes in Computer Science, volume 3243, pages 181-188. Springer.

Carota, L., Indiveri, G., \& Dante, V. (2004). A software-hardware selective attention system. Neurocomputing, 58-60:647-653.

Chen, K. \& Wang, D. L. (2001). Perceiving geometric patterns: from spirals to inside/outside relations. IEEE Transactions on Neural Networks, 12:10841102.

Clauset, A. (2005). Finding local community structure in networks. Physical Review E, 72:026132(1-6).

Cook, D. J. \& Holder, L. B. (2000). Graph-based data mining. IEEE Intelligent Systems, 15:32-41.

Corchs, S. \& Deco, G. (2001a). A neurodynamical model for selective visual attention using oscillators. Neural Networks, 14:981-990. 
Corchs, S. \& Deco, G. (2001b). Selective attention in visual search: A neural network of phase oscillators. Neurocomputing, 38-40:1151-1160.

Corral, A., Pérez, C. J., Díaz-Guilera, A., \& Arenas, A. (1995). Synchronization in a lattice model of pulse-coupled oscillators. Physical Review Letters, 75(20):3697-3700.

Crutchfield, J. P. \& Kaneko, K. (1987). Directions in Chaos, chapter Phenomenology of Spatiotemporal Chaos, pages 272-353. World Scientific.

Danon, L., Díaz-Guilera, A., Duch, J., \& Arenas, A. (2005). Comparing community structure identification. Journal of Statistical Mechanics: Theory and Experiment, P09008:1-10.

Danon, L., Duch, J., Arenas, A., \& A.Díaz-Guilera (2007). Large Scale Structure and Dynamics of Complex Networks: From Information Technology to Finance and Natural Science, chapter Community structure identification, pages 93113. World Scientific.

Daw, N. D., O’Doherty, J. P., Dayan, P., Seymour, B., \& Dolan, R. J. (2006). Cortical substrates for exploratory decisions in humans. Nature, 441:876879.

Dawkins, R. (1990). The Selfish Gene. Oxford University Press, second edition.

Díaz-Guilera, A., Pérez, C. J., \& Arenas, A. (1998). Mechanisms of synchronization and pattern formation in a lattice of pulse-coupled oscillators. Physical Review E, 57(4):3820-3828.

Deco, G. \& Rolls, E. T. (2005). Attention, short-term memory, and action selection: A unifying theory. Progress in Neurobiology, 76:236-256.

Desimone, R. \& Duncan, J. (1995). Neural mechanisms of selective visual attention. Annual Review of Neuroscience, 18:193-222.

Donetti, L. \& Muñoz, M. A. (2004). Detecting network communities: a new systematic and powerful algorithm. Journal of Statistical Mechanics: Theory and Experiment, P10012:1-15.

Donetti, L. \& Muñoz, M. A. (2005). Improved spectral algorithm for the detection of network communities. In Modeling Cooperative Behavior in the Social Sciences, volume 779 of AIP Conference Proceedings.

Duch, J. \& Arenas, A. (2005). Community detection in complex networks using extremal optimization. Physical Review E, 72:027104(1-4). 
Eckhorn, R., Bauer, R., Jordan, W., Brosch, M., Kruse, W., Munk, M., \& Reitboeck, H. J. (1988). Coherent oscillation: A mechanism of feature linking in the visual cortex? Biological Cybernetics, 60:121-130.

Eckhorn, R., Reitboeck, H. J., Arndt, M., \& Dicke, P. (1990). Feature linking via synchronization among distributed assemblies: Simulation of results from cat visual cortex. Neural Computation, 2:293-307.

Eckmann, J.-P. \& Moses, E. (2002). Curvature of co-links uncovers hidden thematic layers in the world wide web. Proceedings of the National Academy of Sciences of the USA, 99:5825.

Egeth, H. E. \& Yantis, S. (1997). Visual attention: control, representation, and time course. Annual Review of Psychology, 48:269-297.

Elazary, L. \& Itti, L. (2008). Interesting objects are visually salient. Journal of Vision, 8(3):1-15.

Engel, A. K., König, P., Kreiter, A. K., \& Singer, W. (1991). Interhemispheric synchronization of oscillatory neuronal responses in cat visual cortex. Science, 252:1177-1178.

Erdös, P. \& Rényi, A. (1959). On random graphs. Publicationes Mathematicae, 6:290-297.

Çesmeli, E. \& Wang, D. L. (2000). Motion segmentation based on motion/brightness integration and oscillatory correlation. IEEE Transactions on Neural Networks, 11:935-947.

Faloutsos, M., Faloutsos, P., \& Faloutsos, C. (1999). On power-law relationship of the internet topology. Computer Communication Review, 29:251262.

Flake, G. W., Lawrence, S., Giles, C. L., \& Coetzee, F. M. (2002). Selforganization and identification of web communities. IEEE Computer, 35(3):66-70.

Fortunato, S., Latora, V., \& Marchiori, M. (2004). Method to find community structures based on information centrality. Physical Review E, 70:056104(1-13).

Fredrickson, A. \& Stephanopoulos, G. (1981). Microbial competition. Science, 213(4511):972-979.

Fries, P., Reynolds, J. H., Rorie, A. E., \& Desimone, R. (2001). Modulation of oscillatory neuronal synchronization by selective visual attention. Science, 291:1560-1563. 
Girvan, M. \& Newman, M. E. J. (2002). Community structure in social and biological networks. Proceedings of the National Academy of Sciences of the USA, 99(2):7821-7826.

Gong, P., Nikolaev, A. R., \& van Leeuwen, C. (2003). Scale-invariant fluctuations of the dynamical synchronization in human brain electrical activity. Neuroscience Letter, 336:33-36.

Gottlieb, J. P., Kusunoki, M., \& Goldberg, M. E. (1998). The representation of visual salience in monkey parietal cortex. Nature, 391:481-484.

Grey, C. M., König, P., Engel, A., \& Singer, W. (1989). Oscillatory responses in cat visual cortex exhibit inter-columnar synchronization which reflects global stimulus properties. Nature, 338:334-337.

Gu, X., Yu, D., \& Zhang, L. (2005). Image shadow removal using pulse coupled neural network. IEEE Transaction on Neural Networks, 16(3):692-698.

Guardiola, X., Díaz-Guilera, A., Llas, M., \& Pérez, C. J. (2000). Synchronization, diversity, and topology of networks of integrate and fire oscillators. Physical Review E, 62(4):5565-5569.

Guimerà, R. \& Amaral, L. A. N. (2005). Functional cartography of complex metabolic networks. Nature, 433:895-900.

Guimerà, R., Mossa, S., Turtschi, A., \& Amaral, L. A. N. (2003). The worldwide air transportation network: Anomalous centrality, community structure, and cities' global roles. Proceedings of the National Academy of Sciences of the USA, 102(22):7704-7709.

Guimerà, R., Sales-Pardo, M., \& Amaral, L. A. N. (2004). Modularity from fluctuations in random graphs and complex networks. Physical Review E, 70:025101(1-4).

Han, J.-H., Kushner, S. A., Yiu, A. P., Cole, C. J., Matynia, A., Brown, R. A., Neve, R. L., Guzowski, J. F., Silva, A. J., \& Josselyn, S. A. (2007). Neuronal competition and selection during memory formation. Science, 316(5823):457-460.

Hansel, D. (1992). Synchronization and computation in a chaotic neural network. Physical Review Letters, 68(5):718-721.

Hebb, D. O. (1949). The Organization of Behavior. Wiley: New York. 
Hopfield, J. \& Herz, A. V. M. (1995). Rapid local synchronization of action potentials: Toward computation with coupled integrate-and-fire oscillator neurons. Proceedings of the National Academy of Sciences of the USA, 92:66556662.

Hramov, A. E. \& Koronovskii, A. A. (2005). Generalized synchronization: a modified system approach. Physical Review E, 71:067201(1-4).

Itti, L. \& Koch, C. (2000). A saliency-based search mechanism for overt and covert shifts of visual attention. Vision Research, 40:1489-1506.

Itti, L. \& Koch, C. (2001a). Computational modelling of visual attention. Nature Reviews Neuroscience, 2:194-203.

Itti, L. \& Koch, C. (2001b). Feature combination strategies for saliency-based visual attention systems. Journal of Electronic Imaging, 10(1):161-169.

Itti, L., Koch, C., \& Niebur, E. (1998). A mode of saliency-based visual attention for rapid scene analysis. IEEE Transactions on Pattern Analysis and Machine Intelligence, 20(11):1254-1259.

Izhikevich, E. M. (2004). Which model to use for cortical spiking neurons? IEEE Transactions on Neural Networks, 15(5):1063-1070.

Jeong, H., Tombor, B., Albert, R., Oltvai, Z. N., \& Barabási, A.-L. (2000). The large scale organization of metabolic networks. Nature, 407:651-654.

Jermakowicz, W. J. \& Casagrande, V. A. (2007). Neural networks a century after cajal. Brain Research Reviews, 55(2):264-284.

Johnson, J. L. (1994). Pulse-coupled neural nets: translation, rotation, scale, distortion, and intensity signal invariance for images. Applied Optics, 33(26):6239-6253.

Johnson, J. L. \& Padgett, M. L. (1999). Pcnn models and applications. IEEE Transactions on Neural Networks, 10(3):480-498.

Kandel, E. R., Schwartz, J. H., \& Jessell, T. M. (2000). Fundamentos da neurociência e do comportamento. Guanabara Koogan.

Kaneko, K. (1986). Collapse of tori and genesis of chaos in dissipative systems. World Scientific Publishing Co Pte Ltd.

Kaneko, K. (1989). Pattern dynamics in spatiotemporal chaos. Physica D, 34: $1-41$. 
Kaneko, K. (1990). Clustering, coding, switching, hierarchical ordering, and control in a network of chaotic elements. Physica D, 41:137-172.

Kaneko, K. (1994). Relevance of dynamic clustering to biological networks. Physica D, 75:55-73.

Karypis, G., Han, E.-H., \& Kumar, V. (1999). Chameleon: hierarchical clustering using dynamic modeling. IEEE Computer, 32:68-75.

Kazanovich, Y. \& Borisyuk, R. (2002). Object selection by an oscillatory neural network. Biosystems, 67:103-111.

Kim, Y. J., Grabowecky, M., Paller, K. A., Muthu, K., \& Suzuki, S. (2007). Attention induces synchronization-based response gain in steady-state visual evoked potentials. Nature Neuroscience, 10(1):117-125.

Kinser, J. M. (1999). Foveation by a pulse-coupled neural network. IEEE Transaction on Neural Networks, 10(3):621-625.

Koch, C. (1998). Biophysics of Computation: Information Processing in Single Neurons. Oxford University Press.

Koch, C. \& Ullman, S. (1985). Shifts in selective visual attention: Towards the underlying neural circuitry. Human Neurobiology, 4:219-227.

Kuntimad, G. \& Ranganath, H. S. (1999). Perfect image segmentation using pulse coupled neural networks. IEEE Transaction on Neural Networks, 10(3):591-598.

Kuramoto, Y. (1991). Colletive synchronization fo pulse-coupled oscillators and excitable units. Physica D, 50:15-30.

Lee, D. (2006). Best to go with what you know? Nature, 441:822-823.

Li, Z. \& Itti, L. (2008). Visual attention guided video compression. In Vision Science Society Annual Meeting (VSSO8).

Linsay, P. S. \& Wang, D. L. (1998). Fast numerical integration of relaxation oscillator networks based on singular limit solution. IEEE Transactions on Neural Networks, 9(3):523-532.

Lusseau, D., Schneider, K., Boisseau, O. J., Haase, P., Slooten, E., \& Dawson, S. M. (2003). The bottlenose dolphin community of doubtful sound features a large proportion of long-lasting associations. can geographic isolation explain this unique trait? Behavioral Ecology and Sociobiology, 54:396-405. 
Martinez, A., Ramanathan, D., Foxe, J., Javitt, D., \& Hillyard, S. (2007). The role of spatial attention in the selection of real and illusory objects. The Journal of Neuroscience, 27(30):7963-7973.

Milgram, S. (1967). The small world problem. Psychology Today, 1(1):60-67.

Minsky, M. \& Papert, S. (1969). Perceptrons an introduction to computational geometry. MIT Press.

Mirollo, R. E. \& Strogatz, S. H. (1990). Synchronization of pulse-coupled biological oscillators. SIAM J. Appl. Math., 50(6):1645-1662.

Mitchell, T. M. (1997). Machine Learning. McGraw-Hill.

Montoya, J. M. \& Solé, R. V. (2002). Small world patterns in food webs. Journal of Theoretical Biololgy, 214:405-412.

Murthy, V. N. \& Fetz, E. E. (1992). Coherent 25- to 35-hz oscillations in the sensorimotor cortex of awake behaving monkeys. Proceedings of the National Academy of Sciences of the United States of America, 89(12):5670-5674.

Newman, M. E. J. (2003). The structure and function of complex networks. SIAM Review, 45:167-256.

Newman, M. E. J. (2004a). Detecting community structure in networks. The European Physical Journal B, 38:321-330.

Newman, M. E. J. (2004b). Fast algorithm for detecting community structure in networks. Physical Review E, 69:066133(1-5).

Newman, M. E. J. \& Girvan, M. (2004). Finding and evaluating community structure in networks. Physical Review E, 69:026113(1-15).

Niebur, E. \& Koch, C. (1994). A model for neuronal implementation of selective visual attention based on temporal correlation among neurons. Journal of Computational Neuroscience, 1:141-158.

Niebur, E., Koch, C., \& Rosin, C. (1993). An oscillation-based model for the neuronal basis of attention. Vision Research, 33:2789-2802.

O’Craven, K. M., Downing, P. E., \& Kanwisher, N. (1999). fmri evidence for objects as the units of attentional selection. Nature, 401:584-587.

Palla, G., Derényi, I., Farkas, I., \& Vicsek, T. (2005). Uncovering the overlapping community structure of complex networks in nature and society. Nature, 435:814-818.

Pashler, H. (1998). The psychology of attention. MIT Press, Cambridge, MA. 
Pecora, L. M. \& Carroll, T. L. (1990). Synchronization in chaotic systems. Physical Review Letters, 64:821-823.

Pfeifer, R., Lungarella, M., \& Iida, F. (2007). Self-organization, embodiments, and biologically inspired robotics. Science, 318:1088-1093.

Pikovsky, A., Rosenblum, M., \& Kurths, J. (2001). Synchronization: A universal concept in nonlinear sciences. Cambridge University Press.

Pons, P. \& Latapy, M. (2006). Computing communities in large networks using random walks. Journal of Graph Algorithms and Applications, 10:191-218.

Quiles, M. G., Breve, F., Romero, R. A. F., \& Zhao, L. (2008a). Visual selection with feature contrast-based inhibition in a network of integrate and fire neurons. In The 4rd International Conference on Natural Computation (ICNC), pages 601-605, Jinan, China.

Quiles, M. G., Breve, F., Zhao, L., \& Romero, R. (2007a). A visual selection mechanism based on network of chaotic wilson-cowan oscillators. In 7 th International Conference on Intelligent Systems Design and Applications (ISDA), pages 919-924, Rio de Janeiro - Brasil.

Quiles, M. G., Romero, R. A. F., \& Zhao, L. (2006). A pulse-coupled neural network as a simplified bottom-up visual attention model. In IEEE Proceedings of the Ninth Brazilian Symposium on Artificial Neural Networks (SBRN), pages $178-183$.

Quiles, M. G., Zhao, L., Alonso, R. L., \& Romero, R. A. F. (2008b). Particle competition for complex network community detection. Chaos (Woodbury), 18:1-10 (DOI: 10.1063/1.2956982).

Quiles, M. G., Zhao, L., Breve, F., \& Romero, R. A. F. (2009). A network of integrate and fire neurons for visual selection. Neurocomputing, In Press:111 (DOI: 10.1016/j.neucom.2008.10.024).

Quiles, M. G., Zhao, L., \& Romero, R. (2007b). A selection mechanism based on a pulse-coupled neural network. In The 20th International Joint Conference on Neural Networks (IJCNN), pages 1566-1571, Orlando-US.

Radicchi, F., Castellano, C., Cecconi, F., Loreto, V., \& Parisi, D. (2004). Defining and identifying communities in networks. Proceedings of the National Academy of Sciences of the USA, 101:2658-2663.

Ravasz, E. \& Barabasi, A.-L. (2003). Hierarchical organization in complex networks. Physical Review E, 67:026112(1-7). 
Reichardt, J. \& Bornholdt, S. (2004). Detecting fuzzy community structure in complex networks with a potts model. Physical Review Letters, 93:218701(14).

Revounsuo, A. \& Newman, J. (1999). Binding and consciousness. Consciousness and Cognition, 8(2):123-127.

Rhouma, M. B. H. \& Frigui, H. (2001). Self-organization of pulse-coupled oscillator with application to clustering. IEEE Transaction on Patter Analysis and Machine Intelligence, 23(2): 180-195.

Richard, A. M., Lee, H., \& Vecera, S. P. (2008). Attentional spreading in objectbased attention. Journal of Experimental Psychology: Human Perception and Performance, 34(4):842-853.

Roelfsema, P. R., Lamme, V. A. F., \& Spekreijse, H. (1998). Object-based attention in the primary visual cortex of the macaque monkey. Nature, 395:376381.

Rosenblum, M. G., Pikovsky, A. S., \& Kurths, J. (1996). Phase synchronization of chaotic oscillators. Physical Review Letters, 76(11):1804-1807.

Rosenblum, M. G., Pikovsky, A. S., \& Kurths, J. (1997). From phase to lag synchronization in coupled chaotic oscillators. Physical Review Letters, 78(22):4193-4196.

Schaeffer, S. E. (2007). Graph clustering. Computer Science Review, 1:27-34.

Scott, J. (2000). Social network analysis: a handbook. Sage, London, second edition edition.

Sejnowski, T. J. \& Paulsen, O. (2006). Network of oscillations: Emerging computational principles. The Journal of Neuroscience, 26(6):1673-1676.

Shannon, C. E. (1948). A mathematical theory of communication. Bell System Technical Journal, 27:379-423.

Shinn-Cunningham, B. G. (2008). Object-based auditory and visual attention. Trends in Cognitive Sciences, 12(5):182-186.

Siagian, C. \& Itti, L. (2008). Rapid biologically-inspired scene classification using features shared with visual attention. IEEE Transactions on Pattern Analysis and Machine Intelligence, 29(2):300-312.

Sponrs, O. (2002). Network analysis, complexity, and brain function. Complexity, 8:56-60. 
Strogatz, S. H. (2001). Exploring complex networks. Nature, 410:268-276.

Sun, Y. \& Fisher, R. (2003). Object-based visual attention for computer vision. Artificial Intelligence, 146:77-123.

Terman, D. \& Wang, D. L. (1995). Global competition and local cooperation in a network of neural oscillators. Physica D, 81:148-176.

Timme, M., Geisel, T., \& Wolf, F. (2006). Speed of synchronization in complex networks of neural oscillators: Analytic results based on random matrix theory. Chaos, 16:015108:1-15.

Tsotsos, J. K., Culhane, S. M., Wai, W. Y. K., Lai, Y., Davis, N., \& Nuflo, F. (1995). Modeling visual attention via selective tuning. Artificial Intelligence, 78:507-545.

Uchida, A., McAllister, R., Meucci, R., \& Roy, R. (2003). Generalized synchronization of chaos in identical systems with hidden degrees of freedom. Physical Review Letters, 91(17):174101(1-4).

van der Pol, B. (1926). On 'relaxation oscillations'. Philosophical Magazine, 2(11):978-992.

von der Malsburg, C. (1981). The correlation theory of brain function. Technical report, Internal report 81-2: Max-Planck Institute for Biophysical Chemistry, Göttingen, Germany.

von der Malsburg, C. \& Schneider, W. (1986). A neural cocktail-party processor. Biological Cybernetics, 54:29-40.

Walther, D. (2006). Interactions of visual attention and object recognition: Computational modeling, algorithms, and psychophysics. PhD thesis, California Institute of Technology.

Walther, D. \& Koch, C. (2006). Modeling attention to salient proto-objects. Neural Networks, 19:1395-1407.

Walther, D., Rutishauser, U., Cock, C., \& Perona, P. (2005). Selective visual attention enables learning and recognition of multiples objects in cluttered scenes. Computer Vision and Image Understanding, 100:41-63.

Wang, D. L. (1999). Object selection based on oscillatory correlation. Neural Networks, 12:579-592.

Wang, D. L. (2005). The time dimension for scene analysis. IEEE Transactions on Neural Networks, 16(6):1401-1426. 
Wang, D. L. \& Brown, G. J. (1999). Separation of speech from interfering sounds based on oscillatory correlation. IEEE Transactions on Neural Networks, 10:684-697.

Wang, D. L., Kristjansson, A., \& Nakayama, K. (2005). Efficient visual search without top-down or bottom-up guidance. Perception \& Psychophysics, 67(2):239-253.

Wang, D. L. \& Liu, X. (2002). Scene analysis by integrating primitive segmentation and associative memory. IEEE Transactions on Systems, Man and Cybernetics - Part B: Cybernetics, 32:254-268.

Wang, D. L. \& Terman, D. (1995). Locally excitatory globally inhibitory oscillator networks. IEEE Transactions on Neural Networks, 6(1):283-286.

Wang, D. L. \& Terman, D. (1996). Image segmentation based on oscillatory correlation. Technical report, Center for Cognitive Science, The Ohio State University, Columbus, Ohio, EUA.

Wang, D. L. \& Terman, D. (1997). Image segmentation based on oscillatory correlation. Neural Computation, 9:805-836.

Wang, X. F. \& Chen, G. (2002). Synchronization in scale-free dynamical networks: robustness and fragility. IEEE Transactions on Circuits and Systems - Part I, 49:54-62.

Wang, X. F. \& Chen, G. (2003). Complex networks: small-world, scale-free and beyond. IEEE Circuits and Systems Magazine, 3(1):6-20.

Ward, L. M. (2003). Synchronous neural oscillations and cognitive processes. TRENDS in Cognitive Science, 7(12):553-559.

Watts, D. J. \& Strogatz, S. H. (1998). Collective dynamics of 'small-world' networks. Nature, 393:440-442.

West, G. B., Brown, J. H., \& Enquist, B. J. (1999). A general model for the structure, and algometry of plant vascular systems. Nature, 400:122-126.

Wilson, H. R. \& Cowan, J. D. (1972). Excitatory and inhibitory interactions in localized populations of model neurons. Biophysical Journal, 12:1-24.

Wolfe, J. M. \& Horowitz, T. S. (2004). What attributes guide the deployment of visual attention and how do they do it ? Nature Review Neuroscience, 5:495-501.

Wrigley, S. N. \& Brown, G. J. (2004). A computational model of auditory selective attention. IEEE Transactions on Neural Networks, 15(5):1151-1 163. 
Wu, F. \& Huberman, B. A. (2004). Finding communities in linear time: a physics approach. The European Physical Journal B, 38:331-338.

Yantis, S. (1998). Attention, chapter Control of visual attention, pages 223256. Psychology Press, London.

Yantis, S. (2000). Attention and Performance XVIII, volume 18, chapter Goaldirected and stimulus-driven determinants of attentional control, pages 73103. MIT Press, Cambridge.

Yantis, S. (2005). How visual salience wins the battle for awareness. Nature Neuroscience, 8:975-977.

Yu, B. \& Zhang, L. (2004). Pulse-coupled neural networks for contour and motion matchings. IEEE Transaction on Neural Networks, 15(5):1186-1201.

Zachary, W. W. (1977). An information flow model for conflict and fission in small groups. Journal of Anthropological Research, 33:452-473.

Zhao, L., Breve, F., Quiles, M., \& Romero, R. (2007). Visual selection and shifting mechanisms based on a network of chaotic wilson-cowan oscillators. In The 3rd International Conference on Natural Computation (ICNC'O7), pages 754-762, Haikou-China.

Zhao, L. \& Macau, E. E. N. (2001). A network of dynamically coupled chaotic maps for scene segmentation. IEEE Transactions on Neural Networks, 12(6): 1375-1385.

Zhao, L., Macau, E. E. N., \& Omar, N. (2000). Scene segmentation of the chaotic oscillator network. International Journal of Bifurcation and Chaos, 10(7):1697-1708.

Zhou, H. (2003). Distance, dissimilarity index, and network community structure. Physical Review E, 67:061901(1-8).

Zhou, H. \& Lipowsky, R. (2004). Network brownian motion: A new method to measure vertex-vertex proximity and to identify communities and subcommunities. In International Conference on Computational Science, pages 1062-1069. 